\title{
LISTA TAXONÓMICA ACTUALIZADA DE LOS INSECTOS ASOCIADOS A PROSOPIS PALLIDA (HUMB. \& BONPL. EX. WILD.) KUNTH (FABACEAE) DE LA REGIÓN PIURA, PERÚ
}

\author{
Gino Juárez-Noé ${ }^{1, *}$ \& Uzbekia González-Coronado² \\ ${ }^{1}$ Distrito de Piura, Región de Piura-Perú. \\ Email: norbiol@hotmail.com — ORCID iD: https://orcid.org/0000-0002-8847-6059 \\ ${ }^{2}$ Distrito de Piura, Región de Piura-Perú. \\ Email: issa.gonzalez06@gmail.com — ORCID iD: https://orcid.org/0000-0001-5920-7549
}

*Autor para correspondencia: norbiol@hotmail.com

\section{RESUMEN}

Prosopis pallida es un componente importante para las comunidades de insectos, proporcionando alimento como tejidos vegetales, savia, néctar y/o polen y sirviendo además como lugar de refugio y reproducción. Se presenta una lista taxonómica actualizada y comentada de los insectos asociados a Prosopis pallida (Humb. \& Bonpl. ex. Wild.) Kunth de la región Piura al noroeste de Perú, con base en recolectas y revisión de material depositado en colecciones entomológicas. Se adicionan 59 especies y se completa la identificación de 40 géneros y siete morfoespecies citadas anteriormente, quedando la lista final conformada por 189 especies, 175 géneros, 84 familias y 12 órdenes. Los órdenes Coleoptera con 69 especies, Hymenoptera con 36 especies y las familias Coccinellidae y Formicidae con 11 y 10 especies respectivamente son las más diversas, además se confirma a Enallodiplosis discordis Gagné, 1994 atacando árboles de Prosopis pallida en territorio peruano. Del total de especies registradas, 68 son fitófagos, 16 son succionadores de savia, 49 son depredadores, 17 son parasitoides y 18 son polinizadores. Para todas las especies registradas se incluyen datos de colecta y distribución por provincia y paisaje ecológico.

Palabras clave. Insectos; fitófagos; succionadores de savia; parasitoides; depredadores; polinizadores; Prosopis pallida; algarrobo; Región Piura; Perú.

\section{ABSTRACT}

Update taxonomic checklist of insects associated with Prosopis pallida (Humb. \& Bonpl. ex. Wild.) Kunth (Fabaceae) from Piura region, Peru

Prosopis pallida it is an important component for insect communities providing food as plant tissues, sap, nectar, pollen and/or also serving as a place of refuge and reproduction. A update taxonomic and commented checklist of insects associated with Prosopis pallida (Humb. \& Bonpl. ex. Wild.) Kunth from Piura region in Perú is presented based on collections of specimens and review of the material deposited in entomological collections. 59 species are added and the identification of 40 genera and seven morphospecies previously cited is completed, with which the checklist is made up of 189 species, 175 genera, 84 families y 12 orders. The orders Coleoptera with 69 species, Hymenoptera with 36 species and families Coccinellidae and Formicidae with 11 and 10 species respectively are the most diverse, also it confirmed to Enallodiplosis discordis Gagné, 1994 attacking $P$. pallida trees in Perúvian territory. Of the total species recorder 68 are phytophagous, 16 are sap suckers, 49 are predators, 17 are parasitoids and 18 are pollinators. It is included for each species data collection and distribution by province and ecological landscape.

Keywords. Insects; phytophagous; sap suckers; parasitoids; predators; pollinators; update; Prosopis pallida; algarrobo; Piura region; Peru.

Recibido/Received: 21/12/2019; Aceptado/Accepted: 23/04/2020; Publicado en línea/Published online: 01/09/2020

Cómo citar este artículo/Citation: Juárez-Noé, G. \& González-Coronado, U. 2020. Lista taxonómica actualizada de los insectos asociados a Prosopis pallida (Humb. \& Bonpl. ex. Wild.) Kunth (Fabaceae) de la región Piura, Perú. Graellsia, 76(2): e110. https://doi.org/10.3989/graellsia.2020.v76.263

Copyright: (C) 2020 SAM \& CSIC. This is an open-access article distributed under the terms of the Creative Commons Attribution 4.0 International (CC BY 4.0) License. 


\section{Introducción}

El género Prosopis L. (Fabaceae) contiene 47 especies que se distribuyen principalmente en zonas áridas y semiáridas del norte y sur de América, suroeste de Asia y norte de África, siendo su distribución en el continente americano desde el suroeste de América del Norte hasta la Patagonia en Argentina en América del Sur (Palacios et al., 2011). Sus especies que incluyen árboles, arbustos y raramente sub-arbustos tienen la capacidad de tolerar sequías y condiciones edáficas adversas (salinidad y alcalinidad), razón por la cual poseen una posición dominante en la vegetación leñosa de ecosistemas secos y áridos del mundo y de Ámerica (Fagg \& Stewart, 1994).

Prosopis pallida (Humb. \& Bonpl. ex. Wild.) Kunth es originaria de las costas áridas y desérticas de Perú y Ecuador (Burghardt et al., 2010; Depenthal \& Meitzner-Yoder, 2018), aunque ha sido introducida y cultivada en Brasil, Bolivia, Puerto Rico, Hawaii, Pakistán, India, Australia y el territorio del Sáhara (Depenthal \& Meitzner-Yoder, 2018; Dostert et al., 2012). En Perú, P. pallida, llamada comúnmente "algarrobo", es la especie dominante a lo largo de la zona costera y de los ecosistemas secos del país, estando restringida a las regiones centro y norte desde la región Ancash hasta la región Tumbes, entre los $0 \mathrm{~m}$ y $1500 \mathrm{~m}$ de altitud, teniendo su máxima presencia y extensión en la región Piura (Mom et al., 2002; Burghardt et al., 2010; Dostert et al., 2012; Depenthal \& Meitzner-Yoder, 2018).

En la región Piura, $P$. pallida es uno de los árboles más valiosos e importantes desde el punto de vista económico y ecológico en los ecosistemas secos que comprenden los bosques estacionalmente secos y el desierto costero. Económicamente tiene una importancia gravitante especialmente para la población rural debido a la gran variedad de bienes y servicios que pueden obtenerse de su madera y frutos (alimento para humanos y animales, madera y carbón, agroforestería, entre otros) (Díaz-Celis, 1995; Grados et al., 2000; Llontop-Llaque, 2013; Depenthal \& MeitznerYoder, 2018), mientras que ecológicamente es importante debido a que aumenta el contenido de nitrógeno, carbono, fosforo y el contenido orgánico en el suelo reduciendo la alcalinidad y salinidad (Pasiecznik, 2001; Whaley et al., 2010; Dostert et al., 2012; Depenthal \& Meitzner-Yoder, 2018); asimismo afecta al microclima del bosque a través del sombreado y captura de humedad (Depenthal \& Meitzner-Yoder, 2018), además de servir como hábitat para la fauna local especialmente reptiles, mamíferos, aves, insectos y arácnidos (Núñez-Sacarías, 1993; Juárez et al., 2016; Cruzado-Jacinto et al., 2019).

Desde hace varios años se viene presentando en los bosques secos de las regiones de Tumbes, Piura y Lambayeque la declinación y muerte de $P$. pallida, causada principalmente por agentes bióticos tales como insectos. Llontop-Llaque (2013) en su estudio sobre impactos del cambio climático y medidas de adaptación para la conservación de los bosques secos, manifiesta que la declinación de árboles de algarrobo se debe a insectos plaga pertenecientes a las familias Tortricidae, Cecidomyiidae y Noctuidae, SENASA (2016) en su informe sobre la situación fitosanitaria de $P$. pallida en la costa norte de Perú registró ocho especies de insectos plaga atacando al algarrobo, mientras que Chipana-Auris (2019) resalta que el díptero Enallodiplosis discordis Gagné, 1994 es la principal causa de la declinación de $P$. pallida en la región Lambayeque.

En la región Piura de Perú, donde existe una mayor extensión de bosques de algarrobo, existen algunos trabajos acerca de la riqueza de insectos en P. pallida. Así, Domínguez (1982) realizó el primer estudio sobre la fauna entomológica en los algarrobales de Piura donde reportó 142 especies de insectos, mientras que Núñez-Sacarías (1993) elaboró una lista de insectos en Prosopis de las regiones de Ica y Piura registrando en total 176 especies de los cuales 97 correspondieron a los algarrobos de Piura. Sin embargo, las investigaciones más recientes son las realizadas por Juárez et al. (2016) quienes evaluaron la cantidad de especies de insectos asociados a $P$. pallida dentro del campus de la Universidad de Piura registrando 128 especies y el de Juárez \& González (2016a) quienes añadieron seis especies de coleópteros quedando la lista conformada por 134 especies, siendo este el último dato disponible. Por ello, en la presente investigación con la adición de 59 especies, 18 familias, 3 órdenes y la completa identificación de 40 géneros y siete morfoespecies citados anteriormente, se actualiza la lista taxonómica y la cantidad de insectos asociados a $P$. pallida de la región Piura.

\section{Material y métodos}

\section{ÁREA DE ESTUDIO}

El estudio se realizó en diferentes zonas ubicadas dentro de los hábitats conformados por $P$. pallida dentro de la región Piura. Estos hábitats ocupan la mayor parte de la superficie territorial regional abarcando las ocho provincias políticas (Piura, Sullana, Talara, Paita, Sechura, Morropón, Huancabamba y Ayabaca), un rango altitudinal desde el nivel del mar hasta los $1000 \mathrm{~m}$ de altitud y cinco tipos de paisajes ecológicos (matorral xérico, desierto costero, bosques estacionalmente secos ribereños, bosques estacionalmente secos de llanura y bosques estacionalmente secos de colina y montaña) (More et al., 2014; MINAM, 2018). El clima en este tipo de hábitats es desértico y semi desértico con temperaturas máximas de $39{ }^{\circ} \mathrm{C}$ (de enero a marzo) y mínimas de $18{ }^{\circ} \mathrm{C}$ (junio a septiembre), mientras que las precipitaciones son generalmente estacionales (diciembre a abril), con una media que puede llegar a los $80 \mathrm{~mm}$ por mes siendo aún mayor 
en eventos como El Niño, Oscilación del Sur (ENOS) (More et al., 2014).

\section{Metodología}

Todas las especies registradas se basaron en colectas de especímenes y revisión de material depositado en colecciones entomológicas. El trabajo de campo fue realizado por los autores del manuscrito a través de recolectas en 25 localidades de muestreo que abarcaron las ocho provincias de la región y un rango altitudinal desde el nivel del mar hasta los $1000 \mathrm{~m}$ de altitud aproximadamente (Apéndice I). Las colectas tuvieron una duración de un día por localidad y se llevaron a cabo bimensualmente desde enero de 2014 a noviembre de 2019 (seis muestreos por año con un total de 36 muestreos). En cada localidad se instalaron dos parcelas rectangulares de 0.50 ha cada una $(100 \mathrm{~m}$ de ancho por $50 \mathrm{~m}$ de largo) ubicadas en dirección norte y separadas $500 \mathrm{~m}$ (MINAM, 2015), a su vez cada parcela se dividió en cuatro cuadrantes de $50 \mathrm{~m}$ de ancho por $25 \mathrm{~m}$ de largo las cuales fueron enumeradas siguiendo las manecillas del reloj (Tricone \& Anderson, 2018). Dentro de cada parcela se evaluaron plántulas de $0.50 \mathrm{~m}$ a $1 \mathrm{~m}$ de altura y árboles de $1.5 \mathrm{~m}$ a $4 \mathrm{~m}$ de altura con un DAP desde $20 \mathrm{~cm}$ hasta $90 \mathrm{~cm}$. En total fueron evaluadas 850 plantas de algarrobo (550 árboles y 300 plántulas).

La recolecta de insectos se realizó por medio de colecta manual, agitación de follaje y red entomológica. La colecta manual consistió en la búsqueda activa y minuciosa de larvas, pupas, ninfas y adultos en hojas, ramas, troncos, inflorescencias y raíces (cuando estaban expuestas sobre la superficie); para la agitación de follaje se colocó un paraguas invertido cubierto con tela blanca debajo de ramas y hojas, se escogieron 4 ramas alrededor del diámetro de copa y se realizaron 5 golpeteos por rama (en intervalos de uno en uno por separado) (Juárez et al., 2016), mientras que para la red entomológica se utilizó una vara de $1.20 \mathrm{~m}$ de largo unida a un anillo metálico de $30 \mathrm{~cm}$ de diámetro con tul de forma cónica con malla de $0.1 \mathrm{~mm}$ y $90 \mathrm{~cm}$ de largo realizándose 4 pases dobles alrededor del diámetro de copa.

Asimismo, la revisión de material de la colección donde se encuentran depositados los ejemplares citados por Juárez et al. (2016) para el campus de la Universidad de Piura, permitió completar la identificación de 40 géneros y siete morfoespecies citados en dicha lista.

Para la identificación de los especímenes colectados y de los ejemplares depositados se utilizaron los trabajos de Barber (1936), Blake (1950), Fisher (1950), Van Dyke (1953), Kulzer (1958), Marcuzzi (1961), Gidaspow (1963), Freude (1967), Cobos (1972, 1980), Monné (1972), Peña (1973, 1994), Noonan (1981), Binda \& Joly (1991), Straneo (1986), Galileo \& Martins (1996, 2007), Martins (1999, 2002, 2003), González (2007), Naviaux (2007), Moore
\& Diéguez (2008), Aguirre-Tapiero (2009), Ferrer (2011), Opitz (2013), Silvestro et al. (2015), Ratcliffe (2018), Giraldo-Mendoza \& Flores (2019) y LópezGarcía et al. (2019) dentro de Coleoptera; Naumann (1968), Goulet \& Huber (1993), van Achterberg (1993), Willink \& Roig-Alsina (1995), Carpenter \& Garcete-Barrett (2002), Fernández (2003), Fernández \& Sharkey (2006), Rasmussen \& González (2017) y Bolton (2019) dentro de Hymenoptera; Lamas (1972), Thompson (1991), Ribeiro \& Carvalho (1998), Artigas \& Hengst (1999), Kits et al. (2008), Bertolaccini et al. (2010), Mengual \& Thompson (2011), López et al. (2012), Korytkowski (2014) y Kameneva \& Korneyev (2016) dentro de Diptera; Goding (1929), Burckhardt (1994), Dealy (2000), Zamudio \& Claps (2005), Wilson et al. (2009), Rengifo-Correa \& González (2011), Simbaqueda et al. (2014) y Panizzi \& Grazia (2015) dentro de Hemiptera; Dugdale (1988), D'Abrera (1994, 1995), Razowski et al. (2008), Dombroskie (2011), Reyes-Gallego et al. (2012) dentro de Lepidoptera; Caudell (1912), Rehn (1939), Grant (1964), Carbonell \& Descamps (1978), Otte (1979), Song (2009) y Cadena-Castañeda \& Cardona-Granda (2015) dentro de Orthoptera; Roth (1998) y TaucareRíos et al. (2018) dentro de Blattodea; Garrison et al. (2006, 2010) dentro de Odonata; Rivera (2001) dentro de Mantodea; Soto-Rodríguez et al. (2017) dentro Thysanoptera. Algunos de los especímenes colectados fueron depositados en la colección del Museo de Entomología de la Universidad Nacional de Tumbes, Perú (MEUNT).

La información obtenida se presenta a modo de listado taxonómico (orden, familia, subfamilia, género y especie) comentado, ordenado siguiendo la clasificación de Aspöck \& Aspöck (2007) para Neuroptera, Sharkey (2007) para Hymenoptera, Bouchard et al. (2011) para Coleoptera, Cryan \& Urban (2012) para Hemiptera, Ingrisch (2011) para Orthoptera, Mound (2013) para Thysanoptera, Pape et al. (2011) para Diptera, van Nieukerken et al. (2011) para Lepidoptera, Beccaloni \& Eggleton (2013) para Blattodea, Dijkstra et al. (2013) para Odonata y Rivera \& Vergara-Cobián (2017) para Mantodea.

Los taxones citados por primera vez se indican con una cruz $(\dagger)$. Para cada especie se incluye su distribución por provincia (Piura [PIU], Sullana [SULL], Sechura [SECH], Paita [PAI], Talara [TAL], Morropón [MORR], Huancabamba [HUA] y/o Ayabaca [AYA]) y paisaje ecológico (Matorral Xérico [MatX], Desierto costero [DESc], Bosques estacionalmente seco ribereño [BESr], Bosques estacionalmente seco de llanura [BES11] y/o Bosques estacionalmente secos de colina y montaña [BESc-m]) (More et al., 2014; MINAM, 2018), además datos de colecta siendo la secuencia del material examinado la siguiente: número de ejemplares $\widehat{\partial} \hat{\sigma}, q+q$, código de registro cuando procedió de material de revisión de colecciones entomológicas, país, provincia, distrito, localidad, coordenadas 
geográficas, altitud, fecha de captura, colector (leg.) y tipo de captura.

\section{Resultados y discusión}

En total 1034 ejemplares fueron recuperados a través de los métodos de colecta utilizados de los cuales 59 especies, 51 géneros, 18 familias y 3 órdenes no estaban previamente registradas en las listas de insectos asociados a $P$. pallida de la región Piura (Juárez et al., 2016; Juárez \& González, 2016a), siendo los órdenes Blattodea, Odonata, Dermaptera y las familias Blaberidae, Blattidae, Kalotermitidae, Coenagrionidae, Libellulidae, Labiduridae, Cleridae, Meloidae, Anthicidae, Platygastridae, Crabronidae, Tiphiidae, Gryllidae, Trydactilidae, Asilidae, Tabanidae, Miridae y Coreidae los nuevos taxones añadidos.

El material reportado por Juárez et al. (2016) permitió completar la identificación previa de: Blennidus Motschulsky, 1865, Stelidota Erichson, 1843, Psyllobora Chevrolat, 1837, Gymnetis MacLeay, 1819, Agrilaxia Kerremans, 1903, Heterachthes Newman, 1840, Acanthoscelides Schilsky, 1905, Pandeleteius Schönherr, 1834, Parepitragus Casey, 1907 y Prohylitus Kaszab, 1964 dentro de Coleoptera; Brachymeria Westwood, 1829, Chrysocharis Förster, 1856, Trichogramma Westwood, 1833, Aphytis Howard, 1900, Cotesia Cameron, 1891, Brachygastra Perty, 1833, Cephalotes Latreille, 1802, Crematogaster Lund, 1831, Pseudomyrmex Lund, 1831, Nannotrigona Cockerell, 1922, Xylocopa Latreille, 1802 y una morfoespecie de Pteromalidae dentro de Hymenoptera; Aphis Linnaeus, 1758, Dechacona Young, 1968, Hemiberlesia Leonardi, 1897, Heteropsylla Crawford, 1914, Dysdercus Audinet-Serville, 1835, Zelus Fabricius, 1803, Nezara Amyot \& Serville, 1843 y una morfoespecie de Membracidae dentro de Hemiptera; Agromyza Fallén, 1810, Enallodiplosis Gagne, 1994, Euxesta Loew, 1867, Eucelatoria Townsend, 1909, Chrysomya Robineau-Desvoidy, 1830, Cochliomyia Townsend, 1918, Musca Linnaeus, 1758 y una morfoespecie de Therevidae y Lonchaidae dentro de Diptera; Schistocerca Stal, 1873, Orphulina GiglioTos, 1894, Lactista Saussure, 1884 y dos morfoespecies de Proscopiidae dentro de Orthoptera; Chrysoperla Steinmann, 1964 y una morfoespecie de Myrmeleontidae dentro de Neuroptera y de Omiodes Guenée, 1854 dentro de Lepidoptera.

Cuatro de las morfoespecies citadas por Juárez et al. (2016) pertenecientes a las familias Aleyrodidae, Coccidae, Gracillaridae y Gelechiidae, las cuales no se lograron identificar, no fueron cosideradas en el conteo final de especies del presente trabajo, además estos mismos autores consideraron a Lasioderma serricorne (Fabricius, 1792) dentro de Anobiidae, sin embargo, aquí lo consideramos dentro de Ptinidae (Bouchard et al., 2011). Por lo tanto, la nueva lista taxonómica de los insectos asociados a $P$. pallida de la región Piura se actualizó a 12 órdenes, 84 familias, 175 géneros y 189 especies, de las cuales 62 únicamente han sido identificadas hasta el nivel de género.

Se ha comprobado que existe una estrecha interrelación recíproca entre las diferentes especies de Prosopis y la fauna silvestre (Domínguez, 1982; Núñez-Sacarías, 1993; Toro et al., 1993; Chiappa et al., 1997; Toro, 2002; Juárez et al., 2016; CruzadoJacinto et al., 2019). Varios estudios han demostrado que $P$. pallida es un componente importante en el hábitat de los insectos proporcionando un sitio de alimentación, refugio y reproducción, que, en determinadas circunstancias, producen pérdidas económicas (insectos plaga) y en otras ocasiones (controladores biológicos y polinizadores) ayudan a la supervivencia de esta importante especie vegetal (Huertas, 1987; Núñez-Sacarías, 1993; Llontop-Llaque, 2013; SENASA, 2016; Juárez et al., 2016).

Así, en el presente trabajo se pudo comprobar que algunas plántulas y árboles de $P$. pallida presentaban algún tipo de deterioro (defoliación, marchitez, coloración blanca y/o amarillenta de foliolos, descortezamiento y barrenamiento de ramas y troncos, destrucción de frutos y semillas) producido por insectos. Domínguez (1982), Núñez-Sacarías (1993) y Juárez et al. (2016) también detectaron los mismos daños en algarrobos de la región Piura, sin embargo, podrían existir otros factores (no tratados aquí) tal como lo afirman Llontop-Llaque (2013) y Juárez et al. (2016) quienes mencionan que los daños causados por insectos están en estrecha relación con factores climáticos (temperatura, precipitaciones, humedad relativa), los cuales influyen en el desarrollo y supervivencia de P. pallida. Del mismo modo, se pudo comprobar la existencia de algunos controladores biológicos regulando las poblaciones de insectos dañinos, ayudando a la supervivencia del algarrobo en la región Piura (Núñez-Sacarías, 1993; Juárez et al., 2016).

Entre los productores de daños, se encontraron algunos defoliadores (producen marchitez, decoloración, defoliación) tales como $E$. discordis, la cual se confirma su presencia sobre $P$. pallida (LlontopLlaque, 2013; Chipana-Auris, 2019), anteriormente registrada sobre Prosopis limensis Bentham (Whaley et al., 2019; Gagné \& Whaley, 2020), asimismo se confirma su presencia en Perú, anteriormente solo se reportaba para Chile y Argentina asociado a Prosopis tamarugo F. Phil (Gagné \& Jaschhof, 2017). Eccopsis galapagana Razowski \& Landry, 2008 cuyas larvas se observaron pegando y cubriendo los foliolos de plántulas y árboles con seda blanca muy fina, esta especie también ha sido reportada atacando a Prosopis juliflora (Sw.) DC. y Prosopis alba Griseb. en Colombia y Chile (Vargas, 2011; Reyes-Gallego et al., 2012), mientras que en Perú ha sido reportada recientemente atacando a P. pallida en las regiones de Tumbes y Piura (SENASA, 2016; Vargas-Ortiz et al., 2017). Melipotis, 
cuyas larvas fueron observadas defoliando plántulas y árboles y atacando el interior de troncos de árboles; varias especies de Melipotis como Melipotis cellaris (Guenée, 1852), Melipotis trujillensis Dognin, 1912 y Melipotis walkeri Butler, 1892 han sido reportadas atacando a $P$. tamarugo en Chile (Vargas \& Bobadilla, 2000; Vargas, 2010). Heteropsylla obscura Muddiman, Hodkinson \& Hollis, 1992 y Empoasca sin identificar sp. 1 fueron observadas sobre foliolos de plántulas y árboles; estas mismas especies fueron observados por Mormontoy del Pino (2015) y SENASA (2016) para los algarrobos de las regiones de Lambayeque, Piura y Tumbes, afirmando que producen entre el $30 \%$ a $50 \%$ de daños sobre los foliolos.

Del mismo modo, se encontraron algunos barrenadores de tallos y troncos de árboles como Sinoxylon unidentatum (Fabricius, 1801), Sinoxylon anale Lesne, 1897 y Dolichobostrychus angustus (Steinheil, 1872) (Bostrichidae) cuyas larvas y adultos se observaron barrenando la corteza interna de $P$. pallida. Estas especies ya fueron reportadas por Juárez (2014), Juárez et al. (2015, 2016), Juárez \& González (2016b) y Juárez-Noé \& González-Coronado (2018, 2019) atacando árboles de P. pallida en la región Piura, sin embargo, aún siguen siendo consideradas como plagas cuarentenarias no presentes en Perú por el Servicio Nacional de Sanidad Agraria (SENASA, 2020). Destacan también los cerambícidos Eburia pilosa Erichson, 1834 y Achryson lineolatum Erichson, 1847 cuyos adultos se observaron barrenando la corteza exterior árboles (Juárez et al., 2016), Córdova et al. (2000) y Mazzuferi (2000) resaltan la importancia de los daños que producen algunos cerambícidos en Prosopis flexuosa DC. en Argentina.

Los frutos y semillas son atacadas generalmente por brúchidos tales como Callosobruchus maculatus (Fabricius, 1775), Amblycerus piurae (Pierce, 1915), Acanthoscelides obtectus Say, 1831, Acanthoscelides suramerica Johnson, 1990 y microlepidópteros como Plodia interpunctella Hübner, 1813, Laspeyresia sp y Cryptophlebia sp (Domínguez, 1982; NúñezSacarías, 1993; Juárez et al., 2016), sin embargo, se observó siendo atacadas también por Gymnetis merops Ratcliffe, 2018 y Gymnetis stellata Latreille, 1833. En Perú, estas especies han sido reportadas sobre frutos maduros de especies frutales como Citrus unshiu Marcov., Vitis vinifera L., Spondias purpurea L., Persea americana Mill., Opuntia ficus-indica (L.) Mill., Psidium guajava L., Citrus x limon (L.) Osbeck y Musa sp (Morón et al., 1997; Juárez \& González, 2015; Ratcliffe, 2018; Juárez-Noé \& GonzálezCoronado, 2019), por lo que los registros presentados aquí confirman que estas especies de coleópteros consumen también frutos maduros de P. pallida. Algunos hemípteros como Stictopelta acutula (Fairmaire, 1846) y Vanduzea sin identificar sp 1 se observaron succionando savia en ramas, tallos y troncos de plántulas y árboles produciendo al poco tiempo manchas circulares e irregulares blanquecinas; estas especies no han sido mencionadas anteriormente en $P$. pallida (Domínguez, 1982; Núñez-Sacarías, 1993; Juárez et al., 2016; SENASA, 2016). Piezogaster obscuratus (Montando, 1899) se observó alimentándose de savia sobre ramas y troncos de árboles; esta especie fue reportada por primera vez para Perú desde la región Piura por Juárez \& González (2016c) asociada a P. pallida, por lo que los registros presentados aquí demuestran que este hemíptero ya se estableció definitivamente en los algarrobos de la región Piura.

Entre los insectos beneficiosos para el algarrobo se encuentran algunos controladores biológicos y polinizadores. Entre los primeros destacan Paraneda pallidula (Mulsant, 1850), Paraneda sin identificar sp 1, Hippodamia convergens Guerin-Meneville, 1842, Cheilomenes sexmaculata (Fabricius, 1781), Cycloneda sanguinea (Linnaeus, 1763) y Zagreus hexasticta (Crotch, 1874) cuyas larvas y adultos se comportan como depredadores de ninfas y adultos de áfidos y cóccidos (González, 2007). Es importante mencionar que $P$. pallidula, Paraneda sin identificar sp 1, H. convergens, Brachygastra lecheguana, Polistes versicolor, Pachodynerus sin identificar sp 1, Polybia sin identificar sp 1 y Dorymyrmex pyramicus peruvianus Wheeler, 1919 fueron observadas depredando larvas de E. discordis, este mismo comportamiento fue registrado por Juárez et al. (2016) y ChipanaAuris (2019) en algarrobos de las regiones de Piura y Lambayeque respectivamente, lo que demuestra que estas especies constituyen importantes controladores biológicos de este tipo de díptero. Asimismo, destacan Cotesia flavipes Cameron, 1891, Digonogastra rimac (Wolcott, 1929) y Habrobracon hebetor (Say, 1836) cuyos adultos se comportan como parasitoides principalmente de microlepidópteros (Núñez-Sacarías, 1993; Juárez et al., 2016).

Domínguez (1982), Núñez-Sacarías (1993) y Juárez et al. (2016) no hacen mención de insectos polinizadores en $P$. pallida, sin embargo, algunas especies citadas aquí tales como los adultos de Apis mellifera Linnaeus, 1758, Leptotes trigemmatus (Butler, 1881), Villa sin identificar sp 1 y Pachodynerus sin identificar sp 1 también han sido mencionadas como agentes polinizadores de $P$. tamarugo, $P$. flexuosa y Prosopis strombulifera (Lam.) Benth. en Chile (Toro et al., 1993; Chiappa et al., 1997; Toro, 2002), lo que sugiere la importancia que tienen estas especies en la reproducción de Prosopis en Sudamérica. Asimismo, especial atención deberían tener otras especies citadas aquí como Xylocopa (Schonnherria) piurensis Cockerell, 1912, Nannotrigona mellaria (Smith, 1862), Brachygastra lecheguana (Latreille, 1824), Polistes (Aphanilopterus) versicolor versicolor (Olivier, 1791), Hemipenthes sin identificar sp 1 , Thyridantrax sin identificar sp 1, Palpada sin identificar sp 1, Allograpta piurana Shannon, 1927 y Hemiargus ramon (Dognin, 1887) las cuales 
también fueron observadas con mucha frecuencia visitando inflorescencias de $P$. pallida. A su vez, algunas especies polinizadoras juegan también otros roles ecológicos dentro de $P$. pallida, tal es el caso de $B$. lecheguana, $P$. versicolor y Pachodynerus sin identificar sp 1 que se comportan como depredadores de poblaciones de larvas de lepidópteros y E. discordis (Núñez-Sacarías, 1993; Juárez et al., 2016; ChipanaAuris, 2019); de Palpada sin identificar sp 1 y A. piurana cuyas larvas depredan ninfas y adultos de áfidos y cóccidos (Mengual et al., 2009), mientras que las larvas de L. trigemmatus son consideradas como plaga en inflorescencias y flores de $P$. tamarugo y P. flexuosa (Bobadilla et al., 1987; Toro et al., 1993).

Por último, desde hace varias décadas, la actividad antropogénica (tala indiscriminada, cambios en el uso del suelo, deforestación, degradación) viene siendo una amenaza latente en la conservación de los bosques de $P$. pallida en la región Piura, la cual influye negativamente en los procesos ecológicos que realiza dentro del ecosistema. Por ello, se hace necesario plantear estrategias para su gestión y conservación debido a la importancia ecológica que tiene como especie clave dentro de los bosques estacionalmente secos y como hábitat para los insectos y fauna en general en la costa norte de Perú (Domínguez, 1982; Núñez-Sacarías, 1993; Juárez et al., 2016; CruzadoJacinto et al., 2019).

\section{LisTA TAXONÓMICA}

Orden ODONATA Fabricius, $1793+$

Suborden Zygoptera Selys, $1854 \uparrow$

Familia Coenagrionidae Kirby, $1890 \dagger$

Género Ischnura Charpentier, $1840 \dagger$

1. Ischnura $\sin$ identificar sp. $1 . \dagger$ (Fig. 1)

Material examinado. PERÚ. 1 o, Piura, Castilla, Universidad Nacional de Piura, $05^{\circ} 10^{\prime} 51^{\prime \prime} \mathrm{S}-80^{\circ} 37^{\prime} 31^{\prime \prime} \mathrm{O}, 29 \mathrm{msnm}$, 2-II-2015, U. González leg., red entomológica, Bosque estacionalmente seco de llanura; 1 q, Sullana, Salitral, 451'27"S-8040'52"O, 40 msnm, 6-IV-2016, G. Juárez leg., red entomológica, Bosque estacionalmente seco de llanura; 1 q, Talara, Lobitos, $4^{\circ} 27^{\prime} 10^{\prime \prime} \mathrm{S}-81^{\circ} 16^{\prime} 40^{\prime \prime} \mathrm{O}, 12 \mathrm{msnm}, 27-\mathrm{VI}-$ 2014, G. Juárez leg., red entomológica, Desierto costero; 1 ㅇ, Paita, $05^{\circ} 04^{\prime} \mathrm{S}-81^{\circ} 06^{\prime} \mathrm{O}, 10 \mathrm{msnm}, 7-\mathrm{IX}-2013$, G. Juárez leg., red entomológica, Bosque estacionalmente seco de llanura; 1 ㅇ, Sechura, Desierto de Sechura, $05^{\circ} 34^{\prime} \mathrm{S}-81^{\circ} 16^{\prime} \mathrm{O}$, 10 msnm, 13-XII-2013, G. Juárez leg., red entomológica, Desierto costero; 1 + , Morropón, Piedra del Toro, 051'ㅅ- $80^{\circ} 49^{\prime} \mathrm{O}, 1225 \mathrm{msnm}, 29-\mathrm{VII}-2013$, U. González leg., red entomológica, Bosque estacionalmente seco de colina; Huancabamba, Huarmaca, $05^{\circ} 34^{\prime} 04^{\prime \prime} \mathrm{S}-79^{\circ} 31^{\prime} 26^{\prime \prime} \mathrm{O}$, 1223 msnm, 26-VII-2016, G. Juárez leg., red entomológica, Bosque estacionalmente seco de colina; 1 q, 1 $\delta$, Ayabaca, Suyo, 430'45"S-8002'10"O, 450 msnm, 15-XI-2013, G. Juárez leg., Bosque estacionalmente seco de colina.

Distribución (Provincia) (Paisaje ecológico). (PIU, SUll, TAL, PAI, SECH, MORR, AYA, HUA) (MatX, DESc, BESr, BESll, BESc-m).

Comentario. Los adultos se encuentran sobre hojas de plántulas y árboles, en solitario.
Suborden Anisoptera Selys, $1854 \uparrow$

Familia Libellulidae Leach, $1815 \dagger$

Género Pantala Hagen, $1861 \dagger$

\section{Pantala flavescens (Fabricius, 1758) $\dagger$}

Material eXAminado. PERÚ. 2 o $o$, Piura, Catacaos, 05'15'42"S-8040'27"O, 29 msnm, 16-VII-2016, U. González leg., red entomológica, Bosque estacionalmente seco ribereño; 1 +, 1 $\hat{\text {, }}$ Piura, Universidad de Piura, 0510'11"S-80³6'51"O, 29 msnm, 27-IX-2018, U. González leg., red entomológica, Bosque estacionalmente seco de llanura; 2 웅, 2 우오, Sullana, Lancones, $4^{\circ} 38^{\prime} 27^{\prime \prime} \mathrm{S}-80^{\circ} 32^{\prime} 55^{\prime \prime} \mathrm{O}$, 190 msnm, 14-XI-2015, G. Juárez leg., red entomológica, Bosque estacionalmente seco de colina; 1 क, Talara, Los Órganos, $4^{\circ} 10^{\prime} 38^{\prime \prime} \mathrm{S}-81^{\circ} 07^{\prime} 27^{\prime \prime} \mathrm{O}, 12 \mathrm{msnm}, 05-\mathrm{V}-2017$, G. Juárez leg., red entomológica, Desierto; 1 ㅇ, Talara, El Alto, 416'04"S-81 ${ }^{\circ} 13^{\prime} 09^{\prime \prime} \mathrm{O}$, 300 msnm, 13-X-2017, G. Juárez leg., red entomológica, Bosque estacionalmente seco de montaña; 1 옹 Paita, $05^{\circ} 04^{\prime} \mathrm{S}-81^{\circ} 06^{\prime} \mathrm{O}, 10 \mathrm{msnm}, 21-\mathrm{II}-2017$, G. Juárez leg., red entomológica, Bosque estacionalmente seco de llanura; 1 ㅇ, Sechura, Illescas, $05^{\circ} 58^{\prime} \mathrm{S}-81^{\circ} 05^{\prime} \mathrm{O}, 10 \mathrm{msnm}$, 12-XII-2017, U. González leg., red entomológica, Matorral Xérico; 1 ơ, Sechura, Sechura, $05^{\circ} 34^{\prime} \mathrm{S}-81^{\circ} 16^{\prime} \mathrm{O}, 16 \mathrm{msnm}$, 24-VI-2017, U. González leg., red entomológica, Desierto costero; 1 , Morropón, Chulucanas, $05^{\circ} 05^{\prime} \mathrm{S}-80^{\circ} 99^{\prime} \mathrm{O}$, 350 msnm, 22-I-2015, G. Juárez leg., red entomológica, Bosque estacionalmente seco de colina; 2 우, Morropón, Morropón, $05^{\circ} 05^{\prime} 51^{\prime \prime} \mathrm{S}-80^{\circ} 09^{\prime} 44^{\prime \prime} \mathrm{O}, 557 \mathrm{msnm}, 23-\mathrm{I}-2015$, G. Juárez leg., red entomológica, Bosque estacionalmente seco de colina; Huancabamba, Huarmaca, $05^{\circ} 34^{\prime} 04^{\prime \prime S}-79^{\circ} 31^{\prime} 26^{\prime \prime} \mathrm{O}$, 1223 msnm, 26-VII-2016, G. Juárez leg., red entomológica, Bosque estacionalmente seco de colina; $2 \hat{\jmath} \hat{\partial}$, Ayabaca, Paimas, 4³7'37"S-7956'43"O, 473 msnm, 26-VII-2015, G. Juárez leg., red entomológica, Bosque estacionalmente seco de llanura.

Distribución (Provincia) (PAisaje ecológico). (PIU, SUlL, TAL, PAI, SECH, MORR, AYA, HUA) (MatX, DESc, BESr, BESll, BESc-m).

COMENTARIO. Los adultos se encuentran sobre hojas de plántulas y árboles, en solitario.

Orden DERMAPTERA DeGeer, $1773 \dagger$

Familia Labiduridae Verhoeff, $1902 \uparrow$

Género Labidura Leach, 1815 †

3. Labidura riparia (Pallas, 1773) $\dagger$

Material examinado. PERÚ. 1 , Piura, Castilla, Universidad Nacional de Piura, $05^{\circ} 10^{\prime} 51^{\prime \prime} \mathrm{S}-80^{\circ} 37^{\prime} 31^{\prime \prime} \mathrm{O}, 29 \mathrm{msnm}, 2-\mathrm{II}-$ 2018, U. González leg., colecta manual, Bosque estacionalmente seco de llanura; 1 \&, Piura, Universidad de Piura, 0510'11"S-80³6'51"O, 29 msnm, 29-VI-2017, G. Juárez leg., colecta manual, Bosque estacionalmente seco de llanura; 1 ,

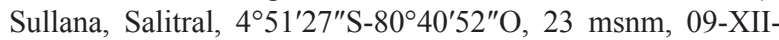
2015, G. Juárez leg., colecta manual, Bosque estacionalmente seco de llanura; 1 9, Talara, El Alto, $4^{\circ} 16^{\prime} 04^{\prime \prime} \mathrm{S}-81^{\circ} 13^{\prime} 09^{\prime \prime} \mathrm{O}$, 8 msnm, 21-IX-2017, G. Juárez leg., colecta manual, Desierto costero; 1 o , Paita, $05^{\circ} 04^{\prime} \mathrm{S}-81^{\circ} 06^{\prime} \mathrm{O}, 10 \mathrm{msnm}, 2$-VIII-2017, G. Juárez leg., colecta manual, Bosque estacionalmente seco de llanura; 1 ㅇ, Sechura, Illescas, $05^{\circ} 58^{\prime} \mathrm{S}-81^{\circ} 05^{\prime} \mathrm{O}, 10 \mathrm{msnm}$, 12-XII-2017, U. González leg., colecta manual, Matorral Xérico; 1 ㅇ, Morropón, Chulucanas, $05^{\circ} 05^{\prime} \mathrm{S}-80^{\circ} 99^{\prime} \mathrm{O}$, 350 msnm, 13-VIII-2018, G. Juárez leg., colecta manual, Bosque estacionalmente seco de colina; 2 우, Morropón, Morropón, $05^{\circ} 05^{\prime} 51^{\prime \prime} \mathrm{S}-80^{\circ} 09^{\prime} 44^{\prime \prime} \mathrm{O}$, $557 \mathrm{msnm}, 23-\mathrm{I}-2015$, G. Juárez leg., colecta manual, Bosque estacionalmente seco

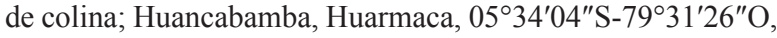


1223 msnm, 26-VII-2016, G. Juárez leg., colecta manual,

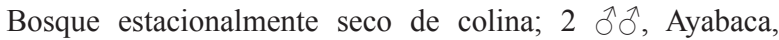
Paimas, 437'37"S-7956'43"O, 473 msnm, 26-VII-2015, G. Juárez leg., colecta manual, Bosque estacionalmente seco de llanura.

Distribución (Provincia) (Paisaje ecológico). (PIU, SUll, TAL, PAI, SECH, MORR, AYA, HUA) (MatX, DESc, BESr, BESIl, BESc-m).

Comentario. Los adultos se encuentran a ras del suelo cercano al tronco y sobre hojas, ramas y troncos de plántulas y árboles, en solitario. Controlador biológico importante, ninfas y adultos son depredadores de larvas de lepidópteros, ninfas y adultos de áfidos, larvas de coleópteros (Rondón \& Vergara, 2003).

Orden ORTHOPTERA Olivier, 1879

Suborden Ensifera Chopard, 1920

Familia Tettigoniidae Krauss, 1902

Subfamilia Conocephalinae Burmeister, 1838

Género Conocephalus Thunberg, 1815

4. Conocephalus sin identificar sp. 1

Material examinado. PERÚ. 1 \%, Piura, Universidad de Piura, 05¹0'11"S-80³6'51"O, 29 msnm, 04-IV-2015, U. González leg., red entomológica, Bosque estacionalmente seco de llanura; 1 9, Sullana, Salitral, $4^{\circ} 51^{\prime} 27^{\prime \prime} \mathrm{S}-80^{\circ} 40^{\prime} 52^{\prime \prime} \mathrm{O}$, 23 msnm, 28-X-2017, G. Juárez leg., red entomológica, Bosque estacionalmente seco de llanura; 1 , Talara, El Alto, $4^{\circ} 16^{\prime} 04^{\prime \prime} \mathrm{S}-81^{\circ} 13^{\prime} 09^{\prime \prime} \mathrm{O}, 5$ msnm, 23-IV-2015, G. Juárez leg., red entomológica, Desierto; 3 우, Paita, Miguel Checa, 454'S-8048'O, 10 msnm, 12-III-2016, G. Juárez leg., red entomológica, Bosque estacionalmente seco de llanura; 1 , Sechura, Vice, $05^{\circ} 25^{\prime} \mathrm{S}-81^{\circ} 46^{\prime} \mathrm{O}, 10 \mathrm{msnm}, 17-\mathrm{VIII}-2015$, U. González leg., red entomológica, Desierto costero; 2 우우, Sechura, Illescas, $05^{\circ} 58^{\prime} \mathrm{S}-81^{\circ} 05^{\prime} \mathrm{O}, 10 \mathrm{msnm}, 12-\mathrm{XI}-2017$, U. González leg., red entomológica, Matorral Xérico; 1 ㅇ, Morropón, Morropón, 0505'51"S-8009'44"O, 557 msnm, 14-V-2017, G. Juárez leg., red entomológica, Bosque estacionalmente seco de colina; $2 \hat{\partial} \hat{\partial}$, Ayabaca, Paimas, 4³7'37"S-7956'43"O, 473 msnm, 26-VII-2015, G. Juárez leg., red entomológica, Bosque estacionalmente seco de llanura; Huancabamba, Huarmaca, $05^{\circ} 34^{\prime} 04^{\prime \prime} \mathrm{S}-79^{\circ} 31^{\prime} 26^{\prime \prime} \mathrm{O}$, 1223 msnm, 26-VII-2016, G. Juárez leg., red entomológica, Bosque estacionalmente seco de colina.

Distribución (PROVINCIA) (PAISAJE ECOlÓgICO). (PIU, SULL, TAL, PAI, SECH, MORR, HUA, AYA) (MatX, DESc, BESr, BESll, BESc-m).

COMENTARIO. Los adultos y ninfas se encuentran sobre hojas de plántulas y árboles, en solitario o en grupo de dos a tres individuos. Insecto que se comporta como fitófago, ninfas y adultos causan defoliación. El número de individuos colectados aumentó en época de lluvia (diciembre-marzo). Especie citada también por Juárez et al. (2016).

Género Neoconocephalus Karny, $1907 \dagger$

5. Neoconocephalus $\sin$ identificar sp. $1 . \dagger$

Material examinado. PERÚ. 1 , Piura, Universidad de Piura, 05 ${ }^{\circ} 10^{\prime} 11^{\prime \prime S}-80^{\circ} 36^{\prime} 51^{\prime \prime} \mathrm{O}, 29$ msnm, 04-IV-2015, U. González leg., red entomológica, Bosque estacionalmente seco de llanura; 1 q, Sullana, Salitral, $4^{\circ} 51^{\prime} 27^{\prime \prime} \mathrm{S}-80^{\circ} 40^{\prime} 52^{\prime \prime} \mathrm{O}$, 23 msnm, 28-X-2017, G. Juárez leg., red entomológica, Bosque estacionalmente seco de llanura; 1 , Talara, El Alto, $4^{\circ} 16^{\prime} 04^{\prime \prime} \mathrm{S}-81^{\circ} 13^{\prime} 09^{\prime \prime} \mathrm{O}, 5$ msnm, 23-IV-2015, G. Juárez leg.,

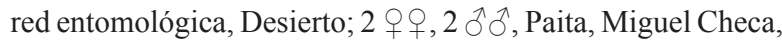
$4^{\circ} 54^{\prime} \mathrm{S}-80^{\circ} 48^{\prime} \mathrm{O}, 10 \mathrm{msnm}, 12-\mathrm{III}-2016$, G. Juárez leg., red entomológica, Bosque estacionalmente seco de llanura; 1 ㅇ, Sechura, Vice, $05^{\circ} 25^{\prime} \mathrm{S}-81^{\circ} 46^{\prime} \mathrm{O}, 10 \mathrm{msnm}, 17-\mathrm{VIII}-2015$, U. González leg., red entomológica, Desierto costero; 2 우우, Sechura, Illescas, $05^{\circ} 58^{\prime} \mathrm{S}-81^{\circ} 05^{\prime} \mathrm{O}, 10 \mathrm{msnm}, 12-\mathrm{XI}-2017$, U. González leg., red entomológica, Matorral Xérico; 1 우, Morropón, Morropón, 0505'51"S-8009'44"O, 557 msnm, 14-V-2017, G. Juárez leg., red entomológica, Bosque estacionalmente seco de colina; $2 \hat{\partial} \widehat{\partial}$, Ayabaca, Paimas, 4³7'37"S-7956'43"O, 473 msnm, 26-VII-2015, G. Juárez leg., red entomológica, Bosque estacionalmente seco de llanura; Huancabamba, Huarmaca, $05^{\circ} 34^{\prime} 04^{\prime \prime} \mathrm{S}-79^{\circ} 31^{\prime} 26^{\prime \prime} \mathrm{O}$, 1223 msnm, 26-VII-2016, G. Juárez leg., red entomológica, Bosque estacionalmente seco de colina.

Distribución (Provincia) (PAISAJE ECOlÓGICO). (PIU, SULL, TAL, PAI, SECH, MORR, HUA, AYA) (MatX, DESc, BESr, BESll, BESc-m).

Comentario. Los adultos y ninfas se encuentran sobre hojas de plántulas y árboles, en solitario. Insecto que se comporta como fitófago, ninfas y adultos causan defoliación. El número de individuos colectados aumentó en época de lluvia (diciembre-marzo).

Subfamilia Phaneropterinae Burmeister, $1838 \dagger$

Género Ceraia Brunner von Wattenwyl, $1891 \dagger$

6. Ceraia $\sin$ identificar sp. $1 . \dagger$

Material examinado. PERÚ. 1 q, Piura, Universidad de Piura, 05¹0'11"S-80³6'51"O, 29 msnm, 04-IV-2015, U. González leg., red entomológica, Bosque estacionalmente seco de llanura; 1 क, Piura, Catacaos, $05^{\circ} 15^{\prime} 42^{\prime \prime} \mathrm{S}-80^{\circ} 40^{\prime} 27^{\prime \prime} \mathrm{O}$, 29 msnm, 16-VII-2017, U. González leg., red entomológica, Bosque estacionalmente seco ribereño; 1 , Sullana, Salitral, 451'27"S-8040'52"O, 23 msnm, 28-X-2017, G. Juárez leg., red entomológica, Bosque estacionalmente seco de llanura; 1 ㅇ, Talara, El Alto, $4^{\circ} 16^{\prime} 04^{\prime \prime} \mathrm{S}-81^{\circ} 13^{\prime} 09^{\prime \prime} \mathrm{O}, 5 \mathrm{msnm}, 23$-IV2015, G. Juárez leg., red entomológica, Desierto costero; 2 우, Paita, Miguel Checa, $4^{\circ} 54^{\prime} \mathrm{S}-80^{\circ} 48^{\prime} \mathrm{O}, 10 \mathrm{msnm}, 12-\mathrm{III}-2016$, G. Juárez leg., red entomológica, Bosque estacionalmente seco de llanura; 1 o , Sechura, Vice, $05^{\circ} 25^{\prime} \mathrm{S}-81^{\circ} 46^{\prime} \mathrm{O}, 10 \mathrm{msnm}$, 17-VIII-2015, U. González leg., red entomológica, Desierto costero; 1 †, Morropón, Chulucanas, $05^{\circ} 05^{\prime} \mathrm{S}-80^{\circ} 99^{\prime} \mathrm{O}$, 350 msnm, 13-VIII-2018, G. Juárez leg., red entomológica, Bosque estacionalmente seco de llanura.

Distribución (Provincia) (PAISAJE ECOLÓgico). (PIU, SULL, PAI, TAL, SECH, MORR) (BESr, BESIl, DESc).

Comentario. Los adultos y ninfas se encuentran sobre hojas de plántulas y árboles, en solitario. Insecto que se comporta como fitófago, ninfas y adultos causan defoliación. El número de individuos colectados aumentó en época de lluvia (diciembre-marzo).

\section{Género Scudderia Stål, $1873 \dagger$}

7. Scudderia sin identificar sp. $1 . \dagger$

Material examinado. PERÚ. 1 \%, Piura, Universidad de Piura, 5¹0'11"S-80³6'51"O, 29 msnm, 14-V-2019, U. González leg., red entomológica, Bosque estacionalmente seco de llanura; 1 \& , Piura, Catacaos, $5^{\circ} 15^{\prime} 42^{\prime \prime} \mathrm{S}-80^{\circ} 40^{\prime} 27^{\prime \prime} \mathrm{O}, 29 \mathrm{msnm}$, 16-VII-2017, U. González leg., red entomológica, Bosque estacionalmente seco ribereño; 1 +, Sullana, Salitral, 451'27"S-8040'52"O, 23 msnm, 28-X-2017, G. Juárez leg., red entomológica, Bosque estacionalmente seco de llanura; 1 ㅇ, Talara, El Alto, $4^{\circ} 16^{\prime} 04^{\prime \prime} \mathrm{S}-81^{\circ} 13^{\prime} 09^{\prime \prime} \mathrm{O}, 5 \mathrm{msnm}$, 23-IV-2016, G. Juárez leg., red entomológica, Desierto costero; 2 우, Paita, Miguel Checa, $4^{\circ} 54^{\prime} \mathrm{S}-80^{\circ} 48^{\prime} \mathrm{O}, 10 \mathrm{msnm}$, 
22-II-2017, G. Juárez leg., red entomológica, Bosque estacionalmente seco de llanura; 1 q, Sechura, Vice, $5^{\circ} 25^{\prime} \mathrm{S}-81^{\circ} 46^{\prime} \mathrm{O}$, 10 msnm, 17-VIII-2016, U. González leg., red entomológica, Desierto costero; 1 + , Morropón, Chulucanas, $5^{\circ} 05^{\prime} \mathrm{S}-80^{\circ} 99^{\prime} \mathrm{O}$, 350 msnm, 13-VIII-2018, G. Juárez leg., red entomológica, Bosque estacionalmente seco de llanura.

Distribución (Provincia) (Paisaje ecológico). (PIU, SUll, PAi, TAL, SECH, MORR) (BESr, BESll, DESc).

COMENTARIO. Los adultos se encuentran sobre hojas de plántulas y árboles, en solitario. Insecto que se comporta como fitófago, ninfas y adultos causan defoliación. El número de individuos colectados aumentó en época de lluvia (diciembre-marzo).

Familia Gryllidae Laicharting, $1781 \dagger$

Subfamilia Gryllinae Laicharting, $1781 \uparrow$

Género Gryllus Linnaeus, $1758 \dagger$

8. Gryllus sin identificar sp $1 \dagger$

Material examinado. Perú. 3 oo , Piura, Catacaos, 5¹5'42"S-8040'27"O, 29 msnm, 06-II-2017, U. González leg., colecta manual, Bosque estacionalmente seco de llanura; 2 우우, $2 \widehat{\partial} \hat{\partial}$, Piura, Universidad de Piura, $5^{\circ} 10^{\prime} 11^{\prime \prime} \mathrm{S}-80^{\circ} 36^{\prime} 51^{\prime \prime} \mathrm{O}$, 29 msnm, 26-II-2016, U. González leg., colecta manual, Bosque estacionalmente seco de llanura; 1 , Piura, Castilla, Universidad Nacional de Piura, $5^{\circ} 10^{\prime} 51^{\prime \prime} \mathrm{S}-80^{\circ} 37^{\prime} 31^{\prime \prime} \mathrm{O}$, 29 msnm, 14-III-2018, G. Juárez leg., colecta manual, Bosque estacionalmente seco ribereño; 2 우, Sullana, Querecotillo, 450'24"S-80³8'57"O, 23 msnm, 19-I-2016, G. Juárez leg., colecta manual, Bosque estacionalmente seco de llanura; 2 우, Paita, 504'S-81 $06^{\prime} \mathrm{O}, 10$ msnm, 2-VIII-2017, G. Juárez leg., colecta manual, Bosque estacionalmente seco de llanura; 1 , Talara, El Alto, $4^{\circ} 16^{\prime} 04^{\prime \prime} \mathrm{S}-81^{\circ} 13^{\prime} 09^{\prime \prime} \mathrm{O}, 300 \mathrm{msnm}, 13-\mathrm{V}-2016$, colecta manual, G. Juárez leg., Bosque estacionalmente seco de colina; 2 우, $2 \delta^{\wedge} \delta^{\lambda}$, Sechura, Vice, $5^{\circ} 25^{\prime} \mathrm{S}-81^{\circ} 46^{\prime} \mathrm{O}, 10 \mathrm{msnm}$, 2-II-2015, U. González leg., red entomológica, Desierto; 2 우우, Sechura, Illescas, $5^{\circ} 58^{\prime} \mathrm{S}-81^{\circ} 05^{\prime} \mathrm{O}, 10 \mathrm{msnm}, 12-\mathrm{XI}-2017$, U. González leg., red entomológica, Matorral Xérico; 3 กิ ô, Morropón, Chulucanas, $5^{\circ} 05^{\prime} \mathrm{S}-80^{\circ} 99^{\prime} \mathrm{O}, 350 \mathrm{msnm}, 05-\mathrm{III}-$ 2017, G. Juárez leg., red entomológica, Bosque estacionalmente seco de colina; $1 \widehat{O}^{\lambda}$, Ayabaca, Suyo, $4^{\circ} 30^{\prime} 45^{\prime \prime} \mathrm{S}-80^{\circ} 00^{\prime} 10^{\prime \prime} \mathrm{O}$, 408 msnm, 23-X-2015, G. Juárez leg., red entomológica, Bosque estacionalmente seco de colina; Huancabamba, Huarmaca, 5³4'04"S-79³1'26"O, 1223 msnm, 26-VII-2016, G. Juárez leg., red entomológica, Bosque estacionalmente seco de colina.

Distribución (Provincia) (Paisaje ecológico). (PIU, SUlL, PAi, TAL, SECH, MORR, AYA, HUA) (MatX, DESc, BESr, BES1l, BESc-m).

Comentario. Los adultos y ninfas se encuentran sobre hojas, ramas y troncos de plántulas y árboles, en solitario o en grupos de dos o más individuos. Insecto que se comporta como fitófago, ninfas y adultos causan defoliación principalmente en plántulas. El número de individuos colectados aumentó en época de lluvia (diciembre-marzo).

Familia Tridactylidae Brullé, $1835 \dagger$

Subfamilia Tridactylinae Brullé, $1835 \uparrow$

Género Ellipes Scudder, $1902 \dagger$

9. Ellipes occidentalis Günther, $1977 \dagger$

Material examinado. PERÚ. 2 9 , Piura, Universidad de Piura, $5^{\circ} 10^{\prime} 11^{\prime \prime} \mathrm{S}-80^{\circ} 36^{\prime} 51^{\prime \prime} \mathrm{O}, 29 \mathrm{msnm}, 26-\mathrm{II}-2016$, U. González leg., colecta manual, Bosque estacionalmente seco de llanura; 1 \&, Piura, Castilla, Universidad Nacional de Piura, 5¹0'51"S-80³7'31"O, 29 msnm, 14-III-2018, G. Juárez leg., colecta manual, Bosque estacionalmente seco ribereño; 1 , Sullana, Querecotillo, 450'24"S-80³8'57"O, 23 msnm, 19-I2016, G. Juárez leg., colecta manual, Bosque estacionalmente seco de llanura; 1 , Paita, $5^{\circ} 04^{\prime} \mathrm{S}-81^{\circ} 06^{\prime} \mathrm{O}, 10 \mathrm{msnm}, 2$-VIII2017, G. Juárez leg., colecta manual, Bosque estacionalmente seco de llanura; 1 ㅇ, Talara, El Alto, $4^{\circ} 16^{\prime} 04^{\prime \prime} \mathrm{S}-81^{\circ} 13^{\prime} 09^{\prime \prime} \mathrm{O}$, 300 msnm, 13-V-2016, colecta manual, G. Juárez leg., Bosque estacionalmente seco de colina; 2 우, Sechura, Vice, $5^{\circ} 25^{\prime} \mathrm{S}-81^{\circ} 46^{\prime} \mathrm{O}, 10 \mathrm{msnm}, 2-\mathrm{II}-2015$, U. González leg., colecta manual, Desierto; 1 +, Sechura, Illescas, $5^{\circ} 58^{\prime} \mathrm{S}-81^{\circ} 05^{\prime} \mathrm{O}, 10 \mathrm{msnm}, 12-\mathrm{XI}-2017$, U. González leg., red entomológica, Matorral Xérico; 2 우, Morropón, Chulucanas, $5^{\circ} 05^{\prime} \mathrm{S}-80^{\circ} 99^{\prime} \mathrm{O}, 350 \mathrm{msnm}, 05-\mathrm{III}-2017$, G. Juárez leg., red entomológica, Bosque estacionalmente seco de colina; $1 \hat{\delta}$, Ayabaca, Suyo, 430'45"S-80 00'10"O, 408 msnm, 23-X-2015, G. Juárez leg., red entomológica, Bosque estacionalmente seco de colina; Huancabamba, Huarmaca, 5³4'04"S-79³1'26"O, 1223 msnm, 26-VII-2016, G. Juárez leg., red entomológica, Bosque estacionalmente seco de colina.

Distribución (Provincia) (Paisaje ecológico). (PIU, SUlL, PAi, TAL, SECH, MORR, AYA, HUA) (MatX, DESc, BESr, BESll, BESc-m).

Comentario. Los adultos se encuentran en tierra húmeda al ras del suelo muy cercanos al tronco y/o escondidos en grietas del tronco; al parecer utiliza al algarrobo como sitio de descanso y refugio. El número de individuos colectados aumentó en época de lluvia (diciembre-marzo).

Familia Proscopiidae Serville, 1838

Subfamilia Proscopiinae Serville, 1838

Género Anchotatus Brunner von Wattenwyl, 1890

10. Anchotatus brevicornis (Caudell, 1912) (Fig. 2)

Material examinado. PERÚ. 1 \%, Piura, Castilla, Universidad Nacional de Piura, 5 $10^{\prime} 51^{\prime \prime} \mathrm{S}-80^{\circ} 37^{\prime} 31^{\prime \prime} \mathrm{O}, 29 \mathrm{msnm}, 17-\mathrm{IV}-$ 2018, U. González leg., red entomológica, Bosque estacionalmente seco de ribereño; 1 , Piura, Universidad de Piura, 5¹0'11"S-80³6'51"O, 29 msnm, 16-VII-2018, G. Juárez leg., colecta manual, Bosque estacionalmente seco de llanura; 1 , Sullana, Querecotillo, 450'24"S-80 $38^{\prime} 57^{\prime \prime} \mathrm{O}, 23 \mathrm{msnm}$, 21-X-2017, G. Juárez leg., red entomológica, Bosque estacionalmente seco de llanura; 1 q, Talara, Los Órganos, $4^{\circ} 10^{\prime} 38^{\prime \prime} \mathrm{S}-81^{\circ} 07^{\prime 2} 27^{\prime \prime} \mathrm{O}, 12 \mathrm{msnm}, 11-\mathrm{VIIi}-2017$, G. Juárez leg., colecta manual, Bosque estacionalmente seco de llanura; 1 ,

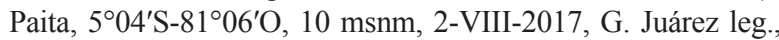
red entomológica, Bosque estacionalmente seco de llanura; 1 O, Sechura, Vice, $5^{\circ} 25^{\prime} \mathrm{S}-81^{\circ} 46^{\prime} \mathrm{O}, 10 \mathrm{msnm}, 12-\mathrm{IV}-2017$, U. González leg., red entomológica, Desierto costero; 1 + , Sechura, Illescas, $5^{\circ} 58^{\prime} \mathrm{S}-81^{\circ} 05^{\prime} \mathrm{O}, 10 \mathrm{msnm}, 12-\mathrm{XI}-2017$, U. González leg., red entomológica, Matorral Xérico; 1 †, Morropón, Chulucanas, $5^{\circ} 05^{\prime} \mathrm{S}-80^{\circ} 99^{\prime} \mathrm{O}, 350$ msnm, 14-VI-2017, G. Juárez leg., red entomológica, Bosque estacionalmente seco de colina; Ayabaca, Suyo, $4^{\circ} 30^{\prime} 45^{\prime \prime} \mathrm{S}-80^{\circ} 00^{\prime} 10^{\prime \prime} \mathrm{O}, 408 \mathrm{msnm}, 23-\mathrm{X}-2015$, G. Juárez leg., red entomológica, Bosque estacionalmente seco de colina; Huancabamba, Huarmaca, 534'04"S-79³1'26"O, 1223 msnm, 26-VII-2016, G. Juárez leg., red entomológica, Bosque estacionalmente seco de colina.

Distribución (Provincia) (PAisaje ecológico). (PIU, SUlL, PAI, TAL, SECH, MORR, AYA, HUA) (MatX, DESc, BESr, BES1l, BESc-m).

Comentario. Especie citada como morfoespecie 1 en Juárez et al. (2016). Los adultos y ninfas se encuentran sobre hojas, ramas y troncos de plántulas y árboles, en solitario o en pareja. Insecto que se comporta como fitófago, ninfas y adultos causan defoliación. Especie citada también por Domínguez (1982). 


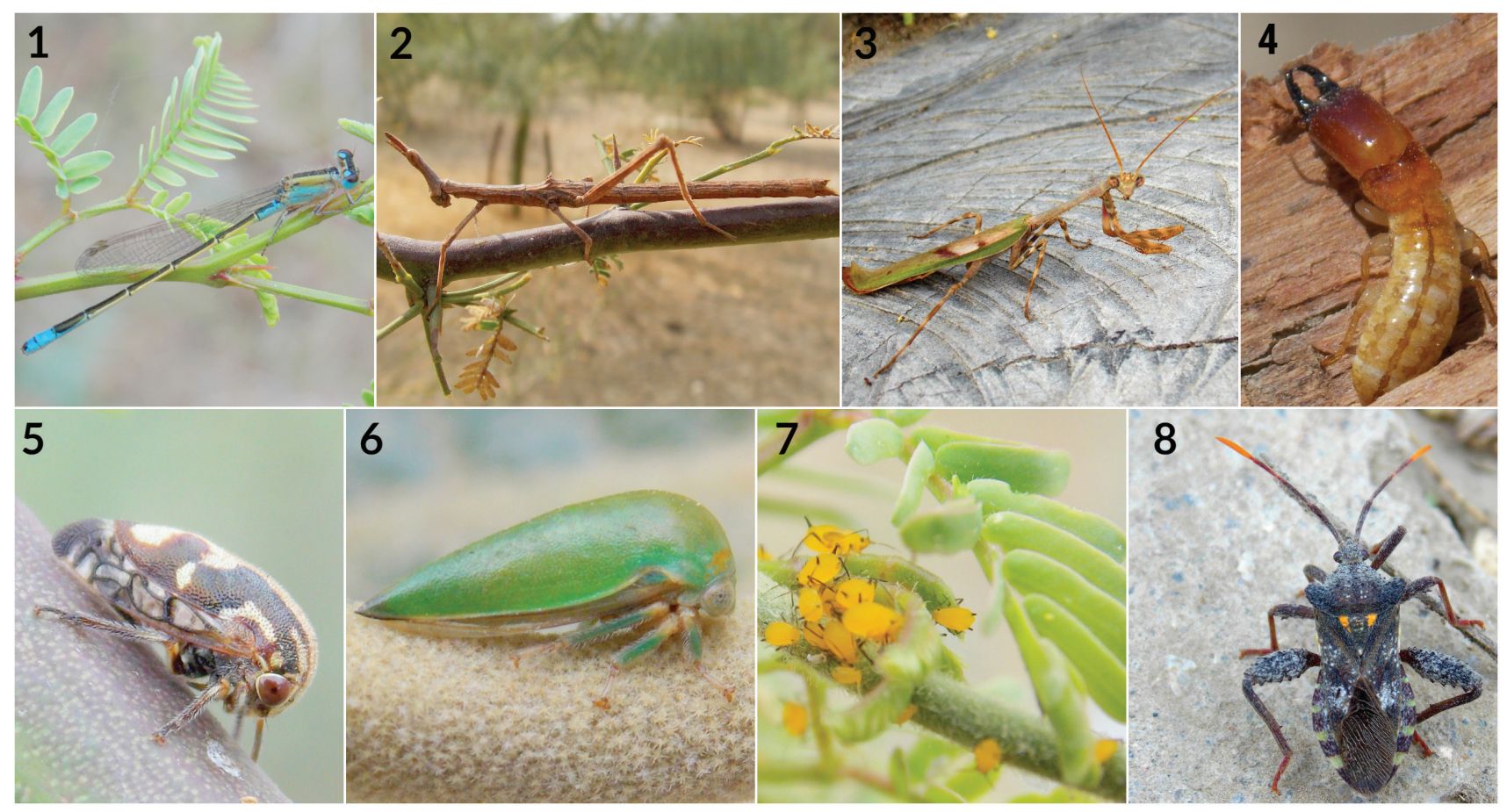

Figs. 1-8.- Habitus. 1. Ischnura sin identificar sp 1. 2. Anchotatus brevicornis (Caudell, 1912). 3. Pseudovates peruviana (Rehn, 1911). 4. Incisitermes immigrans (Snyder, 1922). 5. Vanduzea sin identificar sp 1. 6. Stictopelta acutula (Fairmaire, 1846). 7. Aphis nerii Boyer, 1841. 8. Piezogaster obscuratus (Montandon, 1898). [Fotografías G. Juárez y U. González].

Figs. 1-8.- Habitus. 1. Ischnura unidentified sp 1. 2. Anchotatus brevicornis (Caudell, 1912). 3. Pseudovates peruviana (Rehn, 1911). 4. Incisitermes immigrans (Snyder, 1922). 5. Vanduzea unidentified sp 1. 6. Stictopelta acutula (Fairmaire, 1846). 7. Aphis nerii Boyer, 1841. 8. Piezogaster obscuratus (Montandon, 1898). [Photographs by G. Juárez and U. González].

Familia Acrididae MacLeay, 1821

Subfamilia Cyrtacanthacridinae Kirby, 1910

Género Schistocerca Stål, 1873

\section{Schistocerca interrita Scudder, 1889}

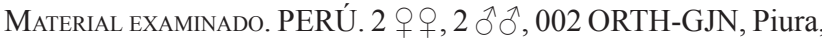
Universidad de Piura, 5 $10^{\prime} 11^{\prime \prime} \mathrm{S}-80^{\circ} 36^{\prime} 51^{\prime \prime} \mathrm{O}, 29 \mathrm{msnm}$, 13-II-2014, U. González leg., red entomológica, Bosque estacionalmente seco de llanura; 2 우, 1 ${ }^{\lambda}$, Piura, Castilla, Universidad Nacional de Piura, $5^{\circ} 10^{\prime} 51^{\prime \prime} \mathrm{S}-80^{\circ} 37^{\prime} 31^{\prime \prime} \mathrm{O}$, 29 msnm, 14-III-2017, G. Juárez leg., red entomológica, Bosque estacionalmente ribereño; 2 + 9 , Sullana, Salitral, 451'27"S-8040'52"O, 23 msnm, 11-V-2017, G. Juárez leg., red entomológica, Bosque estacionalmente seco de llanura; 2 우우, Sullana, Lancones, $4^{\circ} 38^{\prime} 27^{\prime \prime} \mathrm{S}-80^{\circ} 32^{\prime} 55^{\prime \prime} \mathrm{O}, 190 \mathrm{msnm}$, 20-XII-2015, G. Juárez leg., red entomológica, Bosque estacionalmente seco de colina; 1 ․ Paita, $5^{\circ} 04^{\prime} \mathrm{S}-81^{\circ} 06^{\prime} \mathrm{O}$, 10 msnm, 2-VIII-2017, G. Juárez leg., red entomológica, Bosque estacionalmente seco de llanura; 1 \%, Talara, Los Órganos, $4^{\circ} 10^{\prime} 38^{\prime \prime} \mathrm{S}-81^{\circ} 07^{\prime} 27^{\prime \prime} \mathrm{O}, 12 \mathrm{msnm}, 15-\mathrm{IV}-2016$, G. Juárez leg., red entomológica, Desierto costero; 1 \%, Talara, El Alto, $4^{\circ} 16^{\prime} 04^{\prime \prime} \mathrm{S}-81^{\circ} 13^{\prime} 09^{\prime \prime} \mathrm{O}, 300 \mathrm{msnm}, 13-\mathrm{V}-2016$, red entomológica, G. Juárez leg., Bosque estacionalmente seco de colina; 3 우, Sechura, Vice, $5^{\circ} 25^{\prime} \mathrm{S}-81^{\circ} 46^{\prime} \mathrm{O}, 10 \mathrm{msnm}$, 2-II-2017, U. González leg., red entomológica, Desierto costero; 1 ㅇ, Sechura, Illescas, $5^{\circ} 58^{\prime} \mathrm{S}-81^{\circ} 05^{\prime} \mathrm{O}, 10 \mathrm{msnm}$, 12-XI-2017, U. González leg., red entomológica, Matorral

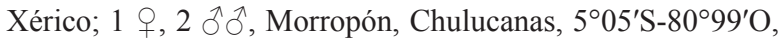
350 msnm, 05-III-2017, G. Juárez leg., red entomológica, Bosque estacionalmente seco de colina; $1 \hat{\partial}$, Ayabaca, Suyo, $4^{\circ} 30^{\prime} 45^{\prime \prime} \mathrm{S}-80^{\circ} 00^{\prime} 10^{\prime \prime} \mathrm{O}, 408 \mathrm{msnm}, 23-\mathrm{X}-2015$, G. Juárez leg., red entomológica, Bosque estacionalmente seco de colina; Huancabamba, Huarmaca, 534'04"S-79³1'26"O, 1223 msnm, 26-VII-2016, G. Juárez leg., red entomológica, Bosque estacionalmente seco de colina.

Distribución (Provincia) (Paisaje ecológico). (PIU, SUlL, PAi, TAL, SECH, MORR, AYA, HUA) (MatX, DESc, BESr, BESll, BESc-m).

Comentario. Especie citada como Schistocerca sp en Juárez et al. (2016). Los adultos y ninfas se encuentran sobre hojas, ramas y troncos de plántulas y árboles, en solitario o en grupos de dos o más individuos. Insecto que se comporta como fitófago, ninfas y adultos causan defoliación. El número de individuos colectados aumentó en época de lluvia (diciembre-marzo).

\section{Subfamilia Oedipodinae Walker, 1871}

Género Trimerotropis Stål, 1873

12. Trimerotropis ochraceipennis reedi Liebermann, 1945

Material examinado. PERÚ. 2 ఏ̄ô, 006 ORTH-GJN, Piura, Universidad de Piura, 5 $5^{\circ} 10^{\prime} 11^{\prime \prime} \mathrm{S}-80^{\circ} 36^{\prime} 51^{\prime \prime} \mathrm{O}, 29 \mathrm{msnm}$, 13-II-2014, U. González leg., red entomológica, Bosque estacionalmente seco de llanura; 1 ㅇ, $2 \hat{\jmath} \hat{\jmath}$, Piura, Castilla, Universidad Nacional de Piura, $5^{\circ} 10^{\prime} 51^{\prime \prime} \mathrm{S}-80^{\circ} 37^{\prime} 31^{\prime \prime} \mathrm{O}$, 29 msnm, 14-III-2017, G. Juárez leg., red entomológica, Bosque estacionalmente ribereño; 2 우, Sullana, Lancones, 4³8'27"S-80³2'55"O, 190 msnm, 20-XII-2015, G. Juárez leg., red entomológica, Bosque estacionalmente seco de colina; 1 ㅇ, Paita, $5^{\circ} 04^{\prime} \mathrm{S}-81^{\circ} 06^{\prime} \mathrm{O}, 10 \mathrm{msnm}, 2$-VIII-2017, G. Juárez leg., red entomológica, Bosque estacionalmente seco de llanura; 1 ㅇ, Talara, Los Órganos, $4^{\circ} 10^{\prime} 38^{\prime \prime} \mathrm{S}-81^{\circ} 07^{\prime} 27^{\prime \prime} \mathrm{O}$, 12 msnm, 15-IV-2016, G. Juárez leg., red entomológica, 


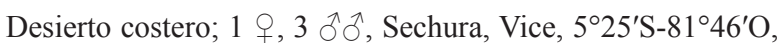
10 msnm, 2-II-2017, U. González leg., red entomológica, Desierto costero; 1 o, Sechura, Illescas, $5^{\circ} 58^{\prime} \mathrm{S}-81^{\circ} 05^{\prime} \mathrm{O}$, 10 msnm, 12-XI-2017, U. González leg., red entomológica, Matorral Xérico; 2 우, Morropón, Chulucanas, $5^{\circ} 05^{\prime} \mathrm{S}-80^{\circ} 99^{\prime} \mathrm{O}$, $350 \mathrm{msnm}$, 05-III-2017, G. Juárez leg., red entomológica, Bosque estacionalmente seco de colina;

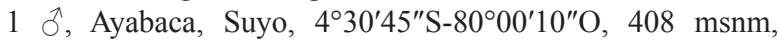
23-X-2015, G. Juárez leg., red entomológica, Bosque estacionalmente seco de colina; Huancabamba, Huarmaca, 5³4'04"S-79³1'26"O, 1223 msnm, 26-VII-2016, G. Juárez leg., red entomológica, Bosque estacionalmente seco de colina.

Distribución (Provincia) (Paisaje ecológico). (PIU, SUll, PAi, TAL, SECH, MORR, AYA, HUA) (MatX, DESc, BESr, BESll, BESc-m).

Comentario. Con la consulta de Rehn (1939) se llegó a la conclusión que la especie citada como Lactista sp en Juárez et al. (2016) se trata de T. ochraceipennis reedi. Los adultos y ninfas se encuentran sobre hojas, ramas y troncos de plántulas y árboles, en solitario o en grupo de dos a cuatro individuos. Insecto que se comporta como fitófago, ninfas y adultos causan defoliación. El número de individuos colectados aumentó en época de lluvia (diciembre-marzo). Especie citada también por Domínguez (1982).

Subfamilia Gomphocerinae Fieber, 1853

Género Orphulella Giglio-Tos, 1894

13. Orphulella punctata (De Geer, 1773)

Material eXaminado. PERÚ. 1 o, 008 ORTH-GJN, Piura,

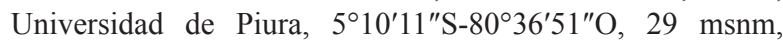
13-II-2014, U. González leg., red entomológica, Bosque estacionalmente seco de llanura; 1 , , Piura, Castilla, Universidad Nacional de Piura, 5¹0'51"S-80³7'31'O, 29 msnm, 14-III2017, G. Juárez leg., red entomológica, Bosque estacionalmente ribereño; 2 우오. Sullana, Lancones, $4^{\circ} 38^{\prime} 27^{\prime \prime} \mathrm{S}-80^{\circ} 32^{\prime} 55^{\prime \prime} \mathrm{O}$, 190 msnm, 20-XII-2015, G. Juárez leg., red entomológica, Bosque estacionalmente seco de colina; 1 , Paita, $5^{\circ} 04^{\prime} \mathrm{S}-81^{\circ} 06^{\prime} \mathrm{O}, 10 \mathrm{msnm}, 2-\mathrm{VIII}-2017$, G. Juárez leg., red entomológica, Bosque estacionalmente seco de llanura; 1 ㅇ, Talara, Los Órganos, $4^{\circ} 10^{\prime} 38^{\prime \prime} \mathrm{S}-81^{\circ} 07^{\prime} 27^{\prime \prime} \mathrm{O}, 12 \mathrm{msnm}$, 15-IV-2016, G. Juárez leg., red entomológica, Desierto costero; 1 ㅇ, Sechura, Vice, $5^{\circ} 25^{\prime} \mathrm{S}-81^{\circ} 46^{\prime} \mathrm{O}, 10 \mathrm{msnm}$, 2-II-2017, U. González leg., red entomológica, Desierto costero; 1 \%, Sechura, Illescas, $5^{\circ} 58^{\prime} \mathrm{S}-81^{\circ} 05^{\prime} \mathrm{O}, 10 \mathrm{msnm}$, 12-XI-2017, U. González leg., red entomológica, Matorral Xérico; 2 우우, Morropón, Chulucanas, $5^{\circ} 05^{\prime} \mathrm{S}-80^{\circ} 99^{\prime} \mathrm{O}$, 350 msnm, 05-III-2017, G. Juárez leg., red entomológica, Bosque estacionalmente seco de colina; $1 \hat{\jmath}$, Ayabaca, Suyo, 430'45"S-8000'10"O, 408 msnm, 23-X-2015, G. Juárez leg., red entomológica, Bosque estacionalmente seco de colina; Huancabamba, Huarmaca, 5³4'04"S-79³1'26"O, 1223 msnm, 26-VII-2016, G. Juárez leg., red entomológica, Bosque estacionalmente seco de colina.

Distribución (Provincia) (Paisaje ecológico). (PIU, SUlL, PAi, TAL, SECH, MORR, AYA, HUA) (MatX, DESc, BESr, BESll, BESc-m).

Comentario. Con la consulta de Otte (1979) se llegó a la conclusión que la especie citada como Orphulina sp en Juárez et al. (2016) se trata de $O$. punctata. Los adultos y ninfas se encuentran sobre hojas, ramas y troncos de plántulas y árboles, en solitario o en grupo de dos a cuatro individuos. Insecto que se comporta como fitófago, ninfas y adultos causan defoliación. El número de individuos colectados aumentó en época de lluvia (diciembre-marzo). Especie citada también por Domínguez (1982).
Orden MANTODEA Burmeister, 1838

Familia Mantidae Latreille, 1802

Subfamilia Vatinae Stål, 1877

Género Pseudovates Saussure, 1869

14. Pseudovates peruviana (Rehn, 1911) (Fig. 3)

Material examinado. PERÚ. 1 + , Piura, Castilla, Universidad Nacional de Piura, $5^{\circ} 10^{\prime} 51^{\prime \prime} \mathrm{S}-80^{\circ} 37^{\prime} 31^{\prime \prime} \mathrm{O}, 29 \mathrm{msnm}$, 14-III-2017, G. Juárez leg., red entomológica, Bosque estacionalmente ribereño; 1 †, Piura, Universidad de Piura, 5॰10'11"S-80³6'51"O, 29 msnm, 11-III-2015, U. González leg., red entomológica, Bosque estacionalmente seco de llanura; 1 , Sullana, Salitral, $4^{\circ} 51^{\prime} 27^{\prime \prime} \mathrm{S}-80^{\circ} 40^{\prime} 52^{\prime \prime} \mathrm{O}$, 23 msnm, 25-X-2015, G. Juárez leg., red entomológica, Bosque estacionalmente seco de llanura; 1 , Talara, Los Órganos, $4^{\circ} 10^{\prime} 38^{\prime \prime} \mathrm{S}-81^{\circ} 07^{\prime} 27^{\prime \prime} \mathrm{O}, 12 \mathrm{msnm}, 15-\mathrm{VI}-$ 2016, G. Juárez leg., red entomológica, Desierto costero; 1 q, Talara, Lobitos, $4^{\circ} 27^{\prime} 10^{\prime \prime} \mathrm{S}-81^{\circ} 16^{\prime} 40^{\prime \prime} \mathrm{O}, 12 \mathrm{msnm}$, 03-IV-2017, G. Juárez leg., red entomológica, desierto costero; 1 , Paita, La Huaca, $4^{\circ} 54^{\prime} \mathrm{S}-80^{\circ} 57^{\prime} \mathrm{O}, 27 \mathrm{msnm}$, 17-XII-2015, U. González leg., red entomológica, Bosque estacionalmente seco de llanura; 1 + , Sechura, Vice, 5²5'S-81 ${ }^{\circ} 46^{\prime} \mathrm{O}, 10 \mathrm{msnm}, 08-\mathrm{II}-2018$, U. González leg., red entomológica, Desierto costero; 1 , Sechura, Sechura, 5³4'S-81¹6'O, 16 msnm, 11-IX-2018, U. González leg., red entomológica, Bosque estacionalmente seco de llanura; 1 ㅇ, Morropón, Chulucanas, $5^{\circ} 05^{\prime} \mathrm{S}-80^{\circ} 99^{\prime} \mathrm{O}, 350 \mathrm{msnm}$, 07-XI-2015, G. Juárez leg., red entomológica, Bosque estacionalmente seco de colina; 2 우, Morropón, Morropón, $5^{\circ} 05^{\prime} 51^{\prime \prime S}-80^{\circ} 09^{\prime} 44^{\prime \prime} \mathrm{O}, 557$ msnm, 04-IX-2017, G. Juárez leg., red entomológica, Bosque estacionalmente seco de colina.

Distribución (Provincia) (Paisaje ecológico). (PIU, SUlL, PAI, TAL, SECH, MORR) (DESc, BESr, BESll, BESc-m).

Comentario. Los adultos y ninfas se encuentran sobre hojas y ramas de árboles, en solitario o en grupo de dos individuos. Insecto que se comporta como controlador biológico, ninfas y adultos son depredadores de un sin número de insectos como lepidópteros, coleópteros, hemípteros, dípteros. Especie citada también por Juárez et al. (2016).

Orden BLATTODEA Brunner von Wattenwyl, $1882 \dagger$

Familia Blaberidae Saussure, $1864 \dagger$

Subfamilia Blaberinae Saussure, $1864 \dagger$

Género Blaberus Serville, $1831 \dagger$

15. Blaberus sin identificar sp. $1 . \dagger$

Material examinado. PERÚ. 1 o, Piura, Castilla, $5^{\circ} 10^{\prime} 51^{\prime \prime} \mathrm{S}-80^{\circ} 37^{\prime} 31^{\prime \prime} \mathrm{O}, 29 \mathrm{msnm}, 12-\mathrm{IV}-2016$, U. González leg., colecta manual, Bosque estacionalmente seco ribereño;

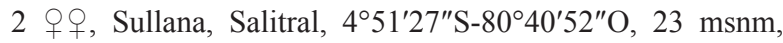
25-VII-2017, G. Juárez leg., colecta manual, Bosque estacionalmente seco de llanura; 2 우, Talara, Los Órganos, $4^{\circ} 10^{\prime} 38^{\prime \prime} \mathrm{S}-81^{\circ} 07^{\prime 2} 29^{\prime \prime} \mathrm{O}, 12$ msnm, 11-IX-2018, G. Juárez leg., colecta manual, Desierto costero; 1 ㅇ, Paita, $5^{\circ} 04^{\prime} \mathrm{S}-81^{\circ} 06^{\prime} \mathrm{O}$, 10 msnm, 17-X-2018, G. Juárez leg., colecta manual, Bosque estacionalmente seco de llanura; 3 우, Sechura, Vice, 525'S-8146'O, 10 msnm, 06-XII-2017, U. González leg., colecta manual, Desierto costero; Morropón, Chulucanas, 505'S-8099'O, 350 msnm, 05-III-2017, G. Juárez leg., colecta manual, Bosque estacionalmente seco de colina; 2

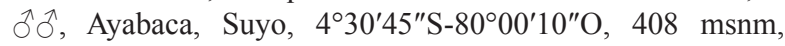
23-X-2015, G. Juárez leg., colecta manual, Bosque estacionalmente seco de colina; Huancabamba, Huarmaca, 5³4'04"S-79³1'26"O, 1223 msnm, 26-VII-2016, G. Juárez leg., colecta manual, Bosque estacionalmente seco de colina. 
Distribución (Provincia) (Paisaje ecológico). (PIU, SUlL, PAI, TAL, SECH, MORR, AYA, HUA) (DESc, BESr, BESll, BESc-m).

Comentario. Los adultos y ninfas se encuentran principalmente sobre tronco de árboles, escondidas en grietas, en solitario o en grupos de dos o más individuos, incluso también en el interior de troncos muertos. Es omnívora, insecto que se comporta como fitófago, ninfas y adultos se alimentan de madera viva o muerta.

Subfamilia Pycnoscelinae $\uparrow$

Género Pycnoscelus Scudder, $1862 \dagger$

16. Pycnoscelus surinamensis (Linnaeus, 1758) $\dagger$

Material eXAminado. PERÚ. 1 +, Piura, Castilla, 5¹0'51"S-80³7'31"O, 29 msnm, 12-IV-2016, U. González leg., colecta manual, Bosque estacionalmente seco ribereño; 2 우, Sullana, Salitral, $4^{\circ} 51^{\prime} 27^{\prime \prime} \mathrm{S}-80^{\circ} 40^{\prime} 52^{\prime \prime} \mathrm{O}, 23 \mathrm{msnm}$, 25-VII-2017, G. Juárez leg., colecta manual, Bosque estacionalmente seco de llanura; 2 우, Talara, Los Órganos, $4^{\circ} 10^{\prime} 38^{\prime \prime} \mathrm{S}-81^{\circ} 07^{\prime} 29^{\prime \prime} \mathrm{O}, 12$ msnm, 11-IX-2018, G. Juárez leg., colecta manual, Desierto costero; 1 ㅇ, Paita, $5^{\circ} 04^{\prime} \mathrm{S}-81^{\circ} 06^{\prime} \mathrm{O}$, 10 msnm, 17-X-2018, G. Juárez leg., colecta manual, Bosque estacionalmente seco de llanura; 3 오, Sechura, Vice, 5²5'S-81 $46^{\prime} \mathrm{O}, 10 \mathrm{msnm}, 06-X \mathrm{II}-2017$, U. González leg., colecta manual, Desierto costero; Morropón, Chulucanas, 505'S-8099'O, 350 msnm, 05-III-2017, G. Juárez leg., colecta manual, Bosque estacionalmente seco de colina.

Distribución (Provincia) (Paisaje ecológico). (PIU, SUlL, PAi, TAL, SECH, MORR) (DESc, BESr, BESll, BESc-m).

Comentario. Los adultos y ninfas se encuentran principalmente sobre tronco de árboles, escondidas en grietas, en solitario o en grupos de dos o más individuos, incluso también en el interior de troncos muertos. Es omnívora, insecto que se comporta como fitófago, ninfas y adultos se alimentan de madera viva o muerta.

Familia Blattidae Latreille, $1810 \dagger$

Subfamilia Blattinae Latreille, $1810 \dagger$

Género Periplaneta Burmeister, $1838 \dagger$

17. Periplaneta americana Linnaeus, $1758 \dagger$

Material eXaminado. PERÚ. 3 oㅇ, Piura, Catacaos, 5¹5'42"S-8040'27"O, 29 msnm, 16-VII-2016, U. González leg., colecta manual, Bosque estacionalmente seco de llanura; 1 ㅇ, Piura, Castilla, $5^{\circ} 10^{\prime} 51^{\prime \prime} \mathrm{S}-80^{\circ} 37^{\prime} 31^{\prime \prime} \mathrm{O}, 29 \mathrm{msnm}$, 12-IV-2016, U. González leg., colecta manual, Bosque estacionalmente seco ribereño; 3 우, 2 $\hat{\delta} \hat{\delta}$, Piura, Universidad de Piura, 510'11"S-80³6'51"O, 29 msnm, 27-IX-2018, U. González leg., colecta manual, Bosque estacionalmente seco de llanura; 2 우, Sullana, Salitral, 4 ${ }^{\circ} 51^{\prime} 27^{\prime \prime} \mathrm{S}-80^{\circ} 40^{\prime} 52^{\prime \prime} \mathrm{O}$, 23 msnm, 18-I-2016, G. Juárez leg., colecta manual, Bosque estacionalmente seco de llanura; 1 q, Talara, Los Órganos, $4^{\circ} 10^{\prime} 38^{\prime \prime} \mathrm{S}-81^{\circ} 07^{\prime} 27^{\prime \prime} \mathrm{O}, 12$ msnm, 05-V-2017, G. Juárez leg., colecta manual, Desierto costero; 1 , , Paita, $5^{\circ} 04^{\prime} \mathrm{S}-81^{\circ} 06^{\prime} \mathrm{O}$, 10 msnm, 21-II-2017, G. Juárez leg., colecta manual, Bosque estacionalmente seco de llanura; 1 , Sechura, Vice, 5²5'S-81 ${ }^{\circ} 46^{\prime} \mathrm{O}, 10 \mathrm{msnm}, 12-\mathrm{XII}-2017$, U. González leg., colecta manual, Desierto costero; $1 \hat{\delta}$, Sechura, Sechura,

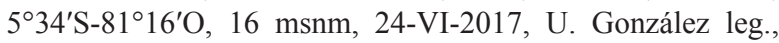
colecta manual, Bosque estacionalmente seco de llanura; 1 q, Morropón, Chulucanas, $5^{\circ} 05^{\prime} \mathrm{S}-80^{\circ} 99^{\prime} \mathrm{O}, 350 \mathrm{msnm}$, 22-I-2015, G. Juárez leg., colecta manual, Bosque estacionalmente seco de colina; 2 우, Morropón, Morropón, $5^{\circ} 05^{\prime} 51^{\prime \prime} \mathrm{S}-80^{\circ} 09^{\prime} 44^{\prime \prime} \mathrm{O}, 557 \mathrm{msnm}, 23-\mathrm{I}-2015$, G. Juárez leg., colecta manual, Bosque estacionalmente seco de colina;

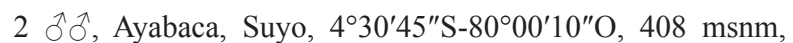
23-X-2015, G. Juárez leg., colecta manual, Bosque estacionalmente seco de colina; Huancabamba, Huarmaca, 5³4'04"S-79³1'26"O, 1223 msnm, 26-VII-2016, G. Juárez leg., colecta manual, Bosque estacionalmente seco de colina.

Distribución (Provincia) (Paisaje ecológico). (PIU, SUll, PAi, TAL, SECH, MORR, HUA, AYA) (DESc, BESr, BESll, BESc-m).

Comentario. Los adultos y ninfas se encuentran cercano a troncos y escondidos en grietas sobre el tronco de árboles, en solitario o en grupo de dos individuos. Generalmente presente en árboles ubicados en ciudades cercanos a tachos de basura. Especie omnívora.

Familia Kalotermitidae Froggatt, $1896 \uparrow$

Género Incisitermes Froggatt, $1906 \dagger$

18. Incisitermes immigrans (Snyder, 1922) $\uparrow$ (Fig. 4)

Material examinado. PERÚ. 2 우, Talara, Los Órganos, $4^{\circ} 10^{\prime} 38^{\prime \prime} \mathrm{S}-81^{\circ} 07^{\prime} 27^{\prime \prime} \mathrm{O}, 12 \mathrm{msnm}, 15-\mathrm{VI}-2016$, G. Juárez leg., colecta manual, Desierto costero; 1 $\partial^{\lambda}$, Talara, El Alto, $4^{\circ} 16^{\prime} 04^{\prime \prime} \mathrm{S}-81^{\circ} 13^{\prime} 09^{\prime \prime} \mathrm{O}, 300 \mathrm{msnm}, 23-\mathrm{IX}-2016$, G. Juárez leg., colecta manual, Bosque estacionalmente seco de colina;

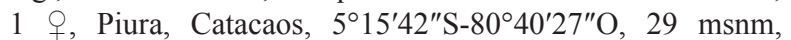
16-VII-2016, U. González leg., colecta manual, Bosque estacionalmente seco de llanura; 2 오, Piura, Castilla, 5¹0'51"S-80³7'31"O, 29 msnm, 12-IV-2016, U. González leg., colecta manual, Bosque estacionalmente seco ribereño.

Distribución (Provincia) (Paisaje ecológico). (PIU, TAL) (DESc, BESr, BESll, BESc-m).

Comentario. Los adultos y ninfas se encuentran en el interior de troncos árboles vivos o muertos formando colonias de más de 200 individuos. Insecto que se comporta como fitófago, ninfas y adultos son consumidores de madera viva o muerta (Scheffrahn et al., 2009).

Orden THYSANOPTERA Haliday, 1836

Suborden Terebrantia Haliday, 1836

Familia Thripidae Stevens, 1829

Subfamilia Thripinae Stephens, 1829

Género Frankiniella Karny, 1910

19. Frankiniella sin identificar sp. 1.

Material examinado. Perú. 2 qo, Piura, Catacaos, 5¹5'42"S-8040'27"O, 29 msnm, 16-VII-2016, U. González leg., colecta manual, Bosque estacionalmente seco de llanura; 1 q, Perú, Piura, Castilla, $5^{\circ} 10^{\prime} 51^{\prime \prime} \mathrm{S}-80^{\circ} 37^{\prime} 31^{\prime \prime} \mathrm{O}$, 29 msnm, 12-IV-2016, U. González leg., colecta manual, Bosque estacionalmente seco ribereño; 1 \&, Piura, Universidad de Piura, 510'11"S-80³6'51"O, $29 \mathrm{msnm}$, 27-IX-2018, U. González leg., colecta manual, Bosque estacionalmente seco de llanura; 1 +, Sullana, Salitral, 451'27"S-8040'52"O, 23 msnm, 18-I-2016, G. Juárez leg., colecta manual, Bosque estacionalmente seco de llanura; 1 q, Talara, Los Órganos, $4^{\circ} 10^{\prime} 38^{\prime \prime} \mathrm{S}-81^{\circ} 07^{\prime} 27^{\prime \prime} \mathrm{O}, 12 \mathrm{msnm}$, 05-V-2017, G. Juárez leg., colecta manual, Desierto costero; 1 q, Paita, $5^{\circ} 04^{\prime} \mathrm{S}-81^{\circ} 06^{\prime} \mathrm{O}, 10 \mathrm{msnm}, 21-\mathrm{II}-2017$, G. Juárez leg., colecta manual, Bosque estacionalmente seco de llanura.

Distribución (Provincia) (Paisaje ecológico). (PIU, SUlL, PAi, TAL) (DESc, BESr, BESIl).

Comentario. Los adultos y ninfas se encuentran sobre hojas de plántulas y árboles, en solitario o en grupo de dos a cuatro individuos. Insecto que se comporta como fitófago, ninfas y adultos se alimentan de foliolos. Especie citada también por Núñez-Sacarías (1993) y Juárez et al. (2016). 
Orden HEMIPTERA Linnaeus, 1758

Suborden Auchenorrhyncha

Familia Cicadellidae Latreille, 1802

Género Dechacona Young, 1968

20. Dechacona missionum (Berg, 1879)

Material examinado. Perú. 1 q, 002 HeM-GJN, Perú, Piura, Universidad de Piura, 5 $5^{\circ} 10^{\prime} 11^{\prime \prime} \mathrm{S}-80^{\circ} 36^{\prime} 51^{\prime \prime} \mathrm{O}, 29 \mathrm{msnm}$, 27-IX-2018, U. González leg., colecta manual, Bosque estacionalmente seco de llanura; 2 우, Piura, Castilla, Universidad Nacional de Piura, $5^{\circ} 10^{\prime} 51^{\prime \prime} \mathrm{S}-80^{\circ} 37^{\prime} 31^{\prime \prime} \mathrm{O}$, 29 msnm, 14-III-2017, G. Juárez leg., colecta manual, Bosque estacionalmente ribereño; 1 + Sullana, Salitral, 451'27"S-8040'52"O, 23 msnm, 18-I-2016, G. Juárez leg., colecta manual, Bosque estacionalmente seco de llanura; 1 , Talara, Los Órganos, $4^{\circ} 10^{\prime} 38^{\prime \prime} \mathrm{S}-81^{\circ} 07^{\prime} 27^{\prime \prime} \mathrm{O}, 12 \mathrm{msnm}, 05-\mathrm{V}$ 2017, G. Juárez leg., colecta manual, Desierto costero; 2 우, Paita, $5^{\circ} 04^{\prime} \mathrm{S}-81^{\circ} 06^{\prime} \mathrm{O}, 10 \mathrm{msnm}, 21-\mathrm{II}-2017$, G. Juárez leg., colecta manual, Bosque estacionalmente seco de llanura; $1 \hat{\jmath}$, Sechura, Sechura, $5^{\circ} 34^{\prime} \mathrm{S}-81^{\circ} 16^{\prime} \mathrm{O}, 16 \mathrm{msnm}, 24-\mathrm{VI}-2017$, U. González leg., colecta manual, Bosque estacionalmente seco de llanura.

Distribución (Provincia) (Paisaje ecológico). (PIU, SUll, PAI, TAL, SECH) (DESc, BESr, BESIl).

Comentario. Especie citada como Dechacona sp en Juárez et al. (2016). Los adultos y ninfas se encuentran sobre hojas y ramas principalmente de plántulas, aunque también en árboles, en solitario o en grupo de dos a cuatro individuos. Insecto que se comporta como fitófago, ninfas y adultos se comportan como succionadores de savia.

Género Empoasca Walsh, $1862 \uparrow$

21. Empoasca sin identificar sp. $1 . \dagger$

Material eXaminado. PERÚ. 2 9 , , Piura, Universidad de Piura, 5॰10'11"S-80³6'51"O, 29 msnm, 27-IX-2018, U. González leg., colecta manual, Bosque estacionalmente seco de llanura; 2 오, Piura, Castilla, Universidad Nacional de Piura, 5 $10^{\prime} 51^{\prime \prime} \mathrm{S}-80^{\circ} 37^{\prime} 31^{\prime \prime} \mathrm{O}, 29 \mathrm{msnm}, 11-\mathrm{V}-2019$, G. Juárez leg., colecta manual, Bosque estacionalmente ribereño; 2 우, Sullana, Salitral, $4^{\circ} 51^{\prime} 27^{\prime \prime} \mathrm{S}-80^{\circ} 40^{\prime} 52^{\prime \prime} \mathrm{O}, 23 \mathrm{msnm}$, 11-V-2017, U. González leg., colecta manual, Bosque estacionalmente seco de llanura; 1 , , Sullana, Lancones, 4³8'27"S-80³2'55"O, 190 msnm, 20-XII-2017, G. Juárez leg., colecta manual, Bosque estacionalmente seco de colina; 1 ㅇ, Paita, $5^{\circ} 04^{\prime} \mathrm{S}-81^{\circ} 06^{\prime} \mathrm{O}, 10 \mathrm{msnm}, 2-\mathrm{VIII}-2017$, G. Juárez leg., colecta manual, Bosque estacionalmente seco de llanura.

Distribución (Provincia) (Paisaje ecológico). (PIU, SUll, PAi) (BESr, BESll, BESc-m).

Comentario. Los adultos y ninfas se encuentran sobre hojas principalmente de plántulas, aunque también en árboles, en solitario o en grupo de dos a más individuos. Insecto que se comporta como fitófago, ninfas y adultos son succionadores de savia.

Familia Membracidae Rafinesque, 1815

Género Vanduzea Goding, 1893 †

22. Vanduzea sin identificar sp. $1 . \dagger$ (Fig. 5)

Material eXaminado. PERÚ. 2 우, Piura, Universidad de Piura, $5^{\circ} 10^{\prime} 11^{\prime \prime} \mathrm{S}-80^{\circ} 36^{\prime} 51^{\prime \prime} \mathrm{O}, 29$ msnm, 27-IX-2018, U. González leg., colecta manual, Bosque estacionalmente seco de llanura; 1 옹 Piura, Universidad de Piura, $5^{\circ} 10^{\prime} 11^{\prime \prime} \mathrm{S}-80^{\circ} 36^{\prime} 51^{\prime \prime} \mathrm{O}$, 29 msnm, 27-IX-2019, G. Juárez leg., colecta manual, Bosque estacionalmente seco de llanura.

Distribución (Provincia) (Paisaje ecológico). (PIU) (BESIl).
COMEnTario. Los adultos y ninfas se encuentran sobre hojas y ramas de plántulas y árboles, siempre en solitario. Insecto fitófago, ninfas y adultos se comportan como succionadores de savia.

\section{Género Stictopelta Stål, 1869}

23. Stictopelta acutula (Fairmaire, 1846) (Fig. 6)

Material EXAminado. PERÚ. 1 , 011 HEM-GJN, Piura, Universidad de Piura, 510'11"S-80³6'51"O, 29 msnm, 27-IX-2018, U. González leg., colecta manual, Bosque estacionalmente seco de llanura; 1 ㅇ, Piura, Universidad de Piura, $5^{\circ} 10^{\prime} 11^{\prime \prime} \mathrm{S}-80^{\circ} 36^{\prime} 51^{\prime \prime} \mathrm{O}$, 29 msnm, 27-IX-2019, G. Juárez leg., colecta manual, Bosque estacionalmente seco de llanura. 1 \&, Sullana, Salitral, 451'27"S-8040'52"O, 23 msnm, 11-V-2017, U. González leg., colecta manual, Bosque estacionalmente seco de llanura.

Distribución (Provincia) (Paisaje ecológico). (PIU, SULL) (BES11).

Comentario. Especie citada como morfoespecie 1 en Juárez et al. (2016). Los adultos y ninfas se encuentran sobre hojas y ramas de plántulas y árboles, en solitario. Insecto fitófago, ninfas y adultos se comportan como succionadores de savia.

Familia Cicadidae Westwood, 1840

Género Carineta Amyot \& Serville, 1843

24. Carineta sin identificar sp. 1.

Material examinado. PERÚ. 1 o, Piura, Catacaos, 5¹5'42"S-8040'27"O, 29 msnm, 12-VII-2018, U. González leg., colecta manual, Bosque estacionalmente seco de llanura; 1 O, Piura, Castilla, $5^{\circ} 10^{\prime} 51^{\prime \prime} \mathrm{S}-80^{\circ} 37^{\prime} 31^{\prime \prime} \mathrm{O}, 29 \mathrm{msnm}, 08$-IV2017, U. González leg., colecta manual, Bosque estacionalmente seco ribereño; 2 우, 2 $\hat{\jmath}$, Piura, Universidad de Piura, 5¹0'11"S-80³6'51"O, 29 msnm, 23-I-2018, U. González leg., colecta manual, Bosque estacionalmente seco de lla-

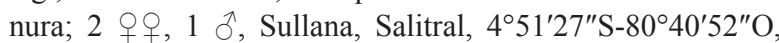
23 msnm, 18-I-2016, G. Juárez leg., colecta manual, Bosque estacionalmente seco de llanura; 1 옹, Talara, Los Órganos, $4^{\circ} 10^{\prime} 38^{\prime \prime} \mathrm{S}-81^{\circ} 07^{\prime} 27^{\prime \prime} \mathrm{O}, 12 \mathrm{msnm}, 05-\mathrm{V}-2017$, G. Juárez leg., colecta manual, Desierto costero; 2 우, $2 \hat{\jmath} \widehat{\partial}$, Paita, 504'S-8106 'O, 10 msnm, 21-II-2017, G. Juárez leg., colecta manual, Bosque estacionalmente seco de llanura; 1 +, Sechura, Vice, $5^{\circ} 25^{\prime} \mathrm{S}-81^{\circ} 46^{\prime} \mathrm{O}, 10 \mathrm{msnm}, 12-\mathrm{XII}-2017$, U. González leg., colecta manual, Desierto costero; 1 đે, Sechura, Sechura, 5³4'S-81²16'O, 16 msnm, 24-VI-2017, U. González leg., colecta manual, Bosque estacionalmente seco de llanura; 3 우우, Morropón, Chulucanas, $5^{\circ} 05^{\prime} \mathrm{S}-80^{\circ} 99^{\prime} \mathrm{O}, 350 \mathrm{msnm}$, 22-I-2015, G. Juárez leg., colecta manual, Bosque estacionalmente seco de colina.

Distribución (Provincia) (Paisaje ecológico). (PIU, SUll, PAi, TAL, SECH, MORR) (DESc, BESr, BESIl, BESc-m).

Comentario. Los adultos y ninfas se encuentran en ramas y troncos de árboles, en solitario. Insecto fitófago, adultos se comportan como succionadores de savia. El número de individuos colectados aumentó en época de lluvia (diciembre-marzo). Especie citada también por Juárez et al. (2016).

Suborden Sternorrhyncha

Familia Coccidae Fallén, 1814

Coccidae sin identificar sp. 1.

Material examinado. PERÚ. 2 oo, Piura, Castilla, 5॰10'51"S-80³7'31"O, 29 msnm, 18-IV-2019, U. González leg., colecta manual, Bosque estacionalmente seco ribereño; 2 우오, Piura, Universidad de Piura, $5^{\circ} 10^{\prime} 11^{\prime \prime} \mathrm{S}-80^{\circ} 36^{\prime} 51^{\prime \prime} \mathrm{O}$, 29 msnm, 23-I-2018, U. González leg., colecta manual, Bosque estacionalmente seco de llanura. 
Distribución (Provincia) (Paisaje ecológico). (PIU) (BESr, BESII).

Comentario. Los adultos se fijan principalmente sobre ramas de plántulas y árboles, en solitario o grupos de dos a seis individuos. Insecto que se comporta como succionador de savia.

Familia Diaspididae Targioni Tozzetti, 1868

Género Hemiberlesia Leonardi, 1897

25. Hemiberlesia rapax (Comstock, 1881)

Material examinado. PeRÚ. 4 우, Piura, Castilla, 5 10'51"S-80³7'31"O, 29 msnm, 18-IV-2019, U. González leg., colecta manual, Bosque estacionalmente seco ribereño; 2 우, 016 HEM-GJN, Piura, Universidad de Piura, $5^{\circ} 10^{\prime} 11^{\prime \prime} \mathrm{S}-80^{\circ} 36^{\prime} 51^{\prime \prime} \mathrm{O}, 29$ msnm, 23-I-2018, U. González leg., colecta manual, Bosque estacionalmente seco de llanura;

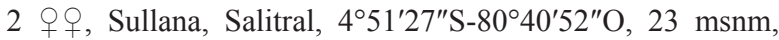
18-I-2016, G. Juárez leg., colecta manual, Bosque estacionalmente seco de llanura; 2 우, Talara, Los Órganos, $4^{\circ} 10^{\prime} 38^{\prime \prime} \mathrm{S}-81^{\circ} 07^{\prime 2} 27^{\prime \prime} \mathrm{O}, 12$ msnm, 05-V-2017, G. Juárez leg., colecta manual, Desierto costero; 2 $\circ$,, Paita, $5^{\circ} 04^{\prime} \mathrm{S}-81^{\circ} 06^{\prime} \mathrm{O}$, 10 msnm, 21-II-2017, G. Juárez leg., colecta manual, Bosque estacionalmente seco de llanura.

Distribución (Provincia) (Paisaje ecológico). (PIU, SUlL, PAi) (DESc, BESr, BESIl).

Comentario. Especie citada como Hemiberlesia sp en Juárez et al. (2016). Los adultos se fijan sobre ramas y troncos de plántulas y árboles formando hileras de más de cinco individuos. Insecto que se comporta como succionador de savia. Especie citada también por Núñez-Sacarías (1993).

\section{Familia Aphididae}

Genero Aphis Linnaeus, 1758

\section{Aphis craccivora Koch, 1854}

Material examinado. Perú. 2 우, 020 HEM-GJN, Piura, Universidad de Piura, 5 $5^{\circ} 10^{\prime} 11^{\prime \prime} \mathrm{S}-80^{\circ} 36^{\prime} 51^{\prime \prime} \mathrm{O}, 29 \mathrm{msnm}$, 12-IV-2016, U. González leg., colecta manual, Bosque estacionalmente seco ribereño; 3 q , Sullana, Salitral, 451'27"S-8040'52"O, 23 msnm, 25-VII-2017, G. Juárez leg., colecta manual, Bosque estacionalmente seco de llanura; 1 o, Talara, Los Órganos, $4^{\circ} 10^{\prime} 38^{\prime \prime} \mathrm{S}-81^{\circ} 07^{\prime} 29^{\prime \prime} \mathrm{O}, 12 \mathrm{msnm}$, 11-IX-2018, G. Juárez leg., colecta manual, Desierto costero;

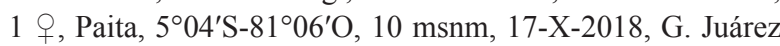
leg., colecta manual, Bosque estacionalmente seco de llanura; 2 우오, Sechura, Vice, $5^{\circ} 25^{\prime} \mathrm{S}-81^{\circ} 46^{\prime} \mathrm{O}, 10 \mathrm{msnm}, 06-\mathrm{XII}-$ 2017, U. González leg., colecta manual, Desierto costero; Morropón, Chulucanas, $5^{\circ} 05^{\prime} \mathrm{S}-80^{\circ} 99^{\prime} \mathrm{O}, 350 \mathrm{msnm}, 05-\mathrm{III}-$ 2017, G. Juárez leg., colecta manual, Bosque estacionalmente

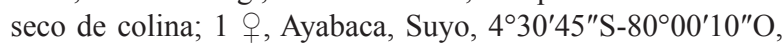
408 msnm, 23-X-2015, G. Juárez leg., colecta manual, Bosque estacionalmente seco de colina; 1 , Huancabamba, Huarmaca, 5³4'04"S-79³1'26"O, 1223 msnm, 26-VII-2016, G. Juárez leg., colecta manual, Bosque estacionalmente seco de colina.

Distribución (Provincia) (Paisaje ecológico). (PIU, SULL, PAI, TAL, SECH, MORR, HUA, AYA) (DESc, BESr, BESll, BESc-m).

Comentario. Especie citada como Aphis sp 1 en Juárez et al. (2016). Los adultos y ninfas se encuentran sobre hojas y ramas de plántulas y árboles formando grupos de más de 20 individuos. Insecto que se comporta como succionador de savia. Especie citada también por Núñez-Sacarías (1993).
27. Aphis nerii Boyer, 1841 (Fig. 7)

Material examinado. Perú. 5 o 9,021 HEM-GJN, Piura,

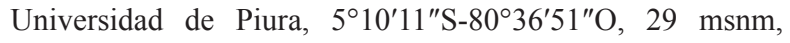
12-IV-2016, U. González leg., colecta manual, Bosque estacionalmente seco ribereño; 4 우, Sullana, Salitral, 451'27"S-8040'52"O, 23 msnm, 25-VII-2017, G. Juárez leg., colecta manual, Bosque estacionalmente seco de llanura; 2 우, Talara, Los Órganos, $4^{\circ} 10^{\prime} 38^{\prime \prime} \mathrm{S}-81^{\circ} 07^{\prime} 29^{\prime \prime} \mathrm{O}, 12 \mathrm{msnm}$, 11-IX-2018, G. Juárez leg., colecta manual, Desierto costero; 2 우오, Paita, $5^{\circ} 04^{\prime} \mathrm{S}-81^{\circ} 06^{\prime} \mathrm{O}, 10 \mathrm{msnm}, 17-\mathrm{X}-2018$, G. Juárez leg., colecta manual, Bosque estacionalmente seco de llanura; 3 우우, Sechura, Vice, $5^{\circ} 25^{\prime} \mathrm{S}-81^{\circ} 46^{\prime} \mathrm{O}, 10 \mathrm{msnm}, 06-\mathrm{XII}-$ 2017, U. González leg., colecta manual, Desierto costero; Morropón, Chulucanas, $5^{\circ} 05^{\prime} \mathrm{S}-80^{\circ} 99^{\prime} \mathrm{O}, 350 \mathrm{msnm}, 05-\mathrm{III}-$ 2017, G. Juárez leg., colecta manual, Bosque estacionalmente seco de colina; $2 \widehat{O}^{\wedge} \widehat{O}^{\prime}$, Ayabaca, Suyo, $4^{\circ} 30^{\prime} 45^{\prime \prime} \mathrm{S}-80^{\circ} 00^{\prime} 10^{\prime \prime} \mathrm{O}$, 408 msnm, 23-X-2015, G. Juárez leg., colecta manual, Bosque estacionalmente seco de colina; 3 우오, Huancabamba, Huarmaca, 5³4'04"S-79³1'26"O, 1223 msnm, 26-VII-2016, G. Juárez leg., colecta manual, Bosque estacionalmente seco de colina.

Distribución (Provincia) (Paisaje ecológico). (PIU, SUlL, PAi, TAL, SECH, MORR, HUA, AYA) (DESc, BESr, BESll, BESc-m).

Comentario. Especie citada como Aphis sp 2 en Juárez et al. (2016). Los adultos y ninfas se encuentran sobre hojas y ramas de plántulas y árboles formando grupos de más de 20 individuos. Insecto que se comporta como succionador de savia.

Familia Psyllidae Latreille, 1807

Género Heteropsylla Crawford, 1914

28. Heteropsylla obscura Muddiman, Hodkinson \& Hollis, 1992

Material examinado. Perú. 3 우, 023 HEM-GJN, Piura, Universidad de Piura, $5^{\circ} 10^{\prime} 11^{\prime \prime} \mathrm{S}-80^{\circ} 36^{\prime} 51^{\prime \prime} \mathrm{O}, 29 \mathrm{msnm}$, 10-V-2017, U. González leg., colecta manual, Bosque estacionalmente seco ribereño; 2 우, Piura, Universidad de Piura, 5¹0'11"S-80³6'51"O, 29 msnm, 17-V-2019, U. González leg., colecta manual, Bosque estacionalmente seco de llanura;

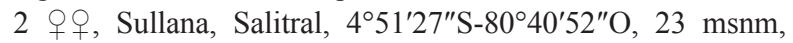
25-VII-2017, G. Juárez leg., colecta manual, Bosque estacionalmente seco de llanura; 2 우, Talara, Los Órganos, $4^{\circ} 10^{\prime} 38^{\prime \prime} \mathrm{S}-81^{\circ} 07^{\prime 2} 29^{\prime \prime} \mathrm{O}, 12$ msnm, 11-IX-2018, G. Juárez leg., colecta manual, Desierto costero; 1 \% , Paita, $5^{\circ} 04^{\prime} \mathrm{S}-81^{\circ} 06^{\prime} \mathrm{O}$, 10 msnm, 17-X-2018, G. Juárez leg., colecta manual, Bosque estacionalmente seco de llanura; 3 우, Sechura, Vice, 5²5'S-814ㅇ'O, 10 msnm, 06-XII-2017, U. González leg., colecta manual, Desierto costero; Morropón, Chulucanas, 505'S-8099'O, 350 msnm, 05-III-2017, G. Juárez leg., colecta manual, Bosque estacionalmente seco de colina.

Distribución (Provincia) (Paisaje ecológico). (PIU, SUll, PAi, TAL, SECH, MORR) (DESc, BESr, BESIl, BESc-m).

Comentario. Especie citada como Heteropsylla sp en Juárez et al. (2016). Los adultos y ninfas se encuentran sobre hojas de plántulas y árboles formando grupos de más de cinco individuos. Insecto que se comporta como succionador de savia.

Familia Aleyrodidae Westwood, 1840

Aleyrodidae sin identificar sp. 1.

Material examinado. PERÚ. 2 o $ᄋ$, Piura, Universidad de Piura, 5॰10'11"S-80³6'51"O, 29 msnm, 10-V-2017, U. González leg., colecta manual, Bosque estacionalmente seco ribereño; 2 우, $2 \hat{\delta} \widehat{\partial}$, Piura, Universidad de Piura, 5¹0'11"S-80³6'51"O, 29 msnm, 17-V-2019, U. González leg., colecta manual, Bosque estacionalmente seco de llanura. 
Distribución (Provincia) (Paisaje ecológico). (PIU) (BESr, BESIl).

Comentario. Adultos se encuentran sobre hojas de plántulas y mayormente de árboles, en solitario o grupos de dos a ocho individuos. Insecto que se comporta como succionador de savia.

\section{Suborden Heteroptera}

Familia Pyrrhocoridae Dohrn, 1859

Género Dysdercus Audinet-Serville, 1835

29. Dysdercus peruvianus Serville, 1835

Material examinado. PERÚ. 1 q, Piura, Catacaos, $5^{\circ} 15^{\prime} 42^{\prime \prime} \mathrm{S}-80^{\circ} 40^{\prime} 27^{\prime \prime} \mathrm{O}, 29$ msnm, 16-VII-2016, U. González leg., colecta manual, Bosque estacionalmente seco de llanura; 2 우, Piura, Castilla, $5^{\circ} 10^{\prime} 51^{\prime \prime} \mathrm{S}-80^{\circ} 37^{\prime} 31^{\prime \prime} \mathrm{O}, 29 \mathrm{msnm}$, 12-IV-2016, U. González leg., colecta manual, Bosque estacionalmente seco ribereño; $2 \hat{\partial} \hat{\partial}, 026$ HEM-GJN, Piura, Universidad de Piura, $5^{\circ} 10^{\prime} 11^{\prime \prime} \mathrm{S}-80^{\circ} 36^{\prime} 51^{\prime \prime} \mathrm{O}, 29 \mathrm{msnm}$, 27-IX-2018, U. González leg., colecta manual, Bosque estacionalmente seco de llanura; 1 +, Sullana, Salitral, 451'27"S-8040'52"O, 23 msnm, 18-I-2016, G. Juárez leg., colecta manual, Bosque estacionalmente seco de llanura; 1 , Talara, Los Órganos, $4^{\circ} 10^{\prime} 38^{\prime \prime} \mathrm{S}-81^{\circ} 07^{\prime} 27^{\prime \prime} \mathrm{O}, 12 \mathrm{msnm}, 05-\mathrm{V}$ 2017, G. Juárez leg., colecta manual, Desierto costero; 2 우우, $1 \mathrm{O}^{\lambda}$, Paita, 504'S-8106' O, 10 msnm, 21-II-2017, G. Juárez leg., colecta manual, Bosque estacionalmente seco de llanura; $1 \delta^{\lambda}$, Sechura, Vice, $5^{\circ} 25^{\prime} \mathrm{S}-81^{\circ} 46^{\prime} \mathrm{O}, 10 \mathrm{msnm}, 12-\mathrm{XII}-2017$,

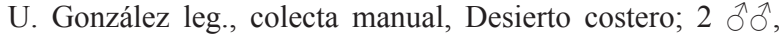
Sechura, Sechura, $5^{\circ} 34^{\prime} \mathrm{S}-81^{\circ} 16^{\prime} \mathrm{O}, 16 \mathrm{msnm}, 24-\mathrm{VI}-2017$, U. González leg., colecta manual, Bosque estacionalmente seco de llanura; 2 우으. Morropón, Chulucanas, $5^{\circ} 05^{\prime} \mathrm{S}-80^{\circ} 99^{\prime} \mathrm{O}$, 350 msnm, 22-I-2015, G. Juárez leg., colecta manual, Bosque estacionalmente seco de colina; 1 ㅇ, Morropón, Morropón, 505'51"S-8009'44"O, 557 msnm, 23-I-2015, G. Juárez leg., colecta manual, Bosque estacionalmente seco de colina; $1 \partial^{\lambda}$, Ayabaca, Suyo, $4^{\circ} 30^{\prime} 45^{\prime \prime} \mathrm{S}-80^{\circ} 00^{\prime} 10^{\prime \prime} \mathrm{O}, 408 \mathrm{msnm}$, 23-X-2015, G. Juárez leg., colecta manual, Bosque estacionalmente seco de colina; $1 \hat{\delta}$, Huancabamba, Huarmaca, 5³4'04"S-79³1'26"O, 1223 msnm, 26-VII-2016, G. Juárez leg., colecta manual, Bosque estacionalmente seco de colina.

Distribución (Provincia) (Paisaje ecológico). (PIU, SUlL, PAI, TAL, SECH, MORR, HUA, AYA) (DESc, BESr, BESll, BESc-m).

Comentario. Especie citada como Dysdercus sp en Juárez et al. (2016). Los adultos y ninfas se encuentran sobre hojas y ramas de plántulas y árboles, en solitario o en grupos de dos a más individuos. Insecto que se comporta como succionador de savia.

Familia Nabidae Costa, 1853

Género Nabis Latreille, 1802

30. Nabis sin identificar sp. 1.

Material examinado. Perú. 2 ōô, Piura, Universidad de Piura, 510'11"S-80³6'51"O, 29 msnm, 27-IX-2018, U. González leg., colecta manual, Bosque estacionalmente seco de llanura; 1 o, Sullana, Salitral, 4 $4^{\circ} 51^{\prime} 27^{\prime \prime} \mathrm{S}-80^{\circ} 40^{\prime} 52^{\prime \prime} \mathrm{O}$, 23 msnm, 18-I-2016, G. Juárez leg., colecta manual, Bosque estacionalmente seco de llanura; 2 우, Talara, Los Órganos, $4^{\circ} 10^{\prime} 38^{\prime \prime} \mathrm{S}-81^{\circ} 07^{\prime} 27^{\prime \prime} \mathrm{O}, 12 \mathrm{msnm}, 05-\mathrm{V}-2017$, G. Juárez leg., colecta manual, Desierto costero; 1 , $1 \hat{\delta}$, Paita, $5^{\circ} 04^{\prime} \mathrm{S}-81^{\circ} 06^{\prime} \mathrm{O}, 10 \mathrm{msnm}, 21-\mathrm{II}-2017$, G. Juárez leg., colecta manual, Bosque estacionalmente seco de llanura.

Distribución (Provincia) (Paisaje ecológico). (PIU, SUll, PAi) (BES11).
Comentario. Los adultos y ninfas se encuentran sobre hojas y ramas de plántulas y árboles, en solitario. Insecto que se comporta como controlador biológico (Romero et al., 2007). Especie citada también por Núñez-Sacarías (1993) y Juárez et al. (2016).

Familia Miridae Hahn, $1831 \dagger$

Género Dagbertus Distant, $1904 \dagger$

31. Dagbertus sin identificar sp. $1 . \dagger$

Material examinado. Perú. $2 \delta^{\lambda} \delta^{\lambda}$ Piura, Universidad de Piura, 510'11"S-80³6'51"O, 29 msnm, 13-III-2019, U. González leg., colecta manual, Bosque estacionalmente seco de llanura; 2 우오, Sullana, Salitral, $4^{\circ} 51^{\prime} 27^{\prime \prime} \mathrm{S}-80^{\circ} 40^{\prime} 52^{\prime \prime} \mathrm{O}, 23 \mathrm{msnm}, 28-\mathrm{V}$ 2014, G. Juárez leg., colecta manual, Bosque estacionalmente seco de llanura.

Distribución (Provincia) (Paisaje ecológico). (PIU, SULL) (BES11).

Comentario. Los adultos y ninfas se encuentran sobre hojas de plántulas y árboles, en solitario o en grupos de dos a cuatro individuos. Insecto que se comporta como succionador de savia.

Familia Reduviidae Latreille, 1807

Género Zelus Fabricius, 1803

32. Zelus nugax Stal, 1862

Material examinado. PERÚ. 2 우, Piura, Castilla, Universidad Nacional de Piura, 5 $5^{\circ} 0^{\prime} 51^{\prime \prime} \mathrm{S}-80^{\circ} 37^{\prime} 31^{\prime \prime} \mathrm{O}, 29 \mathrm{msnm}, 2-\mathrm{II}-$ 2018, U. González leg., colecta manual, Bosque estacionalmente seco ribereño; $1 \hat{\sigma}, 031$ HEM-GJN, Piura, Universidad de Piura, $5^{\circ} 10^{\prime} 11^{\prime \prime} \mathrm{S}-80^{\circ} 36^{\prime} 51^{\prime \prime} \mathrm{O}, 29 \mathrm{msnm}, 27-\mathrm{IX}-2014$, U. González leg., colecta manual, Bosque estacionalmente seco de llanura; 1 +, Sullana, Salitral, $4^{\circ} 51^{\prime} 27^{\prime \prime} \mathrm{S}-80^{\circ} 40^{\prime} 52^{\prime \prime} \mathrm{O}$, 23 msnm, 6-IV-2017, G. Juárez leg., colecta manual, Bosque estacionalmente seco de llanura; 2 ईิे, Talara, Lobitos, $4^{\circ} 27^{\prime} 10^{\prime \prime} \mathrm{S}-81^{\circ} 16^{\prime} 40^{\prime \prime} \mathrm{O}, 12 \mathrm{msnm}, 27-\mathrm{VI}-2015$, G. Juárez leg., colecta manual, Desierto costero; 1 , , Paita, $5^{\circ} 04^{\prime} \mathrm{S}-81^{\circ} 06^{\prime} \mathrm{O}$, 10 msnm, 7-IX-2015, G. Juárez leg., colecta manual, Bosque estacionalmente seco de llanura; 3 ईิे, Paita, Vichayal, $4^{\circ} 51^{\prime} 55^{\prime \prime S}-81^{\circ} 04^{\prime} 19^{\prime \prime} \mathrm{O}, 10$ msnm, 20-X-2018, Gino Juárez leg., colecta manual, Bosque estacionalmente seco de llanura; 1 을 Sechura, Desierto de Sechura, $5^{\circ} 34^{\prime} \mathrm{S}-81^{\circ} 16^{\prime} \mathrm{O}, 10 \mathrm{msnm}$, 13-XII-2016, G. Juárez leg., colecta manual, Desierto costero; 1 ․, Sechura, Illescas, $5^{\circ} 58^{\prime} \mathrm{S}-81^{\circ} 05^{\prime} \mathrm{O}, 10 \mathrm{msnm}$, 12-XI-2017, U. González leg., red entomológica, Matorral Xérico; 1 ㅇ, Morropón, Piedra del Toro, $5^{\circ} 11^{\prime} \mathrm{S}-80^{\circ} 49^{\prime} \mathrm{O}$, 1225 msnm, 29-VII-2016, G. Juárez leg., colecta manual, Bosque estacionalmente seco de colina; $1 \hat{\jmath}$, Ayabaca,

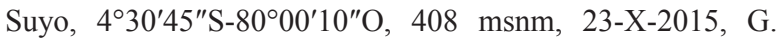
Juárez leg., colecta manual, Bosque estacionalmente seco de colina; Huancabamba, Huarmaca, $5^{\circ} 34^{\prime} 04^{\prime \prime} \mathrm{S}-79^{\circ} 31^{\prime} 26^{\prime \prime} \mathrm{O}$, 1223 msnm, 26-VII-2016, G. Juárez leg., colecta manual, Bosque estacionalmente seco de colina.

Distribución (Provincia) (Paisaje ecológico). (PIU, SUlL, PAi, TAL, SECH, MORR, HUA, AYA) (MatX, DESc, BESr, BES1l, BESc-m).

Comentario. Especie citada como Zelus sp en Juárez et al. (2016). Los adultos y ninfas se encuentran en hojas y ramas de plántulas y árboles, en solitario. Insecto que se comporta como controlador biológico, depredando a un sin número de insectos fitófagos (principalmente áfidos), incluso a coccinélidos que se comportan como controladores biológicos (PotinTéllez, 2008). Especie citada también por Domínguez (1982) y Núñez-Sacarías (1993). 
Familia Rhopalidae Amyot \& Serville, 1843

Género Harmostes Burmeister, 1835

33. Harmostes sin identificar sp. 1.

Material examinado. PERÚ. 2 o , Piura, Castilla, Universidad Nacional de Piura, $5^{\circ} 10^{\prime} 51^{\prime \prime} \mathrm{S}-80^{\circ} 37^{\prime} 31^{\prime \prime} \mathrm{O}$, 29 msnm, 2-II-2018, U. González leg., colecta manual, Bosque estacionalmente seco ribereño; $2 \hat{\delta}$, Piura, Universidad de Piura, 5 $5^{\circ} 10^{\prime} 11^{\prime \prime} \mathrm{S}-80^{\circ} 36^{\prime} 51^{\prime \prime} \mathrm{O}, 29 \mathrm{msnm}, 12-\mathrm{X}-2016$, U. González leg., colecta manual, Bosque estacionalmente seco

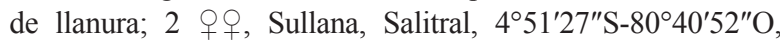
23 msnm, 6-IV-2017, G. Juárez leg., colecta manual, Bosque estacionalmente seco de llanura; 1 옹, Paita, $5^{\circ} 04^{\prime} \mathrm{S}-81^{\circ} 06^{\prime} \mathrm{O}$, 10 msnm, 7-IX-2015, G. Juárez leg., colecta manual, Bosque estacionalmente seco de llanura; 1 $\hat{O}$, Paita, Vichayal, 451'55"S-81 04'19"O, 10 msnm, 20-X-2018, Gino Juárez leg., colecta manual, Bosque estacionalmente seco de llanura; 2 우우, Sechura, Desierto de Sechura, $5^{\circ} 34^{\prime} \mathrm{S}-81^{\circ} 16^{\prime} \mathrm{O}, 10 \mathrm{msnm}$, 13-XII-2016, G. Juárez leg., colecta manual, Desierto costero.

Distribución (Provincia) (Paisaje ecológico). (PIU, SUlL, PAi, $\mathrm{SECH})(\mathrm{DESc}, \mathrm{BESr}, \mathrm{BES} 11)$.

Comentario. Especie citada también por Juárez et al. (2016).

Familia Pentatomidae Leach, 1815

Género Trincavellius Distant, 1900

34. Trincavellius sin identificar sp. 1.

Material examinado. PERÚ. 1, Piura, Castilla, Universidad Nacional de Piura, $5^{\circ} 10^{\prime} 51^{\prime \prime} \mathrm{S}-80^{\circ} 37^{\prime} 31^{\prime \prime} \mathrm{O}, 29 \mathrm{msnm}, 2-\mathrm{II}-$ 2018, U. González leg., colecta manual, Bosque estacionalmente seco ribereño; 1 $\widehat{\partial}$, Piura, Universidad de Piura, $5^{\circ} 10^{\prime} 11^{\prime \prime S}-80^{\circ} 36^{\prime} 51^{\prime \prime} \mathrm{O}, 29$ msnm, 12-X-2016, U. González leg., colecta manual, Bosque estacionalmente seco de llanura. Distribución (Provincia) (Paisaje ecológico). (PIU) (BESIl).

Comentario. Especie citada también por Juárez et al. (2016).

Género Podisus Herrich-Schäffer, 1851

35. Podisus sin identificar sp. 1.

Material examinado. PERÚ. 1 , Piura, Castilla, Universidad Nacional de Piura, 5 $5^{\circ} 10^{\prime} 51^{\prime \prime} \mathrm{S}-80^{\circ} 37^{\prime} 31^{\prime \prime} \mathrm{O}, 29 \mathrm{msnm}, 2-\mathrm{II}-$ 2018, U. González leg., colecta manual, Bosque estacionalmente seco ribereño; 1 + , Piura, Universidad de Piura, $5^{\circ} 10^{\prime} 11^{\prime \prime} \mathrm{S}-80^{\circ} 36^{\prime} 51^{\prime \prime} \mathrm{O}, 29 \mathrm{msnm}, 12-\mathrm{X}-2016$, U. González leg., colecta manual, Bosque estacionalmente seco de llanura; 2 우, Paita, $5^{\circ} 04^{\prime} \mathrm{S}-81^{\circ} 06^{\prime} \mathrm{O}, 10 \mathrm{msnm}, 7-\mathrm{IX}-2015$, G. Juárez leg., colecta manual, Bosque estacionalmente seco de llanura; $1 \widehat{\partial}^{\lambda}$, Paita, Vichayal, $4^{\circ} 51^{\prime} 55^{\prime \prime} \mathrm{S}-81^{\circ} 04^{\prime} 19^{\prime \prime} \mathrm{O}$, 10 msnm, 20-X-2018, Gino Juárez leg., colecta manual, Bosque estacionalmente seco de llanura; $1 \hat{\jmath}$, Talara, Lobitos, $4^{\circ} 27^{\prime} 10^{\prime \prime} \mathrm{S}-81^{\circ} 16^{\prime} 40^{\prime \prime} \mathrm{O}, 12$ msnm, 27-VI-2015, G. Juárez leg., colecta manual, Desierto costero.

Distribución (Provincia) (Paisaje ecológico). (PIU, PAI, TAL) (DESc, BESr, BESll).

Comentario. Los adultos y ninfas se encuentran sobre hojas y ramas de plántulas y árboles, en solitario. Insecto que se comporta como controlador biológico. Especie citada también por Núñez-Sacarías (1993) y Juárez et al. (2016).

Género Nezara Amyot \& Serville, 1845

36. Nezara viridula (Linnaeus, 1758)

Material examinado. PERÚ. 1 + Piura, Castilla, Universidad Nacional de Piura, $5^{\circ} 10^{\prime} 51^{\prime \prime} \mathrm{S}-80^{\circ} 37^{\prime} 31^{\prime \prime} \mathrm{O}, 29 \mathrm{msnm}, 2$-II2018, U. González leg., colecta manual, Bosque estacionalmente seco ribereño; 2 $\widehat{\partial}, 036$ HEM-GJN, Piura, Universidad de Piura, $5^{\circ} 10^{\prime} 11^{\prime \prime} \mathrm{S}-80^{\circ} 36^{\prime} 51^{\prime \prime} \mathrm{O}, 29 \mathrm{msnm}, 12-\mathrm{X}-2016$, U.
González leg., colecta manual, Bosque estacionalmente seco de llanura; 1 옹 Sullana, Salitral, $4^{\circ} 51^{\prime} 27^{\prime \prime S}-80^{\circ} 40^{\prime} 52^{\prime \prime} \mathrm{O}$, 23 msnm, 6-IV-2017, G. Juárez leg., colecta manual, Bosque estacionalmente seco de llanura; 1 + , Paita, $5^{\circ} 04^{\prime} \mathrm{S}-81^{\circ} 06^{\prime} \mathrm{O}$, 10 msnm, 7-IX-2015, G. Juárez leg., colecta manual, Bosque estacionalmente seco de llanura; 1 त, Paita, Vichayal, 451'55"S-8104'19"O, 10 msnm, 20-X-2018, Gino Juárez leg., colecta manual, Bosque estacionalmente seco de llanura; 2 우, Sechura, Sechura, $5^{\circ} 34^{\prime} \mathrm{S}-81^{\circ} 16^{\prime} \mathrm{O}, 10 \mathrm{msnm}, 13-\mathrm{XII}-$ 2016, G. Juárez leg., colecta manual, Bosque estacionalmente seco de llanura.

Distribución (Provincia) (Paisaje ecológico). (PIU, SUlL, PAi, SECH) (BESr, BESll).

Comentario. Especie citada como Nezara sp en Juárez et al. (2016). Los adultos y ninfas se encuentran sobre hojas y ramas de plántulas y árboles, en solitario. Insecto que se comporta como succionador de savia.

Familia Coreidae Leach, $1815 \dagger$

Género Piezogaster Amyot \& Serville, $1843 \dagger$

37. Piezogaster obscuratus (Montandon, 1898) $†$ (Fig. 8)

Material examinado. PERÚ. 1 , Piura, Castilla, Universidad Nacional de Piura, $5^{\circ} 10^{\prime} 51^{\prime \prime} \mathrm{S}-80^{\circ} 37^{\prime} 31^{\prime \prime} \mathrm{O}, 29 \mathrm{msnm}$, 12-IV-2017, U. González leg., colecta manual, Bosque estacionalmente seco ribereño; $1 \hat{\jmath}$, Piura, Universidad de Piura, $5^{\circ} 10^{\prime} 11^{\prime \prime} \mathrm{S}-80^{\circ} 36^{\prime} 51^{\prime \prime} \mathrm{O}, 29 \mathrm{msnm}, \quad 12-\mathrm{X}-$ 2016, U. González leg., colecta manual, Bosque estacionalmente seco de llanura; $2 \hat{\delta} \hat{\delta}$, Piura, Catacaos, 5¹5'42"S-8040'27"O, 29 msnm, 16-VII-2016, U. González leg., colecta manual, Bosque estacionalmente seco de llanura; $1 \widehat{o}^{\lambda}$, Piura, Castilla, $5^{\circ} 10^{\prime} 51^{\prime \prime} \mathrm{S}-80^{\circ} 37^{\prime} 31^{\prime \prime} \mathrm{O}, 29 \mathrm{msnm}, 12-\mathrm{IV}-$ 2016, U. González leg., colecta manual, Bosque estacionalmente seco ribereño.

Distribución (Provincia) (Paisaje ecológico). (PIU) (BESr, BESIl).

Comentario. Los adultos y ninfas se encuentran sobre hojas, ramas y troncos de árboles, en solitario. Insecto que se comporta como succionador de savia.

Orden NEUROPTERA Linnaeus, 1758

Familia Chrysopidae Schneider, 1851

Subfamilia Chrysopinae Schneider, 1851

Género Chrysoperla Steinmann, 1964

38. Chrysoperla externa (Hagen, 1861)

Material examinado. PERÚ. 2 q + Piura, Catacaos, $5^{\circ} 15^{\prime} 42^{\prime \prime} \mathrm{S}-80^{\circ} 40^{\prime} 27^{\prime \prime} \mathrm{O}, 29 \mathrm{msnm}, 26-\mathrm{II}-2018$, U. González leg., red entomológica, Bosque estacionalmente seco de llanura; 1 , , Piura, Castilla, Universidad Nacional de Piura, 5¹0'51"S-80³7'31"O, 29 msnm, 12-IV-2017, U. González leg., red entomológica, Bosque estacionalmente seco ribereño; 1 $\widehat{\jmath}, 041$ NEU-GJN, Piura, Universidad de Piura, 5¹0'11"S-80³6'51"O, 29 msnm, 27-V-2019, U. González leg., red entomológica, Bosque estacionalmente seco de

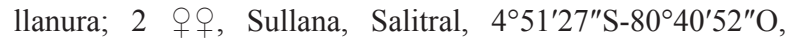
23 msnm, 28-III-2019, G. Juárez leg., red entomológica, Bosque estacionalmente seco de llanura; 1 \%, Talara, Los Órganos, $4^{\circ} 10^{\prime} 38^{\prime \prime} \mathrm{S}-81^{\circ} 07^{\prime} 27^{\prime \prime} \mathrm{O}, 12 \mathrm{msnm}, 05-\mathrm{V}-2017$, G. Juárez leg., red entomológica, Desierto costero; 1 ते, Paita, $5^{\circ} 04^{\prime} \mathrm{S}-81^{\circ} 06^{\prime} \mathrm{O}, 10 \mathrm{msnm}, 21-\mathrm{II}-2017$, G. Juárez leg., red entomológica, Bosque estacionalmente seco de llanura; 1 , Sechura, Vice, $5^{\circ} 25^{\prime} \mathrm{S}-81^{\circ} 46^{\prime} \mathrm{O}, 10 \mathrm{msnm}, 12-\mathrm{XII}-2017$, U. González leg., red entomológica, Desierto costero; 1 ô, Sechura, Sechura, $5^{\circ} 34^{\prime} \mathrm{S}-81^{\circ} 16^{\prime} \mathrm{O}, 16 \mathrm{msnm}, 24-\mathrm{VI}-2017$, U. González leg., red entomológica, Bosque estacionalmente 
seco de llanura; 1 ㅇ, Morropón, Chulucanas, $5^{\circ} 05^{\prime} \mathrm{S}-80^{\circ} 99^{\prime} \mathrm{O}$, 350 msnm, 22-I-2015, G. Juárez leg., red entomológica, Bosque estacionalmente seco de colina; $1 \hat{\delta}$, Ayabaca, Suyo, $4^{\circ} 30^{\prime} 45^{\prime \prime} \mathrm{S}-80^{\circ} 00^{\prime} 10^{\prime \prime} \mathrm{O}, 408$ msnm, 23-X-2015, G. Juárez leg., red entomológica, Bosque estacionalmente seco de colina; $1 \delta^{\lambda}$, Huancabamba, Huarmaca, 534'04"S-79³1'26"O, 1223 msnm, 26-VII-2016, G. Juárez leg., red entomológica, Bosque estacionalmente seco de colina.

Distribución (Provincia) (Paisaje ecológico). (PIU, SUll, PAi, TAL, SECH, MORR) (DESc, BESr, BESll, BESc-m).

Comentario. Especie citada como Chrysoperla sp en Juárez et al. (2016). Los adultos se encuentran sobre hojas y ramas de plántulas y árboles, en solitario. Insecto que se comporta como controlador biológico, larvas y adultos depredan principalmente áfidos y larvas de lepidópteros (Núñez, 1988).

Familia Myrmeleontidae Latreille, 1803

Subfamilia Palparinae Banks, 1912

Género Millerleon Stange, 1989

39. Millerleon subdolus (Walker, 1853)

Material examinado. PERÚ. 2 우, Piura, Catacaos, $5^{\circ} 15^{\prime} 42^{\prime \prime} \mathrm{S}-80^{\circ} 40^{\prime 2} 7^{\prime \prime} \mathrm{O}, 29 \mathrm{msnm}, 26-\mathrm{II}-2018$, U. González leg., colecta manual, Bosque estacionalmente seco de llanura; 1 \&, Piura, Castilla, Universidad Nacional de Piura, 5 $10^{\prime} 51^{\prime \prime}$ S-80³7'31"O, 29 msnm, 12-IV-2017, U. González leg., red entomológica, Bosque estacionalmente seco ribereño; 2 ภิ $\hat{\partial}, 048$ NEU-GJN, Piura, Universidad de Piura, $5^{\circ} 10^{\prime} 11^{\prime \prime} \mathrm{S}-80^{\circ} 36^{\prime} 51^{\prime \prime} \mathrm{O}, 29 \mathrm{msnm}, 27-\mathrm{V}-2019$, U. González leg., colecta manual, Bosque estacionalmente seco de lla-

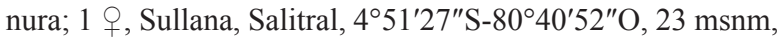
28-III-2019, G. Juárez leg., colecta manual, Bosque estacionalmente seco de llanura; 2 우, Talara, Los Órganos, $4^{\circ} 10^{\prime} 38^{\prime \prime} \mathrm{S}-81^{\circ} 07^{\prime} 27^{\prime \prime} \mathrm{O}, 12 \mathrm{msnm}, 05-\mathrm{V}-2017$, G. Juárez

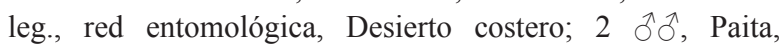
$5^{\circ} 04^{\prime} \mathrm{S}-81^{\circ} 06^{\prime} \mathrm{O}, 10 \mathrm{msnm}, 21-\mathrm{II}-2017$, G. Juárez leg., colecta manual, Bosque estacionalmente seco de llanura; 1 ô, Sechura, Vice, $5^{\circ} 25^{\prime} \mathrm{S}-81^{\circ} 46^{\prime} \mathrm{O}, 10 \mathrm{msnm}, 12-\mathrm{XII}-2017$, U. González leg., colecta manual, Desierto costero; 1 , Sechura, Sechura,

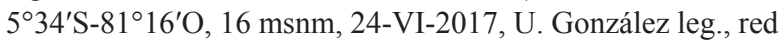
entomológica, Bosque estacionalmente seco de llanura; 2 우우, Morropón, Chulucanas, $5^{\circ} 05^{\prime} \mathrm{S}-80^{\circ} 99^{\prime} \mathrm{O}, 350 \mathrm{msnm}, 22-\mathrm{I}-$ 2015, G. Juárez leg., colecta manual, Bosque estacionalmente seco de colina.

Distribución (Provincia) (Paisaje ecológico). (PIU, SUll, PAI, TAL, SECH) (DESc, BESr, BESll).

Comentario. Especie citada como morfoespecie 1 en Juárez et al. (2016). Los adultos se encuentran sobre hojas y ramas de plántulas y árboles, en solitario. Insecto que se comporta como controlador biológico (Stange, 1989).

Orden COLEOPTERA Linnaeus, 1758

Suborden Adephaga Schellenberg, 1806

Familia Carabidae Latreille, 1802

Subfamilia Cicindelinae Latreille, 1802

Género Cicindelidia Linnaeus, 1758

\section{Cicindelidia trifasciata Fabricius, 1871}

Material examinado. PERÚ. 1 \%, Piura, Castilla, $5^{\circ} 10^{\prime} 51^{\prime \prime} \mathrm{S}-80^{\circ} 37^{\prime} 31^{\prime \prime} \mathrm{O}, \quad 29 \mathrm{msnm}, \quad 12-\mathrm{IV}-2016, \quad$ U. González leg., colecta manual, Bosque estacionalmente seco ribereño; 3 우, $3 \hat{\jmath} \widehat{\jmath}$, Piura, Universidad de Piura, 5¹0'11"S-80³6'51"O, 29 msnm, 19-II-2017, U. González leg., colecta manual, Bosque estacionalmente seco de lla-

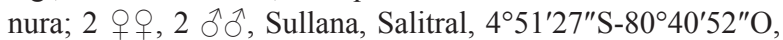
23 msnm, 18-I-2016, G. Juárez leg., colecta manual,
Bosque estacionalmente seco de llanura; 1 , Talara, Los Órganos, $4^{\circ} 10^{\prime} 38^{\prime \prime} \mathrm{S}-81^{\circ} 07^{\prime} 27^{\prime \prime} \mathrm{O}, 12 \mathrm{msnm}, 05-\mathrm{V}-2017$, G. Juárez leg., colecta manual, Desierto costero; 3 우, Paita, $5^{\circ} 04^{\prime} \mathrm{S}-81^{\circ} 06^{\prime} \mathrm{O}, 10 \mathrm{msnm}, 21-\mathrm{II}-2017$, G. Juárez leg., colecta manual, Bosque estacionalmente seco de llanura; 1 ㅇ, Sechura, Vice, $5^{\circ} 25^{\prime} \mathrm{S}-81^{\circ} 46^{\prime} \mathrm{O}, 10 \mathrm{msnm}, 12-\mathrm{XII}-2017$, U. González leg., colecta manual, Desierto costero; 1 స, Sechura, Sechura, 53 $34^{\prime} \mathrm{S}-81^{\circ} 16^{\prime} \mathrm{O}, 16$ msnm, 24-VI-2017, U. González leg., colecta manual, Bosque estacionalmente seco de llanura; $1 \hat{\jmath}$, Sechura, Laguna Napique, $5^{\circ} 34^{\prime} \mathrm{S}-81^{\circ} 16^{\prime} \mathrm{O}, 16 \mathrm{msnm}$, 24-VI-2019, U. González leg., colecta manual, Bosque estacionalmente seco ribereño; 3 우, Morropón, Chulucanas, $5^{\circ} 05^{\prime} \mathrm{S}-80^{\circ} 99^{\prime} \mathrm{O}$, $350 \mathrm{msnm}$, 22-I-2015, G. Juárez leg., colecta manual, Bosque estacionalmente seco de colina; 2 우우, Morropón, Morropón, 505'51"S-8009'44"O, 557 msnm, 23-I-2015, G. Juárez leg., colecta manual, Bosque estacionalmente seco de colina; $1 \hat{\partial}$, Ayabaca, Suyo, $4^{\circ} 30^{\prime} 45^{\prime \prime} \mathrm{S}-80^{\circ} 00^{\prime} 10^{\prime \prime} \mathrm{O}, 408 \mathrm{msnm}, 23-\mathrm{X}-2015$, G. Juárez leg., colecta manual, Bosque estacionalmente seco de colina;

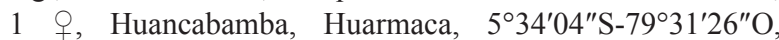
1223 msnm, 26-VII-2016, G. Juárez leg., colecta manual, Bosque estacionalmente seco de colina.

Distribución (Provincia) (Paisaje ecológico). (PIU, SUll, PAi, TAL, SECH, MORR, HUA, AYA) (DESc, BESr, BESIl, BESc-m).

Comentario. Los adultos se encuentran a ras del suelo cercanos al tronco y escondidas en grietas de troncos de árboles, en solitario. Insecto que se comporta como controlador biológico, adultos depredan larvas de lepidópteros, larvas y adultos de coleópteros, ninfas y adultos de hemípteros (Pearson et al., 1999). La cantidad de individuos colectados aumentó en época de lluvia (diciembre-marzo). Especie citada también por Juárez \& González (2016a).

\section{Género Tetracha Hope, 1838}

41. Tetracha chilensis (Laporte, 1834)

Material examinado. PERÚ. 2 우, 1 ô, Piura, Universidad de Piura, 510'11"S-80³6'51"O, 29 msnm, 19-II-2017, U. González leg., colecta manual, Bosque estacionalmente seco de

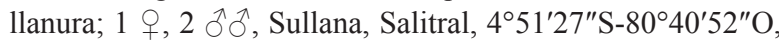
23 msnm, 18-I-2016, G. Juárez leg., colecta manual, Bosque estacionalmente seco de llanura; 2 우, Talara, Los Órganos, $4^{\circ} 10^{\prime} 38^{\prime \prime} \mathrm{S}-81^{\circ} 07^{\prime} 27^{\prime \prime} \mathrm{O}, 12 \mathrm{msnm}, 05-\mathrm{V}-2017$, G. Juárez

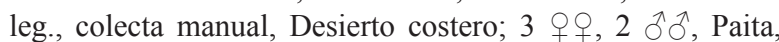
$5^{\circ} 04^{\prime} \mathrm{S}-81^{\circ} 06^{\prime} \mathrm{O}, 10 \mathrm{msnm}, 21-\mathrm{II}-2017$, G. Juárez leg., colecta manual, Bosque estacionalmente seco de llanura; 1 \%, Sechura, Vice, $5^{\circ} 25^{\prime} \mathrm{S}-81^{\circ} 46^{\prime} \mathrm{O}, 10 \mathrm{msnm}, 12-\mathrm{XII}-2017$, U. González leg., colecta manual, Desierto costero; 1 $\delta, 1$ ㅇ, Sechura, Laguna Napique, $5^{\circ} 34^{\prime} \mathrm{S}-81^{\circ} 16^{\prime} \mathrm{O}, 16$ msnm, 24-VI-2019, U. González leg., colecta manual, Bosque estacionalmente seco ribereño; 2 우, Morropón, Chulucanas, $5^{\circ} 05^{\prime} \mathrm{S}-80^{\circ} 99^{\prime} \mathrm{O}$, 350 msnm, 22-I-2015, G. Juárez leg., colecta manual, Bosque

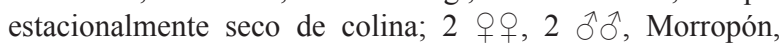
Morropón, $5^{\circ} 05^{\prime} 51^{\prime \prime} \mathrm{S}-80^{\circ} 09^{\prime} 44^{\prime \prime} \mathrm{O}, 557 \mathrm{msnm}, 23-\mathrm{I}-2015$, G. Juárez leg., colecta manual, Bosque estacionalmente seco de colina; $1 \hat{\mathrm{O}}, 1$ ․, Ayabaca, Suyo, $4^{\circ} 30^{\prime} 45^{\prime \prime} \mathrm{S}-80^{\circ} 00^{\prime} 10^{\prime \prime} \mathrm{O}$, 408 msnm, 23-X-2015, G. Juárez leg., colecta manual, Bosque estacionalmente seco de colina; 1 + , Huancabamba, Huarmaca, 5³4'04"S-79³1'26"O, 1223 msnm, 26-VII-2016, G. Juárez leg., colecta manual, Bosque estacionalmente seco de colina.

Distribución (Provincia) (Paisaje ecológico). (PIU, SUlL, PAI, TAL, SECH, MORR, HUA, AYA) (DESc, BESr, BESIl, BESc-m). 
Comentario. Adultos se encuentran a ras del suelo cercanos a troncos y escondidas en grietas de troncos de árboles, en solitario. Insecto que se comporta como controlador biológico, adultos depredan larvas de lepidópteros, larvas y adultos de coleópteros, ninfas y adultos de hemípteros (Naviaux, 2007). La cantidad de individuos colectados aumentó en época de lluvia (diciembre-marzo). Especie citada también por Juárez \& González (2016a).

Subfamilia Carabinae Latreille, 1802

Género Calosoma Weber, 1801

42. Calosoma (Castrida) abbreviatum Chaudoir, 1869

Material examinado. PERÚ. 2 9 , 2 $\widehat{\jmath}$, Piura, Universidad de Piura, 5 $5^{\circ} 10^{\prime} 11^{\prime \prime S}-80^{\circ} 36^{\prime} 51^{\prime \prime} \mathrm{O}, 29 \mathrm{msnm}, 19-\mathrm{II}-2017$, U. González leg., colecta manual, Bosque estacionalmente seco de llanura; 1 9 , Piura, Castilla, $5^{\circ} 10^{\prime} 51^{\prime \prime} \mathrm{S}-80^{\circ} 37^{\prime} 31^{\prime \prime} \mathrm{O}$, 29 msnm, 12-IV-2016, U. González leg., colecta manual, Bosque estacionalmente seco ribereño; 1 ${ }^{\lambda}$, Piura, Castilla, Universidad Nacional de Piura, $5^{\circ} 10^{\prime} 51^{\prime \prime} \mathrm{S}-80^{\circ} 37^{\prime} 31^{\prime \prime} \mathrm{O}$, 29 msnm, 12-IV-2017, U. González leg., colecta manual, Bosque estacionalmente seco ribereño; 2 웅, $2 \hat{\delta} \widehat{\delta}$, Sullana, Salitral, $4^{\circ} 51^{\prime} 27^{\prime \prime} \mathrm{S}-80^{\circ} 40^{\prime} 52^{\prime \prime} \mathrm{O}, 23 \mathrm{msnm}, 18-\mathrm{I}-2016$, G. Juárez leg., colecta manual, Bosque estacionalmente seco de llanura; 2 우우, Talara, Los Órganos, $4^{\circ} 10^{\prime} 38^{\prime \prime} \mathrm{S}-81^{\circ} 07^{\prime} 27^{\prime \prime} \mathrm{O}$, 12 msnm, 05-V-2017, G. Juárez leg., colecta manual, Desierto costero; 2 우, $2 \widehat{\partial}^{\widehat{\partial}}$, Paita, $5^{\circ} 04^{\prime} \mathrm{S}-81^{\circ} 06^{\prime} \mathrm{O}, 10 \mathrm{msnm}, 21-\mathrm{II}-$ 2017, G. Juárez leg., colecta manual, Bosque estacionalmente seco de llanura; 1 ㅇ, Sechura, Vice, $5^{\circ} 25^{\prime} \mathrm{S}-81^{\circ} 46^{\prime} \mathrm{O}, 10 \mathrm{msnm}$, 12-XII-2017, U. González leg., colecta manual, Desierto costero; 1 $\hat{O}^{\lambda}$, Sechura, Laguna Ñapique, $5^{\circ} 34^{\prime} \mathrm{S}-81^{\circ} 16^{\prime} \mathrm{O}$, 16 msnm, 24-VI-2019, U. González leg., colecta manual, Bosque estacionalmente seco ribereño; 1 \&, Sechura, Illescas, $5^{\circ} 58^{\prime} \mathrm{S}-81^{\circ} 05^{\prime} \mathrm{O}, 10 \mathrm{msnm}, 12-\mathrm{XI}-2017$, U. González leg., red entomológica, Matorral Xérico; 3 우, 2 సึ $\sigma^{\lambda}$, Morropón, Chulucanas, $5^{\circ} 05^{\prime} \mathrm{S}-80^{\circ} 99^{\prime} \mathrm{O}, 350$ msnm, 22-I-2015, G. Juárez leg., colecta manual, Bosque estacionalmente seco de colina;

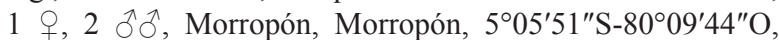
557 msnm, 23-I-2015, G. Juárez leg., colecta manual, Bosque estacionalmente seco de colina; 1 , Ayabaca, Suyo, $4^{\circ} 30^{\prime} 45^{\prime \prime} \mathrm{S}-80^{\circ} 00^{\prime} 10^{\prime \prime} \mathrm{O}, 408 \mathrm{msnm}, 23-\mathrm{X}-2015$, G. Juárez leg., colecta manual, Bosque estacionalmente seco de colina;

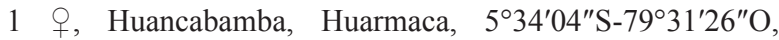
1223 msnm, 26-VII-2016, G. Juárez leg., colecta manual, Bosque estacionalmente seco de colina.

Distribución (Provincia) (Paisaje ecológico). (PIU, SUlL, PAi, TAL, SECH, MORR, HUA, AYA) (MatX, DESc, BESr, BESll, BESc-m).

COMENTARIO. Los adultos se encuentran a ras del suelo cercanos a troncos y escondidas en grietas de troncos de árboles, en solitario. Insecto que se comporta como controlador biológico, adultos depredan larvas de lepidópteros, larvas y adultos de coleóptero, ninfas y adultos de hemípteros (Gidaspow, 1963). La cantidad de individuos colectados aumentó en época de lluvia (diciembre-marzo). Especie citada también por Juárez et al. (2016).

Subfamilia Harpalinae Bonelli, 1810

Género Blennidus Motschulsky, 1865

43. Blennidus peruvianus (Dejean, 1828)

Material examinado. Perú. 3 o 9,2 $\widehat{o}, 050$ COL-GJN, Piura, Universidad de Piura, $5^{\circ} 10^{\prime} 11^{\prime \prime} \mathrm{S}-80^{\circ} 36^{\prime} 51^{\prime \prime} \mathrm{O}$, 29 msnm, 19-II-2017, U. González leg., colecta manual, Bosque estacionalmente seco de llanura; 2 ô, Piura, Castilla, Universidad Nacional de Piura,
5¹0'51"S-80³7'31"O, 29 msnm, 12-IV-2017, U. González leg., colecta manual, Bosque estacionalmente seco ribereño; 2 우우, 1 o, Sullana, Salitral, $4^{\circ} 51^{\prime} 27^{\prime \prime} \mathrm{S}-80^{\circ} 40^{\prime} 52^{\prime \prime} \mathrm{O}$, 23 msnm, 18-I-2016, G. Juárez leg., colecta manual, Bosque estacionalmente seco de llanura; 1 ㅇ, Talara, Los Órganos, $4^{\circ} 10^{\prime} 38^{\prime \prime} \mathrm{S}-81^{\circ} 07^{\prime} 27^{\prime \prime} \mathrm{O}, 12 \mathrm{msnm}, 05-\mathrm{V}-2017$, G. Juárez leg., colecta manual, Desierto costero; 2 우, $3 \hat{\jmath} \hat{\delta}$, Paita, 504'S-8106'O, 10 msnm, 21-II-2017, G. Juárez leg., colecta manual, Bosque estacionalmente seco de llanura; $1 \hat{\partial}$, Sechura, Laguna Ñapique, $5^{\circ} 34^{\prime} \mathrm{S}-81^{\circ} 16^{\prime} \mathrm{O}, 16 \mathrm{msnm}, 24-\mathrm{VI}-$ 2019, U. González leg., colecta manual, Bosque estacionalmente seco ribereño; 2 우, $2 \hat{\jmath} \widehat{\jmath}$, Morropón, Chulucanas, $5^{\circ} 05^{\prime} \mathrm{S}-80^{\circ} 99^{\prime} \mathrm{O}, 350 \mathrm{msnm}, 22-\mathrm{I}-2015$, G. Juárez leg., colecta manual, Bosque estacionalmente seco de colina.

Distribución (Provincia) (Paisaje ecológico). (PIU, SUll, PAi, TAL, SECH, MORR) (DESc, BESr, BESll, BESc-m).

Comentario. Especie citada como Blennidus sp en Juárez et al. (2016). Los adultos se encuentran a ras del suelo cercanos a troncos y escondidas en grietas de troncos de árboles, en solitario. Insecto que se comporta como controlador biológico. La cantidad de individuos colectados aumentó en época de lluvia (diciembre-marzo)

Género Notiobia Dejean, $1821 \dagger$

44. Notiobia (Anisotarsus) peruviana (Dejean, 1829) †

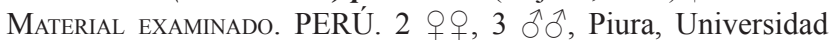
de Piura, 510'11"S-80³6'51"O, 29 msnm, 19-II-2017, U. González leg., colecta manual, Bosque estacionalmente seco de llanura; 1 $\hat{O}$, Piura, Castilla, Universidad Nacional de Piura, 5¹0'51"S-80³7'31"O, 29 msnm, 12-IV-2017, U. González leg., colecta manual, Bosque estacionalmente seco

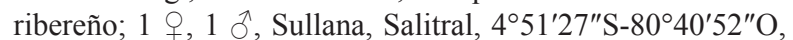
23 msnm, 18-I-2016, G. Juárez leg., colecta manual, Bosque estacionalmente seco de llanura; 1 $\hat{\delta}$, Talara, Los Órganos, $4^{\circ} 10^{\prime} 38^{\prime \prime} \mathrm{S}-81^{\circ} 07^{\prime} 27^{\prime \prime} \mathrm{O}, 12 \mathrm{msnm}, 05-\mathrm{V}-2017$, G. Juárez leg., colecta manual, Desierto costero; 2 우, 2 해, Paita, $5^{\circ} 04^{\prime} \mathrm{S}-81^{\circ} 06^{\prime} \mathrm{O}, 10 \mathrm{msnm}, 21-\mathrm{II}-2017$, G. Juárez leg., colecta manual, Bosque estacionalmente seco de llanura; 1 t, 1 ㅇ, Sechura, Laguna Napique, $5^{\circ} 34^{\prime} \mathrm{S}-81^{\circ} 16^{\prime} \mathrm{O}, 16 \mathrm{msnm}$, 24-VI2019, U. González leg., colecta manual, Bosque estacionalmente seco ribereño; 3 우, $2 \widehat{\delta} \widehat{\partial}$, Morropón, Chulucanas, $5^{\circ} 05^{\prime} \mathrm{S}-80^{\circ} 99^{\prime} \mathrm{O}, 350 \mathrm{msnm}, 22-\mathrm{I}-2015$, G. Juárez leg., colecta manual, Bosque estacionalmente seco de colina.

Distribución (Provincia) (Paisaje ecológico). (PIU, SUll, PAI, TAL, SECH, MORR) (DESc, BESr, BESIl, BESc-m).

ComentaRIo. Los adultos se encuentran a ras del suelo cercanos a troncos y escondidas en grietas de troncos de árboles, en solitario. Insecto que se comporta como controlador biológico. La cantidad de individuos colectados aumentó en época de lluvia (diciembre-marzo).

\section{Suborden Polyphaga Emery, 1886}

Familia Scarabaeidae Latreille, 1802

Subfamilia Scarabaeinae Latreille, 1802

Género Canthon Hoffmannsegg, $1817 \dagger$

45. Canthon fuscipes Erichson, $1847 \dagger$

Material examinado. Perú. 2 $q$, 1 $\hat{0}$, Piura, Universidad de Piura, $5^{\circ} 10^{\prime} 11^{\prime \prime S}-80^{\circ} 36^{\prime} 51^{\prime \prime} \mathrm{O}, 29 \mathrm{msnm}, 19-\mathrm{II}-2017$, U. González leg., colecta manual, Bosque estacionalmente seco de llanura; $2 \hat{\jmath}$, Piura, Castilla, Universidad Nacional de Piura, 5¹0'51"S-80³7'31"O, 29 msnm, 12-IV-2017, U. González leg., colecta manual, Bosque estacionalmente seco ribereño; $1 \hat{\partial}$, Sullana, Salitral, 451'27"S-80 $40^{\prime} 52^{\prime \prime} \mathrm{O}$, 23 msnm, 18-I-2016, G. Juárez leg., colecta manual, Bosque 
estacionalmente seco de llanura; 1 ㅇ, Talara, Los Órganos, $4^{\circ} 10^{\prime} 38^{\prime \prime} \mathrm{S}-81^{\circ} 07^{\prime} 27^{\prime \prime} \mathrm{O}, 12$ msnm, 05-V-2017, G. Juárez leg., colecta manual, Desierto costero; 1 + Paita, $5^{\circ} 04^{\prime} \mathrm{S}-81^{\circ} 06^{\prime} \mathrm{O}$, 10 msnm, 21-II-2017, G. Juárez leg., colecta manual, Bosque estacionalmente seco de llanura; $1 \hat{\jmath}$, Sechura, Laguna Ñapique, 53 $34^{\prime} \mathrm{S}-81^{\circ} 16^{\prime} \mathrm{O}, 16$ msnm, 24-VI-2019, U. González leg., colecta manual, Bosque estacionalmente seco ribereño; 1 q, Morropón, Chulucanas, $5^{\circ} 05^{\prime} \mathrm{S}-80^{\circ} 99^{\prime} \mathrm{O}, 350 \mathrm{msnm}, 22-\mathrm{I}-$ 2015, G. Juárez leg., colecta manual, Bosque estacionalmente seco de colina.

Distribución (Provincia) (Paisaje ecológico). (PIU, SUlL, PAi, TAL, SECH, MORR) (DESc, BESr, BESll, BESc-m).

Comentario. Los adultos se encuentran a ras del suelo muy cercanos a troncos de árboles, en solitario o en grupo de dos a cuatro individuos. Ocasionalmente se observaron individuos escondidos en grietas de troncos.

Subfamilia Rutelinae MacLeay, 1819

Género Paranomala Casey, 1915

46. Paranomala undulata peruviana Guérin-Méneville, 1831

Material examinado. PERÚ. 1 †, 1 1 , Piura, Universidad de Piura, 5¹0'11"S-80³6'51"O, 29 msnm, 19-II-2017, U. González leg., agitación de follaje, Bosque estacionalmente seco de llanura; 2 우, Piura, Castilla, $5^{\circ} 10^{\prime} 51^{\prime \prime} \mathrm{S}-80^{\circ} 37^{\prime} 31^{\prime \prime} \mathrm{O}, 29 \mathrm{msnm}$, 12-IV-2016, U. González leg., colecta manual, Bosque estacionalmente seco ribereño; 1 $\hat{O}, 1$ \&, Piura, Castilla, Universidad Nacional de Piura, $5^{\circ} 10^{\prime} 51^{\prime \prime} \mathrm{S}-80^{\circ} 37^{\prime} 31^{\prime \prime} \mathrm{O}$, 29 msnm, 12-IV-2017, U. González leg., agitación de follaje, Bosque estacionalmente seco ribereño; 2 우, $1 \hat{\delta}$, Sullana,

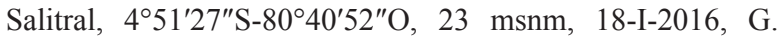
Juárez leg., red entomológica, Bosque estacionalmente seco de llanura; 1 \%, Talara, Los Órganos, $4^{\circ} 10^{\prime} 38^{\prime \prime} \mathrm{S}-81^{\circ} 07^{\prime} 27^{\prime \prime} \mathrm{O}$, 12 msnm, 05-V-2017, G. Juárez leg., colecta manual, Desierto

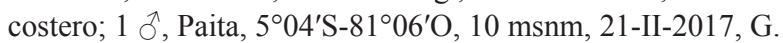
Juárez leg., colecta manual, Bosque estacionalmente seco de llanura; 1 q, 1 o , Sechura, Vice, $5^{\circ} 25^{\prime} \mathrm{S}-81^{\circ} 46^{\prime} \mathrm{O}, 10 \mathrm{msnm}$, 12-XII-2017, U. González leg., agitación de follaje, Desierto costero; 1 ^ै, 1 ㅇ, Sechura, Laguna Ñapique, $5^{\circ} 34^{\prime} \mathrm{S}-81^{\circ} 16^{\prime} \mathrm{O}$, 16 msnm, 24-VI-2019, U. González leg., agitación de follaje, Bosque estacionalmente seco ribereño; 1 +, $2 \widehat{\delta} \widehat{\delta}$, Morropón, Chulucanas, $5^{\circ} 05^{\prime} \mathrm{S}-80^{\circ} 99^{\prime} \mathrm{O}, 350 \mathrm{msnm}$, 22-I-2015, G. Juárez leg., agitación de follaje, Bosque estacionalmente seco de colina; 1 q, $1 \mathrm{\partial}^{\top}$, Morropón, Morropón, $5^{\circ} 05^{\prime} 51^{\prime \prime} \mathrm{S}-80^{\circ} 09^{\prime} 44^{\prime \prime} \mathrm{O}$, 557 msnm, 23-I-2015, G. Juárez leg., colecta manual, Bosque estacionalmente seco de colina; 1 , Ayabaca, Suyo, $4^{\circ} 30^{\prime} 45^{\prime \prime} \mathrm{S}-80^{\circ} 00^{\prime} 10^{\prime \prime} \mathrm{O}, 408$ msnm, 23-X-2015, G. Juárez leg., agitación de follaje, Bosque estacionalmente seco de colina;

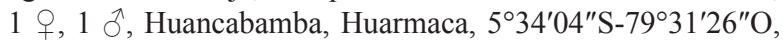
1223 msnm, 26-VII-2016, G. Juárez leg., agitación de follaje, Bosque estacionalmente seco de colina.

Distribución (Provincia) (Paisaje ecológico). (PIU, SUll, PAi, TAL, SECH, MORR, HUA, AYA) (DESc, BESr, BESll, BESc-m).

Comentario. Los adultos se encuentran sobre hojas de plántulas y árboles, en solitario o en grupo de dos individuos. Insecto que se comporta como fitófago, larvas se alimentan de raíces, los adultos causan defoliación (Mondaca, 2012). Especie citada también por Juárez et al. (2016).

Subfamilia Dynastinae MacLeay, 1819

Género Cyclocephala Dejean, 1821

47. Cyclocephala sin identificar sp. 1.

Material examinado. PERÚ. 1 \%, Piura, Universidad de Piura, 5¹0'11"S-80³6'51"O, 29 msnm, 19-II-2017, U. González leg., agitación de follaje, Bosque estacionalmente seco de llanura; 1 + , Piura, Castilla, Universidad Nacional de Piura, 5¹0'51"S-80³7'31"O, 29 msnm, 12-IV-2017, U. Gonzálezleg., agitación de follaje, Bosque estacionalmente seco ribereño; $1 \widehat{\partial}$, Sullana, Salitral, 4 $51^{\prime} 27^{\prime \prime}$ S- $80^{\circ} 40^{\prime} 52^{\prime \prime} \mathrm{O}, 23 \mathrm{msnm}, 18-\mathrm{I}-2016$, G. Juárez leg., agitación de follaje, Bosque estacionalmente seco de llanura; 1 \%, Talara, Los Órganos, $4^{\circ} 10^{\prime} 38^{\prime \prime} \mathrm{S}-81^{\circ} 07^{\prime} 27^{\prime \prime} \mathrm{O}$, 12 msnm, 05-V-2017, G. Juárez leg., colecta manual, Desierto costero; 1 đे, Paita, $5^{\circ} 04^{\prime} \mathrm{S}-81^{\circ} 06^{\prime} \mathrm{O}, 10 \mathrm{msnm}, 21-\mathrm{II}-2017$, G. Juárez leg., colecta manual, Bosque estacionalmente seco de llanura; 1 ㅇ, Sechura, Vice, $5^{\circ} 25^{\prime} \mathrm{S}-81^{\circ} 46^{\prime} \mathrm{O}, 10 \mathrm{msnm}, 12-\mathrm{XII}-$ 2017, U. González leg., agitación de follaje, Desierto costero; 1 ô, Sechura, Laguna Napique, $5^{\circ} 34^{\prime} \mathrm{S}-81^{\circ} 16^{\prime} \mathrm{O}, 16 \mathrm{msnm}$, 24-VI-2019, U. González leg., agitación de follaje, Bosque estacionalmente seco ribereño; 2 우, Morropón, Chulucanas, $5^{\circ} 05^{\prime} \mathrm{S}-80^{\circ} 99^{\prime} \mathrm{O}, 350 \mathrm{msnm}, 22-\mathrm{I}-2015$, G. Juárez leg., agitación de follaje, Bosque estacionalmente seco de colina; 1 , , Morropón, Morropón, 505'51"S-8009'44"O, 557 msnm, 23-I2015, G. Juárez leg., colecta manual, Bosque estacionalmente seco de colina; 2 우, Ayabaca, Suyo, $4^{\circ} 30^{\prime} 45^{\prime \prime} \mathrm{S}-80^{\circ} 00^{\prime} 10^{\prime \prime} \mathrm{O}$, 408 msnm, 23-X-2015, G. Juárez leg., agitación de follaje, Bosque estacionalmente seco de colina; $1 \hat{\delta}$, Huancabamba, Huarmaca, 5³4'04"S-79³1'26"O, 1223 msnm, 26-VII-2016, G. Juárez leg., agitación de follaje, Bosque estacionalmente seco de colina.

Distribución (Provincia) (Paisaje ecológico). (PIU, SUll, PAi, TAL, SECH, MORR, HUA, AYA) (DESc, BESr, BESIl, BESc-m).

Comentario. Los adultos se encuentran sobre hojas de plántulas y árboles, en solitario o en grupo de dos individuos. Insecto plaga que se comporta como fitófago, larvas se alimentan de raíces, adultos causan defoliación (Mondaca, 2011). Especie citada también por Juárez et al. (2016).

Género Tomarus Erichson, 1847

48. Tomarus maimon Erichson, 1847

Material examinado. PERÚ. 2 $+9,2$ $\widehat{\jmath}$, Piura, Universidad de Piura, $5^{\circ} 10^{\prime} 11^{\prime \prime} \mathrm{S}-80^{\circ} 36^{\prime} 51^{\prime \prime} \mathrm{O}, 29 \mathrm{msnm}, 19-\mathrm{II}-2017$, U. González leg., colecta manual, Bosque estacionalmente seco de llanura; 1 , Piura, Castilla, Universidad Nacional de Piura, $5^{\circ} 10^{\prime} 51^{\prime \prime} \mathrm{S}-80^{\circ} 37^{\prime} 31^{\prime \prime} \mathrm{O}, 29 \mathrm{msnm}, 12$-IV2017, U. González leg., colecta manual, Bosque estacio-

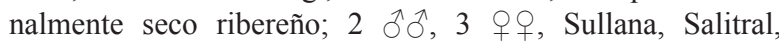
451'27"S-8040'52"O, 23 msnm, 18-I-2016, G. Juárez leg., colecta manual, Bosque estacionalmente seco de llanura; 1 ㅇ, Talara, Los Órganos, $4^{\circ} 10^{\prime} 38^{\prime \prime} \mathrm{S}-81^{\circ} 07^{\prime} 27^{\prime \prime} \mathrm{O}, 12 \mathrm{msnm}$, 05-V-2017, G. Juárez leg., colecta manual, Desierto costero; 1 ㅊ, 2 우우, Paita, $5^{\circ} 04^{\prime} \mathrm{S}-81^{\circ} 06^{\prime} \mathrm{O}, 10 \mathrm{msnm}, 21-\mathrm{II}-2017$, G. Juárez leg., colecta manual, Bosque estacionalmente seco de llanura; 2 우, Sechura, Vice, $5^{\circ} 25^{\prime} \mathrm{S}-81^{\circ} 46^{\prime} \mathrm{O}, 10 \mathrm{msnm}$, 12-XII-2017, U. González leg., colecta manual, Desierto costero; 1 ㄱ, 1 q, Sechura, Laguna Ñapique, $5^{\circ} 34^{\prime} \mathrm{S}-81^{\circ} 16^{\prime} \mathrm{O}$, 16 msnm, 24-VI-2019, U. González leg., colecta manual, Bosque estacionalmente seco ribereño; 3 우 $ᄋ, 1$, Morropón, Chulucanas, $5^{\circ} 05^{\prime} \mathrm{S}-80^{\circ} 99^{\prime} \mathrm{O}, 350 \mathrm{msnm}$, 22-I-2015, G. Juárez leg., colecta manual, Bosque estacionalmente seco de colina;

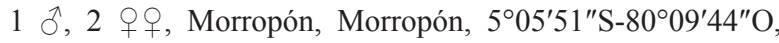
557 msnm, 23-I-2015, G. Juárez leg., colecta manual, Bosque estacionalmente seco de colina; 1 , Ayabaca, Suyo, $4^{\circ} 30^{\prime} 45^{\prime \prime} \mathrm{S}-80^{\circ} 00^{\prime} 10^{\prime \prime} \mathrm{O}, 408$ msnm, 23-X-2015, G. Juárez leg., agitación de follaje, Bosque estacionalmente seco de colina; 1 गे, 1 ㅇ, Huancabamba, Huarmaca, 534'04"S-79³1'26"O, 1223 msnm, 26-VII-2016, G. Juárez leg., agitación de follaje, Bosque estacionalmente seco de colina. 
Distribución (Provincia) (Paisaje ecológico). (PIU, SUlL, PAi, TAL, SECH, MORR) (DESc, BESr, BESIl, BESc-m).

Comentario. Los adultos se encuentran escondidos sobre y/o en grietas de troncos, las larvas se encuentran enterradas alrededor del tronco y/o de plántulas, incluso también cercano a raíces (cuando estaban al descubierto sobre la superficie). Insecto que se comporta como fitófago, larvas se alimentan de raíces (Escalona \& Joly, 2006). El número de individuos colectados aumentó en época de lluvia (diciembre-marzo). Especie citada también por Juárez et al. (2016).

Subfamilia Cetoniinae Leach, 1815

Género Gymnetis MacLeay, 1819

49. Gymnetis stellata Latreille, 1833 †

Material examinado. PERÚ. 1 + Piura, Castilla, Universidad Nacional de Piura, $5^{\circ} 10^{\prime} 51^{\prime \prime} \mathrm{S}-80^{\circ} 37^{\prime} 31^{\prime \prime} \mathrm{O}, 29 \mathrm{msnm}, 12-\mathrm{V}-$ 2015, U. González leg., colecta manual, Bosque estacionalmente seco ribereño; 1 , Piura, Castilla, Universidad Nacional de Piura, $5^{\circ} 10^{\prime} 51^{\prime \prime} \mathrm{S}-80^{\circ} 37^{\prime} 31^{\prime \prime} \mathrm{O}, 29 \mathrm{msnm}, 12$-VI2017, G. Juárez leg., colecta manual, Bosque estacionalmente seco de llanura.

Distribución (Provincia) (Paisaje ecológico). (PIU) (BESr, BES11).

Comentario. Los adultos se encuentran sobre frutos maduros en árboles, en solitario o en grupo de dos a cuatro individuos. Insecto se comporta como fitófago.

50. Gymnetis merops Ratcliffe, 2018

Material examinado. Perú. 2 o 052 COL-GJN, Piura,

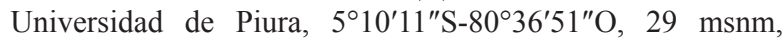
21-IV-2014, U. González leg., colecta manual, Bosque estacionalmente seco de llanura; 1 , 1 $\hat{\text {, }}$, Piura, Castilla, Universidad Nacional de Piura, 5²10'51"S-80³7'31"O, 29 msnm, 12-IV-2017, U. González leg., colecta manual, Bosque estacionalmente seco ribereño; $1 \hat{\partial}$, Sullana, Salitral, 451'27"S-8040'52"O, 23 msnm, 18-I-2016, G. Juárez leg., colecta manual, Bosque estacionalmente seco de llanura; 2 우, Talara, Los Órganos, $4^{\circ} 10^{\prime} 38^{\prime \prime} \mathrm{S}-81^{\circ} 07^{\prime} 27^{\prime \prime} \mathrm{O}, 12 \mathrm{msnm}$, 05-V-2017, G. Juárez leg., colecta manual, Desierto costero; 1 §ิ, Paita, $5^{\circ} 04^{\prime} \mathrm{S}-81^{\circ} 06^{\prime} \mathrm{O}, 10 \mathrm{msnm}, 21-\mathrm{II}-2017$, G. Juárez leg., colecta manual, Bosque estacionalmente seco de llanura; 1 q, Sechura, Vice, $5^{\circ} 25^{\prime} \mathrm{S}-81^{\circ} 46^{\prime} \mathrm{O}, 10 \mathrm{msnm}, 12-\mathrm{XII}-2017$, U. González leg., colecta manual, Desierto costero; 1 ก, 1 †, Sechura, Laguna Ñapique, $5^{\circ} 34^{\prime} \mathrm{S}-81^{\circ} 16^{\prime} \mathrm{O}, 16 \mathrm{msnm}$, 24-VI-2019, U. González leg., colecta manual, Bosque estacionalmente seco ribereño; $1 \hat{\jmath}$, Morropón, Chulucanas, $5^{\circ} 05^{\prime} \mathrm{S}-80^{\circ} 99^{\prime} \mathrm{O}, 350 \mathrm{msnm}, 22-\mathrm{I}-2015$, G. Juárez leg., colecta manual, Bosque estacionalmente seco de colina; 2 우우, Morropón, Morropón, 505'51"S-8009'44"O, 557 msnm, 23-I-2015, G. Juárez leg., colecta manual, Bosque estacionalmente seco de colina.

Distribución (Provincia) (Paisaje ecológico). (PIU, SUll, PAi, TAL, SECH, MORR) (DESc, BESr, BESIl, BESc-m).

Comentario. Especie citada como Gymnetis sp en Juárez et al. (2016). Los adultos se encuentran sobre frutos maduros en árboles, en solitario o en grupo de dos a cuatro individuos. Insecto que se comporta como fitófago.

Familia Buprestidae Leach, 1815

Subfamilia Polycestinae Lacordaire, 1857

Género Polycesta Dejean, $1833 \dagger$

51. Polycesta (Nemaphorus) excavata Blanchard, $1846 \dagger$

Material examinado. PERÚ. 4 9 , Piura, Universidad de Piura, $5^{\circ} 10^{\prime} 11^{\prime \prime} \mathrm{S}-80^{\circ} 36^{\prime} 51^{\prime \prime} \mathrm{O}, 29 \mathrm{msnm}, 19-\mathrm{II}-2017$, U.
González leg., colecta manual, Bosque estacionalmente seco de llanura; 2 우, Piura, Castilla, $5^{\circ} 10^{\prime} 51^{\prime \prime} \mathrm{S}-80^{\circ} 37^{\prime} 31^{\prime \prime} \mathrm{O}$, 29 msnm, 12-IV-2016, U. González leg., colecta manual, Bosque estacionalmente seco ribereño; 1 , 2 우, Piura, Castilla, Universidad Nacional de Piura, $5^{\circ} 10^{\prime} 51^{\prime \prime} \mathrm{S}-80^{\circ} 37^{\prime} 31^{\prime \prime} \mathrm{O}, 29 \mathrm{msnm}, 12-\mathrm{IV}-2017$, U. González leg., agitación de follaje, Bosque estacionalmente seco ribereño; 2 우오, Sullana, Salitral, 4 ${ }^{\circ} 51^{\prime} 27^{\prime \prime} \mathrm{S}-80^{\circ} 40^{\prime} 52^{\prime \prime} \mathrm{O}$, 23 msnm, 18-I-2016, G. Juárez leg., agitación de follaje, Bosque estacionalmente seco de llanura; 2 우, 1 ते, Talara, Los Órganos, $4^{\circ} 10^{\prime} 38^{\prime \prime} \mathrm{S}-81^{\circ} 07^{\prime} 27^{\prime \prime} \mathrm{O}, 12 \mathrm{msnm}, 05-\mathrm{V}-$ 2017, G. Juárez leg., colecta manual, Desierto costero; 2 우우, Paita, $5^{\circ} 04^{\prime} \mathrm{S}-81^{\circ} 06^{\prime} \mathrm{O}, 10 \mathrm{msnm}, 21-\mathrm{II}-2017$, G. Juárez leg., agitación de follaje, Bosque estacionalmente seco de llanura; 1 ㅇ, $1{ }^{\lambda}$, Sechura, Vice, $5^{\circ} 25^{\prime} \mathrm{S}-81^{\circ} 46^{\prime} \mathrm{O}$, 10 msnm, 12-XII-2017, U. González leg., colecta manual, Desierto costero; 2 ถิ่, Sechura, Laguna Ñapique, 5³4'S-81¹6'O, 16 msnm, 24-VI-2019, U. González leg., colecta manual, Bosque estacionalmente seco ribereño; 2 오오, Sechura, Illescas, $5^{\circ} 58^{\prime} \mathrm{S}-81^{\circ} 05^{\prime} \mathrm{O}, 10 \mathrm{msnm}, 12$-XI2017, U. González leg., red entomológica, Matorral Xérico; 3 우우, Morropón, Chulucanas, $5^{\circ} 05^{\prime} \mathrm{S}-80^{\circ} 99^{\prime} \mathrm{O}, 350 \mathrm{msnm}$, 22-I-2015, G. Juárez leg., agitación de follaje, Bosque estacionalmente seco de colina; 2 우, Ayabaca, Suyo, 4³0'45"S-8000'10"O, 408 msnm, 23-X-2015, G. Juárez leg., colecta manual, Bosque estacionalmente seco de colina;

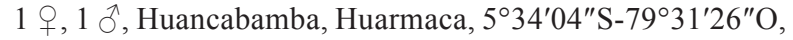
1223 msnm, 26-VII-2016, G. Juárez leg., agitación de follaje, Bosque estacionalmente seco de colina.

Distribución (Provincia) (Paisaje ecológico). (PIU, SUll, Pai, TAL, SECH, MORR, AYA, HUA) (MatX, DESc, BESr, BESll, BESc-m).

Comentario. Los adultos se encuentran sobre ramas y troncos de árboles, en solitario, las larvas cavan galerías en el interior de troncos. Insecto que se comporta como fitófago, larvas barrenan el interior del tronco, mientras que los adultos descortezan exterior del tronco (Moore \& Diéguez, 2008).

Subfamilia Buprestinae Leach, 1815

Género Agrilaxia Kerremans, 1903

52. Agrilaxia acuminata Cobos, 1972 (Fig. 9)

Material examinado. Perú. 2 $9+$, 055 COL-GJN, Piura, Universidad de Piura, $5^{\circ} 10^{\prime} 11^{\prime \prime} \mathrm{S}-80^{\circ} 36^{\prime} 51^{\prime \prime} \mathrm{O}, 29 \mathrm{msnm}$, 19-II-2017, U. González leg., colecta manual, Bosque estacionalmente seco de llanura; 2 우, Piura, Castilla,

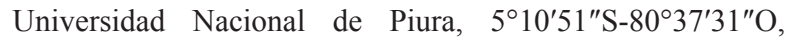
29 msnm, 12-IV-2017, U. González leg., agitación de follaje, Bosque estacionalmente seco ribereño; 1 , Sullana, Salitral, 451'27"S-8040'52"O, 23 msnm, 18-I-2016, G. Juárez leg., agitación de follaje, Bosque estacionalmente seco de llanura; 1 ㅇ, 1 o․, Talara, Los Órganos, $4^{\circ} 10^{\prime} 38^{\prime \prime} \mathrm{S}-81^{\circ} 07^{\prime} 27^{\prime \prime} \mathrm{O}$, 12 msnm, 05-V-2017, G. Juárez leg., colecta manual, Desierto costero; 1 ․ Paita, $5^{\circ} 04^{\prime} \mathrm{S}-81^{\circ} 06^{\prime} \mathrm{O}, 10 \mathrm{msnm}, 21-\mathrm{II}-2017$, G. Juárez leg., agitación de follaje, Bosque estacionalmente seco de llanura; 1 q, $1 \delta^{\lambda}$, Sechura, Vice, $5^{\circ} 25^{\prime} \mathrm{S}-81^{\circ} 46^{\prime} \mathrm{O}, 10 \mathrm{msnm}$, 12-XII-2017, U. González leg., colecta manual, Desierto costero; 1 ô, Sechura, Laguna Napique, $5^{\circ} 34^{\prime} \mathrm{S}-81^{\circ} 16^{\prime} \mathrm{O}$, 16 msnm, 24-VI-2019, U. González leg., colecta manual, Bosque estacionalmente seco ribereño; 3 q 9,1 đ̂, Morropón, Chulucanas, $5^{\circ} 05^{\prime} \mathrm{S}-80^{\circ} 99^{\prime} \mathrm{O}, 350 \mathrm{msnm}, 22-\mathrm{I}-2015$, G. Juárez leg., agitación de follaje, Bosque estacionalmente seco de colina.

Distribución (Provincia) (PAisaje ecológico). (PIU, SUlL, PAi, TAL, SECH, MORR) (DESc, BESr, BESll, BESc-m). 
Comentario. Especie citada como Agrilaxia sp en Juárez et al. (2016). Los adultos se encuentran sobre hojas, ramas, troncos de plántulas y árboles, en solitario o en grupo de dos a cuatro individuos. Insecto plaga que se comporta como fitófago, larvas barrenan el interior del tronco, mientras que los adultos descortezan exterior del tronco (Cobos, 1980). Especie citada también por Domínguez (1982) como Anthaxia (Agrilaxia) acuminata.

Género Chrysobothris Eschscholtz, 1829

53. Chrysobothris sin identificar sp. 1.

Material examinado. PERÚ. 3 + , Piura, Universidad de Piura, $5^{\circ} 10^{\prime} 11^{\prime \prime} \mathrm{S}-80^{\circ} 36^{\prime} 51^{\prime \prime} \mathrm{O}, 29 \mathrm{msnm}, 19-\mathrm{II}-2017$, U. González leg., colecta manual, Bosque estacionalmente seco de llanura; 4 우우우우, Piura, Castilla, 510'51"S-80³7'31"O, 29 msnm, 12-IV-2016, U. González leg., colecta manual, Bosque estacionalmente seco ribereño; $2 \hat{\partial} \hat{\partial}$, Piura, Castilla, Universidad Nacional de Piura, $5^{\circ} 10^{\prime} 51^{\prime \prime} \mathrm{S}-80^{\circ} 37^{\prime} 31^{\prime \prime} \mathrm{O}, 29 \mathrm{msnm}, 12-\mathrm{IV}-$ 2017, U. González leg., agitación de follaje, Bosque estacionalmente seco ribereño; 2 우, $1 \hat{\jmath}$, Sullana, Salitral, 451'27"S-8040'52"O, 23 msnm, 18-I-2016, G. Juárez leg., colecta manual, Bosque estacionalmente seco de llanura; $1 \hat{\partial}$, Talara, Los Órganos, $4^{\circ} 10^{\prime} 38^{\prime \prime} \mathrm{S}-81^{\circ} 07^{\prime} 27^{\prime \prime} \mathrm{O}, 12 \mathrm{msnm}, 05-\mathrm{V}$ 2017, G. Juárez leg., colecta manual, Desierto costero; 1 우 Paita, $5^{\circ} 04^{\prime} \mathrm{S}-81^{\circ} 06^{\prime} \mathrm{O}, 10 \mathrm{msnm}, 21-\mathrm{II}-2017$, G. Juárez leg., agitación de follaje, Bosque estacionalmente seco de llanura;

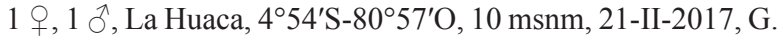
Juárez leg., agitación de follaje, Bosque estacionalmente seco de llanura; 3 우, Sechura, Vice, $5^{\circ} 25^{\prime} \mathrm{S}-81^{\circ} 46^{\prime} \mathrm{O}, 10 \mathrm{msnm}$, 12-XII-2017, U. González leg., agitación de follaje, Desierto costero; $1 \hat{\jmath}$, Sechura, Laguna Napique, $5^{\circ} 34^{\prime} \mathrm{S}-81^{\circ} 16^{\prime} \mathrm{O}$, 16 msnm, 24-VI-2019, U. González leg., colecta manual, Bosque estacionalmente seco ribereño; 1 + , Sechura, Illescas, $5^{\circ} 58^{\prime} \mathrm{S}-81^{\circ} 05^{\prime} \mathrm{O}, 10 \mathrm{msnm}, 12-\mathrm{XI}-2017$, U. González leg., red entomológica, Matorral Xérico; 2 우, Morropón, Chulucanas, $5^{\circ} 05^{\prime} \mathrm{S}-80^{\circ} 99^{\prime} \mathrm{O}, 350 \mathrm{msnm}, 22-\mathrm{I}-2015$, G. Juárez leg., agitación de follaje, Bosque estacionalmente seco de colina;

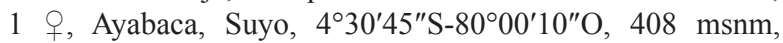
23-X-2015, G. Juárez leg., colecta manual, Bosque estacionalmente seco de colina; 1 , Huancabamba, Huarmaca, 5³4'04"S-79³1'26"O, 1223 msnm, 26-VII-2016, G. Juárez leg., agitación de follaje, Bosque estacionalmente seco de colina.

Distribución (Provincia) (Paisaje ecológico). (PIU, SUlL, PAI, TAL, SECH, MORR, AYA, HUA) (MatX, DESc, BESr, BESIl, BESc-m).

Comentario. Los adultos se encuentran sobre ramas y troncos de árboles, en solitario o en grupo de dos a cuatro individuos. Insecto que se comporta como fitófago, larvas barrenan el interior del tronco, mientras que los adultos descortezan exterior del tronco. Especie citada también Domínguez (1982) y por Juárez et al. (2016)

Familia Elateridae Leach, 1815

Subfamilia Agrypninae Candèze, 1857

Género Aeolus Leach, 1815

54. Aeolus sin identificar sp. 1.

Material examinado. Perú. 2 우, Piura, Universidad de Piura, 5 10'11"S-80³6'51"O, 29 msnm, 19-II-2017, U. González leg., agitación de follaje, Bosque estacionalmente seco de llanura; 2 우, Piura, Castilla, $5^{\circ} 10^{\prime} 51^{\prime \prime} \mathrm{S}-80^{\circ} 37^{\prime} 31^{\prime \prime} \mathrm{O}, 29 \mathrm{msnm}$, 12-IV-2016, U. González leg., colecta manual, Bosque estacionalmente seco ribereño; $2 \hat{\jmath} \hat{\partial}, 1$ \&, Piura, Castilla, Universidad Nacional de Piura, $5^{\circ} 10^{\prime} 51^{\prime \prime} \mathrm{S}-80^{\circ} 37^{\prime} 31^{\prime \prime} \mathrm{O}$,
29 msnm, 12-IV-2017, U. González leg., agitación de follaje, Bosque estacionalmente seco ribereño; 1 Sullana, Salitral, 451'27"S-8040'52"O, 23 msnm, 18-I-2016, G. Juárez leg., colecta manual, Bosque estacionalmente seco de llanura; 1 , Sechura, Vice, $5^{\circ} 25^{\prime} \mathrm{S}-81^{\circ} 46^{\prime} \mathrm{O}, 10 \mathrm{msnm}, 12-\mathrm{XII}-2017$, U. González leg., agitación de follaje, Desierto costero; 1 ㅇ, 1 $\hat{o}$, Sechura, Laguna Napique, $5^{\circ} 34^{\prime} \mathrm{S}-81^{\circ} 16^{\prime} \mathrm{O}, 16 \mathrm{msnm}, 24-\mathrm{VI}-$ 2019, U. González leg., colecta manual, Bosque estacionalmente seco ribereño.

Distribución (Provincia) (Paisaje ecológico). (PIU, SUlL, $\mathrm{SECH})(\mathrm{DESc}, \mathrm{BESr}, \mathrm{BES} 11)$.

Comentario. Los adultos se encuentran sobre ramas y troncos de árboles, en solitario. Insecto que se comporta como fitófago. Especie citada también por Juárez \& González (2016a).

\section{Género Heteroderes Latreille, $1834 \dagger$}

\section{Heteroderes amplicollis (Gyllenhal, 1817) $\dagger$}

Material examinado. Perú. 1 q, Piura, Universidad de Piura, 5 10'11"S-80³6'51"O, 29 msnm, 19-II-2017, U. González leg., agitación de follaje, Bosque estacionalmente seco de llanura; 1 ๙ , 1 क , Piura, Castilla, Universidad Nacional de Piura, 5¹0'51"S-80³7'31"O, 29 msnm, 12-IV-2017, U. González leg., agitación de follaje, Bosque estacionalmente seco ribereño; 1 옹, Sechura, Vice, $5^{\circ} 25^{\prime} \mathrm{S}-81^{\circ} 46^{\prime} \mathrm{O}, 10 \mathrm{msnm}, 12-\mathrm{XII}-$ 2017, U. González leg., agitación de follaje, Desierto costero; 1 ô, Sechura, Laguna Napique, $5^{\circ} 34^{\prime} \mathrm{S}-81^{\circ} 16^{\prime} \mathrm{O}, 16 \mathrm{msnm}$, 24-VI-2019, U. González leg., colecta manual, Bosque estacionalmente seco ribereño.

Distribución (Provincia) (Paisaje ecológico). (PIU, SECH) (DESc, BESr, BESll).

Comentario. Los adultos se encuentran sobre ramas y troncos de árboles, en solitario. Insecto plaga que se comporta como fitófago.

Género Conoderus Eschscholtz, 1829

56. Conoderus $\sin$ identificar sp. 1.

Material eXaminado. PERÚ. 2 9 , Piura, Universidad de Piura, 5¹0'11"S-80³6'51"O, 29 msnm, 19-II-2017, U. González leg., colecta manual, Bosque estacionalmente seco de llanura; 2 우, Piura, Castilla, Universidad Nacional de Piura, 5¹0'51"S-80³7'31"O, 29 msnm, 12-IV-2017, U. González leg., agitación de follaje, Bosque estacionalmente seco ribereño; 1 ․ Sullana, Salitral, $4^{\circ} 51^{\prime} 27^{\prime \prime} \mathrm{S}-80^{\circ} 40^{\prime} 52^{\prime \prime} \mathrm{O}$, 23 msnm, 18-I-2016, G. Juárez leg., colecta manual, Bosque estacionalmente seco de llanura; $1 \hat{\jmath}, 1$, Talara, Los Órganos, $4^{\circ} 10^{\prime} 38^{\prime \prime} \mathrm{S}-81^{\circ} 07^{\prime} 27^{\prime \prime} \mathrm{O}, 12 \mathrm{msnm}, 05-\mathrm{V}-2017$, G. Juárez leg., colecta manual, Desierto costero; 3 우, Paita, $5^{\circ} 04^{\prime} \mathrm{S}-81^{\circ} 06^{\prime} \mathrm{O}, 10 \mathrm{msnm}, 21-\mathrm{II}-2017$, G. Juárez leg., agitación de follaje, Bosque estacionalmente seco de llanura; 1 , La Huaca, 454'S-8057'O, 10 msnm, 21-II-2017, G. Juárez leg., agitación de follaje, Bosque estacionalmente seco de llanura; 2 우, Sechura, Vice, $5^{\circ} 25^{\prime} \mathrm{S}-81^{\circ} 46^{\prime} \mathrm{O}, 10 \mathrm{msnm}, 12-\mathrm{XII}-$ 2017, U. González leg., agitación de follaje, Desierto costero; $2 \partial^{\lambda}$, Sechura, Laguna Ñapique, $5^{\circ} 34^{\prime} \mathrm{S}-81^{\circ} 16^{\prime} \mathrm{O}, 16 \mathrm{msnm}$, 24-VI-2019, U. González leg., colecta manual, Bosque estacionalmente seco ribereño; 1 q, Morropón, Chulucanas, $5^{\circ} 05^{\prime} \mathrm{S}-80^{\circ} 99^{\prime} \mathrm{O}, 350 \mathrm{msnm}, 22-\mathrm{I}-2015$, G. Juárez leg., agitación de follaje, Bosque estacionalmente seco de colina.

Distribución (Provincia) (PAisaje ecológico). (PIU, SULL, PAI, TAL, SECH, MORR) (DESc, BESr, BESll, BESc-m).

COMENTARIO. Los adultos se encuentran sobre hojas, ramas y troncos de árboles, en solitario. Insecto que se comporta como fitófago. Especie citada también por Juárez et al. (2016). 
57. Conoderus sin identificar sp. $2 . \dagger$

Material examinado. Perú. 1 क, Piura, Universidad de Piura, $5^{\circ} 10^{\prime} 11^{\prime \prime} \mathrm{S}-80^{\circ} 36^{\prime} 51^{\prime \prime} \mathrm{O}, 29 \mathrm{msnm}, 19-\mathrm{II}-2017$, U. González leg., colecta manual, Bosque estacionalmente seco de llanura; 1 q, Piura, Castilla, Universidad Nacional de Piura, 5¹0'51"S-80³7'31"O, 29 msnm, 12-IV-2017, U. González leg., agitación de follaje, Bosque estacionalmente seco ribereño.

Distribución (Provincia) (Paisaje ecológico). (PIU) (BESr, BESIl).

Comentario. Los adultos se encuentran sobre hojas, ramas y troncos de árboles, en solitario. Insecto que se comporta como fitófago.

Subfamilia Cardiophorinae Candéze, 1859

Género Horistonotus Candéze, 1860

58. Horistonotus sin identificar sp. 1.

Material examinado. PERÚ. 1 q, Piura, Universidad de Piura, 5¹0'11"S-80³6'51"O, 29 msnm, 19-II-2017, U. González leg., colecta manual, Bosque estacionalmente seco de llanura; 1 q, Piura, Castilla, Universidad Nacional de Piura, 5¹0'51"S-80³7'31"O, 29 msnm, 12-IV-2017, U. González leg., agitación de follaje, Bosque estacionalmente seco ribereño; 1 ㅇ, Sechura, Vice, $5^{\circ} 25^{\prime} \mathrm{S}-81^{\circ} 46^{\prime} \mathrm{O}, 10 \mathrm{msnm}, 12-\mathrm{XII}-$ 2017, U. González leg., agitación de follaje, Desierto costero; $1 \hat{\jmath}$, Sechura, Laguna Napique, $5^{\circ} 34^{\prime} \mathrm{S}-81^{\circ} 16^{\prime} \mathrm{O}, 16 \mathrm{msnm}$, 24-VI-2019, U. González leg., colecta manual, Bosque estacionalmente seco ribereño.

Distribución (Provincia) (Paisaje ecológico). (PIU, SECH) (DES, BESr, BESIl).

COMEnTARIo. Los adultos se encuentran sobre hojas, ramas y troncos de árboles, en solitario. Insecto que se comporta como fitófago. Especie citada también por Juárez \& González (2016a).

Familia Dermestidae Latreille, 1804

Subfamilia Megatominae Leach, 1815

Género Trogoderma Dejean, 1821

59. Trogoderma in identificar sp. 1.

Material eXaminado. PERÚ. 2 9 , Piura, Universidad de Piura, 5¹0'11"S-80³6'51"O, 29 msnm, 19-II-2017, U. González leg., colecta manual, Bosque estacionalmente seco de llanura; 1 क, Piura, Castilla, Universidad Nacional de Piura, 5¹0'51"S-80³7'31"O, 29 msnm, 12-IV-2017, U. González leg., colecta manual, Bosque estacionalmente seco ribereño.

Distribución (Provincia) (Paisaje ecológico). (PIU) (BESr, BES11).

COMENTARIO. Los adultos se encuentran sobre frutos maduros destruidos previamente por brúchidos. Insecto que se comporta como fitófago. Especie citada también por Núñez-Sacarías (1993) y Juárez et al. (2016).

Familia Bostrichidae Latreille, 1802

Subfamilia Bostrichinae Latreille, 1802

Género Dolichobostrychus Lesne, 1899

60. Dolichobostrychus angustus Steinheil, 1872 (Fig. 10)

Material examinado. PERÚ. 2 우, Piura, Universidad de Piura, 5¹0'11"S-80³6'51"O, 29 msnm, 19-II-2017, U. González leg., colecta manual, Bosque estacionalmente seco de llanura; 1 ㅇ, Piura, Castilla, Universidad Nacional de Piura, 5 10'51"S-80³7'31"O, 29 msnm, 12-IV-2017, U. González leg., colecta manual, Bosque estacionalmente seco ribereño.

Distribución (Provincia) (Paisaje ecológico). (PIU) (BESr, BESIl).

Comentario. Los adultos se encuentran sobre ramas y troncos de árboles, en solitario. Insecto que se comporta como fitófago. Especie citada también por Juárez \& González (2016a).
Género Amphicerus LeConte, 1861

61. Amphicerus (Amphicerus) cornutus (Pallas, 1772)

Material examinado. PERÚ. $2+q$, Piura, Universidad de Piura, 5¹0'11"S-80³6'51"O, 29 msnm, 19-II-2017, U. González leg., colecta manual, Bosque estacionalmente seco de llanura; 1 ㅇ, Piura, Castilla, Universidad Nacional de Piura, 5¹0'51"S-80³7'31"O, 29 msnm, 12-IV-2017, U. González leg., colecta manual, Bosque estacionalmente seco ribereño; 1 ㅇ, Sullana, Salitral, 451'27"S-8040'52"O, 23 msnm, 18-I2016, G. Juárez leg., colecta manual, Bosque estacionalmente seco de llanura

Distribución (Provincia) (Paisaje ecológico). (PIU, SUlL) (BESr, BES1l).

COMENTARIo. Los adultos se encuentran sobre ramas y troncos de árboles, en solitario. Insecto plaga que se comporta como fitófago. Especie citada también por Juárez et al. (2016).

Género Micrapate Casey, 1898

62. Micrapate scabrata (Erichson, 1847)

Material eXAminado. PERÚ. 3 우, Piura, Universidad de Piura, 5॰10'11"S-80³6'51"O, 29 msnm, 19-II-2017, U. González leg., colecta manual, Bosque estacionalmente seco de llanura; 2 우, Piura, Castilla, Universidad Nacional de Piura, 5¹0'51"S-80³7'31"O, 29 msnm, 12-IV-2017, U. González leg., colecta manual, Bosque estacionalmente seco ribereño;

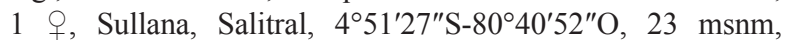
18-I-2016, G. Juárez leg., colecta manual, Bosque estacionalmente seco de llanura; $2 \hat{\delta} \bar{\partial}$,Talara, Los Órganos, $4^{\circ} 10^{\prime} 38^{\prime \prime} \mathrm{S}-81^{\circ} 07^{\prime} 27^{\prime \prime} \mathrm{O}, 12$ msnm, 05-V-2017, G. Juárez leg., colecta manual, Desierto costero.

Distribución (Provincia) (Paisaje ecológico). (PIU, SUlL, TAL) (DESc, BESr, BESll).

Comentario. De acuerdo con Lesne (1896) se llegó a la conclusión de que la especie citada como Micrapate humeralis por Juárez et al. (2016) corresponde a M. scabrata. Los adultos se encuentran sobre ramas y troncos de árboles, en solitario. Insecto que se comporta como fitófago.

Género Sinoxylon Duftschmid, 1825

63. Sinoxylon unidentatum Fabricius, 1801

Material examinado. Perú. 3 $q$ o, $1 \hat{\jmath}$, Piura, Universidad de Piura, 5¹0'11"S-80³6'51"O, 29 msnm, 19-II-2017, U. González leg., colecta manual, Bosque estacionalmente seco

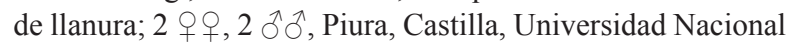
de Piura, 510'51"S-80³7'31"O, 29 msnm, 12-IV-2017, U. González leg., colecta manual, Bosque estacionalmente seco ribereño.

Distribución (Provincia) (Paisaje ecológico). (PIU) (BESr, BES11).

Comentario. Los adultos se encuentran sobre ramas y troncos de árboles, en solitario. Insecto que se comporta como fitófago. Especie citada también por Juárez et al. (2016).

64. Sinoxylon anale Lesne, $1897 \dagger$ (Fig. 11)

Material EXAminado. PERÚ. 19,1 $\uparrow$, Piura, Castilla, Universidad Nacional de Piura, $5^{\circ} 10^{\prime} 51^{\prime \prime} \mathrm{S}-80^{\circ} 37^{\prime} 31^{\prime \prime} \mathrm{O}, 29 \mathrm{msnm}$, 12-IV-2017, U. González leg., colecta manual, Bosque estacionalmente seco ribereño; 1 ㅇ, Morropón, Chulucanas, 505'S-8099'O, 350 msnm, 22-I-2015, G. Juárez leg., agitación de follaje, Bosque estacionalmente seco de colina.

Distribución (Provincia) (Paisaje ecológico). (PIU, MORR) (BESr, BESc-m).

COMEnTARIO. Los adultos se encuentran sobre ramas y troncos de árboles, en solitario. Insecto que se comporta como fitófago. 
Familia Ptinidae Latreille, 1802

Subfamilia Ptininae Latreille, 1802

Género Ptinus Linnaeus, 1767

65. Ptinus sin identificar sp. 1.

Material examinado. PERÚ. 3 + 9 , Piura, Castilla, Universidad Nacional de Piura, $5^{\circ} 10^{\prime} 51^{\prime \prime} \mathrm{S}-80^{\circ} 37^{\prime} 31^{\prime \prime} \mathrm{O}, 29 \mathrm{msnm}, 12-\mathrm{IV}-$

2017, U. González leg., agitación de follaje, Bosque estacionalmente seco ribereño; 2 우, Talara, Los Órganos, $4^{\circ} 10^{\prime} 38^{\prime \prime} \mathrm{S}-81^{\circ} 07^{\prime} 27^{\prime \prime} \mathrm{O}, 12$ msnm, 05-V-2017, G. Juárez leg., agitación de follaje, Desierto costero.

Distribución (Provincia) (Paisaje ecológico). (PIU, TAL) (BESr, DESc).

COMENTARIO. Los adultos se encuentran sobre hojas de plántulas y árboles, en solitario. Insecto que se comporta como fitófago. Especie citada también por Juárez et al. (2016).

Subfamilia Xyletininae Gistel, 1848

Género Lasioderma Stephens, 1835

66. Lasioderma serricorne Fabricius, 1792

Material eXaminado. PERÚ. 1 + , Piura, Castilla, Universidad

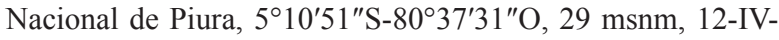
2017, U. González leg., agitación de follaje, Bosque estacionalmente seco ribereño; 2 q 9 , Piura, Universidad de Piura, $5^{\circ} 10^{\prime} 11^{\prime \prime} \mathrm{S}-80^{\circ} 36^{\prime} 51^{\prime \prime} \mathrm{O}, 29 \mathrm{msnm}, 19-\mathrm{II}-2017$, U. González leg., colecta manual, Bosque estacionalmente seco de llanura.

Distribución (Provincia) (Paisaje ecológico). (PIU) (BESr, BESl1).
COMEnTARIO. Los adultos se encuentran sobre hojas y escondidas en galerías o grietas de troncos de árboles, en solitario. Insecto que se comporta como fitófago. Especie citada también por Núñez-Sacarías (1993) y Juárez et al. (2016).

Familia Cleridae Latreille, $1802 \dagger$

Subfamilia Neorthopleurinae Opitz, $2009 \dagger$

Género Neorthopleura Barr, 1976 †

67. Neorthopleura guayasensis Opitz, $2013 \dagger$

Material examinado. PERÚ. 2 오, Piura, Castilla, Universidad Nacional de Piura, $5^{\circ} 10^{\prime} 51^{\prime \prime} \mathrm{S}-80^{\circ} 37^{\prime} 31^{\prime \prime} \mathrm{O}, 29 \mathrm{msnm}, 12-\mathrm{IV}-$ 2017, U. González leg., agitación de follaje, Bosque estacionalmente seco ribereño; 2 우, Piura, Universidad de Piura, 5¹0'11"S-80³6'51"O, 29 msnm, 19-II-2017, U. González leg., agitación de follaje, Bosque estacionalmente seco de llanura.

Distribución (Provincia) (Paisaje ecológico). (PIU) (BESr, BESIl).

COMENTARIo. Los adultos se encuentran sobre hojas de plántulas y árboles, en solitario. Insecto que se comporta como fitófago (Opitz, 2013).

Subfamilia Hydnocerinae Spinola, $1844 \dagger$

Género Phyllobaenus Dejean, $1833 \dagger$

68. Phyllobaenus sin identificar sp. $1 . \dagger$

Material examinado. PERÚ. 2 o 9 , Piura, Castilla, Universidad Nacional de Piura, $5^{\circ} 10^{\prime} 51^{\prime \prime} \mathrm{S}-80^{\circ} 37^{\prime} 31^{\prime \prime} \mathrm{O}, 29 \mathrm{msnm}$,
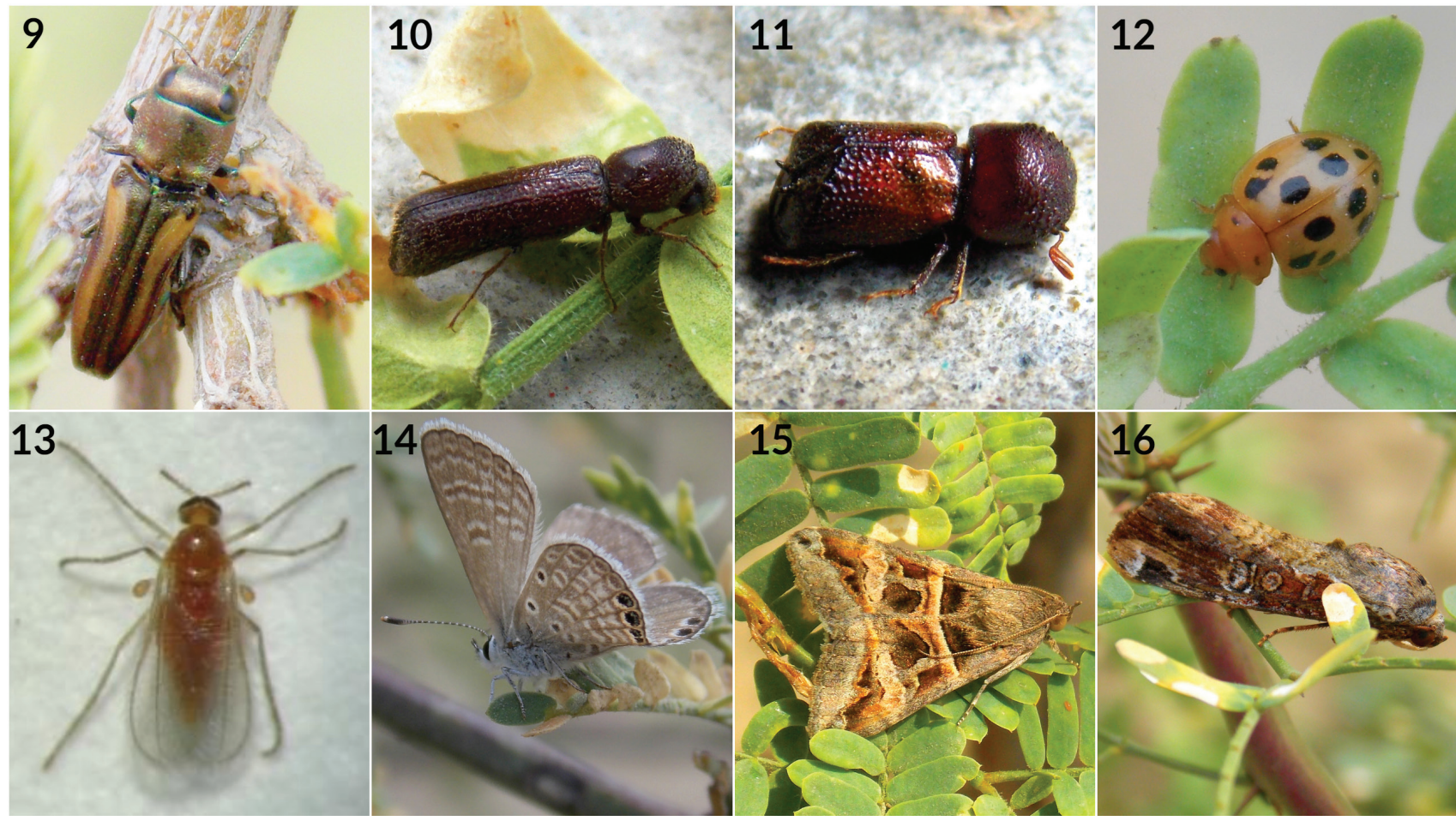

Figs. 9-16.- Habitus. 9. Agrilaxia acuminata (Cobos, 1972). 10. Dolichobostrychus angustus (Steinheil, 1872). 11. Sinoxylon anale Lesne, 1897. 12. Zagreus hexasticta (Crotch, 1874). 13. Enallodiplosis discordis Gagné, 1994. 14. Hemiargus ramon (Dognin, 1887). 15. Melipotis sin identificar sp 1. 16. Magusa sin identificar sp 1. [Fotografías G. Juárez y U. González; Fotografía 13 Jorge Llontop].

Figs. 9-16.- Habitus. 9. Agrilaxia acuminata (Cobos, 1972). 10. Dolichobostrychus angustus (Steinheil, 1872). 11. Sinoxylon anale Lesne, 1897. 12. Zagreus hexasticta (Crotch, 1874). 13. Enallodiplosis discordis Gagné, 1994. 14. Hemiargus ramon (Dognin, 1887). 15. Melipotis unidentified sp 1. 16. Magusa unidentified sp 1. [Photographs by G. Juárez and U. González; Photography 13 by Jorge Llontop]. 
12-IV-2017, U. González leg., agitación de follaje, Bosque estacionalmente seco ribereño; 1 क , Piura, Universidad de Piura, 5¹0'11"S-80³6'51"O, 29 msnm, 19-II-2017, U. González leg., agitación de follaje, Bosque estacionalmente seco de llanura.

Distribución (Provincia) (Paisaje ecológico). (PIU) (BeSr, BESIl).

Comentario. Adultos se encuentran sobre hojas de plántulas y árboles, en solitario. Insecto que se comporta como fitófago.

Familia Nitidulidae Latreille, 1802

Subfamilia Nitidulinae Latreille, 1802

Género Lobiopa Erichson, 1834

69. Lobiopa $\sin$ identificar sp. 1.

Material examinado. PERÚ. 1 9059 COL-GJN, Piura, Universidad de Piura, $5^{\circ} 10^{\prime} 11^{\prime \prime} \mathrm{S}-80^{\circ} 36^{\prime} 51^{\prime \prime} \mathrm{O}, 29 \mathrm{msnm}$, 19-II-2017, U. González leg., agitación de follaje, Bosque estacionalmente seco de llanura; 1 , Piura, Castilla, Universidad Nacional de Piura, $5^{\circ} 10^{\prime} 51^{\prime \prime} \mathrm{S}-80^{\circ} 37^{\prime} 31^{\prime \prime} \mathrm{O}$, 29 msnm, 12-IV-2017, U. González leg., agitación de follaje, Bosque estacionalmente seco ribereño; 1 , , Sullana, Salitral, 451'27"S-8040'52"O, 23 msnm, 18-I-2016, G. Juárez leg., colecta manual, Bosque estacionalmente seco de llanura; 2 우오, Ayabaca, Suyo, $4^{\circ} 30^{\prime} 45^{\prime \prime} \mathrm{S}-80^{\circ} 00^{\prime} 10^{\prime \prime} \mathrm{O}, 408 \mathrm{msnm}$, 23-X-2015, G. Juárez leg., agitación de follaje, Bosque estacionalmente seco de colina; 1 을 Huancabamba, Huarmaca, 5³4'04"S-79³1'26"O, 1223 msnm, 26-VII-2016, G. Juárez leg., agitación de follaje, Bosque estacionalmente seco de colina.

Distribución (Provincia) (Paisaje ecológico). (PIU, SULL, AYA, HUA) (BESr, BESll, BESc-m).

Comentario. De acuerdo con Habeck (2002) se llegó a la conclusión que la especie mencionada como Stelidota sp en Juárez et al. (2016) se trata del género Lobiopa. Los adultos se encuentran sobre hojas y ramas de árboles, en solitario, así como también en frutos maduros destruidos por bruchidos. Insecto plaga que se comporta como fitófago.

Familia Coccinellidae Latreille, 1807

Subfamilia Coccinellinae Latreille, 1807

Género Scymnus Kugelann, 1794

70. Scymnus (Pullus) rubicundus Erichson, 1847

Material eXAminado. PERÚ. 1 \%, Piura, Catacaos, $5^{\circ} 15^{\prime} 42^{\prime \prime} \mathrm{S}-80^{\circ} 40^{\prime} 27^{\prime \prime} \mathrm{O}, 29$ msnm, 06-II-2017, U. González leg., colecta manual, Bosque estacionalmente seco de llanura; 2 우오, Piura, Universidad de Piura, $5^{\circ} 10^{\prime} 11^{\prime \prime} \mathrm{S}-80^{\circ} 36^{\prime} 51^{\prime \prime} \mathrm{O}$, 29 msnm, 26-II-2016, U. González leg., agitación de follaje, Bosque estacionalmente seco de llanura; 2 우, Piura, Castilla, Universidad Nacional de Piura, $5^{\circ} 10^{\prime} 51^{\prime \prime} \mathrm{S}-80^{\circ} 37^{\prime} 31^{\prime \prime} \mathrm{O}$, 29 msnm, 14-III-2018, G. Juárez leg., agitación de follaje, Bosque estacionalmente seco ribereño; 2 우, Sullana, Querecotillo, 450'24"S-80³8'57"O, 23 msnm, 19-I-2016, G. Juárez leg., colecta manual, Bosque estacionalmente seco de llanura; 2 우, Paita, $5^{\circ} 04^{\prime} \mathrm{S}-81^{\circ} 06^{\prime} \mathrm{O}, 10 \mathrm{msnm}, 2$-VIII2017, G. Juárez leg., colecta manual, Bosque estacionalmente seco de llanura; 1 을, Talara, El Alto, $4^{\circ} 16^{\prime} 04^{\prime \prime} \mathrm{S}-81^{\circ} 13^{\prime} 09^{\prime \prime} \mathrm{O}$, 300 msnm, 13-V-2016, colecta manual, G. Juárez leg., Bosque estacionalmente seco de colina; 2 우우 1 $\hat{\sigma}$, Sechura, Vice, $5^{\circ} 25^{\prime} \mathrm{S}-81^{\circ} 46^{\prime} \mathrm{O}, 10 \mathrm{msnm}, 2-\mathrm{II}-2015$, U. González leg., red entomológica, Desierto; $1 \hat{\jmath}$, Morropón, Chulucanas, $5^{\circ} 05^{\prime} \mathrm{S}-80^{\circ} 99^{\prime} \mathrm{O}, 350 \mathrm{msnm}, 05-\mathrm{III}-2017$, G. Juárez leg., agitación de follaje, Bosque estacionalmente seco de colina; 1 , Ayabaca, Suyo, $4^{\circ} 30^{\prime} 45^{\prime \prime} \mathrm{S}-80^{\circ} 00^{\prime} 10^{\prime \prime} \mathrm{O}, 408 \mathrm{msnm}, 23-\mathrm{X}-2015$, G. Juárez leg., colecta manual, Bosque estacionalmente seco de colina; Huancabamba, Huarmaca, 5³4'04"S-79³1'26"O, 1223 msnm, 26-VII-2016, G. Juárez leg., red entomológica, Bosque estacionalmente seco de colina.

Distribución (Provincia) (Paisaje ecológico). (PIU, SUll, PAi, TAL, SECH, MORR, HUA, AYA) (DESc, BESr, BESll, BESc-m).

Comentario. Adultos se encuentran sobre hojas de plántulas y árboles, en solitario. Insecto que se comporta como controlador biológico, adultos depredan principalmente ninfas y adultos de áfidos. Especie citada también por Domínguez (1982) y Juárez et al. (2016).

\section{Scymnus (Pullus) loewii Mulsant, $1850 \dagger$}

Material examinado. PERÚ. 2 9 , Piura, Universidad de Piura, 5॰10'11"S-80³6'51"O, 29 msnm, 26-II-2016, U. González leg., agitación de follaje, Bosque estacionalmente seco de llanura; 1 , , Piura, Castilla, Universidad Nacional de Piura, 5¹0'51"S-80³7'31"O, 29 msnm, 14-III-2018, G. Juárez leg., agitación de follaje, Bosque estacionalmente seco ribereño; 2 우우, Sechura, Vice, $5^{\circ} 25^{\prime} \mathrm{S}-81^{\circ} 46^{\prime} \mathrm{O}, 10 \mathrm{msnm}, 2-\mathrm{II}-2015$, U. González leg., red entomológica, Desierto costero.

Distribución (Provincia) (Paisaje ecológico). (PIU, SECH) (DESc, BESr, BESll).

Comentario. Los adultos se encuentran sobre hojas de plántulas y árboles, en solitario o en grupo de dos o más individuos. Insecto que se comporta como controlador biológico, los adultos depredan principalmente ninfas y adultos de áfidos (González, 2007).

Género Scymnobius Casey, 1899

72. Scymnobius galapagoensis (Waterhouse, 1845)

Material examinado. PERÚ. 3 우, Piura, Catacaos, 5¹5'42"S-8040'27"O, 29 msnm, 06-II-2017, U. González leg., agitación de follaje, Bosque estacionalmente seco de llanura; 4 오오오, Piura, Universidad de Piura, 5॰10'11"S-80³6'51"O, 29 msnm, 26-II-2016, U. González leg., agitación de follaje, Bosque estacionalmente seco de llanura; 2 우, Piura, Castilla, Universidad Nacional de Piura, 5¹0'51"S-80³7'31"O, 29 msnm, 14-III-2018, G. Juárez leg., agitación de follaje, Bosque estacionalmente seco ribereño; 1 P, Sullana, Querecotillo, 4 ${ }^{\circ} 50^{\prime} 24^{\prime \prime} \mathrm{S}-80^{\circ} 38^{\prime} 57^{\prime \prime} \mathrm{O}$, 23 msnm, 19-I-2016, G. Juárez leg., colecta manual, Bosque estacionalmente seco de llanura; 1 q, Paita, $5^{\circ} 04^{\prime} \mathrm{S}-81^{\circ} 06^{\prime} \mathrm{O}$, 10 msnm, 2-VIII-2017, G. Juárez leg., agitación de follaje, Bosque estacionalmente seco de llanura; 1 q, Talara, El Alto, $4^{\circ} 16^{\prime} 04^{\prime \prime} \mathrm{S}-81^{\circ} 13^{\prime} 09^{\prime \prime} \mathrm{O}, 300 \mathrm{msnm}, 13-\mathrm{V}-2016$, colecta manual, G. Juárez leg., Bosque estacionalmente seco de colina; $2 \delta^{\Uparrow} \partial^{\lambda}$, Sechura, Vice, $5^{\circ} 25^{\prime} \mathrm{S}-81^{\circ} 46^{\prime} \mathrm{O}, 10 \mathrm{msnm}, 2-\mathrm{II}-2015$, U. González leg., red entomológica, Desierto costero; 1 ㅇ, Sechura, Laguna Napique, $5^{\circ} 34^{\prime} \mathrm{S}-81^{\circ} 16^{\prime} \mathrm{O}, 16 \mathrm{msnm}, 24-\mathrm{VI}-$ 2019, U. González leg., colecta manual, Bosque estacionalmente seco ribereño; 2 우, Sechura, Illescas, $5^{\circ} 58^{\prime} \mathrm{S}-81^{\circ} 05^{\prime} \mathrm{O}$, 10 msnm, 12-XI-2017, U. González leg., agitación de follaje, Matorral Xérico; 1 ㅇ, Morropón, Chulucanas, $5^{\circ} 05^{\prime} \mathrm{S}-80^{\circ} 99^{\prime} \mathrm{O}$, 350 msnm, 05-III-2017, G. Juárez leg., agitación de follaje, Bosque estacionalmente seco de colina; 2 우, Ayabaca, Suyo, $4^{\circ} 30^{\prime} 45^{\prime \prime} \mathrm{S}-80^{\circ} 00^{\prime} 10^{\prime \prime} \mathrm{O}, 408 \mathrm{msnm}, 23-\mathrm{X}-2015$, G. Juárez leg., colecta manual, Bosque estacionalmente seco de colina; Huancabamba, Huarmaca, 5³4'04"S-79॰31'26"O, 1223 msnm, 26-VII-2016, G. Juárez leg., red entomológica, Bosque estacionalmente seco de colina.

Distribución (Provincia) (PAisaje ecológico). (PIU, SUlL, PAi, TAL, SECH, MORR, HUA, AYA) (MatX, DESc, BESr, BESll, BESc-m). 
Comentario. Los adultos se encuentran sobre hojas de plántulas y árboles, en solitario o en grupo de dos o más individuos. Insecto que se comporta como controlador biológico, los adultos depredan principalmente ninfas y adultos de áfidos (González, 2007). Especie citada también por Juárez et al. (2016).

Género Zagreus Mulsant, 1850 †

73. Zagreus hexasticta (Crotch, 1874) $\uparrow$ (Fig. 12)

Material examinado. PERÚ. 2 oo, Piura, Catacaos, $5^{\circ} 15^{\prime} 42^{\prime \prime} \mathrm{S}-80^{\circ} 40^{\prime} 27^{\prime \prime} \mathrm{O}, \quad 29 \mathrm{msnm}, \quad 06-\mathrm{II}-2017$, U. González leg., agitación de follaje, Bosque estacionalmente seco de llanura; 2 우, Piura, Universidad de Piura, 5 10'11"S-80³6'51"O, 29 msnm, 26-II-2016, U. González leg., agitación de follaje, Bosque estacionalmente seco de llanura; 2 우, Piura, Castilla, Universidad Nacional de Piura, 5 $10^{\prime} 51^{\prime \prime} \mathrm{S}-80^{\circ} 37^{\prime} 31^{\prime \prime} \mathrm{O}, 29 \mathrm{msnm}, 14-\mathrm{III}-2018$, G. Juárez leg., colecta manual, Bosque estacionalmente seco ribe-

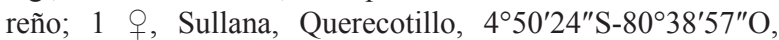
23 msnm, 19-I-2016, G. Juárez leg., colecta manual, Bosque estacionalmente seco de llanura; 1 \% , Paita, $5^{\circ} 04^{\prime} \mathrm{S}-81^{\circ} 06^{\prime} \mathrm{O}$, 10 msnm, 2-VIII-2017, G. Juárez leg., agitación de follaje, Bosque estacionalmente seco de llanura; 1 , Talara, El Alto, $4^{\circ} 16^{\prime} 04^{\prime \prime} \mathrm{S}-81^{\circ} 13^{\prime} 09^{\prime \prime} \mathrm{O}, 300 \mathrm{msnm}, 13-\mathrm{V}-2016$, colecta manual, G. Juárez leg., Bosque estacionalmente seco de colina; 1 J, 1 क , Sechura, Vice, $5^{\circ} 25^{\prime} \mathrm{S}-81^{\circ} 46^{\prime} \mathrm{O}, 10 \mathrm{msnm}, 2-\mathrm{II}-$ 2015, U. González leg., agitación de follaje, Desierto costero; 2 우, Sechura, Laguna Ñapique, $5^{\circ} 34^{\prime} \mathrm{S}-81^{\circ} 16^{\prime} \mathrm{O}, 16 \mathrm{msnm}$, 24-VI-2019, U. González leg., colecta manual, Bosque estacionalmente seco ribereño; ; 1 + 1 d , Morropón, Chulucanas, $5^{\circ} 05^{\prime} \mathrm{S}-80^{\circ} 99^{\prime} \mathrm{O}, 350 \mathrm{msnm}, 05-\mathrm{III}-2017$, G. Juárez leg., red entomológica, Bosque estacionalmente seco de colina.

Distribución (Provincia) (Paisaje ecológico). (PIU, SUlL, PAi, TAL, SECH, MORR) (DESc, BESr, BESll, BESc-m).

Comentario. Los adultos se encuentran sobre hojas y ramas de plántulas y árboles, en solitario. Insecto que se comporta como controlador biológico, los adultos depredan principalmente ninfas y adultos de áfidos y cóccidos (González, 2007).

Género Psyllobora Chevrolat, 1837

74. Psyllobora confluens Fabricius, 1801

Material examinado. PERÚ. 1 q, Piura, Catacaos, $5^{\circ} 15^{\prime} 42^{\prime \prime} \mathrm{S}-80^{\circ} 40^{\prime} 27^{\prime \prime} \mathrm{O}, 29 \mathrm{msnm}, 06-\mathrm{II}-2017$, U. González leg., colecta manual, Bosque estacionalmente seco de llanura; 1 +, 061 COL-GJN, Piura, Universidad de Piura, $5^{\circ} 10^{\prime} 11^{\prime \prime} \mathrm{S}-80^{\circ} 36^{\prime} 51^{\prime \prime} \mathrm{O}, 29 \mathrm{msnm}, 26-\mathrm{II}-2016$, U. González leg., agitación de follaje, Bosque estacionalmente seco de llanura; 1 , Piura, Castilla, Universidad Nacional de Piura, 5 10'51"S-80³7'31"O, 29 msnm, 14-III-2018, G. Juárez leg., agitación de follaje, Bosque estacionalmente seco ribereño; 2 우오, Sullana, Querecotillo, 450'24"S-80³8'57"O, 23 msnm, 19-I-2016, G. Juárez leg., agitación de follaje, Bosque estacionalmente seco de llanura; 1 ․ Paita, $5^{\circ} 04^{\prime} \mathrm{S}-81^{\circ} 06^{\prime} \mathrm{O}$, 10 msnm, 2-VIII-2017, G. Juárez leg., colecta manual, Bosque estacionalmente seco de llanura; 2 우, Talara, El Alto, $4^{\circ} 16^{\prime} 04^{\prime \prime} \mathrm{S}-81^{\circ} 13^{\prime} 09^{\prime \prime} \mathrm{O}, 300 \mathrm{msnm}, 13-\mathrm{V}-2016$, agitación de follaje, G. Juárez leg., Bosque estacionalmente seco de colina; 1 ㅇ, Sechura, Vice, $5^{\circ} 25^{\prime} \mathrm{S}-81^{\circ} 46^{\prime} \mathrm{O}, 10 \mathrm{msnm}$, 2-II-2015, U. González leg., red entomológica, Desierto

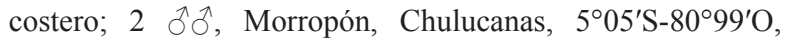
350 msnm, 05-III-2017, G. Juárez leg., agitación de follaje, Bosque estacionalmente seco de colina; 1 , Ayabaca, Suyo, $4^{\circ} 30^{\prime} 45^{\prime \prime} \mathrm{S}-80^{\circ} 00^{\prime} 10^{\prime \prime} \mathrm{O}, 408$ msnm, 23-X-2015, G. Juárez leg., agitación de follaje, Bosque estacionalmente seco de colina;

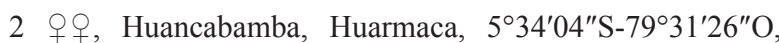
1223 msnm, 26-VII-2016, G. Juárez leg., colecta manual, Bosque estacionalmente seco de colina.

Distribución (Provincia) (Paisaje ecológico). (PIU, SUlL, PAI, TAL, SECH, MORR, AYA, HUA) (DESc, BESr, BESIl, BESc-m).

Comentario. Especie citada como Psyllobora sp en Juárez et al. (2016). Los adultos se encuentran sobre hojas de plántulas y árboles, en solitario. Larvas y adultos se alimentan de hongos en especial de aquellos que forman una cubierta blanquecina sobre los foliolos de plántulas y árboles (González, 2007).

\section{Género Coleomegilla Timberlake, 1920}

\section{Coleomegilla maculata bisexpunctata Latreille, 1833}

Material examinado. PERÚ. 2 우, Piura, Catacaos, 5¹5'42"S-8040'27"O, 29 msnm, 06-II-2017, U. González leg., colecta manual, Bosque estacionalmente seco de llanura; 3 우우, Piura, Universidad de Piura, $5^{\circ} 10^{\prime} 11^{\prime \prime} \mathrm{S}-80^{\circ} 36^{\prime} 51^{\prime \prime} \mathrm{O}$, 29 msnm, 26-II-2016, U. González leg., colecta manual, Bosque

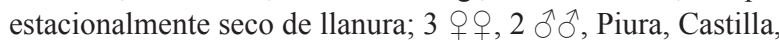
Universidad Nacional de Piura, 5 $5^{\circ} 10^{\prime} 51^{\prime \prime} \mathrm{S}-80^{\circ} 37^{\prime} 31^{\prime \prime} \mathrm{O}$, 29 msnm, 14-III-2018, G. Juárez leg., agitación de follaje, Bosque estacionalmente seco ribereño; 2 q, Sullana, Querecotillo, 4 ${ }^{\circ} 50^{\prime} 24^{\prime \prime} \mathrm{S}-80^{\circ} 38^{\prime} 57^{\prime \prime} \mathrm{O}, 23 \mathrm{msnm}, 19-\mathrm{I}-2016, \mathrm{G}$. Juárez leg., colecta manual, Bosque estacionalmente seco de llanura; 1 o , Paita, $5^{\circ} 04^{\prime} \mathrm{S}-81^{\circ} 06^{\prime} \mathrm{O}, 10 \mathrm{msnm}, 2-\mathrm{VIII}-2017$, G. Juárez leg., colecta manual, Bosque estacionalmente seco de llanura

Distribución (Provincia) (Paisaje ecológico). (PIU, SUlL, PAI) (BESr, BESll).

Comentario. Los adultos se encuentran sobre hojas y ramas de plántulas y árboles, en solitario o en grupos de dos a cuatro individuos. Insecto que se comporta como controlador biológico, los adultos depredan principalmente ninfas y adultos de áfidos (González, 2007). Especie citada también por NúñezSacarías (1993) y Juárez et al. (2016).

\section{Género Cycloneda Crotch, 1871}

76. Cycloneda sanguinea (Linnaeus, 1763)

Material examinado. 3 우, Piura, Universidad de Piura, $5^{\circ} 10^{\prime} 11^{\prime \prime} \mathrm{S}-80^{\circ} 36^{\prime} 51^{\prime \prime} \mathrm{O}, 29 \mathrm{msnm}, 26-\mathrm{II}-2016$, U. González leg., agitación de follaje, Bosque estacionalmente seco de llanura; 4 우웅, $2 \hat{\jmath} \hat{\jmath}$, Piura, Castilla, Universidad Nacional de Piura, 510'51"S-80³7'31"O, 29 msnm, 14-III-2018, G. Juárez leg., agitación de follaje, Bosque estacionalmente seco ribereño; 2 우, Sullana, Querecotillo, $4^{\circ} 50^{\prime} 24^{\prime \prime} \mathrm{S}-80^{\circ} 38^{\prime} 57^{\prime \prime} \mathrm{O}$, 23 msnm, 19-I-2016, G. Juárez leg., colecta manual, Bosque estacionalmente seco de llanura; 2 우, Paita, $5^{\circ} 04^{\prime} \mathrm{S}-81^{\circ} 06^{\prime} \mathrm{O}$, 10 msnm, 2-VIII-2017, G. Juárez leg., agitación de follaje, Bosque estacionalmente seco de llanura; 2 우, 1 ऊ; Talara, El Alto, $4^{\circ} 16^{\prime} 04^{\prime \prime} \mathrm{S}-81^{\circ} 13^{\prime} 09^{\prime \prime} \mathrm{O}, 300 \mathrm{msnm}, 13-\mathrm{V}-2016$, colecta manual, G. Juárez leg., Bosque estacionalmente seco de colina;

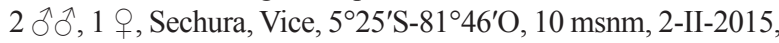
U. González leg., red entomológica, Desierto costero; 3 우우, $3 \delta^{\lambda}$, Sechura, Laguna Napique, $5^{\circ} 34^{\prime} \mathrm{S}-81^{\circ} 16^{\prime} \mathrm{O}, 16 \mathrm{msnm}$, 24-VI-2019, U. González leg., colecta manual, Bosque estacionalmente seco ribereño; 2 $q$,, $1 \hat{\jmath}$, Sechura, Illescas, $5^{\circ} 58^{\prime} \mathrm{S}-81^{\circ} 05^{\prime} \mathrm{O}, 10 \mathrm{msnm}, 12-\mathrm{XI}-2017$, U. González leg., agitación de follaje, Matorral Xérico; 2 + 9 , Morropón, Chulucanas, 505'S-8099'O, 350 msnm, 05-III-2017, G. Juárez leg., agitación de follaje, Bosque estacionalmente seco de colina; 1 , Ayabaca, Suyo, $4^{\circ} 30^{\prime} 45^{\prime \prime} \mathrm{S}-80^{\circ} 00^{\prime} 10^{\prime \prime} \mathrm{O}, 408 \mathrm{msnm}, 23-\mathrm{X}-2015$, G. Juárez leg., colecta manual, Bosque estacionalmente seco de colina; Huancabamba, Huarmaca, 5³4'04"S-79³1'26"O, 
1223 msnm, 26-VII-2016, G. Juárez leg., red entomológica, Bosque estacionalmente seco de colina.

Distribución (Provincia) (Paisaje ecológico). (PIU, SUlL, PAi, TAL, SECH, MORR, AYA, HUA) (MatX, DESc, BESr, BESll, BESc-m).

Comentario. Los adultos y larvas se encuentran sobre hojas y ramas de plántulas y árboles, en solitario o en grupo de dos a más individuos. Insecto que se comporta como controlador biológico, los adultos y larvas depredan principalmente ninfas y adultos de áfidos y larvas de E. discordis (González, 2007). Especie citada también por Domínguez (1982) y Juárez et al. (2016).

Género Cheilomenes Dejean, 1836

77. Cheilomenes sexmaculata Fabricius, 1781

Material examinado. PERÚ. 2 $q+, 1$ ก, Piura, Universidad de Piura, $5^{\circ} 10^{\prime} 11^{\prime \prime S}-80^{\circ} 36^{\prime} 51^{\prime \prime} \mathrm{O}, 29 \mathrm{msnm}, 26-\mathrm{II}-2016$, U. González leg., agitación de follaje, Bosque estacionalmente seco de llanura; 3 우우, 2 $\widehat{\partial}$, Piura, Castilla, Universidad

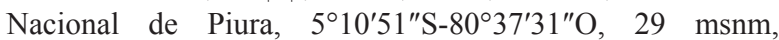
14-III-2018, G. Juárez leg., colecta manual, Bosque estacionalmente seco ribereño; 3 우, Sullana, Querecotillo, 450'24"S-80³8'57"O, 23 msnm, 19-I-2016, G. Juárez leg., colecta manual, Bosque estacionalmente seco de llanura; 1 , Paita, 50 $04^{\prime} \mathrm{S}-81^{\circ} 06^{\prime} \mathrm{O}, 10 \mathrm{msnm}, 2$-VIII-2017, G. Juárez leg., agitación de follaje, Bosque estacionalmente seco de llanura; 2 우우, Talara, El Alto, 4 $16^{\prime} 04^{\prime \prime} \mathrm{S}-81^{\circ} 13^{\prime} 09^{\prime \prime} \mathrm{O}, 300 \mathrm{msnm}$, 13-V-2016, red entomológica, G. Juárez leg., Bosque estacionalmente seco de colina; $1 \mathrm{o}^{\mathrm{N}}$, Sechura, Vice, $5^{\circ} 25^{\prime} \mathrm{S}-81^{\circ} 46^{\prime} \mathrm{O}$, 10 msnm, 2-II-2015, U. González leg., colecta manual,

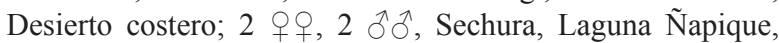
5³4'S-8116'O, 16 msnm, 24-VI-2019, U. González leg., colecta manual, Bosque estacionalmente seco ribereño; 2 우, 1 ô., Morropón, Chulucanas, $5^{\circ} 05^{\prime} \mathrm{S}-80^{\circ} 99^{\prime} \mathrm{O}, 350 \mathrm{msnm}$, 05-III-2017, G. Juárez leg., agitación de follaje, Bosque estacionalmente seco de colina.

Distribución (Provincia) (Paisaje ecológico). (PIU, SUlL, PAi, TAL, SECH, MORR) (DESC, BESr, BESIl, BESc-m).

ComentARIO. Los adultos y larvas se encuentran sobre hojas y ramas de plántulas y árboles, en solitario o en grupo de dos a más individuos. Insecto que se comporta como controlador biológico, los adultos y larvas depredan principalmente ninfas y adultos de áfidos y larvas de E. discordis (González, 2007). Especie citada también por Juárez \& González (2016a).

Género Paraneda Timberlake, 1943

78. Paraneda pallidula guticollis Mulsant, 1850.

Material examinado. Perú. 3 $q+4$ đô, Perú. Piura, Catacaos, $5^{\circ} 15^{\prime} 42^{\prime \prime} \mathrm{S}-80^{\circ} 40^{\prime} 27^{\prime \prime} \mathrm{O}, 29 \mathrm{msnm}, 06-\mathrm{II}-2017$, U. González leg., colecta manual, Bosque estacionalmente seco de llanura; 2 우, 3 $\widehat{\jmath} \widehat{\jmath}$, Piura, Universidad de Piura, $5^{\circ} 10^{\prime} 11^{\prime \prime} \mathrm{S}-80^{\circ} 36^{\prime} 51^{\prime \prime} \mathrm{O}, 29 \mathrm{msnm}, 26-\mathrm{II}-2016$, U. González leg., agitación de follaje, Bosque estacionalmente seco de llanura; 3 우, Piura, Castilla, Universidad Nacional de Piura, 5¹0'51"S-80³7'31"O, 29 msnm, 14-III-2018, G. Juárez leg., agitación de follaje, Bosque estacionalmente seco ribereño; 3 우우, Sullana, Querecotillo, 450'24"S-80 $38^{\prime} 57^{\prime \prime} \mathrm{O}, 23 \mathrm{msnm}$, 19-I-2016, G. Juárez leg., colecta manual, Bosque estacionalmente seco de llanura; 2 오우, 2 충, Paita, $5^{\circ} 04^{\prime} \mathrm{S}-81^{\circ} 06^{\prime} \mathrm{O}$, 10 msnm, 2-VIII-2017, G. Juárez leg., agitación de follaje, Bosque estacionalmente seco de llanura; 2 우, Talara, El Alto, $4^{\circ} 16^{\prime} 04^{\prime \prime} \mathrm{S}-81^{\circ} 13^{\prime} 09^{\prime \prime} \mathrm{O}, 300 \mathrm{msnm}, 13-\mathrm{V}-2016$, colecta manual, G. Juárez leg., Bosque estacionalmente seco de colina; $2 \partial^{\widehat{\partial}}$, Sechura, Vice, $5^{\circ} 25^{\prime} \mathrm{S}-81^{\circ} 46^{\prime} \mathrm{O}, 10 \mathrm{msnm}$,
2-II-2015, U. González leg., red entomológica, Desierto costero; 4 우우우오, Sechura, Laguna Napique, $5^{\circ} 34^{\prime} \mathrm{S}-81^{\circ} 16^{\prime} \mathrm{O}$, 16 msnm, 24-VI-2019, U. González leg., colecta manual, Bosque estacionalmente seco ribereño; 2 우, 1 ㅅ․ Sechura, Illescas, $5^{\circ} 58^{\prime} \mathrm{S}-81^{\circ} 05^{\prime} \mathrm{O}, 10 \mathrm{msnm}, 12-\mathrm{XI}-2017$, U. González

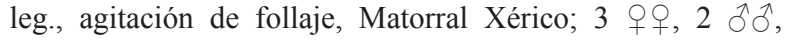
Morropón, Chulucanas, $5^{\circ} 05^{\prime} \mathrm{S}-80^{\circ} 99^{\prime} \mathrm{O}, 350 \mathrm{msnm}, 05-\mathrm{III}-$ 2017, G. Juárez leg., colecta manual, Bosque estacionalmente seco de colina; 2 우, Ayabaca, Suyo, $4^{\circ} 30^{\prime} 45^{\prime \prime} \mathrm{S}-80^{\circ} 00^{\prime} 10^{\prime \prime} \mathrm{O}$, 408 msnm, 23-X-2015, G. Juárez leg., red entomológica, Bosque estacionalmente seco de colina; 2 우, Huancabamba, Huarmaca, 5³4'04"S-79³1'26"O, 1223 msnm, 26-VII-2016, G. Juárez leg., colecta manual, Bosque estacionalmente seco de colina.

Distribución (Provincia) (Paisaje ecológico). (PIU, SUll, PAi, TAL, SECH, MORR, AYA, HUA) (MatX, DESc, BESr, BESll, BESc-m).

Comentario. Los adultos y larvas se encuentran sobre hojas plántulas y árboles, en solitario o en grupos de dos a más individuos. Insecto que se comporta como controlador biológico, los adultos y larvas depredan principalmente ninfas y adultos de áfidos y larvas de E. discordis (González, 2007). Especie citada también por Núñez-Sacarías (1993) y Juárez et al. (2016).

79. Paraneda sin identificar sp. 1.

Material examinado. Perú. 1, $1 \hat{\jmath}$, Piura, Catacaos, 5¹5'42"S-8040'27"O, 29 msnm, 06-II-2017, U. González leg., colecta manual, Bosque estacionalmente seco de llanura; 2 우, 1 `, Piura, Universidad de Piura, $5^{\circ} 10^{\prime} 11^{\prime \prime} \mathrm{S}-80^{\circ} 36^{\prime} 51^{\prime \prime} \mathrm{O}$, 29 msnm, 26-II-2016, U. González leg., agitación de follaje, Bosque estacionalmente seco de llanura; 2 q, , Piura, Castilla,

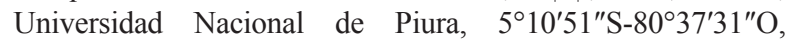
29 msnm, 14-III-2018, G. Juárez leg., agitación de follaje, Bosque estacionalmente seco ribereño; 1 \&, Sullana, Querecotillo, 450'24"S-80³8'57"O, 23 msnm, 19-I-2016, G. Juárez leg., colecta manual, Bosque estacionalmente seco de llanura; 1 , 1 $\mathrm{O}^{\lambda}$, Paita, 504'S-81 ${ }^{\circ} 06^{\prime} \mathrm{O}, 10$ msnm, 2-VIII-2017, G. Juárez leg., agitación de follaje, Bosque estacionalmente seco de llanura; 2 우, Talara, El Alto, $4^{\circ} 16^{\prime} 04^{\prime \prime} \mathrm{S}-81^{\circ} 13^{\prime} 09^{\prime \prime} \mathrm{O}, 300 \mathrm{msnm}, 13-\mathrm{V}-$ 2016, colecta manual, G. Juárez leg., Bosque estacionalmente seco de colina; $1 \delta^{\lambda}$, Sechura, Vice, $5^{\circ} 25^{\prime} \mathrm{S}-81^{\circ} 46^{\prime} \mathrm{O}, 10 \mathrm{msnm}$, 2-II-2015, U. González leg., red entomológica, Desierto costero; 2 우, Sechura, Laguna Ñapique, $5^{\circ} 34^{\prime} \mathrm{S}-81^{\circ} 16^{\prime} \mathrm{O}$, 16 msnm, 24-VI-2019, U. González leg., colecta manual, Bosque estacionalmente seco ribereño; 2 우, Sechura, Illescas,

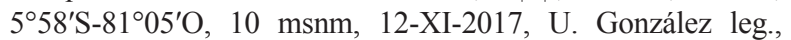

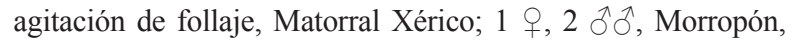
Chulucanas, $5^{\circ} 05^{\prime} \mathrm{S}-80^{\circ} 99^{\prime} \mathrm{O}, 350 \mathrm{msnm}, 05-\mathrm{III}-2017, \mathrm{G}$. Juárez leg., colecta manual, Bosque estacionalmente seco de colina; 1 ㅇ, Ayabaca, Suyo, $4^{\circ} 30^{\prime} 45^{\prime \prime} \mathrm{S}-80^{\circ} 00^{\prime} 10^{\prime \prime} \mathrm{O}, 408 \mathrm{msnm}$, 23-X-2015, G. Juárez leg., red entomológica, Bosque estacionalmente seco de colina; 1 , Huancabamba, Huarmaca, 5³4'04"S-79³1'26"O, 1223 msnm, 26-VII-2016, G. Juárez leg., colecta manual, Bosque estacionalmente seco de colina.

Distribución (Provincia) (Paisaje ecológico). (PIU, SUll, PAi, TAL, SECH, MORR, AYA, HUA) (MatX, DESc, BESr, BESll, BESc-m).

Comentario. Los adultos y larvas se encuentran sobre hojas de plántulas y árboles, en solitario o en grupo de dos a más individuos. Insecto que se comporta como controlador biológico, los adultos y larvas depredan principalmente ninfas y adultos de áfidos y larvas de E. discordis (González, 2007). Especie citada también por Juárez et al. (2016). 
Género Hippodamia Dejean, 1837

80. Hippodamia convergens Guerin-Meneville, 1836

Material examinado. Perú. 1 +2 ô, Piura, Catacaos, $5^{\circ} 15^{\prime} 42^{\prime \prime} \mathrm{S}-80^{\circ} 40^{\prime} 27^{\prime \prime} \mathrm{O}, 29 \mathrm{msnm}, \quad 06-\mathrm{II}-2017$, U. González leg., colecta manual, Bosque estacionalmente seco de llanura; 2 우, 2 $\hat{\jmath}$, Piura, Universidad de Piura, $5^{\circ} 10^{\prime} 11^{\prime \prime} \mathrm{S}-80^{\circ} 36^{\prime} 51^{\prime \prime} \mathrm{O}, 29$ msnm, 26-II-2016,U.Gonzálezleg., agitación de follaje, Bosque estacionalmente seco de llanura;

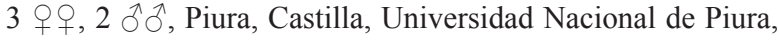
$5^{\circ} 10^{\prime} 51^{\prime \prime S}-80^{\circ} 37^{\prime} 31^{\prime \prime} \mathrm{O}, 29$ msnm, 14-III-2018, G. Juárez leg., agitación de follaje, Bosque estacionalmente seco ribereño; 2 우오, Sullana, Querecotillo, 450'24"S-80 38'57"O, 23 msnm, 19-I-2016, G. Juárez leg., colecta manual, Bosque estacionalmente seco de llanura; $1 \stackrel{+}{\circ} 1$ ô., Paita, $5^{\circ} 04^{\prime} \mathrm{S}-81^{\circ} 06^{\prime} \mathrm{O}$, 10 msnm, 2-VIII-2017, G. Juárez leg., agitación de follaje, Bosque estacionalmente seco de llanura; 2 우, 1 $\delta^{\text {, Talara, El }}$ Alto, $4^{\circ} 16^{\prime} 04^{\prime \prime} \mathrm{S}-81^{\circ} 13^{\prime} 09^{\prime \prime} \mathrm{O}, 300 \mathrm{msnm}, 13-\mathrm{V}-2016$, colecta manual, G. Juárez leg., Bosque estacionalmente seco de colina; $2 \hat{\partial} \partial^{\lambda}$, Sechura, Vice, $5^{\circ} 25^{\prime} \mathrm{S}-81^{\circ} 46^{\prime} \mathrm{O}, 10 \mathrm{msnm}, 2$-II2015, U. González leg., red entomológica, Desierto costero; 2 우우, Sechura, Laguna Ñapique, $5^{\circ} 34^{\prime} \mathrm{S}-81^{\circ} 16^{\prime} \mathrm{O}, 16 \mathrm{msnm}$, 24-VI-2019, U. González leg., colecta manual, Bosque estacionalmente seco ribereño; $2 \stackrel{+}{\circ, 1} \hat{\partial}$, Sechura, Illescas, $5^{\circ} 58^{\prime} \mathrm{S}-81^{\circ} 05^{\prime} \mathrm{O}, 10 \mathrm{msnm}, 12-\mathrm{XI}-2017$, U. González leg., agitación de follaje, Matorral Xérico; 1 , 1 స, Morropón, Chulucanas, $5^{\circ} 05^{\prime} \mathrm{S}-80^{\circ} 99^{\prime} \mathrm{O}, 350 \mathrm{msnm}, 05-\mathrm{III}-2017$, G. Juárez leg., colecta manual, Bosque estacionalmente seco de colina; 3 오, Ayabaca, Suyo, $4^{\circ} 30^{\prime} 45^{\prime \prime} \mathrm{S}-80^{\circ} 00^{\prime} 10^{\prime \prime} \mathrm{O}$, 408 msnm, 23-X-2015, G. Juárez leg., red entomológica, Bosque estacionalmente seco de colina; 2 우, Huancabamba, Huarmaca, 534'04"S-79³1'26"O, 1223 msnm, 26-VII-2016, G. Juárez leg., colecta manual, Bosque estacionalmente seco de colina.

Distribución (Provincia) (Paisaje ecológico). (PIU, SUlL, PAi, TAL, SECH, MORR, AYA, HUA) (MatX, DESc, BESr, BESIl, BESc-m).

Comentario. Los adultos y larvas se encuentran sobre hojas y ramas de plántulas y árboles, en solitario o en grupo de dos a más individuos. Insecto que se comporta como controlador biológico, los adultos y larvas depredan principalmente ninfas y adultos de áfidos y larvas de E. discordis (González, 2007). Especie citada también por Núñez-Sacarías (1993) y Juárez et al. (2016).

Familia Tenebrionidae Latreille, 1802

Subfamilia Pimeliinae Latreille, 1802

Género Psammetichus Latreille, 1804

81. Psammetichus costatus Guérin-Méneville, 1830

Material examinado. Perú. 1 q, 1 ô, Piura, Catacaos, 5¹5'42"S-8040'27"O, 29 msnm, 06-II-2017, U. González leg., colecta manual, Bosque estacionalmente seco de llanura; $2 \delta^{\jmath} \partial^{\lambda}$, Piura, Universidad de Piura, $5^{\circ} 10^{\prime} 11^{\prime \prime} \mathrm{S}-80^{\circ} 36^{\prime} 51^{\prime \prime} \mathrm{O}$, 29 msnm, 26-II-2016, U. González leg., colecta manual, Bosque estacionalmente seco de llanura; 1 ㅇ, 2 $\hat{\partial}$, Piura, Castilla, Universidad Nacional de Piura, $5^{\circ} 10^{\prime} 51^{\prime \prime} \mathrm{S}-80^{\circ} 37^{\prime} 31^{\prime \prime} \mathrm{O}$, 29 msnm, 14-III-2018, G. Juárez leg., colecta manual, Bosque estacionalmente seco ribereño; 2 우, Sullana, Querecotillo, 450'24"S-80³8'57"O, 23 msnm, 19-I-2016, G. Juárez leg., colecta manual, Bosque estacionalmente seco de llanura; 2 우우, 1 그, Paita, $5^{\circ} 04^{\prime} \mathrm{S}-81^{\circ} 06^{\prime} \mathrm{O}, 10 \mathrm{msnm}, 2$-VIII-2017, G. Juárez leg., colecta manual, Bosque estacionalmente seco de llanura; 2 우, Talara, El Alto, $4^{\circ} 16^{\prime} 04^{\prime \prime} \mathrm{S}-81^{\circ} 13^{\prime} 09^{\prime \prime} \mathrm{O}$, 300 msnm, 13-V-2016, colecta manual, G. Juárez leg., Bosque estacionalmente seco de colina; $2 \stackrel{\partial}{\jmath}$, Sechura, Vice,
5²5'S-81 $4{ }^{\circ} 46^{\prime} \mathrm{O}, 10$ msnm, 2-II-2015, U. González leg., colecta manual, Desierto costero; $3+q$, Sechura, Laguna Napique, 5³4'S-81²16'O, 16 msnm, 24-VI-2019, U. González leg., colecta manual, Bosque estacionalmente seco ribereño; 2 우, $2 \mathrm{\partial}^{\hat{O}}$, Sechura, Illescas, $5^{\circ} 58^{\prime} \mathrm{S}-81^{\circ} 05^{\prime} \mathrm{O}, 10 \mathrm{msnm}, 12-\mathrm{XI}-$ 2017, U. González leg., colecta manual, Matorral Xérico; 1 , Morropón, Chulucanas, $5^{\circ} 05^{\prime} \mathrm{S}-80^{\circ} 99^{\prime} \mathrm{O}, 350 \mathrm{msnm}$, 05-III2017, G. Juárez leg., colecta manual, Bosque estacionalmente seco de colina.

Distribución (Provincia) (Paisaje ecológico). (PIU, SUlL, PAI, TAL, SECH, MORR) (MatX, DESc, BESr, BESll, BESc-m).

Comentario. Los adultos se encuentran a ras del suelo cercanos al tronco y sobre ramas y grietas de troncos, incluso en troncos secos y muertos, en solitario o en grupos de más de dos individuos. Especie citada también por Juárez et al. (2016).

82. Psammetichus dissimilis Peña, $1994 \dagger$

Material examinado. Perú. 1 ô, Piura, Catacaos, 5 15'42"S-8040'27"O, 29 msnm, 06-II-2017, U. González leg., colecta manual, Bosque estacionalmente seco de llanura; $1 \delta^{\lambda}$, Piura, Universidad de Piura, 5 $5^{\circ} 10^{\prime} 11^{\prime \prime S}-80^{\circ} 36^{\prime} 51^{\prime \prime} \mathrm{O}$, 29 msnm, 26-II-2016, U. González leg., colecta manual, Bosque estacionalmente seco de llanura; 1 ㅇ, 1 $\hat{\sigma}$, Piura, Castilla, Universidad Nacional de Piura, $5^{\circ} 10^{\prime} 51^{\prime \prime} \mathrm{S}-80^{\circ} 37^{\prime} 31^{\prime \prime} \mathrm{O}$, 29 msnm, 14-III-2018, G. Juárez leg., colecta manual, Bosque estacionalmente seco ribereño; 1 , , Sullana, Querecotillo, 450'24"S-80³8'57"O, 23 msnm, 19-I-2016, G. Juárez leg., colecta manual, Bosque estacionalmente seco de llanura; 1 , 1 ô, Paita, $5^{\circ} 04^{\prime} \mathrm{S}-81^{\circ} 06^{\prime} \mathrm{O}, 10 \mathrm{msnm}, 2-\mathrm{VIII}-2017$, G. Juárez leg., colecta manual, Bosque estacionalmente seco de llanura; 1 o, Talara, El Alto, $4^{\circ} 16^{\prime} 04^{\prime \prime} \mathrm{S}-81^{\circ} 13^{\prime} 09^{\prime \prime} \mathrm{O}, 300 \mathrm{msnm}, 13-\mathrm{V}-$ 2016, colecta manual, G. Juárez leg., Bosque estacionalmente seco de colina; $1 \partial^{\top}$, Sechura, Vice, $5^{\circ} 25^{\prime} \mathrm{S}-81^{\circ} 46^{\prime} \mathrm{O}, 10 \mathrm{msnm}$, 2-II-2015, U. González leg., colecta manual, Desierto costero; 1 +, Sechura, Laguna Ñapique, $5^{\circ} 34^{\prime} \mathrm{S}-81^{\circ} 16^{\prime} \mathrm{O}$, 16 msnm, 24-VI-2019, U. González leg., colecta manual, Bosque estacionalmente seco ribereño; 1 ऽ, Sechura, Illescas, 5 58'S-81ํ5' O, 10 msnm, 12-XI-2017, U. González leg., colecta manual, Matorral Xérico; 1 đ̊, Morropón, Chulucanas, 505'S-8099'O, 350 msnm, 05-III-2017, G. Juárez leg., colecta manual, Bosque estacionalmente seco de colina.

Distribución (Provincia) (Paisaje ecológico). (PIU, SUll, PAi, TAL, SECH, MORR) (MatX, DESc, BESr, BESll, BESc-m).

Comentario. Los adultos se encuentran a ras del suelo cercanos al tronco, sobre ramas y grietas de troncos, incluso en troncos secos y muertos, en solitario.

Género Parepitragus Casey, 1907

83. Parepitragus pulverulentus Marcuzzi, 1961

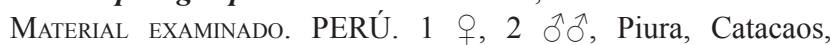
$5^{\circ} 15^{\prime} 42^{\prime \prime} \mathrm{S}-80^{\circ} 40^{\prime} 27^{\prime \prime} \mathrm{O}, 29 \mathrm{msnm}, 06-\mathrm{II}-2017$, U. González leg., colecta manual, Bosque estacionalmente seco de llanura;

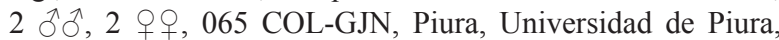
$5^{\circ} 10^{\prime} 11^{\prime \prime} \mathrm{S}-80^{\circ} 36^{\prime} 51^{\prime \prime} \mathrm{O}, 29 \mathrm{msnm}, 26-\mathrm{II}-2016$, U. González leg., colecta manual, Bosque estacionalmente seco de llanura; 1 ㅇ, 1 गे, Piura, Castilla, Universidad Nacional de Piura, 5¹0'51"S-80³7'31"O, 29 msnm, 14-III-2018, G. Juárez leg., colecta manual, Bosque estacionalmente seco ribereño; $2++$, 1 ô, Sullana, Querecotillo, 450'24"S-80³8'57"O, 23 msnm, 19-I-2016, G. Juárez leg., colecta manual, Bosque estacionalmente seco de llanura; 1 , $1 \delta^{\lambda}$, Paita, $5^{\circ} 04^{\prime} \mathrm{S}-81^{\circ} 06^{\prime} \mathrm{O}$, 10 msnm, 2-VIII-2017, G. Juárez leg., agitación de follaje, Bosque estacionalmente seco de llanura; 2 우, $2 \hat{\partial} \hat{\delta}$, Talara, El Alto, $4^{\circ} 16^{\prime} 04^{\prime \prime} \mathrm{S}-81^{\circ} 13^{\prime} 09^{\prime \prime} \mathrm{O}, 300 \mathrm{msnm}, 13-\mathrm{V}-2016$, 
agitación de follaje, G. Juárez leg., Bosque estacionalmente seco de colina; $1 \delta^{\lambda}$, Sechura, Vice, $5^{\circ} 25^{\prime} \mathrm{S}-81^{\circ} 46^{\prime} \mathrm{O}, 10 \mathrm{msnm}$, 2-II-2015, U. González leg., colecta manual, Desierto costero; 2 우, 1 으, Sechura, Laguna Napique, $5^{\circ} 34^{\prime} \mathrm{S}-81^{\circ} 16^{\prime} \mathrm{O}$, 16 msnm, 24-VI-2019, U. González leg., agitación de follaje, Bosque estacionalmente seco ribereño; 1 +, $2 \hat{\partial} \hat{\sigma}$, Sechura, Illescas, 558'S-81 ${ }^{\circ} 05^{\prime} \mathrm{O}, 10$ msnm, 12-XI-2017, U. González leg., agitación de follaje, Matorral Xérico; 1 \%, Morropón, Chulucanas, $5^{\circ} 05^{\prime} \mathrm{S}-80^{\circ} 99^{\prime} \mathrm{O}, 350 \mathrm{msnm}$, 05-III-2017, G. Juárez leg., colecta manual, Bosque estacionalmente seco de colina; 1 ㅇ, Ayabaca, Suyo, $4^{\circ} 30^{\prime} 45^{\prime \prime} \mathrm{S}-80^{\circ} 00^{\prime} 10^{\prime \prime} \mathrm{O}$, 408 msnm, 23-X-2015, G. Juárez leg., red entomológica, Bosque estacionalmente seco de colina; 1 , Huancabamba, Huarmaca, 5³4'04"S-79³1'26"O, 1223 msnm, 26-VII-2016, G. Juárez leg., colecta manual, Bosque estacionalmente seco de colina.

Distribución (Provincia) (Paisaje ecológico). (PIU, SUlL, PAi, TAL, SECH, MORR, HUA, AYA) (MatX, DESc, BESr, BESll, BESc-m).

Comentario. Especie citada como Parepitragus sp en Juárez et al. (2016). Los adultos se encuentran sobre hojas y ramas de plántulas y árboles, en solitario. Especie citada también por Domínguez (1982)

Género Kocakia Kaszab, 1981

84. Kocakia opaca (Kaszab, 1982)

Material examinado. Perú. 1 q, 1 ô, Piura, Catacaos, $5^{\circ} 15^{\prime} 42^{\prime \prime} \mathrm{S}-80^{\circ} 40^{\prime} 27^{\prime \prime} \mathrm{O}, 29 \mathrm{msnm}, 06-\mathrm{II}-2017$, U. González leg., red entomológica, Bosque estacionalmente seco de llanura; $2 \hat{\delta} \widehat{\delta}, 2$ 우, Piura, Universidad de Piura, $5^{\circ} 10^{\prime} 11^{\prime \prime} \mathrm{S}-80^{\circ} 36^{\prime} 51^{\prime \prime} \mathrm{O}, 29 \mathrm{msnm}, 26-\mathrm{II}-2016$, U. González leg., colecta manual, Bosque estacionalmente seco de llanura; 1 , 1 ภ, Piura, Castilla, Universidad Nacional de Piura, 5¹0'51"S-80³7'31"O, 29 msnm, 14-III-2018, G. Juárez leg., colecta manual, Bosque estacionalmente seco ribereño; 2 우, Sullana, Querecotillo, 450'24"S-80 $38^{\prime} 57^{\prime \prime} \mathrm{O}, 23 \mathrm{msnm}$, 19-I-2016, G. Juárez leg., agitación de follaje, Bosque estacionalmente seco de llanura; 1 ㅇ, 1 今, Paita, $5^{\circ} 04^{\prime} \mathrm{S}-81^{\circ} 06^{\prime} \mathrm{O}$, 10 msnm, 2-VIII-2017, G. Juárez leg., agitación de follaje, Bosque estacionalmente seco de llanura; 1 ㅇ, 2 ઈิ $\hat{\sigma}$, Talara, El Alto, $4^{\circ} 16^{\prime} 04^{\prime \prime} \mathrm{S}-81^{\circ} 13^{\prime} 09^{\prime \prime} \mathrm{O}, 300 \mathrm{msnm}, 13-\mathrm{V}-2016$, agitación de follaje, G. Juárez leg., Bosque estacionalmente seco de colina; $1 \mathrm{o}^{\top}$, Sechura, Vice, $5^{\circ} 25^{\prime} \mathrm{S}-81^{\circ} 46^{\prime} \mathrm{O}, 10 \mathrm{msnm}$, 2-II-2015, U. González leg., red entomológica, Desierto costero; 1 ㅇ, 1 ${ }^{\lambda}$, Sechura, Laguna Ñapique, $5^{\circ} 34^{\prime} \mathrm{S}-81^{\circ} 16^{\prime} \mathrm{O}$, 16 msnm, 24-VI-2019, U. González leg., agitación de follaje, Bosque estacionalmente seco ribereño; 2 우, $2 \hat{\jmath} \delta^{\lambda}$, Sechura,

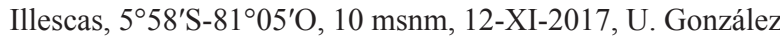
leg., agitación de follaje, Matorral Xérico; 1 ㅇ, Morropón, Chulucanas, $5^{\circ} 05^{\prime} \mathrm{S}-80^{\circ} 99^{\prime} \mathrm{O}$, $350 \mathrm{msnm}$, 05-III-2017, G. Juárez leg., colecta manual, Bosque estacionalmente seco de colina.

Distribución (Provincia) (Paisaje ecológico). (PIU, SUlL, PAi, TAL, SECH, MORR) (MatX, DESc, BESr, BESll, BESc-m).

COMEnTARIo. Los adultos se encuentran sobre hojas y ramas de plántulas y árboles, en solitario, también se encuentran en interior de troncos secos. Especie citada también por Juárez et al. (2016).

Género Sechuranus Flores \& Giraldo, 2019

85. Sechuranus barbatus (Kaszab, 1964)

Material eXAminado. PERÚ. 2 $\widehat{\jmath}, 2$ 우, 070 COL-GJN, Piura, Universidad de Piura, $5^{\circ} 10^{\prime} 11^{\prime \prime} \mathrm{S}-80^{\circ} 36^{\prime} 51^{\prime \prime} \mathrm{O}$, 29 msnm, 26-II-2016, U. González leg., colecta manual,
Bosque estacionalmente seco de llanura; 1 , Piura, Castilla, Universidad Nacional de Piura, $5^{\circ} 10^{\prime} 51^{\prime \prime} \mathrm{S}-80^{\circ} 37^{\prime} 31^{\prime \prime} \mathrm{O}$, 29 msnm, 14-III-2018, G. Juárez leg., colecta manual, Bosque estacionalmente seco ribereño; 1 + , Sullana, Querecotillo, 450'24"S-80³8'57"O, 23 msnm, 19-I-2016, G. Juárez leg., colecta manual, Bosque estacionalmente seco de llanura; 1 , 1 ว , Paita, $5^{\circ} 04^{\prime} \mathrm{S}-81^{\circ} 06^{\prime} \mathrm{O}, 10 \mathrm{msnm}, 2$-VIII-2017, G. Juárez leg., agitación de follaje, Bosque estacionalmente seco

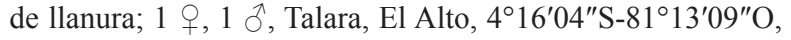
300 msnm, 13-V-2016, red entomológica, G. Juárez leg., Bosque estacionalmente seco de colina; $2 \hat{\jmath} \hat{\jmath}$, Sechura, Vice, $5^{\circ} 25^{\prime} \mathrm{S}-81^{\circ} 46^{\prime} \mathrm{O}, 10 \mathrm{msnm}, 2-\mathrm{II}-2015$, U. González leg., red entomológica, Desierto costero; 2 우, $1 \hat{\delta}$, Sechura, Laguna Ñapique, 53' $\mathrm{S}-81^{\circ} 16^{\prime} \mathrm{O}, 16$ msnm, 24-VI-2019, U. González leg., agitación de follaje, Bosque estacionalmente

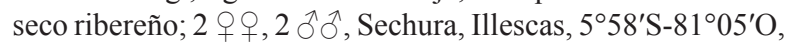
10 msnm, 12-XI-2017, U. González leg., agitación de

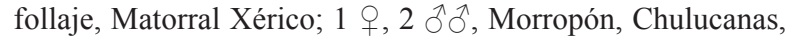
505'S-8099'O, 350 msnm, 05-III-2017, G. Juárez leg., colecta manual, Bosque estacionalmente seco de colina.

Distribución (Provincia) (Paisaje ecológico). (PIU, SUlL, PAi, TAL, SECH, MORR) (MatX, DESc, BESr, BESll, BESc-m).

Comentario. De acuerdo con Giraldo-Mendoza \& Flores (2019) se llegó a la conclusión de que la especie citada como Prohylitus sp en Juárez et al. (2016) se trata de S. barbatus. Los adultos se encuentran sobre hojas y ramas de plántulas y árboles, en solitario.

Subfamilia Tenebrioninae Latreille, 1802

Género Blapstinus Waterhouse, 1845

86. Blapstinus $\sin$ identificar sp. 1.

Material examinado. PERÚ. $2 \hat{o} \widehat{o}, 2$ $q$, , Piura, Universidad de Piura, 510'11"S-80³6'51"O, 29 msnm, 26-II-2016, U. González leg., colecta manual, Bosque estacionalmente seco de llanura; 1 , Piura, Castilla, Universidad Nacional de Piura, 5¹0'51"S-80³7'31"O, 29 msnm, 14-III-2018, G. Juárez leg., colecta manual, Bosque estacionalmente seco ribereño; 1 ㅇ, Sullana, Querecotillo, 450'24"S-80 $38^{\prime} 57^{\prime \prime} \mathrm{O}$, 23 msnm, 19-I-2016, G. Juárez leg., colecta manual, Bosque estacionalmente seco de llanura; 1 ㅇ, 1 $\delta$, Talara, El Alto, $4^{\circ} 16^{\prime} 04^{\prime \prime} \mathrm{S}-81^{\circ} 13^{\prime} 09^{\prime \prime} \mathrm{O}, 300 \mathrm{msnm}, 13-\mathrm{V}-2016$, red entomológica, G. Juárez leg., Bosque estacionalmente seco de colina; $2 \delta^{\lambda} \partial^{\lambda}$, Sechura, Vice, $5^{\circ} 25^{\prime} \mathrm{S}-81^{\circ} 46^{\prime} \mathrm{O}, 10 \mathrm{msnm}, 2-\mathrm{II}-2015$, U. González leg., red entomológica, Desierto costero; 2 우우, $1 \delta^{\lambda}$, Sechura, Laguna Napique, $5^{\circ} 34^{\prime} \mathrm{S}-81^{\circ} 16^{\prime} \mathrm{O}, 16 \mathrm{msnm}$, 24-VI-2019, U. González leg., agitación de follaje, Bosque estacionalmente seco ribereño; 2 우, $2 \overbrace{}^{\lambda} \delta^{\lambda}$, Sechura, Illescas, $5^{\circ} 58^{\prime} \mathrm{S}-81^{\circ} 05^{\prime} \mathrm{O}, 10 \mathrm{msnm}, 12-\mathrm{XI}-2017$, U. González leg., agitación de follaje, Matorral Xérico.

Distribución (Provincia) (PAisaje ecológico). (PIU, SUll, TAL, SECH) (MatX, DESc, BESr, BESll).

Comentario. Los adultos se encuentran a ras del suelo cercanos al tronco, sobre hojas y ramas de plántulas y árboles, en solitario. Especie citada también por Juárez et al. (2016).

\section{Género Ammophorus Guérin, 1830}

87. Ammophorus peruvianus Solier, 1838

Material examinado. Perú. 1 , Piura, Universidad de Piura, 5¹0'11"S-80³6'51"O, 29 msnm, 26-II-2016, U. González leg., colecta manual, Bosque estacionalmente seco de 1lanura; 2 우, Piura, Castilla, Universidad Nacional de Piura, 5¹0'51"S-80³7'31"O, 29 msnm, 14-III-2018, G. Juárez leg., colecta manual, Bosque estacionalmente seco ribereño; 1 ㅇ, 1 ठ․, Sullana, Querecotillo, $4^{\circ} 50^{\prime} 24^{\prime \prime} \mathrm{S}-80^{\circ} 38^{\prime} 57^{\prime \prime} \mathrm{O}$, 
23 msnm, 19-I-2016, G. Juárez leg., agitación de follaje, Bosque estacionalmente seco de llanura; 1 , 1 $\delta$, Talara, El Alto, $4^{\circ} 16^{\prime} 04^{\prime \prime} \mathrm{S}-81^{\circ} 13^{\prime} 09^{\prime \prime} \mathrm{O}, 300 \mathrm{msnm}, 13-\mathrm{V}-2016$, red entomológica, G. Juárez leg., Bosque estacionalmente seco de colina; $1 \partial^{\lambda}$, Sechura, Vice, $5^{\circ} 25^{\prime} \mathrm{S}-81^{\circ} 46^{\prime} \mathrm{O}, 10 \mathrm{msnm}, 2-\mathrm{II}-$ 2015, U. González leg., colecta manual, Desierto costero; 3 우, Sechura, Laguna Ñapique, $5^{\circ} 34^{\prime} \mathrm{S}-81^{\circ} 16^{\prime} \mathrm{O}, 16 \mathrm{msnm}$, 24-VI-2019, U. González leg., agitación de follaje, Bosque

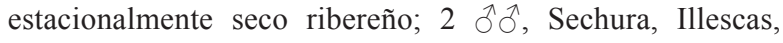
5 58 $8^{\prime} \mathrm{S}-81^{\circ} 05^{\prime} \mathrm{O}, 10 \mathrm{msnm}, 12-\mathrm{XI}-2017$, U. González leg.,

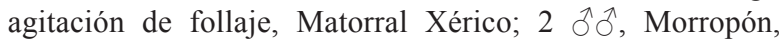
Chulucanas, 5 ${ }^{\circ} 05^{\prime} \mathrm{S}-80^{\circ} 99^{\prime} \mathrm{O}, 350 \mathrm{msnm}$, 05-III-2017, G. Juárez leg., colecta manual, Bosque estacionalmente seco de colina.

Distribución (Provincia) (Paisaje ecológico). (PIU, SUll, PAi, TAL, SECH, MORR) (MatX, DES, BESr, BESll, BESc-m).

Comentario. De acuerdo con Van Dyke (1953) se llegó a la conclusión de que la especie citada como Ammophorus rubripes en Juárez et al. (2016) corresponde a A. peruvianus. Los adultos se encuentran a ras del suelo cercanos al tronco y sobre hojas de plántulas y árboles, en solitario.

Género Pumiliofossorum Silvestro \& Giraldo, $2015 \dagger$

88. Pumiliofossorum sechurae Giraldo \& Flores, $2015 \dagger$

Material eXaminado. PERÚ. 3 9 , Piura, Universidad de Piura, 5¹0'11"S-80³6'51"O, 29 msnm, 26-II-2016, U. González leg., colecta manual, Bosque estacionalmente seco de llanura; 2 오오 1 ㄱ. Piura, Castilla, Universidad Nacional de Piura, 5 10'51"S-80³7'31"O, 29 msnm, 14-III-2018, G. Juárez leg., colecta manual, Bosque estacionalmente seco ribereño; 2 $\hat{\partial}^{\lambda} \hat{\sigma}^{\circ}$, Sechura, Vice, $5^{\circ} 25^{\prime} \mathrm{S}-81^{\circ} 46^{\prime} \mathrm{O}, 10 \mathrm{msnm}, 2-\mathrm{II}-2015$, U. González leg., colecta manual, Desierto costero.

Distribución (Provincia) (Paisaje ecológico). (PIU, SECH) (DESc, BESr, BESll,).

Comentario. Los adultos se encuentran siempre a ras del suelo y/o enterrados cercanos al tronco de plántulas y árboles, en solitario o en grupos de dos a cinco individuos.

Género Zophobas Dejean, 1834

89. Zophobas (Zophobas) opacus (Sahlberg, 1823)

Material examinado. Perú. 2 o 0,2 đ̃र, Piura, Catacaos, $5^{\circ} 15^{\prime} 42^{\prime \prime} \mathrm{S}-80^{\circ} 40^{\prime} 27^{\prime \prime} \mathrm{O}, \quad 29 \mathrm{msnm}, \quad 06-\mathrm{II}-2017$, U. González leg., colecta manual, Bosque estacionalmente seco de llanura; 1 ภ, 2 우, Piura, Universidad de Piura, 510'11"S-80³6'51"O, 29 msnm, 26-II-2016, U. González leg., colecta manual, Bosque estacionalmente seco de llanura; 3 우, 1 ô, Piura, Castilla, Universidad Nacional de Piura, 5¹0'51"S-80³7'31"O, 29 msnm, 14-III-2018, G. Juárez leg., colecta manual, Bosque estacionalmente seco ribereño; 2

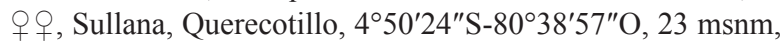
19-I-2016, G. Juárez leg., colecta manual, Bosque estacionalmente seco de llanura; 1 ㅇ, 1 ô, Paita, $5^{\circ} 04^{\prime} \mathrm{S}-81^{\circ} 06^{\prime} \mathrm{O}$, 10 msnm, 2-VIII-2017, G. Juárez leg., colecta manual, Bosque estacionalmente seco de llanura; $2 \hat{\jmath} \widehat{\partial}$, Talara, El Alto, $4^{\circ} 16^{\prime} 04^{\prime \prime} \mathrm{S}-81^{\circ} 13^{\prime} 09^{\prime \prime} \mathrm{O}, 300 \mathrm{msnm}, 13-\mathrm{V}-2016$, colecta manual, G. Juárez leg., Bosque estacionalmente seco de colina; 1 o, 1 ㅇ, Sechura, Vice, $5^{\circ} 25^{\prime} \mathrm{S}-81^{\circ} 46^{\prime} \mathrm{O}, 10 \mathrm{msnm}$, 2-II-2015, U. González leg., colecta manual, Desierto costero; 1 o, 1 ô, Sechura, Laguna Ñapique, $5^{\circ} 34^{\prime} \mathrm{S}-81^{\circ} 16^{\prime} \mathrm{O}$, 16 msnm, 24-VI-2019, U. González leg., colecta manual, Bosque estacionalmente seco ribereño; 1 , $1 \hat{\partial}$, Sechura, Illescas, $5^{\circ} 58^{\prime} \mathrm{S}-81^{\circ} 05^{\prime} \mathrm{O}, 10 \mathrm{msnm}, 12-\mathrm{XI}-2017$, U. González leg., colecta manual, Matorral Xérico; 2 우우, Morropón, Chulucanas, $5^{\circ} 05^{\prime} \mathrm{S}-80^{\circ} 99^{\prime} \mathrm{O}, 350 \mathrm{msnm}$, 05-III-2017, G.
Juárez leg., colecta manual, Bosque estacionalmente seco de colina; 2 우, Ayabaca, Suyo, $4^{\circ} 30^{\prime} 45^{\prime \prime} \mathrm{S}-80^{\circ} 00^{\prime} 10^{\prime \prime} \mathrm{O}$, 408 msnm, 23-X-2015, G. Juárez leg., colecta manual, Bosque estacionalmente seco de colina; 1 , 1 ๙ , Huancabamba, Huarmaca, 53 $34^{\prime} 04^{\prime \prime}$ S-79 $31^{\prime} 26^{\prime \prime} \mathrm{O}, 1223$ msnm, 26-VII-2016, G. Juárez leg., colecta manual, Bosque estacionalmente seco de colina.

Distribución (Provincia) (Paisaje ecológico). (PIU, SUlL, PAI, TAL, SECH, MORR, HUA, AYA) (MatX, DESc, BESr, BESll, BESc-m).

Comentario. Especie citada como Zophobas sp en Juárez \& González (2016a). Los adultos se encuentran a ras del suelo cercanos al tronco y sobre ramas de árboles, en solitario o en grupos de dos individuos.

Familia Meloidae Gyllenhal, $1810 \uparrow$

Nemognathinae Laporte, $1840 \dagger$

Género Zonitis Fabricius, $1775 \dagger$

90. Zonitis cantharoides Kaszab, $1960 \dagger$

Material examinado. $1 \hat{\jmath}$, Piura, Universidad de Piura, 5¹0'11"S-80³6'51"O, 29 msnm, 26-II-2016, U. González leg., colecta manual, Bosque estacionalmente seco de llanura; 1 , Piura, Castilla, Universidad Nacional de Piura, 5¹0'51"S-80³7'31"O, 29 msnm, 14-III-2018, G. Juárez leg., colecta manual, Bosque estacionalmente seco ribereño.

Distribución (Provincia) (Paisaje ecológico). (PIU) (BESr, BESIl).

Familia Anthicidae Latreille, $1819 \dagger$

Subfamilia Anthicinae Latreille, $1819 \dagger$

Género Ischyropalpus Bonadona, 1896 †

91. Ischyropalpus sericans (Erichson, 1834) $\dagger$

Material examinado. 1 , Piura, Universidad de Piura, 5¹0'11"S-80³6'51"O, 29 msnm, 26-II-2016, U. González leg., agitación de follaje, Bosque estacionalmente seco de llanura; 1 ㅇ, Piura, Castilla, Universidad Nacional de Piura, 5¹0'51"S-80³7'31"O, 29 msnm, 14-III-2018, G. Juárez leg., agitación de follaje, Bosque estacionalmente seco ribereño.

Distribución (Provincia) (Paisaje ecológico). (PIU) (BESr, BES11).

Comentario. Los adultos se encuentran sobre hojas y ramas de plántulas y árboles, en solitario. Insecto que se comporta como controlador biológico (Chandler, 2016).

Familia Cerambycidae Latreille, 1802

Subfamilia Cerambycinae Latreille, 1802

Género Achryson Audinet-Serville, 1833

92. Achryson lineolatum Erichson, 1847

Material examinado. $2 \hat{\jmath} \hat{o}, 1 \hat{\jmath}$, Piura, Universidad de Piura, 5॰10'11"S-80³6'51"O, 29 msnm, 13-II-2014, U. González leg., colecta manual, Bosque estacionalmente seco de llanura;

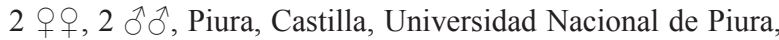
5 $10^{\prime} 51^{\prime \prime} \mathrm{S}-80^{\circ} 37^{\prime} 31^{\prime \prime} \mathrm{O}, 29 \mathrm{msnm}, 14-\mathrm{III}-2017$, G. Juárez leg., colecta manual, Bosque estacionalmente ribereño; 1 , Sullana, Lancones, $4^{\circ} 38^{\prime} 27^{\prime \prime} \mathrm{S}-80^{\circ} 32^{\prime} 55^{\prime \prime} \mathrm{O}, 190 \mathrm{msnm}$, 20-XII-2015, G. Juárez leg., colecta manual, Bosque estacionalmente seco de colina; 1 ㅇ, Paita, $5^{\circ} 04^{\prime} \mathrm{S}-81^{\circ} 06^{\prime} \mathrm{O}$, 10 msnm, 2-VIII-2017, G. Juárez leg., colecta manual, Bosque estacionalmente seco de llanura; 1 ㅇ, 1 $\hat{O}$, Talara, Los Órganos, $4^{\circ} 10^{\prime} 38^{\prime \prime} \mathrm{S}-81^{\circ} 07^{\prime} 27^{\prime \prime} \mathrm{O}, 12 \mathrm{msnm}, 15-\mathrm{IV}-$ 2016, G. Juárez leg., colecta manual, Desierto costero; 1 q, $2 \widehat{\partial} \hat{O}^{\lambda}$, Sechura, Vice, $5^{\circ} 25^{\prime} \mathrm{S}-81^{\circ} 46^{\prime} \mathrm{O}, 10 \mathrm{msnm}, 2-\mathrm{II}-2017$, U. González leg., colecta manual, Desierto costero; 1 ㅇ, Sechura, Illescas, $5^{\circ} 58^{\prime} \mathrm{S}-81^{\circ} 05^{\prime} \mathrm{O}, 10 \mathrm{msnm}, 12-\mathrm{XI}-2017$, U. 


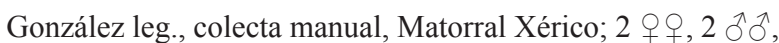
Morropón, Chulucanas, $5^{\circ} 05^{\prime} \mathrm{S}-80^{\circ} 99^{\prime} \mathrm{O}, 350 \mathrm{msnm}, 05-\mathrm{III}-$ 2017, G. Juárez leg., colecta manual, Bosque estacionalmente seco de colina.

Distribución (Provincia) (Paisaje ecológico). (PIU, SUlL, PAi, TAL, SECH, MORR) (DESc, BESr, BESll, BESc-m).

COMENTARIO. Los adultos se encuentran sobre ramas y troncos de árboles, en solitario, las larvas en el interior de troncos. Insecto que se comporta como fitófago, larvas barrenan el interior del tronco, los adultos descortezan exterior del tronco. La cantidad de individuos colectados aumentó en época de lluvia (diciembre-marzo). Especie citada también por Juárez et al. (2016), Domínguez (1982) la reporta como Achryson galapagoensis Linell, 1898, mientras que Núñez-Sacarías (1993) la cita como Achryson philippii Germain, 1897.

Género Eburia Lacordaire, 1830

93. Eburia (Eburia) pilosa (Erichson, 1834)

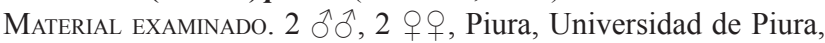
510'11"S-80³6'51"O, 29 msnm, 13-II-2014, U. González leg., colecta manual, Bosque estacionalmente seco de llanura; 2 웅, $2 \hat{\jmath} \widehat{\jmath}$, Piura, Castilla, Universidad Nacional de Piura, 5 10'51"S-80³7'31"O, 29 msnm, 14-III-2017, G. Juárez leg., colecta manual, Bosque estacionalmente ribereño; 1 ,

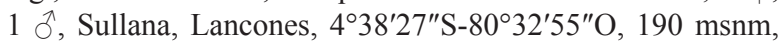
20-XII-2015, G. Juárez leg., colecta manual, Bosque estacionalmente seco de colina; 2 우, $1 \hat{\sigma^{\lambda}}$, Paita, $5^{\circ} 04^{\prime} \mathrm{S}-81^{\circ} 06^{\prime} \mathrm{O}$, 10 msnm, 2-VIII-2017, G. Juárez leg., colecta manual, Bosque estacionalmente seco de llanura; 1 $+1 \hat{\widehat{\partial}}$, Talara, Los Órganos, $4^{\circ} 10^{\prime} 38^{\prime \prime} \mathrm{S}-81^{\circ} 07^{\prime} 27^{\prime \prime} \mathrm{O}, 12$ msnm, 15-IV-2016, G. Juárez leg.,

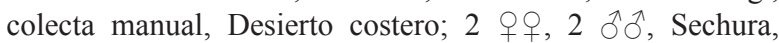
Vice, $5^{\circ} 25^{\prime} \mathrm{S}-81^{\circ} 46^{\prime} \mathrm{O}, 10 \mathrm{msnm}, 2-\mathrm{II}-2017$, U. González leg., colecta manual, Desierto costero; 1 ㅇ, 1 ऽ, Sechura, Illescas, $5^{\circ} 58^{\prime} \mathrm{S}-81^{\circ} 05^{\prime} \mathrm{O}, 10 \mathrm{msnm}, 12-\mathrm{XI}-2017$, U. González leg.,

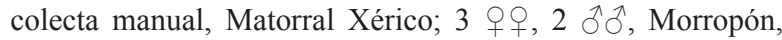
Chulucanas, $5^{\circ} 05^{\prime} \mathrm{S}-80^{\circ} 99^{\prime} \mathrm{O}, 350 \mathrm{msnm}, 05-\mathrm{III}-2017$, G. Juárez leg., colecta manual, Bosque estacionalmente seco de colina; 2 우, $1 \delta^{\top}$, Ayabaca, Suyo, $4^{\circ} 30^{\prime} 45^{\prime \prime} \mathrm{S}-80^{\circ} 00^{\prime} 10^{\prime \prime} \mathrm{O}$, 408 msnm, 23-X-2015, G. Juárez leg., colecta manual, Bosque estacionalmente seco de colina; 1 9, Huancabamba,

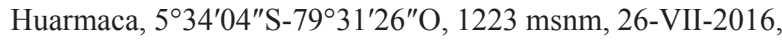
G. Juárez leg., colecta manual, Bosque estacionalmente seco de colina.

Distribución (Provincia) (Paisaje ecológico). (PIU, SUll, PAi, TAL, SECH, MORR, AYA, HUA) (MatX, DESc, BESr, BESll, BESc-m).

COMENTARIO. Los adultos se encuentran sobre ramas y troncos de árboles, en solitario, las larvas en galerías en el interior de troncos. Insecto que se comporta como fitófago, larvas barrenan el interior del tronco, los adultos descortezan exterior del tronco. La cantidad de individuos colectados aumentó en época de lluvia (diciembre-marzo). Especie citada también por Domínguez (1982) y Juárez et al. (2016).

\section{Eburia rufobrunnea Perroud, $1855+$}

Material examinado. 1 $\hat{\lambda}, 1$ o, Piura, Universidad de Piura, $5^{\circ} 10^{\prime} 11^{\prime \prime} \mathrm{S}-80^{\circ} 36^{\prime} 51^{\prime \prime} \mathrm{O}, 29 \mathrm{msnm}, 13-\mathrm{II}-2014$, U. González leg., colecta manual, Bosque estacionalmente seco de llanura; 1 ㅇ, 1 ô, Piura, Castilla, Universidad Nacional de Piura, $5^{\circ} 10^{\prime} 51^{\prime \prime} \mathrm{S}-80^{\circ} 37^{\prime} 31^{\prime \prime} \mathrm{O}, 29 \mathrm{msnm}, 14-\mathrm{III}-2017$, G. Juárez leg., colecta manual, Bosque estacionalmente ribereño; 1 , 1 ô, Talara, Los Órganos, $4^{\circ} 10^{\prime} 38^{\prime \prime} \mathrm{S}-81^{\circ} 07^{\prime} 27^{\prime \prime} \mathrm{O}, 12 \mathrm{msnm}$ 15-IV-2016, G. Juárez leg., colecta manual, Desierto costero.
Distribución (Provincia) (Paisaje ecológico). (PIU, TAL) (DESc, BESr, BESll).

Comentario. Los adultos se encuentran sobre ramas y troncos de árboles, en solitario, las larvas en galerías en el interior de troncos. Insecto que se comporta como fitófago, larvas barrenan el interior del tronco, los adultos descortezan exterior del tronco.

Género Heterachthes Newman, 1840

95. Heterachthes pallidipennis (Thomson, 1865)

Material examinado. 2 q 9,073 COL-GJN, Piura, Universidad

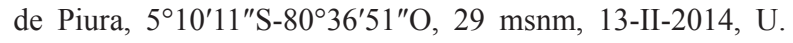
González leg., colecta manual, Bosque estacionalmente seco de llanura; $2 \widehat{\partial} \hat{\jmath}$, Piura, Castilla, Universidad Nacional de Piura, 510'51"S-80³7'31"O, 29 msnm, 14-III-2017, G. Juárez leg., colecta manual, Bosque estacionalmente ribereño;

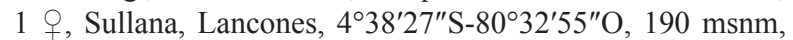
20-XII-2015, G. Juárez leg., colecta manual, Bosque estacionalmente seco de colina; $1 \hat{\jmath}$, Paita, $5^{\circ} 04^{\prime} \mathrm{S}-81^{\circ} 06^{\prime} \mathrm{O}$, 10 msnm, 2-VIII-2017, G. Juárez leg., colecta manual, Bosque estacionalmente seco de llanura; 1 + , Talara, Los Órganos, $4^{\circ} 10^{\prime} 38^{\prime \prime} \mathrm{S}-81^{\circ} 07^{\prime} 27^{\prime \prime} \mathrm{O}, 12$ msnm, 15-IV-2016, G. Juárez leg., colecta manual, Desierto costero.

Distribución (Provincia) (Paisaje ecológico). (PIU, SUlL, PAi, TAL) (DESc, BESr, BESIl).

Comentario. Especie citada como Heterachthes sp en Juárez et al. (2016). Los adultos se encuentran sobre ramas y troncos de árboles, en solitario. Insecto que se comporta como fitófago.

Género Obrium Dejean, $1821 \uparrow$

96. Obrium circunflexum Martins \& Galileo $2004 \dagger$

Material examinado. 1 q, Piura, Universidad de Piura, 5¹0'11"S-80³6'51"O, 29 msnm, 13-II-2014, U. González leg., colecta manual, Bosque estacionalmente seco de lla-

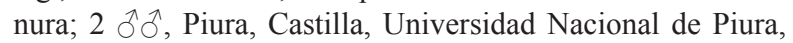
5¹0'51"S-80³7'31"O, 29 msnm, 14-III-2017, G. Juárez leg., colecta manual, Bosque estacionalmente ribereño.

Distribución (Provincia) (Paisaje ecológico). (PIU) (BESr, BES11).

Comentario. Los adultos se encuentran sobre ramas y troncos de árboles, en solitario. Insecto que se comporta como fitófago.

Subfamilia Lamiinae Latreille, $1825 \dagger$

Género Nesozineus Linsley \& Chemsak, $1966 \dagger$

97. Nesozineus peruanus Galileo \& Martins $2007 \dagger$

Material examinado. 3 우, $2 \hat{\jmath} \hat{\jmath}$, Piura, Universidad de Piura, 5¹0'11"S-80³6'51"O, 29 msnm, 13-II-2014, U. González leg., colecta manual, Bosque estacionalmente seco de llanura; 2 ㅅํ, 2 우우, Piura, Castilla, Universidad Nacional de Piura, 5¹0'51"S-80³7'31"O, 29 msnm, 14-III-2017, G. Juárez leg., colecta manual, Bosque estacionalmente ribereño; $1 \hat{\partial}$, Piura, Catacaos, 510'11"S-80³6'51"O, 29 msnm, 13-VII-2016, U. González leg., colecta manual, Bosque estacionalmente seco de llanura.

Distribución (Provincia) (Paisaje ecológico). (PIU) (BESr, BES11).

Comentario. Los adultos se encuentran sobre ramas y troncos de árboles, en solitario. Insecto que se comporta como fitófago. La cantidad de individuos colectados aumentó en época de lluvia (diciembre-marzo).

98. Nesozineus probolus Galileo \& Martins, $1996 \dagger$

Material examinado. 2 우, $2 \hat{\jmath} \hat{\jmath}$, Piura, Universidad de Piura, 5¹0'11"S-80³6'51"O, 29 msnm, 13-II-2014, U. González 
leg., colecta manual, Bosque estacionalmente seco de llanura; $3 \widehat{\jmath} \delta^{\wedge}, 3$ 우, Piura, Castilla, Universidad Nacional de Piura, $5^{\circ} 10^{\prime} 51^{\prime \prime} \mathrm{S}-80^{\circ} 37^{\prime} 31^{\prime \prime} \mathrm{O}, 29$ msnm, 14-III-2017, G. Juárez leg., colecta manual, Bosque estacionalmente ribereño; 1 त, 1 ㅇ, Piura, Catacaos, $5^{\circ} 10^{\prime} 11^{\prime \prime} \mathrm{S}-80^{\circ} 36^{\prime} 51^{\prime \prime} \mathrm{O}, 29 \mathrm{msnm}, 13-\mathrm{VII}-$ 2016, U. González leg., colecta manual, Bosque estacionalmente seco de llanura.

Distribución (Provincia) (Paisaje ecológico). (PIU) (BESr, BESIl).

Comentario. Los adultos se encuentran sobre ramas y troncos de árboles, en solitario. Insecto plaga que se comporta como fitófago. La cantidad de individuos colectados aumentó en época de lluvia (diciembre-marzo).

Familia Chrysomelidae Latreille, 1802

Subfamilia Bruchinae Latreille, 1802

Género Amblycerus Thunberg, 1815

99. Amblycerus piurae (Pierce, 1915)

Material examinado. 2 웅, Piura, Universidad de Piura, 5¹0'11"S-80³6'51"O, 29 msnm, 13-II-2014, U. González leg., colecta manual, Bosque estacionalmente seco de llanura; $2 \hat{\jmath} \widehat{\partial}$, Piura, Castilla, Universidad Nacional de Piura, 5 $10^{\prime} 51^{\prime \prime} \mathrm{S}-80^{\circ} 37^{\prime} 31^{\prime \prime} \mathrm{O}, 29 \mathrm{msnm}, 14-\mathrm{III}-2017$, G. Juárez leg., agitación de follaje, Bosque estacionalmente ribereño; $1 \partial^{\lambda}$, Sullana, Lancones, $4^{\circ} 38^{\prime} 27^{\prime \prime} \mathrm{S}-80^{\circ} 32^{\prime} 55^{\prime \prime} \mathrm{O}, 190 \mathrm{msnm}$, 20-XII-2015, G. Juárez leg., agitación de follaje, Bosque estacionalmente seco de colina; 1 ㅇ, 1 $\hat{\jmath}$, Paita, $5^{\circ} 04^{\prime} \mathrm{S}-81^{\circ} 06^{\prime} \mathrm{O}$, 10 msnm, 2-VIII-2017, G. Juárez leg., agitación de follaje, Bosque estacionalmente seco de llanura; $1 \hat{\jmath}$, Talara, Los Órganos, $4^{\circ} 10^{\prime} 38^{\prime \prime} \mathrm{S}-81^{\circ} 07^{\prime} 27^{\prime \prime} \mathrm{O}, 12 \mathrm{msnm}, 15-\mathrm{IV}-2016$, G. Juárez leg., colecta manual, Desierto costero; 2 우, 1 o, Sechura, Vice, $5^{\circ} 25^{\prime} \mathrm{S}-81^{\circ} 46^{\prime} \mathrm{O}, 10 \mathrm{msnm}, 2-\mathrm{II}-2017$, U.

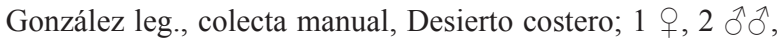
Morropón, Chulucanas, $5^{\circ} 05^{\prime} \mathrm{S}-80^{\circ} 99^{\prime} \mathrm{O}, 350 \mathrm{msnm}$, 05-III2017, G. Juárez leg., colecta manual, Bosque estacionalmente seco de colina. Distribución (Provincia) (Paisaje ecológico). (PIU, SULL, PAI, TAL, SECH, MORR) (DESc, BESr, BESIl, BESc-m).

Comentario. Los adultos se encuentran sobre hojas y frutos de plántulas y árboles, en solitario o en grupos de dos a más individuos, las larvas se encuentran en el interior de frutos. Insecto que se comporta como fitófago, las larvas y adultos se alimentan de frutos maduros e inmaduros. Especie citada también por Domínguez (1982), Núñez-Sacarías (1993) y Juárez et al. (2016).

Género Acanthoscelides Schilsky, 1905

100. Acanthoscelides obtectus (Say, 1831).

Material examinado. Perú. 2 $9+9,077$ COL-GJN, Piura, Universidad de Piura, $5^{\circ} 10^{\prime} 11^{\prime \prime} \mathrm{S}-80^{\circ} 36^{\prime} 51^{\prime \prime} \mathrm{O}, 29 \mathrm{msnm}$, 13-II-2014, U. González leg., colecta manual, Bosque estacionalmente seco de llanura; 2 우, $1 \hat{\jmath}$, Piura, Castilla, Universidad Nacional de Piura, $5^{\circ} 10^{\prime} 51^{\prime \prime} \mathrm{S}-80^{\circ} 37^{\prime} 31^{\prime \prime} \mathrm{O}$, 29 msnm, 14-III-2017, G. Juárez leg., agitación de follaje, Bosque estacionalmente ribereño; 2 우우, 1 ㄱ, Sullana, Lancones, 438'27"S-80³2'55"O, 190 msnm, 20-XII-2015, G. Juárez leg., agitación de follaje, Bosque estacionalmente seco de colina; 1 ㅇ, 1 ${ }^{\lambda}$, Paita, $5^{\circ} 04^{\prime} \mathrm{S}-81^{\circ} 06^{\prime} \mathrm{O}, 10 \mathrm{msnm}$, 2-VIII-2017, G. Juárez leg., colecta manual, Bosque estacionalmente seco de llanura; 3 우, $1 \hat{\jmath}$, Talara, Los Órganos, $4^{\circ} 10^{\prime} 38^{\prime \prime S}-81^{\circ} 07^{\prime} 27^{\prime \prime} \mathrm{O}, 12$ msnm, 15-IV-2016, G. Juárez leg., agitación de follaje, Desierto costero; 2 우, 1 스, Sechura, Vice, $5^{\circ} 25^{\prime} \mathrm{S}-81^{\circ} 46^{\prime} \mathrm{O}, 10 \mathrm{msnm}, 2-\mathrm{II}-2017$, U. González

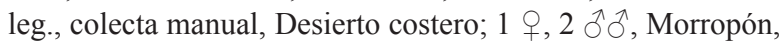

Chulucanas, $5^{\circ} 05^{\prime} \mathrm{S}-80^{\circ} 99^{\prime} \mathrm{O}, 350 \mathrm{msnm}, 05-\mathrm{III}-2017$, G. Juárez leg., colecta manual, Bosque estacionalmente seco de colina.

Distribución (Provincia) (Paisaje ecológico). (PIU, SUlL, PAI, TAL, SECH, MORR) (DESc, BESr, BESll, BESc-m).

Comentario. Especie citada como Acanthoscelides sp en Juárez et al. (2016). Los adultos se encuentran sobre hojas y frutos de plántulas y árboles, en solitario o en grupos de dos o más individuos, las larvas se encuentran en el interior de frutos. Insecto que se comporta como fitófago, las larvas y adultos se alimentan del fruto maduro e inmaduro.

\section{Acanthoscelides suramerica Johnson, $1990 \dagger$}

Material examinado. PERÚ. 2 9 , Piura, Universidad de Piura, 5¹0'11"S-80³6'51"O, 29 msnm, 13-II-2014, U. González leg., agitación de follaje, Bosque estacionalmente seco de llanura; 2 우, Piura, Castilla, Universidad Nacional de Piura, 5¹0'51"S-80³7'31"O, 29 msnm, 14-III-2017, G. Juárez leg., agitación de follaje, Bosque estacionalmente ribereño.

Distribución (Provincia) (Paisaje ecológico). (PIU) (BESr, BES11).

Comentario. Los adultos se encuentran sobre hojas y frutos de plántulas y árboles, en solitario o en grupos de dos individuos, las larvas se encuentran en el interior de frutos. Insecto que se comporta como fitófago, las larvas y adultos se alimentan del fruto maduro e inmaduro.

\section{Género Callosobruchus Pic, 1902}

102. Callosobruchus maculatus (Fabricius, 1775)

Material examinado. PERÚ. 2 우, Piura, Castilla, Universidad Nacional de Piura, 5 $5^{\circ} 0^{\prime} 51^{\prime \prime} \mathrm{S}-80^{\circ} 37^{\prime} 31^{\prime \prime} \mathrm{O}, 29 \mathrm{msnm}, 2-\mathrm{II}-$ 2015, U. González leg., agitación de follaje, Bosque estacionalmente seco ribereño; 2 우, Piura, Universidad de Piura, 5 10'11"S-80³6'51"O, 29 msnm, 13-II-2014, U. González leg., agitación de follaje, Bosque estacionalmente seco de llanura; 1 क, Sullana, Salitral, 451'27"S-8040'52"O, 40 msnm, 6-IV-2016, G. Juárez leg., colecta manual, Bosque estacionalmente seco de llanura; 1 ㅇ, $1 \hat{\jmath}$, Talara, Lobitos, $4^{\circ} 27^{\prime} 10^{\prime \prime} \mathrm{S}-81^{\circ} 16^{\prime} 40^{\prime \prime} \mathrm{O}, 12$ msnm, 27-VI-2014, G. Juárez leg., red entomológica, Desierto costero; 3 우, Sechura, Desierto de Sechura, $5^{\circ} 34^{\prime} \mathrm{S}-81^{\circ} 16^{\prime} \mathrm{O}, 10 \mathrm{msnm}, 13-\mathrm{XII}-2013$, G. Juárez leg., agitación de follaje, Desierto costero.

Distribución (Provincia) (PAisaje ecológico). (PIU, SULL, TAL, SECH) (DESc, BESr, BESIl).

Comentario. Los adultos se encuentran sobre hojas y frutos de plántulas y árboles, en solitario o en grupos de dos o más individuos, las larvas se encuentran en el interior de frutos. Insecto que se comporta como fitófago, larvas y adultos se alimentan de fruto maduro e inmaduro. Especie citada también por Juárez et al. (2016).

\section{Subfamilia Galerucinae Latreille, 1802}

Género Diabrotica Chevrolat, 1837

103. Diabrotica speciosa Baly, 1886

Material examinado. PERÚ. 2 + 9 , Piura, Universidad de Piura, 5¹0'11"S-80³6'51"O, 29 msnm, 04-IV-2015, U. González leg., red entomológica, Bosque estacionalmente seco de llanura; 3 우, Piura, Castilla, Universidad Nacional de Piura, 5¹0'51"S-80³7'31"O, 29 msnm, 2-II-2015, U. González leg., agitación de follaje, Bosque estacionalmente seco ribe-

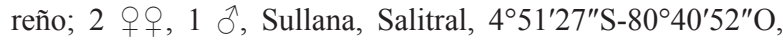
23 msnm, 28-X-2017, G. Juárez leg., red entomológica, Bosque estacionalmente seco de llanura; 1 , $1 \hat{\jmath}$, Talara, El Alto, $4^{\circ} 16^{\prime} 04^{\prime \prime} \mathrm{S}-81^{\circ} 13^{\prime} 09^{\prime \prime} \mathrm{O}, 5 \mathrm{msnm}, 23-\mathrm{IV}-2015$, G. 
Juárez leg., red entomológica, Desierto; 2 우, Sullana, Miguel Checa, $4^{\circ} 54^{\prime} \mathrm{S}-80^{\circ} 48^{\prime} \mathrm{O}, 10 \mathrm{msnm}, 12-\mathrm{III}-2016$, G. Juárez leg., agitación de follaje, Bosque estacionalmente seco de llanura; 1 †, 1 ô, Paita, $5^{\circ} 04^{\prime} \mathrm{S}-81^{\circ} 06^{\prime} \mathrm{O}, 10 \mathrm{msnm}$, 2-VIII-2017, G. Juárez leg., colecta manual, Bosque esta-

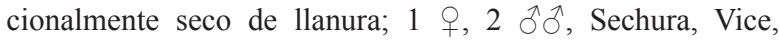
525'S-8146'O, 10 msnm, 17-VIII-2015, U. González leg., colecta manual, Desierto costero; 2 우, Sechura, Illescas, $5^{\circ} 58^{\prime} \mathrm{S}-81^{\circ} 05^{\prime} \mathrm{O}, 10 \mathrm{msnm}, 12-\mathrm{XI}-2017$, U. González leg., colecta manual, Matorral Xérico; 2 + 505'51"S-8009'44"O, 557 msnm, 14-V-2017, G. Juárez leg., agitación de follaje, Bosque estacionalmente seco de colina;

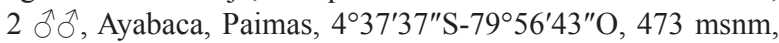
26-VII-2015, G. Juárez leg., agitación de follaje, Bosque estacionalmente seco de llanura; 1 , , Huancabamba, Huarmaca, 5³4'04"S-79³1'26"O, 1223 msnm, 26-VII-2016, G. Juárez leg., red entomológica, Bosque estacionalmente seco de colina.

Distribución (Provincia) (Paisaje ecológico). (PIU, SUlL, PAI, TAL, SECH, MORR, AYA, HUA) (MatX, DESc, BESr, BESll, BESc-m).

Comentario. Los adultos se encuentran sobre hojas y ramas de plántulas y árboles, en solitario o en grupos de dos o más individuos. Insecto que se comporta como fitófago. Especie citada también por Juárez et al. (2016).

104. Diabrotica septemliturata Erichson, 1847

Material examinado. PERÚ. 2 우, Piura, Universidad de Piura, 5 10'11"S-80³6'51"O, 29 msnm, 04-IV-2015, U. González leg., red entomológica, Bosque estacionalmente seco de llanura; 2 우, Piura, Castilla, Universidad Nacional de Piura, 5¹0'51"S-80³7'31"O, 29 msnm, 2-II-2015, U. González leg., agitación de follaje, Bosque estacionalmente seco ribereño.

Distribución (Provincia) (Paisaje ecológico). (PIU) (BESr, BESII).

Comentario. Especie citada como Diabrotica neolineatum en Juárez et al. (2016) el cual pasó a ser sinónimo de D. septemliturata (Derunkov et al., 2013). Adultos se encuentran sobre hojas y ramas de plántulas y árboles, en solitario. Insecto que se comporta como fitófago.

Subfamilia Cryptocephalinae Gyllenhal, 1813

Género Cryptocephalus Geoffroy, 1762

105. Cryptocephalus sin identificar sp. 1.

Material examinado. PERÚ. 1 q, Piura, Universidad de Piura, 5¹0'11"S-80³6'51"O, 29 msnm, 04-IV-2015, U. González leg., agitación de follaje, Bosque estacionalmente seco de llanura; 2 우, Piura, Castilla, Universidad Nacional de Piura, 5¹0'51"S-80³7'31"O, 29 msnm, 2-II-2015, U. González leg., agitación de follaje, Bosque estacionalmente seco ribereño; 2 우, 1 ô, Sullana, Salitral, $4^{\circ} 51^{\prime} 27^{\prime \prime} \mathrm{S}-80^{\circ} 40^{\prime} 52^{\prime \prime} \mathrm{O}$ 23 msnm, 28-X-2017, G. Juárez leg., red entomológica, Bosque estacionalmente seco de llanura; $1 \hat{\jmath}$, Talara, El Alto, $4^{\circ} 16^{\prime} 04^{\prime \prime} \mathrm{S}-81^{\circ} 13^{\prime} 09^{\prime \prime} \mathrm{O}, 5 \mathrm{msnm}, 23-\mathrm{IV}-2015$, G. Juárez leg., colecta manual, Desierto; 1 \&, Sullana, Miguel Checa, 454'S-8048'O, 10 msnm, 12-III-2016, G. Juárez leg., agitación de follaje, Bosque estacionalmente seco de llanura; $1 \hat{\jmath}$, Paita, 504'S-81 ${ }^{\circ} 06^{\prime} \mathrm{O}, 10$ msnm, 2-VIII-2017, G. Juárez leg., colecta manual, Bosque estacionalmente seco de llanura; 1 , 1 ô, Sechura, Vice, $5^{\circ} 25^{\prime} \mathrm{S}-81^{\circ} 46^{\prime} \mathrm{O}, 10 \mathrm{msnm}, 17-\mathrm{VIII}-2015$, U. González leg., colecta manual, Desierto costero; 2 우우, Morropón, Morropón, 505'51"S-8009'44"O, 557 msnm, 14-V-2017, G. Juárez leg., agitación de follaje, Bosque estacionalmente seco de colina.
Distribución (Provincia) (Paisaje ecológico). (PIU, SUlL, PAi, TAL, SECH, MORR) (DESc, BESr, BESIl, BESc-m).

Comentario. Los adultos se encuentran sobre hojas y ramas de plántulas y árboles, en solitario. Insecto que se comporta como fitófago. Especie citada también por Domínguez (1982) y Juárez et al. (2016).

Subfamilia Eumolpinae Hope, $1840 \dagger$

Género Myochrous Dejean, $1837 \dagger$

106. Myochrous geminus Blake, $1950 \dagger$

Material examinado. PERÚ. 2 9 , Piura, Castilla, Universidad Nacional de Piura, 5 $5^{\circ} 0^{\prime} 51^{\prime \prime} \mathrm{S}-80^{\circ} 37^{\prime} 31^{\prime \prime} \mathrm{O}, 29 \mathrm{msnm}, 2-\mathrm{II}-$ 2015, U. González leg., agitación de follaje, Bosque estacionalmente seco ribereño.

Distribución (Provincia) (Paisaje ecológico). (PIU) (BESr).

Comentario. Los adultos se encuentran sobre hojas y ramas de plántulas y árboles, en solitario o en grupos de dos individuos o más. Insecto que se comporta como fitófago.

Familia Curculionidae Latreille, 1802

Subfamilia Entiminae Schöenherr, 1823

Género Pandeleteius Schöenherr, 1834

107. Pandeleteius variegatus (Pierce, 1915).

Material examinado. Perú. 2 oq, 079 COL-GJN, Piura, Universidad de Piura, $5^{\circ} 10^{\prime} 11^{\prime \prime} \mathrm{S}-80^{\circ} 36^{\prime} 51^{\prime \prime} \mathrm{O}, 29 \mathrm{msnm}$, 04-IV-2015, U. González leg., agitación de follaje, Bosque estacionalmente seco de llanura; 2 우, Piura, Castilla, Universidad Nacional de Piura, $5^{\circ} 10^{\prime} 51^{\prime \prime} \mathrm{S}-80^{\circ} 37^{\prime} 31^{\prime \prime} \mathrm{O}$, 29 msnm, 2-II-2015, U. González leg., agitación de follaje, Bosque estacionalmente seco ribereño; 1 , 1 $\hat{\jmath}$, Sullana, Salitral, 451'27"S-8040'52"O, 23 msnm, 28-X-2017, G. Juárez leg., colecta manual, Bosque estacionalmente seco de llanura; $1 \partial^{\lambda}$, Talara, El Alto, $4^{\circ} 16^{\prime} 04^{\prime \prime} \mathrm{S}-81^{\circ} 13^{\prime} 09^{\prime \prime} \mathrm{O}, 5 \mathrm{msnm}$, 23-IV-2015, G. Juárez leg., red entomológica, Desierto; 1 ㅇ, Sullana, Miguel Checa, $4^{\circ} 54^{\prime} \mathrm{S}-80^{\circ} 48^{\prime} \mathrm{O}, 10 \mathrm{msnm}, 12-\mathrm{III}-$ 2016, G. Juárez leg., red entomológica, Bosque estacionalmente seco de llanura; 1 o , Paita, $5^{\circ} 04^{\prime} \mathrm{S}-81^{\circ} 06^{\prime} \mathrm{O}, 10 \mathrm{msnm}$, 2-VIII-2017, G. Juárez leg., colecta manual, Bosque estacionalmente seco de llanura; 1 +, $1 \hat{\jmath}$, Sechura, Vice, 5²5'S-81ํ6' O, 10 msnm, 17-VIII-2015, U. González leg., red entomológica, Desierto costero; 1 \%, Sechura, Illescas, 5 58 $8^{\prime} \mathrm{S}-81^{\circ} 05^{\prime} \mathrm{O}, 10 \mathrm{msnm}, 12-\mathrm{XI}-2017$, U. González leg., colecta manual, Matorral Xérico; 2 우, 1 đૈ, Morropón, Morropón, 505'51"S-8009'44"O, 557 msnm, 14-V-2017, G. Juárez leg., agitación de follaje, Bosque estacionalmente seco de colina; 2 우, Huancabamba, Huarmaca, 5³4'04"S-79³1'26"O, 1223 msnm, 26-VII-2016, G. Juárez leg., red entomológica, Bosque estacionalmente seco de colina.

Distribución (Provincia) (Paisaje ecológico). (PIU, SUlL, PAi, TAL, SECH, MORR, HUA) (MatX, DESc, BESr, BESll, BESc-m).

Comentario. Especie citada como Pandeleteius sp en Juárez et al. (2016). Los adultos se encuentran sobre hojas y ramas de plántulas y árboles, en solitario. Insecto que se comporta como fitófago.

Género Eustylus Sahlberg, $1823 \dagger$

108. Eustylus humilis (Erichson, 1847) †

Material examinado. Perú. 1 \%, Piura, Universidad de Piura, 5¹0'11"S-80³6'51"O, 29 msnm, 04-IV-2015, U. González leg., agitación de follaje, Bosque estacionalmente seco de llanura; 1 , , Piura, Castilla, Universidad Nacional de Piura, 5¹0'51"S-80³7'31"O, 29 msnm, 2-II-2015, U. González 
leg., agitación de follaje, Bosque estacionalmente seco ribe-

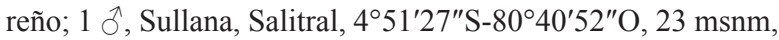
28-X-2017, G. Juárez leg., colecta manual, Bosque estacionalmente seco de llanura; 1 , , Sullana, Miguel Checa, 454'S-8048'O, 10 msnm, 12-III-2016, G. Juárez leg., red entomológica, Bosque estacionalmente seco de llanura; $1 \hat{\partial}$, Paita, $5^{\circ} 04^{\prime} \mathrm{S}-81^{\circ} 06^{\prime} \mathrm{O}, 10 \mathrm{msnm}, 2-\mathrm{VIII}-2017$, G. Juárez leg., colecta manual, Bosque estacionalmente seco de llanura.

Distribución (Provincia) (Paisaje ecológico). (PIU, SUlL, PAi) (BESr, BESIl).

Comentario. Los adultos se encuentran sobre hojas y ramas de plántulas y árboles, en solitario. Insecto que se comporta como fitófago. Especie citada también por Domínguez (1982) como Eustylomorphus squamipunctatus Pierce, 1915.

Orden DIPTERA Linnaeus, 1758

Suborden Nematocera Durimel, 1805

Familia Cecidomyiidae Newman, 1835

Subfamilia Cecidomyiinae

Género Enallodiplosis Gagné, 1994

109. Enallodiplosis discordis Gagné, 1994 (Fig. 13)

Material examinado. PERÚ. 2 우, 083-DIP-GJN, Piura,

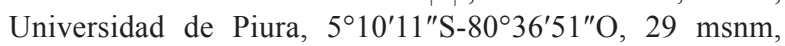
04-IV-2015, U. González leg., red entomológica, Bosque estacionalmente seco de llanura; 1 9, Piura, Castilla, Universidad Nacional de Piura, $5^{\circ} 10^{\prime} 51^{\prime \prime} \mathrm{S}-80^{\circ} 37^{\prime} 31^{\prime \prime} \mathrm{O}$, 29 msnm, 2-II-2015, U. González leg., red entomológica, Bosque estacionalmente seco ribereño; 1 ภे, Sullana, Salitral, 451'27"S-8040'52"O, 23 msnm, 28-X-2017, G. Juárez leg., red entomológica, Bosque estacionalmente seco de llanura; 1 ô., Talara, El Alto, $4^{\circ} 16^{\prime} 04^{\prime \prime} \mathrm{S}-81^{\circ} 13^{\prime} 09^{\prime \prime} \mathrm{O}, 5 \mathrm{msnm}$, 23-IV-2015, G. Juárez leg., red entomológica, Desierto; 1 ㅇ, Sullana, Miguel Checa, $4^{\circ} 54^{\prime} \mathrm{S}-80^{\circ} 48^{\prime} \mathrm{O}, 10 \mathrm{msnm}$, 12-III-2016, G. Juárez leg., red entomológica, Bosque estacionalmente seco de llanura; 1 $\partial^{\lambda}$, Paita, $5^{\circ} 04^{\prime} \mathrm{S}-81^{\circ} 06^{\prime} \mathrm{O}$, 10 msnm, 2-VIII-2017, G. Juárez leg., red entomológica, Bosque estacionalmente seco de llanura; 1 , 1 ㄱ, Sechura, Vice, $5^{\circ} 25^{\prime} \mathrm{S}-81^{\circ} 46^{\prime} \mathrm{O}, 10 \mathrm{msnm}, 17-\mathrm{VIII}-2015$, U. González leg., red entomológica, Desierto costero; 1 †, Morropón, Morropón, $5^{\circ} 05^{\prime} 51^{\prime \prime} \mathrm{S}-80^{\circ} 09^{\prime} 44^{\prime \prime} \mathrm{O}, 557 \mathrm{msnm}, 14-\mathrm{V}-2017$, G. Juárez leg., red entomológica, Bosque estacionalmente seco de colina.

Distribución (Provincia) (Paisaje ecológico). (PIU, SULL, PAi, TAL, SECH, MORR) (DESc, BESr, BES1l, BESc-m).

Comentario. Especie citada como Enallodiplosis sp en Juárez et al. (2016). Los adultos y larvas se encuentran en hojas de plántulas y arboles, en solitario o grupo de dos a cuatro individuos. Insecto que se comporta como fitófago, larvas causan defoliación (Gagné \& Whaley, 2020).

Suborden Brachycera Macquart, 1834

Familia Bombyliidae Latreille, 1802

Subfamilia Anthracinae Latreille,

Género Villa Lioy, 1864

110. Villa sin identificar sp. 1.

Material examinado. PERÚ. 1 , Piura, Universidad de Piura, $5^{\circ} 10^{\prime} 11^{\prime \prime} \mathrm{S}-80^{\circ} 36^{\prime} 51^{\prime \prime} \mathrm{O}, 29 \mathrm{msnm}, 04-\mathrm{IV}-2015$, U. González leg., red entomológica, Bosque estacionalmente seco de llanura; 1 , Piura, Castilla, Universidad Nacional de Piura, 5 $10^{\prime} 51^{\prime \prime} \mathrm{S}-80^{\circ} 37^{\prime} 31^{\prime \prime} \mathrm{O}, 29 \mathrm{msnm}, 2-\mathrm{II}-2015$, U. González leg., red entomológica, Bosque estacionalmente seco ribereño; 2 ठิ ô, Sullana, Salitral, $4^{\circ} 51^{\prime} 27^{\prime \prime} \mathrm{S}-80^{\circ} 40^{\prime} 52^{\prime \prime} \mathrm{O}$, 23 msnm, 28-X-2017, G. Juárez leg., red entomológica, Bosque estacionalmente seco de llanura; $1 \hat{\jmath}$, Talara, El Alto,
4¹6'04"S-81¹3'09"O, 5 msnm, 23-IV-2015, G. Juárez leg., red entomológica, Desierto; 2 우, Sullana, Miguel Checa, 454'S-8048'O, 10 msnm, 12-III-2016, G. Juárez leg., red entomológica, Bosque estacionalmente seco de llanura; 1 , Paita, $5^{\circ} 04^{\prime} \mathrm{S}-81^{\circ} 06^{\prime} \mathrm{O}, 10 \mathrm{msnm}, 2-\mathrm{VIII}-2017$, G. Juárez leg., red entomológica, Bosque estacionalmente seco de llanura; 1 ․ Sechura, Vice, $5^{\circ} 25^{\prime} \mathrm{S}-81^{\circ} 46^{\prime} \mathrm{O}, 10 \mathrm{msnm}, 17-\mathrm{VIII}-2015$, U. González leg., red entomológica, Desierto costero; 1 ㅇ, Morropón, Morropón, 505'51"S-8009'44"O, $557 \mathrm{msnm}$, 14-V-2017, G. Juárez leg., red entomológica, Bosque estacionalmente seco de colina.

Distribución (Provincia) (Paisaje ecológico). (PIU, SUll, PAi, TAL, SECH, MORR) (DESc, BESr, BESll, BESc-m).

COMENTARIO. Los adultos se encuentran sobrevolando y/o posadas sobre las inflorescencias en árboles, también se les encuentra posadas sobre hojas de plántulas y árboles, en solitario. Insecto que se comporta como polinizador (Toro et al., 1993; Chiappa et al., 1997; Toro, 2002). Especie citada también por Juárez et al. (2016).

Género Hemipenthes Loew, 1861

111. Hemipenthes sin identificar sp. 1.

Material examinado. PERÚ. 2 o $o$, Piura, Universidad de Piura, 510'11"S-80³6'51"O, 29 msnm, 04-IV-2015, U. González leg., red entomológica, Bosque estacionalmente seco de llanura; 1 ㅇ, Piura, Castilla, Universidad Nacional de Piura, $5^{\circ} 10^{\prime} 51^{\prime \prime} \mathrm{S}-80^{\circ} 37^{\prime} 31^{\prime \prime} \mathrm{O}, 29 \mathrm{msnm}, 2-\mathrm{II}-2015$, U. González leg., red entomológica, Bosque estacionalmente seco ribereño; 1 ô, Sullana, Salitral, $4^{\circ} 51^{\prime} 27^{\prime \prime} \mathrm{S}-80^{\circ} 40^{\prime} 52^{\prime \prime} \mathrm{O}$, 23 msnm, 28-X-2017, G. Juárez leg., red entomológica, Bosque estacionalmente seco de llanura; 1 ㅇ, Talara, El Alto, $4^{\circ} 16^{\prime} 04^{\prime \prime} \mathrm{S}-81^{\circ} 13^{\prime} 09^{\prime \prime} \mathrm{O}, 5$ msnm, 23-IV-2015, G. Juárez leg., red entomológica, Desierto; 1 †, Sullana, Miguel Checa, 454'S-8048'O, 10 msnm, 12-III-2016, G. Juárez leg., red entomológica, Bosque estacionalmente seco de llanura; 1 ते, Paita, 504'S-81 ${ }^{\circ} 06^{\prime} \mathrm{O}, 10$ msnm, 2-VIII-2017, G. Juárez leg., red entomológica, Bosque estacionalmente seco de llanura; 1 ㅇ, Sechura, Vice, $5^{\circ} 25^{\prime} \mathrm{S}-81^{\circ} 46^{\prime} \mathrm{O}, 10 \mathrm{msnm}, 17-\mathrm{VIII}-2015$, U. González leg., red entomológica, Desierto costero; 1 우, Morropón, Morropón, 505'51"S-8009'44"O, 557 msnm, 14-V-2017, G. Juárez leg., red entomológica, Bosque estacionalmente seco de colina.

Distribución (Provincia) (Paisaje ecológico). (PIU, SUll, PAi, TAL, SECH, MORR) (DESc, BESr, BESll, BESc-m).

Comentario. Los adultos se encuentran sobrevolando y/o posadas sobre inflorescencias en árboles, también se les encuentra posadas sobre hojas de plántulas y árboles, en solitario. Insecto que se comporta como polinizador (Toro et al., 1993; Chiappa et al., 1997; Toro, 2002). Especie citada también por Juárez et al. (2016).

Género Thyridanthrax Osten Sacken, 1886

112. Thyridanthrax sin identificar sp. 1.

Material examinado. PERÚ. 2 우 Piura, Universidad de

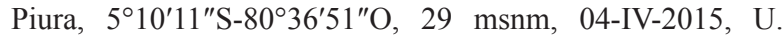
González leg., red entomológica, Bosque estacionalmente seco de llanura; 2 우, Piura, Castilla, Universidad Nacional

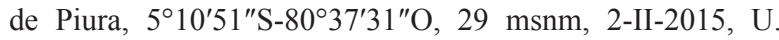
González leg., red entomológica, Bosque estacionalmente seco ribereño; 1 ${ }^{\prime}$, Sullana, Salitral, $4^{\circ} 51^{\prime} 27^{\prime \prime} \mathrm{S}-80^{\circ} 40^{\prime} 52^{\prime \prime} \mathrm{O}$, 23 msnm, 28-X-2017, G. Juárez leg., red entomológica, Bosque estacionalmente seco de llanura; 1 , Talara, El Alto, $4^{\circ} 16^{\prime} 04^{\prime \prime} \mathrm{S}-81^{\circ} 13^{\prime} 09^{\prime \prime} \mathrm{O}, 5$ msnm, 23-IV-2015, G. Juárez leg., red entomológica, Desierto; 1 +, Sullana, Miguel Checa, 
454'S-8048'O, 10 msnm, 12-III-2016, G. Juárez leg., red entomológica, Bosque estacionalmente seco de llanura; 1 , Paita, $5^{\circ} 04^{\prime} \mathrm{S}-81^{\circ} 06^{\prime} \mathrm{O}, 10 \mathrm{msnm}, 2-\mathrm{VIII}-2017$, G. Juárez leg., red entomológica, Bosque estacionalmente seco de llanura; 1 , Sechura, Vice, $5^{\circ} 25^{\prime} \mathrm{S}-81^{\circ} 46^{\prime} \mathrm{O}, 10 \mathrm{msnm}, 17-\mathrm{VIII}-2015$, U. González leg., red entomológica, Desierto costero; 1 ㅇ, Morropón, Morropón, 505'51"S-8009'44"O, 557 msnm, 14-V-2017, G. Juárez leg., red entomológica, Bosque estacionalmente seco de colina.

Distribución (Provincia) (Paisaje ecológico). (PIU, SUlL, PAi, TAL, SECH, MORR) (DESc, BESr, BESIl, BESc-m).

COMENTARIO. Los adultos se encuentran sobrevolando y/o posadas sobre inflorescencias en árboles, también se les encuentra posadas sobre hojas de plántulas y árboles, en solitario. Especie citada también por Juárez et al. (2016).

Familia Asilidae Latreille, $1802 \dagger$

Subfamilia Asilinae Latreille, $1802 \dagger$

Género Efferia Coquillett, $1893 \dagger$

113. Efferia sin identificar sp. $1 . \dagger$

Material examinado. Perú. 1 , Piura, Universidad de Piura, 5¹0'11"S-80³6'51"O, 29 msnm, 04-IV-2015, U. González leg., red entomológica, Bosque estacionalmente seco de llanura; 2 q $\circ$, Piura, Castilla, Universidad Nacional de Piura, 5¹0'51"S-80³7'31"O, 29 msnm, 2-II-2015, U. González leg., red entomológica, Bosque estacionalmente seco ribereño; 1 q, 1 Oे, Sullana, Salitral, 451'27"S-8040'52"O, 23 msnm, 28-X-2017, G. Juárez leg., red entomológica, Bosque estacionalmente seco de llanura; 1 , 1 $\hat{\text {, }}$, Talara, El Alto, $4^{\circ} 16^{\prime} 04^{\prime \prime} \mathrm{S}-81^{\circ} 13^{\prime} 09^{\prime \prime} \mathrm{O}, 5 \mathrm{msnm}, 23-\mathrm{IV}-2015$, G. Juárez leg., red entomológica, Desierto; 1 , , Sullana, Miguel Checa, $4^{\circ} 54^{\prime} \mathrm{S}-80^{\circ} 48^{\prime} \mathrm{O}, 10 \mathrm{msnm}, 12-\mathrm{III}-2016$, G. Juárez leg., red entomológica, Bosque estacionalmente seco de llanura; $1 \hat{\jmath}$, Paita, 504'S-81 ${ }^{\circ} 06^{\prime} \mathrm{O}, 10$ msnm, 2-VIII-2017, G. Juárez leg., red entomológica, Bosque estacionalmente seco de llanura; 1 q, 1 ô, Sechura, Vice, $5^{\circ} 25^{\prime} \mathrm{S}-81^{\circ} 46^{\prime} \mathrm{O}, 10 \mathrm{msnm}, 17$-VIII2015, U. González leg., red entomológica, Desierto costero; 1 ㅇ, Sechura, Illescas, $5^{\circ} 58^{\prime} \mathrm{S}-81^{\circ} 05^{\prime} \mathrm{O}, 10 \mathrm{msnm}, 12-\mathrm{XI}-2017$, U. González leg., red entomológica, Matorral Xérico; 2 우, 1 Ђิ, Morropón, Morropón, 505'51"S-8009'44"O, 557 msnm, 14-V-2017, G. Juárez leg., red entomológica, Bosque estacionalmente seco de colina; $2 \hat{\delta} \hat{\delta}, 1$ क , Ayabaca, Paimas, 4³7'37"S-7956'43"O, 473 msnm, 26-VII-2015, G. Juárez leg., red entomológica, Bosque estacionalmente seco de llanura; 1 , Huancabamba, Huarmaca, $5^{\circ} 34^{\prime} 04^{\prime \prime} \mathrm{S}-79^{\circ} 31^{\prime} 26^{\prime \prime} \mathrm{O}$, 1223 msnm, 26-VII-2016, G. Juárez leg., red entomológica, Bosque estacionalmente seco de colina.

Distribución (Provincia) (Paisaje ecológico). (PIU, SUlL, PAi, TAL, SECH, MORR, AYA, HUA) (MatX, DESc, BESr, BES1l, BESc-m).

Comentario. Los adultos se encuentran sobre hojas, ramas, troncos de plántulas y árboles, en solitario. Insecto que se comporta como controlador biológico. Especie citada también por Domínguez (1982).

Subfamilia Laphriinae Macquart, $1838 \dagger$

Género Atomosia Macquart, $1838 \dagger$

114. Atomosia $\sin$ identificar sp. $1 . \dagger$

Material eXaminado. PERÚ. 1 \%, Piura, Universidad de Piura, 5¹0'11"S-80³6'51"O, 29 msnm, 04-IV-2015, U. González leg., red entomológica, Bosque estacionalmente seco de llanura; 1 , Piura, Castilla, Universidad Nacional de Piura, 510'51"S-80³7'31"O, 29 msnm, 2-II-2015, U. González leg., red entomológica, Bosque estacionalmente seco

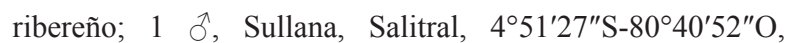
23 msnm, 28-X-2017, G. Juárez leg., red entomológica, Bosque estacionalmente seco de llanura; $1 \hat{\jmath}$, Talara, El Alto, $4^{\circ} 16^{\prime} 04^{\prime \prime} \mathrm{S}-81^{\circ} 13^{\prime} 09^{\prime \prime} \mathrm{O}, 5$ msnm, 23-IV-2015, G. Juárez leg., red entomológica, Desierto; 1 + , Sullana, Miguel Checa, $4^{\circ} 54^{\prime} \mathrm{S}-80^{\circ} 48^{\prime} \mathrm{O}, 10 \mathrm{msnm}, 12-\mathrm{III}-2016$, G. Juárez leg., red entomológica, Bosque estacionalmente seco de llanura; 1 ㅇ, Paita, $5^{\circ} 04^{\prime} \mathrm{S}-81^{\circ} 06^{\prime} \mathrm{O}, 10 \mathrm{msnm}, 2-\mathrm{VIII}-2017$, G. Juárez leg., red entomológica, Bosque estacionalmente seco de llanura; 1 q, Sechura, Vice, $5^{\circ} 25^{\prime} \mathrm{S}-81^{\circ} 46^{\prime} \mathrm{O}, 10 \mathrm{msnm}, 17-\mathrm{VIII}-2015$, U. González leg., red entomológica, Desierto costero; 1 \&, Sechura, Illescas, $5^{\circ} 58^{\prime} \mathrm{S}-81^{\circ} 05^{\prime} \mathrm{O}, 10 \mathrm{msnm}$, 12-XI-2017, U. González leg., red entomológica, Matorral Xérico; 1 స, Morropón, Morropón, 505'51"S-8009'44"O, 557 msnm, 14-V-2017, G. Juárez leg., red entomológica, Bosque estacionalmente seco de colina.

Distribución (Provincia) (Paisaje ecológico). (PIU, SUll, PAI, TAL, SECH, MORR) (MatX, DESc, BESr, BESll, BESc-m).

Comentario. Los adultos se encuentran sobre hojas, ramas, troncos de plántulas y árboles, en solitario. Insecto que se comporta como controlador biológico.

Familia Therevidae Newman, 1834

Subfamilia Therevinae Newman,

Género Notiothereva Metz \& Irwin, 2003

115. Notiothereva bezzii (Kröber, 1911)

Material eXaminado. PERÚ. $1+$, 084DIP-GJN, Piura, Universidad de Piura, 5¹0'11"S-80³6'51"O, 29 msnm, 04-IV-2015, U. González leg., red entomológica, Bosque estacionalmente seco de llanura; 2 우, Piura, Castilla, Universidad Nacional de Piura, 5¹0'51"S-80³7'31"O, 29 msnm, 2-II-2015, U. González leg., red entomológica, Bosque estacionalmente seco ribereño; 1 ô, 1 ㅇ, Sullana, Salitral, 451'27"S-8040'52"O, 23 msnm, 28-X-2017, G. Juárez leg., red entomológica, Bosque estacionalmente seco de llanura; 1 $\partial, 1$ ㅇ, Talara, El Alto, $4^{\circ} 16^{\prime} 04^{\prime \prime} \mathrm{S}-81^{\circ} 13^{\prime} 09^{\prime \prime} \mathrm{O}, 5$ msnm, 23-IV-2015, G. Juárez leg., red entomológica, Desierto; 2 우, Sullana, Miguel Checa, 454'S-8048'O, 10 msnm, 12-III-2016, G. Juárez leg., red entomológica, Bosque estacionalmente seco de llanura; 2 우우, Paita, $5^{\circ} 04^{\prime} \mathrm{S}-81^{\circ} 06^{\prime} \mathrm{O}, 10$ msnm, 2-VIII-2017, G. Juárez leg., red entomológica, Bosque estacionalmente seco de llanura; 1 q, Sechura, Vice, $5^{\circ} 25^{\prime} \mathrm{S}-81^{\circ} 46^{\prime} \mathrm{O}, 10 \mathrm{msnm}, 17$-VIII2015, U. González leg., red entomológica, Desierto costero; 2 우우, Sechura, Illescas, $5^{\circ} 58^{\prime} \mathrm{S}-81^{\circ} 05^{\prime} \mathrm{O}, 10 \mathrm{msnm}, 12$-XI2017, U. González leg., red entomológica, Matorral Xérico;

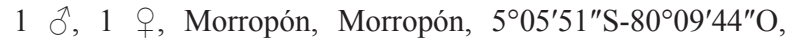
557 msnm, 14-V-2017, G. Juárez leg., red entomológica, Bosque estacionalmente seco de colina.

Distribución (Provincia) (Paisaje ecológico). (PIU, SUll, PAi, TAL, SECH, MORR) (MatX, DESc, BESr, BESll, BESc-m).

Comentario. Especie citada como morfoespecie 1 en Juárez et al. (2016). Los adultos se encuentran sobre hojas, ramas, troncos de plántulas y árboles, en solitario. Insecto que se comporta como controlador biológico.

Género Penniverpa Irwing \& Lyneborg, $1981 \dagger$

116. Penniverpa gracilis (Kröber, 1911) $\dagger$

Material examinado. Perú. 1 $\widehat{\partial}$, Piura, Universidad de Piura, 5¹0'11"S-80³6'51"O, 29 msnm, 04-IV-2015, U. González leg., red entomológica, Bosque estacionalmente seco de llanura; 1 , Piura, Castilla, Universidad Nacional de Piura, 5¹0'51"S-80³7'31"O, 29 msnm, 2-II-2015, U. González leg., red entomológica, Bosque estacionalmente seco ribe-

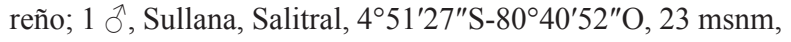


28-X-2017, G. Juárez leg., red entomológica, Bosque estacionalmente seco de llanura; 1 $\hat{\sigma}, 1$ क, Talara, El Alto, $4^{\circ} 16^{\prime} 04^{\prime \prime} \mathrm{S}-81^{\circ} 13^{\prime} 09^{\prime \prime} \mathrm{O}, 5$ msnm, 23-IV-2015, G. Juárez leg., red entomológica, Desierto; 1 \%, Sullana, Miguel Checa, 454'S-8048'O, 10 msnm, 12-III-2016, G. Juárez leg., red entomológica, Bosque estacionalmente seco de llanura; 1 , Paita, $5^{\circ} 04^{\prime} \mathrm{S}-81^{\circ} 06^{\prime} \mathrm{O}, 10 \mathrm{msnm}, 2$-VIII-2017, G. Juárez leg., red entomológica, Bosque estacionalmente seco de llanura; 1 ㅇ, Sechura, Vice, $5^{\circ} 25^{\prime} \mathrm{S}-81^{\circ} 46^{\prime} \mathrm{O}, 10 \mathrm{msnm}, 17-\mathrm{VIII}-2015$, U. González leg., red entomológica, Desierto costero; 2 우, Sechura, Illescas, $5^{\circ} 58^{\prime} \mathrm{S}-81^{\circ} 05^{\prime} \mathrm{O}, 10 \mathrm{msnm}, 12-\mathrm{XI}-2017$, U. González leg., red entomológica, Matorral Xérico; 1 , Morropón, Morropón, 505'51"S-8009'44"O, 557 msnm, 14-V-2017, G. Juárez leg., red entomológica, Bosque estacionalmente seco de colina.

Distribución (Provincia) (Paisaje ecológico). (PIU, SUll, PAi, TAL, SECH, MORR) (MatX, DESc, BESr, BESll, BESc-m).

ComentaRIo. Los adultos se encuentran sobre hojas, ramas, troncos de plántulas y árboles, en solitario. Insecto que se comporta como controlador biológico.

Familia Tabanidae Latreille, $1802 \uparrow$

Subfamilia Tabaninae Latreille, $1802 \uparrow$

Género Tabanus Linnaeus, 1758 †

117. Tabanus occidentalis dorsovittatus Macquart, $1855 \dagger$

Material examinado. PERÚ. 1 $\hat{\jmath}$, Piura, Universidad de Piura, $5^{\circ} 10^{\prime} 11^{\prime \prime} \mathrm{S}-80^{\circ} 36^{\prime} 51^{\prime \prime} \mathrm{O}, 29 \mathrm{msnm}, 04-\mathrm{IV}-2015$, U. González leg., red entomológica, Bosque estacionalmente seco de llanura; 1 , , Piura, Castilla, Universidad Nacional de Piura, 5¹0'51"S-80³7'31"O, 29 msnm, 2-II-2015, U. González leg., red entomológica, Bosque estacionalmente seco ribereño; $1 \stackrel{\partial}{ }$, Sullana, Salitral, $4^{\circ} 51^{\prime} 27^{\prime \prime} \mathrm{S}-80^{\circ} 40^{\prime} 52^{\prime \prime} \mathrm{O}$, 23 msnm, 28-X-2017, G. Juárez leg., red entomológica, Bosque estacionalmente seco de llanura; 1 $\hat{\text {, }}$, Morropón, Morropón, 505'51"S-8009'44"O, 557 msnm, 14-V-2017, G. Juárez leg., red entomológica, Bosque estacionalmente seco de colina.

Distribución (Provincia) (Paisaje ecológico). (PIU, SUlL, MORR) (BESr, BESIl, BESc-m).

Comentario. Los adultos se encuentran sobre hojas de plántulas y árboles, así como también a ras del suelo cercano al tronco, en solitario.

Familia Dolichopodidae Latreille, 1809

Subfamilia Sciapodinae Becker, 1917

Género Condylostylus Bigot, 1859

118. Condylostylus sin identificar sp. 1.

Material eXaminado. PeRÚ. 3 우, Piura, Universidad de Piura, $5^{\circ} 10^{\prime} 11^{\prime \prime} \mathrm{S}-80^{\circ} 36^{\prime} 51^{\prime \prime} \mathrm{O}, 29 \mathrm{msnm}, 04-\mathrm{IV}-2015$, U. González leg., red entomológica, Bosque estacionalmente seco de llanura; 4 우, Piura, Castilla, Universidad Nacional de Piura, $5^{\circ} 10^{\prime} 51^{\prime \prime} \mathrm{S}-80^{\circ} 37^{\prime} 31^{\prime \prime} \mathrm{O}, 29 \mathrm{msnm}, 2-\mathrm{II}-2015$, U. González leg., red entomológica, Bosque estacionalmente seco ribe-

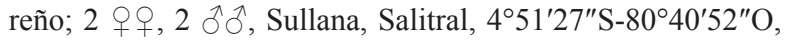
23 msnm, 28-X-2017, G. Juárez leg., red entomológica, Bosque estacionalmente seco de llanura; 1 ㅇ, $2 \hat{\partial} \hat{\partial}$, Talara, El Alto, $4^{\circ} 16^{\prime} 04^{\prime \prime} \mathrm{S}-81^{\circ} 13^{\prime} 09^{\prime \prime} \mathrm{O}, 5$ msnm, 23-IV-2015, G. Juárez leg., red entomológica, Desierto; 2 우, Sullana, Miguel Checa, 45ㄴ' $\mathrm{S}-80^{\circ} 48^{\prime} \mathrm{O}, 10 \mathrm{msnm}, 12-\mathrm{III}-2016$, G. Juárez leg., red entomológica, Bosque estacionalmente seco de lla-

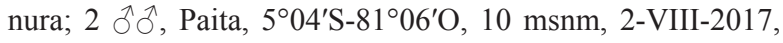
G. Juárez leg., red entomológica, Bosque estacionalmente seco de llanura; $1 \stackrel{+, 2}{2} \partial^{\lambda}$, Sechura, Vice, $5^{\circ} 25^{\prime} \mathrm{S}-81^{\circ} 46^{\prime} \mathrm{O}$, 10 msnm, 17-VIII-2015, U. González leg., red entomológica,
Desierto costero; 2 우오, Sechura, Illescas, $5^{\circ} 58^{\prime} \mathrm{S}-81^{\circ} 05^{\prime} \mathrm{O}$, 10 msnm, 12-XI-2017, U. González leg., red entomológica, Matorral Xérico; 2 우, 2 $\widehat{\jmath}$, Morropón, Morropón, $5^{\circ} 05^{\prime} 51^{\prime \prime} \mathrm{S}-80^{\circ} 09^{\prime} 44^{\prime \prime} \mathrm{O}, 557$ msnm, 14-V-2017, G. Juárez leg., red entomológica, Bosque estacionalmente seco de colina; $2 \delta^{\Uparrow} \mathrm{o}^{\lambda}, 2$ 우, Ayabaca, Paimas, $4^{\circ} 37^{\prime} 37^{\prime \prime} \mathrm{S}-79^{\circ} 56^{\prime} 43^{\prime \prime} \mathrm{O}$, 473 msnm, 26-VII-2015, G. Juárez leg., red entomológica, Bosque estacionalmente seco de llanura; $2 \circ$, , Huancabamba, Huarmaca, 5³4'04"S-79³1'26"O, 1223 msnm, 26-VII-2016, G. Juárez leg., red entomológica, Bosque estacionalmente seco de colina.

Distribución (Provincia) (Paisaje ecológico). (PIU, SUlL, PAi, TAL, SECH, MORR, AYA, HUA) (MatX, DESc, BESr, BESIl, BESc-m).

COMENTARIO. Especie muy activa, se encuentra sobre hojas y ramas de plántulas y árboles, en solitario o grupo de dos a cuatro individuos. Insecto que se comporta como controlador biológico. Especie citada también Núñez-Sacarías (1993) y Juárez et al. (2016).

Familia Syrphidae Latreille, 1802

Subfamilia Eristalinae Newman, 1834

Género Ornidia Lepeletier \& Serville, 1828

119. Ornidia obesa (Fabricius, 1775)

Material examinado. PeRÚ. 1 , Piura, Universidad de Piura, 5¹0'11"S-80³6'51"O, 29 msnm, 04-IV-2015, U. González leg., red entomológica, Bosque estacionalmente seco de llanura; 1 , Piura, Castilla, Universidad Nacional de Piura, 5¹0'51"S-80³7'31"O, 29 msnm, 2-II-2015, U. González leg., red entomológica, Bosque estacionalmente seco ribereño; 1 ô, Sullana, Salitral, $4^{\circ} 51^{\prime} 27^{\prime \prime} \mathrm{S}-80^{\circ} 40^{\prime} 52^{\prime \prime} \mathrm{O}$, 23 msnm, 28-X-2017, G. Juárez leg., red entomológica, Bosque estacionalmente seco de llanura; 1 , Talara, El Alto, $4^{\circ} 16^{\prime} 04^{\prime \prime S}-81^{\circ} 13^{\prime} 09^{\prime \prime} \mathrm{O}, 5$ msnm, 23-IV-2015, G. Juárez leg., red entomológica, Desierto; 1 ․, Sullana, Miguel Checa, 454'S-8048'O, 10 msnm, 12-III-2016, G. Juárez leg., red entomológica, Bosque estacionalmente seco de llanura; 1 స̃, Paita, $5^{\circ} 04^{\prime} \mathrm{S}-81^{\circ} 06^{\prime} \mathrm{O}, 10 \mathrm{msnm}, 2$-VIII-2017, G. Juárez leg., red entomológica, Bosque estacionalmente seco de llanura; $1 \delta^{\lambda}$, Sechura, Vice, $5^{\circ} 25^{\prime} \mathrm{S}-81^{\circ} 46^{\prime} \mathrm{O}, 10 \mathrm{msnm}, 17$-VIII2015, U. González leg., red entomológica, Desierto costero; 1 ㅇ, Sechura, Illescas, $5^{\circ} 58^{\prime} \mathrm{S}-81^{\circ} 05^{\prime} \mathrm{O}, 10 \mathrm{msnm}, 12-\mathrm{XI}-$ 2017, U. González leg., red entomológica, Matorral Xérico;

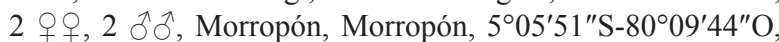
557 msnm, 14-V-2017, G. Juárez leg., red entomológica, Bosque estacionalmente seco de colina; 1 , Ayabaca, Paimas, 4³7'37"S-7956'43"O, 473 msnm, 26-VII-2015, G. Juárez leg., red entomológica, Bosque estacionalmente seco de lla-

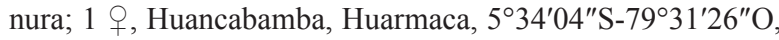
1223 msnm, 26-VII-2016, G. Juárez leg., red entomológica, Bosque estacionalmente seco de colina.

Distribución (Provincia) (Paisaje ecológico). (PIU, SUll, PAi, TAL, SECH, MORR, AYA, HUA) (MatX, DESc, BESr, BESll, BESc-m).

Comentario. Los adultos se encuentran sobre hojas y ramas de plántulas y árboles, sobrevolando y/o posadas sobre inflorescencias. Insecto que se comporta como polinizador (Gilbert, 1981). Especie citada también por Juárez et al. (2016).

Género Palpada Macquart, 1854

120. Palpada sin identificar sp. 1.

Material examinado. PERÚ. 1 , Piura, Universidad de Piura, 5¹0'11"S-80³6'51"O, 29 msnm, 04-IV-2015, U. González 
leg., red entomológica, Bosque estacionalmente seco de llanura; 1 q, Piura, Castilla, Universidad Nacional de Piura, $5^{\circ} 10^{\prime} 51^{\prime \prime} \mathrm{S}-80^{\circ} 37^{\prime} 31^{\prime \prime} \mathrm{O}, 29$ msnm, 2-II-2015, U. González leg., red entomológica, Bosque estacionalmente seco ribereño; 1 ㅇ, Sullana, Salitral, $4^{\circ} 51^{\prime} 27^{\prime \prime} \mathrm{S}-80^{\circ} 40^{\prime} 52^{\prime \prime} \mathrm{O}$, 23 msnm, 28-X-2017, G. Juárez leg., red entomológica, Bosque estacionalmente seco de llanura; 1 , Talara, El Alto, $4^{\circ} 16^{\prime} 04^{\prime \prime} \mathrm{S}-81^{\circ} 13^{\prime} 09^{\prime \prime} \mathrm{O}, 5$ msnm, 23-IV-2015, G. Juárez leg., red entomológica, Desierto; 1 +, Sullana, Miguel Checa, $4^{\circ} 54^{\prime} \mathrm{S}-80^{\circ} 48^{\prime} \mathrm{O}$, $10 \mathrm{msnm}, 12-\mathrm{III}-2016$, G. Juárez leg., red entomológica, Bosque estacionalmente seco de llanura; $1 \hat{\widehat{\partial}}$, Paita, 504'S-8106'O, 10 msnm, 2-VIII-2017, G. Juárez leg., red entomológica, Bosque estacionalmente seco de llanura; 1 on, Sechura, Vice, $5^{\circ} 25^{\prime} \mathrm{S}-81^{\circ} 46^{\prime} \mathrm{O}, 10 \mathrm{msnm}, 17-\mathrm{VIII}-2015$, U. González leg., red entomológica, Desierto costero; 1 †े, Morropón, Morropón, 505'51"S-8009'44"O, $557 \mathrm{msnm}$, 14-V-2017, G. Juárez leg., red entomológica, Bosque estacionalmente seco de colina.

Distribución (Provincia) (Paisaje ecológico). (PIU, SUlL, PAi, TAL, SECH, MORR) (DESc, BESr, BESIl, BESc-m).

Comentario. Los adultos se encuentran sobre hojas y ramas de plántulas y árboles, sobrevolando y/o posadas sobre inflorescencias. Insecto que se comporta como polinizador (Mengual \& Thompson, 2008). Especie citada también por Juárez et al. (2016).

Subfamilia Syrphinae Latreille, 1802

Género Allograpta Osten Sacken, 1875

121. Allograpta piurana Shannon, 1927

Material examinado. PERÚ. 1 , Piura, Universidad de Piura, 5¹0'11"S-80³6'51"O, 29 msnm, 04-IV-2015, U. González leg., red entomológica, Bosque estacionalmente seco de llanura; 1 , Piura, Castilla, Universidad Nacional de Piura, 5¹0'51"S-80³7'31"O, 29 msnm, 2-II-2015, U. González leg., red entomológica, Bosque estacionalmente seco

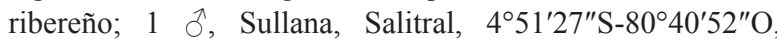
23 msnm, 28-X-2017, G. Juárez leg., red entomológica, Bosque estacionalmente seco de llanura; 1 , Talara, El Alto, $4^{\circ} 16^{\prime} 04^{\prime \prime} \mathrm{S}-81^{\circ} 13^{\prime} 09^{\prime \prime} \mathrm{O}, 5$ msnm, 23-IV-2015, G. Juárez leg., red entomológica, Desierto; 1 \&, Sullana, Miguel Checa, $4^{\circ} 54^{\prime} \mathrm{S}-80^{\circ} 48^{\prime} \mathrm{O}$, $10 \mathrm{msnm}, 12-\mathrm{III}-2016$, G. Juárez leg., red entomológica, Bosque estacionalmente seco de llanura; 1 त, Paita, 504'S-81 ${ }^{\circ} 66^{\prime} \mathrm{O}, 10$ msnm, 2-VIII-2017, G. Juárez leg., red entomológica, Bosque estacionalmente seco de llanura; 1 ô, Sechura, Vice, $5^{\circ} 25^{\prime} \mathrm{S}-81^{\circ} 46^{\prime} \mathrm{O}, 10 \mathrm{msnm}, 17-\mathrm{VIII}-2015$, U. González leg., red entomológica, Desierto costero; 1 , Sechura, Illescas, $5^{\circ} 58^{\prime} \mathrm{S}-81^{\circ} 05^{\prime} \mathrm{O}, 10 \mathrm{msnm}, 12-\mathrm{XI}-2017$, U. González leg., red entomológica, Matorral Xérico; 1 గె, Morropón, Morropón, 505'51"S-8009'44"O, $557 \mathrm{msnm}$, 14-V-2017, G. Juárez leg., red entomológica, Bosque estacionalmente seco de colina; 1 q, Ayabaca, Paimas, 4³7'37"S-7956'43"O, 473 msnm, 26-VII-2015, G. Juárez leg., red entomológica, Bosque estacionalmente seco de llanura; 1 ㅇ, Huancabamba, Huarmaca, 534'04"S-79³1'26"O, 1223 msnm, 26-VII-2016, G. Juárez leg., red entomológica, Bosque estacionalmente seco de colina.

Distribución (Provincia) (Paisaje ecológico). (PIU, SUlL, PAi, TAL, SECH, MORR, AYA, HUA) (MatX, DESc, BESr, BES1l, BESc-m).

COMENTARIO. Adultos se encuentran sobrevolando y/o posadas sobre inflorescencias, posadas sobre hojas de plántulas y árboles. Insecto que se comporta como polinizador y controlador biológico (Mengual et al., 2009). Especie citada también por Domínguez (1982) y Juárez et al. (2016).
Género Eosalpingogaster Hull, $1949 \dagger$

122. Eosalpingogaster nigriventris (Bigot, 1883) $\dagger$

Material examinado. PeRÚ. 1 , Piura, Universidad de Piura, 5¹0'11"S-80³6'51"O, 29 msnm, 04-IV-2015, U. González leg., red entomológica, Bosque estacionalmente seco de llanura; 1 , , Piura, Castilla, Universidad Nacional de Piura, 5¹0'51"S-80³7'31"O, 29 msnm, 2-II-2015, U. González leg., red entomológica, Bosque estacionalmente seco ribe-

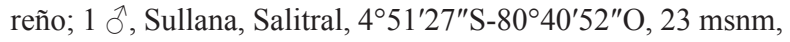
28-X-2017, G. Juárez leg., red entomológica, Bosque estacionalmente seco de llanura; 2 우, Talara, El Alto, $4^{\circ} 16^{\prime} 04^{\prime \prime S}-81^{\circ} 13^{\prime} 09^{\prime \prime} \mathrm{O}, 5$ msnm, 23-IV-2015, G. Juárez leg., red entomológica, Desierto; 1 ㅇ, Sullana, Miguel Checa, $4^{\circ} 54^{\prime} \mathrm{S}-80^{\circ} 48^{\prime} \mathrm{O}, 10 \mathrm{msnm}, 12-\mathrm{III}-2016$, G. Juárez leg., red entomológica, Bosque estacionalmente seco de llanura; 1 ,

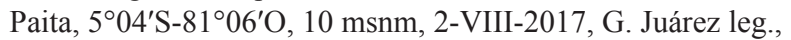
red entomológica, Bosque estacionalmente seco de llanura; 1 $\widehat{\lambda}$, Sechura, Vice, $5^{\circ} 25^{\prime} \mathrm{S}-81^{\circ} 46^{\prime} \mathrm{O}, 10 \mathrm{msnm}, 17-\mathrm{VIII}-2015$, U. González leg., red entomológica, Desierto costero.

Distribución (Provincia) (Paisaje ecológico). (PIU, SUll, PAi, TAL, SECH) (DESc, BESr, BESll).

Comentario. Los adultos se encuentran sobre hojas de plántulas y árboles, sobrevolando y/o posadas sobre inflorescencias. Insecto que se comporta como controlador biológico y polinizador (Mengual \& Thompson, 2011).

Género Dioprosopa (Becker, 1903)

123. Dioprosopa clavata (Fabricius, 1794)

Material examinado. Perú. 2 qo, Piura, Universidad de Piura, 5॰10'11"S-80³6'51"O, 29 msnm, 04-IV-2015, U. González leg., red entomológica, Bosque estacionalmente seco de llanura; 1 , Piura, Castilla, Universidad Nacional de Piura, 5¹0'51"S-80³7'31"O, 29 msnm, 2-II-2015, U. González leg., red entomológica, Bosque estacionalmente seco ribereño; 1 त, Sullana, Salitral, 451'27"S-8040'52"O, 23 msnm, 28-X-2017, G. Juárez leg., red entomológica, Bosque estacionalmente seco de llanura; 1 , , Talara, El Alto, $4^{\circ} 16^{\prime} 04^{\prime \prime} \mathrm{S}-81^{\circ} 13^{\prime} 09^{\prime \prime} \mathrm{O}, 5 \mathrm{msnm}$, 23-IV-2015, G. Juárez leg., red entomológica, Desierto; 1 ㅇ, Sullana, Miguel Checa, $4^{\circ} 54^{\prime} \mathrm{S}-80^{\circ} 48^{\prime} \mathrm{O}, 10 \mathrm{msnm}, 12-\mathrm{III}-2016$, G. Juárez leg., red entomológica, Bosque estacionalmente seco de llanura; 1 , Paita, $5^{\circ} 04^{\prime} \mathrm{S}-81^{\circ} 06^{\prime} \mathrm{O}, 10$ msnm, 2-VIII-2017, G. Juárez leg., red entomológica, Bosque estacionalmente seco de llanura; $1 \delta^{\lambda}$, Sechura, Vice, $5^{\circ} 25^{\prime} \mathrm{S}-81^{\circ} 46^{\prime} \mathrm{O}, 10 \mathrm{msnm}$, 17-VIII-2015, U. González leg., red entomológica, Desierto

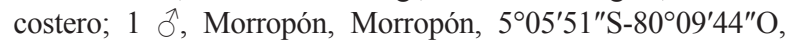
557 msnm, 14-V-2017, G. Juárez leg., red entomológica, Bosque estacionalmente seco de colina.

Distribución (Provincia) (Paisaje ecológico). (PIU, SUlL, PAi, TAL, SECH, MORR) (DESc, BESr, BESIl, BESc-m).

Comentario. Especie citada como Pseudodorus clavatus en Juárez et al. (2016) el cual pasó a ser sinónimo de D. clavata (Kassebeer, 2000). Los adultos se encuentran sobre hojas de plántulas y árboles, sobrevolando y/o posadas sobre inflorescencias. Insecto que se comporta como controlador biológico y polinizador (Arcaya et al., 2018).

Género Baccha Fabricius, 1805

124. Baccha elongata (Fabricius, 1794)

Material examinado. PERÚ. 1 9 , Piura, Universidad de Piura, 5 10'11"S-80³6'51"O, 29 msnm, 04-IV-2015, U. González leg., red entomológica, Bosque estacionalmente seco de llanura; 1 , Piura, Castilla, Universidad Nacional de Piura, 5 10'51"S-80³7'31"O, 29 msnm, 2-II-2015, U. González leg., red entomológica, Bosque estacionalmente seco ribereño. 
Distribución (Provincia) (Paisaje ecológico). (PIU) (BESr, BESIl).

Comentario. Los adultos se encuentran sobre hojas de plántulas y árboles, sobrevolando y/o posadas sobre inflorescencias. Especie citada también por Juárez et al. (2016).

Familia Agromyzidae Fallén, 1823

Subfamilia Agromyzinae Russell, 1924

Género Liriomyza Mik, 1894

125. Liriomyza sativae Blanchard, 1938

Material eXaminado. PERÚ. 1 , 085 DIP-GJN, Piura, Universidad de Piura, $5^{\circ} 10^{\prime} 11^{\prime \prime} \mathrm{S}-80^{\circ} 36^{\prime} 51^{\prime \prime} \mathrm{O}, 29 \mathrm{msnm}$, 04-IV-2015, U. González leg., red entomológica, Bosque estacionalmente seco de llanura; 1 , , Piura, Castilla, Universidad

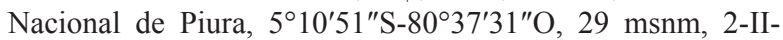
2015, U. González leg., red entomológica, Bosque estacionalmente seco ribereño.

Distribución (Provincia) (Paisaje ecológico). (PIU) (BESr, BESil).

Comentario. Con la consulta de Korytkowski (2014) se llegó a la conclusión que la especie citada como Agromyza sp en Juárez et al. (2016) se trata de L. sativae. Los adultos se encuentran sobre hojas de plántulas y árboles, en solitario. Insecto que se comporta como fitófago (Korytkowski, 2014).

Familia Lonchaeidae Rondani, 1856

Subfamilia Lonchaeinae

Género Silba Macquart, 1851

126. Silba pendula (Bezzi, 1919)

Material eXAminado. PERÚ. 19 , 086 DIP-GJN, Piura, Universidad

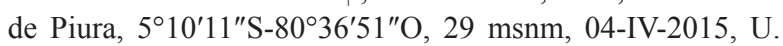
González leg., red entomológica, Bosque estacionalmente seco de llanura; 1 , , Piura, Castilla, Universidad Nacional de Piura, 510'51"S-80³7'31"O, 29 msnm, 2-II-2015, U. González leg., red entomológica, Bosque estacionalmente seco ribereño; $1 \mathrm{O}^{\lambda}$, Sullana, Salitral, $4^{\circ} 51^{\prime} 27^{\prime \prime} \mathrm{S}-80^{\circ} 40^{\prime} 52^{\prime \prime} \mathrm{O}$, 23 msnm, 28-X-2017, G. Juárez leg., red entomológica, Bosque estacionalmente seco de llanura; 1 , Talara, El Alto, 4¹6'04"S-81¹3'09"O, 5 msnm, 23-IV-2015, G. Juárez leg., red entomológica, Desierto; 1 †, Sullana, Miguel Checa, $4^{\circ} 54^{\prime} \mathrm{S}-80^{\circ} 48^{\prime} \mathrm{O}, 10 \mathrm{msnm}, 12-\mathrm{III}-2016$, G. Juárez leg., red entomológica, Bosque estacionalmente seco de llanura; 1 웅 Paita, $5^{\circ} 04^{\prime} \mathrm{S}-81^{\circ} 06^{\prime} \mathrm{O}, 10 \mathrm{msnm}, 2-\mathrm{VIII}-2017$, G. Juárez leg., red entomológica, Bosque estacionalmente seco de llanura; 1 万. Sechura, Vice, $5^{\circ} 25^{\prime} \mathrm{S}-81^{\circ} 46^{\prime} \mathrm{O}, 10 \mathrm{msnm}, 17-\mathrm{VIII}-2015$, U. González leg., red entomológica, Desierto costero.

Distribución (Provincia) (Paisaje ecológico). (PIU, SUll, PAi, TAL, SECH) (DESc, BESr, BESIl).

Comentario. Especie citada como morfoespecie 1 en Juárez et al. (2016). Los adultos se encuentran sobre hojas de plántulas y árboles, en solitario. Insecto que se comporta como fitófago (Korytkowski \& Ojeda, 1971).

Familia Ulidiidae Macquart, 1835

Subfamilia Ulidiinae Macquart, 1835

Género Physiphora Fallen, 1810

127. Physiphora clausa (Macquart, 1843)

Material eXaminado. PERÚ. 1 q, Piura, Universidad de Piura, $5^{\circ} 10^{\prime} 11^{\prime \prime} \mathrm{S}-80^{\circ} 36^{\prime} 51^{\prime \prime} \mathrm{O}, 29 \mathrm{msnm}, 04-\mathrm{IV}-2015$, U. González leg., red entomológica, Bosque estacionalmente seco de llanura; 1 , Piura, Castilla, Universidad Nacional de Piura, 5 $10^{\prime} 51^{\prime \prime} \mathrm{S}-80^{\circ} 37^{\prime} 31^{\prime \prime} \mathrm{O}, 29 \mathrm{msnm}, 2-\mathrm{II}-2015$, U. González leg., red entomológica, Bosque estacionalmente seco ribereño; 1 ठै, Sullana, Salitral, $4^{\circ} 51^{\prime} 27^{\prime \prime} \mathrm{S}-80^{\circ} 40^{\prime} 52^{\prime \prime} \mathrm{O}, 23 \mathrm{msnm}$, 28-X-2017, G. Juárez leg., red entomológica, Bosque estacionalmente seco de llanura; 2 우, Talara, El Alto, $4^{\circ} 16^{\prime} 04^{\prime \prime} \mathrm{S}-81^{\circ} 13^{\prime} 09^{\prime \prime} \mathrm{O}, 5$ msnm, 23-IV-2015, G. Juárez leg., red entomológica, Desierto; 1 q, Sullana, Miguel Checa, 454'S-8048'O, 10 msnm, 12-III-2016, G. Juárez leg., red entomológica, Bosque estacionalmente seco de llanura; $1 \hat{\jmath}$, Paita, $5^{\circ} 04^{\prime} \mathrm{S}-81^{\circ} 06^{\prime} \mathrm{O}, 10 \mathrm{msnm}, 2-\mathrm{VIII}-2017$, G. Juárez leg., red entomológica, Bosque estacionalmente seco de llanura; 1 ${ }^{\lambda}$, Sechura, Vice, $5^{\circ} 25^{\prime} \mathrm{S}-81^{\circ} 46^{\prime} \mathrm{O}, 10 \mathrm{msnm}, 17-\mathrm{VIII}-2015$, U. González leg., red entomológica, Desierto costero; 1 స, Morropón, Morropón, 505'51"S-8009'44"O, 557 msnm, 14-V-2017, G. Juárez leg., red entomológica, Bosque estacionalmente seco de colina.

Distribución (Provincia) (Paisaje ecológico). (PIU, SUll, PAi, TAL, SECH, MORR) (DESc, BESr, BESll, BESc-m).

Comentario. Los adultos se encuentran sobre hojas y ramas de plántulas y árboles, en solitario. Especie citada también por Juárez et al. (2016).

\section{Género Euxesta Loew, 1867}

128. Euxesta mazorca Steyskal, 1974

Material eXaminado. PERÚ. 1 q, 087 DIP-GJN, Piura, Universidad

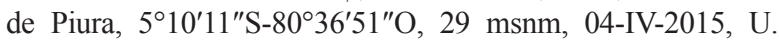
González leg., red entomológica, Bosque estacionalmente seco de llanura; 2 우, Piura, Castilla, Universidad Nacional de Piura, 510'51"S-80³7'31"O, 29 msnm, 2-II-2015, U. González leg., red entomológica, Bosque estacionalmente seco ribereño; $1 \hat{\delta}$, 1 ㅇ, Sullana, Salitral, $4^{\circ} 51^{\prime} 27^{\prime \prime} \mathrm{S}-80^{\circ} 40^{\prime} 52^{\prime \prime} \mathrm{O}, 23 \mathrm{msnm}, 28-\mathrm{X}-$ 2017, G. Juárez leg., red entomológica, Bosque estacionalmente seco de llanura; 1 ㅇ, 1 ภे, Talara, El Alto, $4^{\circ} 16^{\prime} 04^{\prime \prime} \mathrm{S}-81^{\circ} 13^{\prime} 09^{\prime \prime} \mathrm{O}$, 5 msnm, 23-IV-2015, G. Juárez leg., red entomológica, Desierto; 1 옹 Sullana, Miguel Checa, $4^{\circ} 54^{\prime} \mathrm{S}-80^{\circ} 48^{\prime} \mathrm{O}, 10 \mathrm{msnm}, 12-\mathrm{III}-$ 2016, G. Juárez leg., red entomológica, Bosque estacionalmente seco de llanura; $1 \hat{\mathrm{O}}$, Paita, $5^{\circ} 04^{\prime} \mathrm{S}-81^{\circ} 06^{\prime} \mathrm{O}, 10 \mathrm{msnm}, 2$-VIII2017, G. Juárez leg., red entomológica, Bosque estacionalmente seco de llanura; $1 \mathrm{o}^{\wedge}$, Sechura, Vice, $5^{\circ} 25^{\prime} \mathrm{S}-81^{\circ} 46^{\prime} \mathrm{O}, 10 \mathrm{msnm}$, 17-VIII-2015, U. González leg., red entomológica, Desierto

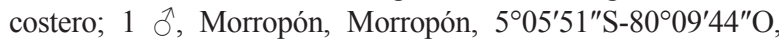
557 msnm, 14-V-2017, G. Juárez leg., red entomológica, Bosque estacionalmente seco de colina.

Distribución (Provincia) (Paisaje ecológico). (PIU, SUll, PAi, TAL, SECH, MORR) (DESc, BESr, BESll, BESc-m).

Comentario. Especie citada como Euxesta sp en Juárez et al. (2016). Los adultos se encuentran sobre hojas y ramas de plántulas y árboles, en solitario.

Género Notogramma Loew, $1867 \dagger$

129. Notogramma sin identificar sp. $1 . \dagger$

Material examinado. PERÚ. 1 , Piura, Universidad de Piura, 5¹0'11"S-80³6'51"O, 29 msnm, 04-IV-2015, U. González leg., red entomológica, Bosque estacionalmente seco de 1lanura; 1 , Piura, Castilla, Universidad Nacional de Piura, 5॰10'51"S-80³7'31"O, 29 msnm, 2-II-2015, U. González leg., red entomológica, Bosque estacionalmente seco ribereño.

Distribución (Provincia) (Paisaje ecológico). (PIU) (BESr, BES11).

Comentario. Los adultos se encuentran sobre hojas y ramas de plántulas y árboles, en solitario.

Familia Muscidae Latreille, 1802

Subfamilia Muscinae Latreille, 1802

Género Musca Linnaeus, 1758

130. Musca domestica Linnaeus, 1758

Material eXaminado. PERÚ. 2 우, 088 DIP-GJN, Piura, Universidad de Piura, 5 $5^{\circ} 10^{\prime} 11^{\prime \prime} \mathrm{S}-80^{\circ} 36^{\prime} 51^{\prime \prime} \mathrm{O}, 29 \mathrm{msnm}$, 04-IV-2015, U. González leg., red entomológica, Bosque 
estacionalmente seco de llanura; 3 우, 2 $\widehat{\partial}$, Piura, Castilla, Universidad Nacional de Piura, $5^{\circ} 10^{\prime} 51^{\prime \prime} \mathrm{S}-80^{\circ} 37^{\prime} 31^{\prime \prime} \mathrm{O}$, 29 msnm, 2-II-2015, U. González leg., red entomológica, Bosque estacionalmente seco ribereño; $2 \hat{\jmath} \hat{\partial}$, Sullana, Salitral, 451'27"S-8040'52"O, 23 msnm, 28-X-2017, G. Juárez leg., red entomológica, Bosque estacionalmente seco de llanura; 2 오오, Talara, El Alto, $4^{\circ} 16^{\prime} 04^{\prime \prime} \mathrm{S}-81^{\circ} 13^{\prime} 09^{\prime \prime} \mathrm{O}, 5 \mathrm{msnm}, 23-\mathrm{IV}-$

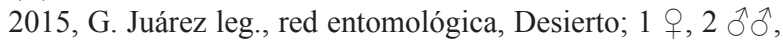
Sullana, Miguel Checa, $4^{\circ} 54^{\prime} \mathrm{S}-80^{\circ} 48^{\prime} \mathrm{O}, 10 \mathrm{msnm}$, 12-III2016, G. Juárez leg., red entomológica, Bosque estacional-

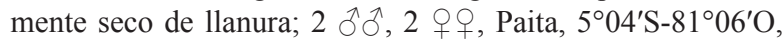
10 msnm, 2-VIII-2017, G. Juárez leg., red entomológica, Bosque estacionalmente seco de llanura; 3 우, $2 \hat{\delta} \bar{\delta}$, Sechura, Vice, $5^{\circ} 25^{\prime} \mathrm{S}-81^{\circ} 46^{\prime} \mathrm{O}, 10 \mathrm{msnm}, 17-\mathrm{VIII}-2015$, U. González leg., red entomológica, Desierto costero; 1 + 1 +, Sechura, Illescas, $5^{\circ} 58^{\prime} \mathrm{S}-81^{\circ} 05^{\prime} \mathrm{O}, 10 \mathrm{msnm}, 12-\mathrm{XI}-2017$, U. González leg., red entomológica, Matorral Xérico; $2 \hat{\jmath} \hat{o}$, Morropón, Morropón, 505'51"S-8009'44"O, 557 msnm, 14-V-2017, G. Juárez leg., red entomológica, Bosque estacionalmente seco

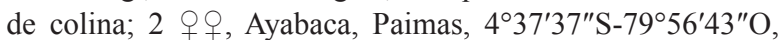
473 msnm, 26-VII-2015, G. Juárez leg., red entomológica, Bosque estacionalmente seco de llanura; 1 ㅇ, 1

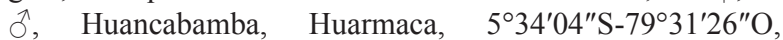
1223 msnm, 26-VII-2016, G. Juárez leg., red entomológica, Bosque estacionalmente seco de colina.

Distribución (Provincia) (Paisaje ecológico). (PIU, SUlL, PAi, TAL, SECH, MORR, AYA, HUA) (MatX, DESc, BESr, BESll, BESc-m).

Comentario. Especie citada como Musca sp en Juárez et al. (2016). Los adultos se encuentran sobre hojas, ramas, troncos de plántulas y árboles, en solitario o en grupo de dos o más individuos.

Familia Calliphoridae Brauer \& Bergenstamm, 1889

Subfamilia Chrysomyinae

Género Chrysomya Robineau-Desvoidy, 1830

131. Chrysomya albiceps (Wiedemann, 1819)

Material eXAminado. PERÚ. 1 +, 090 DIP-GJN, Piura, Universidad de Piura, $5^{\circ} 10^{\prime} 11^{\prime \prime} \mathrm{S}-80^{\circ} 36^{\prime} 51^{\prime \prime} \mathrm{O}, 29 \mathrm{msnm}, 19-\mathrm{II}-2017$, U. González leg., red entomológica, Bosque estacionalmente seco de llanura; 2 우, Piura, Castilla, Universidad Nacional de Piura, 5¹0'51"S-80³7'31"O, 29 msnm, 12-IV-2017, U. González leg., red entomológica, Bosque estacionalmente seco ribereño; 1 , , Sullana, Salitral, $4^{\circ} 51^{\prime} 27^{\prime \prime} \mathrm{S}-80^{\circ} 40^{\prime} 52^{\prime \prime} \mathrm{O}$, 23 msnm, 18-I-2016, G. Juárez leg., red entomológica, Bosque estacionalmente seco de llanura; $1 \hat{\jmath}, 1$ ㅇ, Talara, Los Órganos, $4^{\circ} 10^{\prime} 38^{\prime \prime} \mathrm{S}-81^{\circ} 07^{\prime} 27^{\prime \prime} \mathrm{O}, 12 \mathrm{msnm}, 05-\mathrm{V}-2017$, G. Juárez leg., red entomológica, Desierto costero; 2 우, Paita, $5^{\circ} 04^{\prime} \mathrm{S}-81^{\circ} 06^{\prime} \mathrm{O}, 10 \mathrm{msnm}, 21-\mathrm{II}-2017$, G. Juárez leg., red entomológica, Bosque estacionalmente seco de llanura; $1 \hat{o}$, La Huaca, $4^{\circ} 54^{\prime} \mathrm{S}-80^{\circ} 57^{\prime} \mathrm{O}, 10 \mathrm{msnm}, 21-\mathrm{II}-2017$, G. Juárez leg., red entomológica, Bosque estacionalmente seco de llanura; 2 우, 1 그, Sechura, Vice, $5^{\circ} 25^{\prime} \mathrm{S}-81^{\circ} 46^{\prime} \mathrm{O}, 10 \mathrm{msnm}$, 12-XII-2017, U. González leg., red entomológica, Desierto costero; 1 ô, Sechura, Laguna Ñapique, $5^{\circ} 34^{\prime} \mathrm{S}-81^{\circ} 16^{\prime} \mathrm{O}$, 16 msnm, 24-VI-2019, U. González leg., red entomológica, Bosque estacionalmente seco ribereño; 1 ㅇ, Morropón, Chulucanas, $5^{\circ} 05^{\prime} \mathrm{S}-80^{\circ} 99^{\prime} \mathrm{O}, 350 \mathrm{msnm}, 22-\mathrm{I}-2015$, G. Juárez leg., red entomológica, Bosque estacionalmente seco de colina;

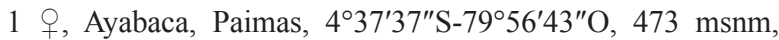
26-VII-2015, G. Juárez leg., red entomológica, Bosque estacionalmente seco de llanura; $1 \hat{\delta}$, Huancabamba, Huarmaca, 5³4'04"S-79³1'26"O, 1223 msnm, 26-VII-2016, G. Juárez leg., red entomológica, Bosque estacionalmente seco de colina.
Distribución (Provincia) (Paisaje ecológico). (PIU, SUll, PAi, TAL, SECH, MORR, AYA, HUA) (DESc, BESr, BESll, BESc-m).

Comentario. Especie citada como Chrysomya sp en Juárez et al. (2016). Los adultos se encuentran sobre hojas, ramas, troncos de plántulas y árboles, en solitario o en grupo de dos a cuatro individuos.

Género Cochliomyia Townsend, 1918

132. Cochliomyia macellaria (Fabricius, 1775)

Material eXAminado. PERÚ. 2 우, 091 DIP-GJN, Piura, Universidad de Piura, $5^{\circ} 10^{\prime} 11^{\prime \prime} \mathrm{S}-80^{\circ} 36^{\prime} 51^{\prime \prime} \mathrm{O}, 29 \mathrm{msnm}$, 19-II-2017, U. González leg., red entomológica, Bosque estacionalmente seco de llanura; 1 \&, Piura, Castilla, Universidad

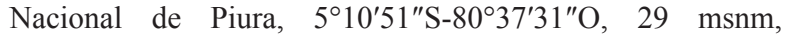
12-IV-2017, U. González leg., red entomológica, Bosque estacionalmente seco ribereño; 1 + , 1 ô, Sullana, Salitral, 451'27"S-8040'52"O, 23 msnm, 18-I-2016, G. Juárez leg., red entomológica, Bosque estacionalmente seco de llanura; 1 옹 Talara, Los Órganos, $4^{\circ} 10^{\prime} 38^{\prime \prime} \mathrm{S}-81^{\circ} 07^{\prime} 27^{\prime \prime} \mathrm{O}, 12 \mathrm{msnm}$, 05-V-2017, G. Juárez leg., red entomológica, Desierto costero; 1 ㅇ, Paita, $5^{\circ} 04^{\prime} \mathrm{S}-81^{\circ} 06^{\prime} \mathrm{O}, 10 \mathrm{msnm}, 21-\mathrm{II}-2017$, G. Juárez leg., red entomológica, Bosque estacionalmente seco de llanura; 1 ô, 1 q, La Huaca, $4^{\circ} 54^{\prime} \mathrm{S}-80^{\circ} 57^{\prime} \mathrm{O}, 10 \mathrm{msnm}$, 21-II-2017, G. Juárez leg., red entomológica, Bosque estacionalmente seco de llanura; 1 , $1 \hat{\jmath}$, Sechura, Vice, 5²5'S-814ㅇ' O, 10 msnm, 12-XII-2017, U. González leg., red entomológica, Desierto costero; $3 \hat{\partial} \hat{\partial}$, Sechura, Laguna Ñapique, $5^{\circ} 34^{\prime} \mathrm{S}-81^{\circ} 16^{\prime} \mathrm{O}, 16$ msnm, 24-VI-2019, U. González leg., red entomológica, Bosque estacionalmente seco ribereño; 1 ㅇ, 1 ๙ิ, Morropón, Chulucanas, $5^{\circ} 05^{\prime} \mathrm{S}-80^{\circ} 99^{\prime} \mathrm{O}, 350 \mathrm{msnm}$, 22-I-2015, G. Juárez leg., red entomológica, Bosque estacionalmente seco de colina; 1 +, $1 \hat{0}$, Ayabaca, Paimas, 4³7'37"S-7956'43"O, 473 msnm, 26-VII-2015, G. Juárez leg., red entomológica, Bosque estacionalmente seco de lla-

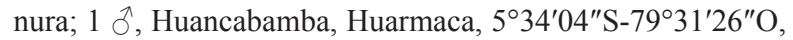
1223 msnm, 26-VII-2016, G. Juárez leg., red entomológica, Bosque estacionalmente seco de colina.

Distribución (Provincia) (Paisaje ecológico). (PIU, SUlL, PAi, TAL, SECH, MORR, AYA, HUA) (DESc, BESr, BESll, BESc-m).

Comentario. Especie citada como Cochliomyia sp en Juárez et al. (2016). Los adultos se encuentran sobre hojas, ramas, troncos de plántulas y árboles, en solitario o en grupo de dos a cuatro individuos.

Familia Sarcophagidae Macquart, 1834

Subfamilia Sarcophaginae

Género Sarcophaga Meigen, 1826

133. Sarcophaga sin identificar sp. 1 .

Material examinado. PERÚ. 2 운, Piura, Universidad de

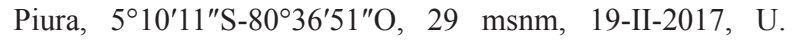
González leg., red entomológica, Bosque estacionalmente seco de llanura; 1 , Piura, Castilla, Universidad Nacional de Piura, 5¹0'51"S-80³7'31"O, 29 msnm, 12-IV-2017, U. González leg., red entomológica, Bosque estacionalmente seco ribereño; $1 \hat{\jmath}$, Sullana, Salitral, 4 ${ }^{\circ} 51^{\prime} 27^{\prime \prime} \mathrm{S}-80^{\circ} 40^{\prime} 52^{\prime \prime} \mathrm{O}$, 23 msnm, 18-I-2016, G. Juárez leg., red entomológica, Bosque estacionalmente seco de llanura; 1 \&, Talara, Los Órganos, $4^{\circ} 10^{\prime} 38^{\prime \prime} \mathrm{S}-81^{\circ} 07^{\prime} 27^{\prime \prime} \mathrm{O}, 12 \mathrm{msnm}, 05-\mathrm{V}-2017$, G. Juárez leg., red entomológica, Desierto costero; 1 , , Paita, $5^{\circ} 04^{\prime} \mathrm{S}-81^{\circ} 06^{\prime} \mathrm{O}, 10 \mathrm{msnm}, 21-\mathrm{II}-2017$, G. Juárez leg., red entomológica, Bosque estacionalmente seco de llanura; $1 \hat{\partial}$,

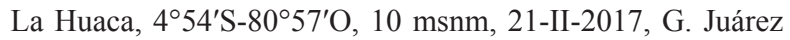


leg., red entomológica, Bosque estacionalmente seco de llanura; $1 \delta^{\wedge}$, Sechura, Vice, $5^{\circ} 25^{\prime} \mathrm{S}-81^{\circ} 46^{\prime} \mathrm{O}, 10 \mathrm{msnm}, 12$-XII2017, U. González leg., red entomológica, Desierto costero; $2 \widehat{o ̂ ̀}^{\hat{\partial}}$, Sechura, Laguna Napique, $5^{\circ} 34^{\prime} \mathrm{S}-81^{\circ} 16^{\prime} \mathrm{O}, 16 \mathrm{msnm}$, 24-VI-2019, U. González leg., red entomológica, Bosque estacionalmente seco ribereño; 1 +, 1 §, Morropón, Chulucanas, $5^{\circ} 05^{\prime} \mathrm{S}-80^{\circ} 99^{\prime} \mathrm{O}, 350 \mathrm{msnm}, 22-\mathrm{I}-2015$, G. Juárez leg., red entomológica, Bosque estacionalmente seco de colina.

Distribución (Provincia) (Paisaje ecológico). (PIU, SUlL, PAi, TAL, SECH, MORR) (DESc, BESr, BESll, BESc-m).

ComentARIO. Los adultos se encuentran sobre hojas, ramas, troncos de plántulas y árboles, a ras del suelo cercano a troncos, en solitario o en grupo de dos a cuatro individuos. Especie citada también por Juárez et al. (2016).

Familia Tachinidae Robineau-Desvoidy, 1830

Subfamilia Exoristinae Robineau-Desvoidy, 1863

Género Eucelatoria Townsend, 1909

134. Eucelatoria digitata Sabrosky, 1981

Material eXaminado. PERÚ. 1 o, 093 DIP-GJN, Piura,

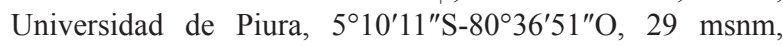
19-II-2017, U. González leg., red entomológica, Bosque estacionalmente seco de llanura; 1 ㅇ, Piura, Castilla, Universidad Nacional de Piura, 5 $10^{\prime} 51^{\prime \prime S}-80^{\circ} 37^{\prime} 31^{\prime \prime} \mathrm{O}, 29 \mathrm{msnm}, 12-\mathrm{IV}-$ 2017, U. González leg., red entomológica, Bosque estacionalmente seco ribereño.

Distribución (Provincia) (Paisaje ecológico). (PIU) (BESr, BESIl).

Comentario. Especie citada como Eucelatoria sp en Juárez et al. (2016). Los adultos se encuentran sobre hojas, ramas, troncos de plántulas y árboles, a ras del suelo cercano a troncos, en solitario o en grupo de dos a cuatro individuos. Insecto que se comporta como controlador biológico, es parasitoide de larvas de lepidópteros (Sabrosky, 1981).

Orden LEPIDOPTERA Linnaeus, 1758

Suborden Glossata Fabricius, 1775

Familia Gracillariidae Staiton, 1854

Gracillariidae sin identificar sp. 1.

Material examinado. PeRÚ. 1 q, Piura, Universidad de Piura, 5¹0'11"S-80³6'51"O, 29 msnm, 19-II-2017, U. González leg., red entomológica, Bosque estacionalmente seco de llanura.

Distribución (Provincia) (Paisaje ecológico). (PIU) (BESIl).

Comentario. Adultos se encuentran posados sobre hojas de plántulas y árboles, siempre en solitario. Insecto plaga que se comporta como fitófago.

Familia Gelechiidae Stainton, 1864

Gelechiidae sin identificar sp. 1.

Material examinado. PERÚ. 1 \%, Piura, Universidad de Piura, 5॰10'11"S-80³6'51"O, 29 msnm, 19-II-2017, U. González leg., red entomológica, Bosque estacionalmente seco de llanura; 1 ㅇ, Piura, Castilla, Universidad Nacional de Piura, 5¹0'51"S-80³7'31"O, 29 msnm, 12-IV-2017, U. González leg., red entomológica, Bosque estacionalmente seco ribereño.

Comentario. Los adultos se encuentran posados sobre hojas de plántulas y árboles, en solitario. Insecto que se comporta como fitófago, las larvas pegan los foliolos con seda blanquecina.

Familia Tortricidae Latreille, 1802

Género Plodia Guenée, 1845

135. Plodia interpunctella Hübner, 1813

Material examinado. PERÚ. 1 9, Piura, Universidad de Piura, 5¹0'11"S-80³6'51"O, 29 msnm, 19-II-2017, U. González leg., red entomológica, Bosque estacionalmente seco de llanura; 1 q, Piura, Castilla, Universidad Nacional de Piura, $5^{\circ} 10^{\prime} 51^{\prime \prime S}-80^{\circ} 37^{\prime} 31^{\prime \prime} \mathrm{O}, 29 \mathrm{msnm}, 12-\mathrm{IV}-2017$, U. González leg., red entomológica, Bosque estacionalmente seco ribereño; 1 ㅇ, Sullana, Salitral, $4^{\circ} 51^{\prime} 27^{\prime \prime} \mathrm{S}-80^{\circ} 40^{\prime} 52^{\prime \prime} \mathrm{O}, 23 \mathrm{msnm}$, 18-I-2016, G. Juárez leg., red entomológica, Bosque estacionalmente seco de llanura; 1 \&, Talara, Los Órganos, $4^{\circ} 10^{\prime} 38^{\prime \prime} \mathrm{S}-81^{\circ} 07^{\prime} 27^{\prime \prime} \mathrm{O}, 12 \mathrm{msnm}, 05-\mathrm{V}-2017$, G. Juárez leg., red entomológica, Desierto costero; 1 +, 1 ô, Sechura, Vice, 525'S-81²6'O, 10 msnm, 12-XII-2017, U. González leg., red entomológica, Desierto costero; $1 \hat{\delta}$, Sechura, Laguna Ñapique, $5^{\circ} 34^{\prime} \mathrm{S}-81^{\circ} 16^{\prime} \mathrm{O}, 16$ msnm, 24-VI-2019, U. González leg., red entomológica, Bosque estacionalmente seco ribereño; 1 ․, Morropón, Chulucanas, $5^{\circ} 05^{\prime} \mathrm{S}-80^{\circ} 99^{\prime} \mathrm{O}, 350 \mathrm{msnm}$, 22-I-2015, G. Juárez leg., red entomológica, Bosque estacionalmente seco de colina.

Distribución (Provincia) (Paisaje ecológico). (PIU, SUlL, TAL, SECH, MORR) (DESc, BESr, BESll, BESc-m).

Comentario. Los adultos se encuentran sobre hojas de plántulas y árboles, en solitario, larvas en el interior de frutos maduros. Insecto que se comporta como fitófago. Especie citada también por Domínguez (1982), Núñez-Sacarías (1993) y Juárez et al. (2016).

Género Cryptophlebia Walsingham, 1900

136. Cryptophlebia sin identificar sp 1

Material eXaminado. PERÚ. 1 , Piura, Universidad de Piura, 5¹0'11"S-80³6'51"O, 29 msnm, 19-II-2017, U. González leg., red entomológica, Bosque estacionalmente seco de llanura; 1 q, Piura, Castilla, Universidad Nacional de Piura, 5¹0'51"S-80³7'31"O, 29 msnm, 12-IV-2017, U. González leg., red entomológica, Bosque estacionalmente seco ribereño; 1 ㅇ, Sullana, Salitral, 451'27"S-8040'52"O, 23 msnm, 18-I2016, G. Juárez leg., red entomológica, Bosque estacionalmente seco de llanura; 1 ㅇ, Paita, $5^{\circ} 04^{\prime} \mathrm{S}-81^{\circ} 06^{\prime} \mathrm{O}, 10 \mathrm{msnm}$, 21-II-2017, G. Juárez leg., red entomológica, Bosque estacionalmente seco de llanura; 1 \&, Talara, Los Órganos, $4^{\circ} 10^{\prime} 38^{\prime \prime} \mathrm{S}-81^{\circ} 07^{\prime} 27^{\prime \prime} \mathrm{O}, 12 \mathrm{msnm}, 05-\mathrm{V}-2017$, G. Juárez leg.,

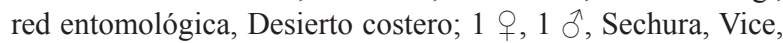
5²5'S-81²6'O, 10 msnm, 12-XII-2017, U. González leg., red entomológica, Desierto costero; $1 \hat{\partial}$, Sechura, Laguna Ñapique, 5³4'S-811'ㅇ, 16 msnm, 24-VI-2019, U. González leg., red entomológica, Bosque estacionalmente seco ribereño. Distribución (Provincia) (Paisaje ecológico). (PIU, SUll, PAi, TAL, SECH) (DESc, BESr, BESll).

Comentario. Los adultos se encuentran sobre hojas de plántulas y árboles, en solitario, las larvas en el interior de frutos maduros. Insecto que se comporta como fitófago. Especie citada también por Juárez et al. (2016).

Género Laspeyresia Hübner, 1825

137. Laspeyresia sin identificar sp. 1.

Material examinado. Perú. 1 , Piura, Universidad de Piura, 5¹0'11"S-80³6'51"O, 29 msnm, 19-II-2017, U. González leg., red entomológica, Bosque estacionalmente seco de llanura; 1 ㅇ, Piura, Castilla, Universidad Nacional de Piura, 5¹0'51"S-80³7'31"O, 29 msnm, 12-IV-2017, U. González leg., red entomológica, Bosque estacionalmente seco ribereño; 1 q, Talara, Los Órganos, $4^{\circ} 10^{\prime} 38^{\prime \prime} \mathrm{S}-81^{\circ} 07^{\prime} 27^{\prime \prime} \mathrm{O}, 12 \mathrm{msnm}$, 05-V-2017, G. Juárez leg., red entomológica, Desierto costero.

Distribución (Provincia) (Paisaje ecológico). (PIU, TAL) (DES, BESr, BESll).

Comentario. Adultos se encuentran sobre hojas de plántulas y árboles, en solitario, las larvas en el interior de frutos maduros. 
Insecto que se comporta como fitófago. Especie citada también por Juárez et al. (2016).

\section{Género Eccopsis Zeller, 1852 †}

138. Eccopsis galapagana Razowski \& Landry, $2008 \dagger$

Material examinado. PERÚ. 1 q, Piura, Universidad de Piura, 5¹0'11"S-80³6'51"O, 29 msnm, 19-II-2017, U. González leg., red entomológica, Bosque estacionalmente seco de llanura; 1 ㅇ, Piura, Castilla, Universidad Nacional de Piura, $5^{\circ} 10^{\prime} 51^{\prime \prime} \mathrm{S}-80^{\circ} 37^{\prime} 31^{\prime \prime} \mathrm{O}, 29 \mathrm{msnm}, 12-\mathrm{IV}-2017$, U. González leg., red entomológica, Bosque estacionalmente seco ribereño; 1 ㅇ, Sullana, Salitral, 451'27"S-8040'52"O, 23 msnm, 18-I2016, G. Juárez leg., red entomológica, Bosque estacionalmente seco de llanura; 1 ㅇ, Sechura, Vice, $5^{\circ} 25^{\prime} \mathrm{S}-81^{\circ} 46^{\prime} \mathrm{O}$, 10 msnm, 12-XII-2017, U. González leg., red entomológica, Desierto costero; $1 \hat{\jmath}$, Sechura, Laguna Napique, 5³4'S-81²16'O, 16 msnm, 24-VI-2019, U. González leg., red entomológica, Bosque estacionalmente seco ribereño.

Distribución (Provincia) (Paisaje ecológico). (PIU, SUll, $\mathrm{SECH})(\mathrm{DESc}, \mathrm{BESr}, \mathrm{BES} 11)$.

Comentario. Los adultos y larvas se encuentran sobre hojas de plántulas y árboles, en solitario. Insecto que se comporta como fitófago, las larvas pegan los foliolos con seda blanquecina.

Familia Riodinidae Grote, 1895

Género Melanis Hübner, 1819

139. Melanis leucophlegma (Stichel, 1910)

Material examinado. PERÚ. 1 q, Piura, Universidad de Piura, 5 10'11"S-80³6'51"O, 29 msnm, 19-II-2017, U. González leg., red entomológica, Bosque estacionalmente seco de llanura; 1 ㅇ, Piura, Castilla, Universidad Nacional de Piura, 5 10'51"S-80³7'31"O, 29 msnm, 12-IV-2017, U. González leg., red entomológica, Bosque estacionalmente seco ribereño. Distribución (Provincia) (Paisaje ecológico). (PIU) (BESr, BESIl).

Comentario. Los adultos se encuentran sobre hojas de plántulas y árboles, en solitario. Especie citada también por Juárez et al. (2016).

\section{Género Lasaia Bates, 1868}

140. Lasaia $\sin$ identificar sp. 1.

Material examinado. PERÚ. 1 \%, Piura, Universidad de Piura, 510'11"S-80³6'51"O, 29 msnm, 19-II-2017, U. González leg., red entomológica, Bosque estacionalmente seco de llanura; 1 , Piura, Castilla, Universidad Nacional de Piura, 510'51"S-80³7'31"O, 29 msnm, 12-IV-2017, U. González leg., red entomológica, Bosque estacionalmente seco ribereño. Distribución (Provincia) (Paisaje ecológico). (PIU) (BESr, BESIl). Comentario. Los adultos se encuentran sobre hojas de plántulas y árboles. Especie citada también por Juárez et al. (2016).

Familia Lycaenidae Leach, 1815

Género Hemiargus Hübner, 1818

141. Hemiargus ramon Dognin, 1887 (Fig. 14)

Material examinado. PERÚ. 1 , Piura, Universidad de Piura, 5¹0'11"S-80³6'51"O, 29 msnm, 19-II-2017, U. González leg., red entomológica, Bosque estacionalmente seco de llanura; 2 우, Piura, Castilla, Universidad Nacional de Piura, 510'51"S-80³7'31"O, 29 msnm, 12-IV-2017, U. González leg., red entomológica, Bosque estacionalmente seco ribereño; 1 ô, Sullana, Salitral, $4^{\circ} 51^{\prime} 27^{\prime \prime} \mathrm{S}-80^{\circ} 40^{\prime} 52^{\prime \prime} \mathrm{O}$, 23 msnm, 18-I-2016, G. Juárez leg., red entomológica, Bosque estacionalmente seco de llanura; 1 \&, Talara, Los Órganos, $4^{\circ} 10^{\prime} 38^{\prime \prime} \mathrm{S}-81^{\circ} 07^{\prime} 27^{\prime \prime} \mathrm{O}, 12 \mathrm{msnm}, 05-\mathrm{V}-$ 2017, G. Juárez leg., red entomológica, Desierto costero;
1 , Paita, $5^{\circ} 04^{\prime} \mathrm{S}-81^{\circ} 06^{\prime} \mathrm{O}, 10 \mathrm{msnm}, 21-\mathrm{II}-2017$, G. Juárez leg., red entomológica, Bosque estacionalmente seco de llanura; $1 \delta^{\prime}$, Sechura, Vice, $5^{\circ} 25^{\prime} \mathrm{S}-81^{\circ} 46^{\prime} \mathrm{O}, 10 \mathrm{msnm}$, 12-XII-2017, U. González leg., red entomológica, Desierto costero; 1 ${ }^{\lambda}$, Sechura, Laguna Ñapique, $5^{\circ} 34^{\prime} \mathrm{S}-81^{\circ} 16^{\prime} \mathrm{O}$, 16 msnm, 24-VI-2019, U. González leg., red entomológica, Bosque estacionalmente seco ribereño; 1 ․ Morropón, Chulucanas, $5^{\circ} 05^{\prime} \mathrm{S}-80^{\circ} 99^{\prime} \mathrm{O}, 350 \mathrm{msnm}, 22-\mathrm{I}-2015$, G. Juárez leg., red entomológica, Bosque estacionalmente seco de colina.

Distribución (Provincia) (Paisaje ecológico). (PIU, SUlL, PAi, TAL, SECH, MORR) (DESc, BESr, BESll, BESc-m).

ComentaRIo. Los adultos se encuentran sobrevolando y/o posadas sobre inflorescencias, en ocasiones también sobre hojas de plántulas y árboles, en solitario. Los adultos se comportan como agentes polinizadores y las larvas como fitófagos (Bobadilla et al., 1987; Toro et al., 1993). Especie citada también por Juárez et al. (2016).

\section{Género Leptotes Scudder, $1876 \uparrow$}

\section{Leptotes trigemmatus (Butler, 1881) $\dagger$}

Material examinado. PERÚ. 1 , Piura, Universidad de Piura, 510'11"S-80³6'51"O, 29 msnm, 19-II-2017, U. González leg., red entomológica, Bosque estacionalmente seco de llanura; 1 , Piura, Castilla, Universidad Nacional de Piura, $5^{\circ} 10^{\prime} 51^{\prime \prime} \mathrm{S}-80^{\circ} 37^{\prime} 31^{\prime \prime} \mathrm{O}, 29 \mathrm{msnm}$, 12-IV-2017, U. González leg., red entomológica, Bosque estacionalmente seco ribereño; 1 $\hat{o}$, Sullana, Salitral, 451'27"S-8040'52"O, 23 msnm, 18-I-2016, G. Juárez leg., red entomológica, Bosque estacionalmente seco de llanura; 1 ㅇ, Talara, Los Órganos, $4^{\circ} 10^{\prime} 38^{\prime \prime} \mathrm{S}-81^{\circ} 07^{\prime} 27^{\prime \prime} \mathrm{O}$, 12 msnm, 05-V-2017, G. Juárez leg., red entomológica, Desierto costero; 1 \%, Paita, $5^{\circ} 04^{\prime} \mathrm{S}-81^{\circ} 06^{\prime} \mathrm{O}, 10 \mathrm{msnm}$, 21-II-2017, G. Juárez leg., red entomológica, Bosque estacionalmente seco de llanura; $1 \hat{\jmath}$, Sechura, Vice, $5^{\circ} 25^{\prime} \mathrm{S}-81^{\circ} 46^{\prime} \mathrm{O}, 10 \mathrm{msnm}, 12-X I I-2017$, U. González leg., red entomológica, Desierto costero; 1 $\hat{0}$, Sechura, Laguna Ñapique, $5^{\circ} 34^{\prime} \mathrm{S}-81^{\circ} 16^{\prime} \mathrm{O}, 16 \mathrm{msnm}, 24$-VI2019, U. González leg., red entomológica, Bosque estacionalmente seco ribereño; 1 + , Morropón, Chulucanas, $5^{\circ} 05^{\prime} \mathrm{S}-80^{\circ} 99^{\prime} \mathrm{O}, 350 \mathrm{msnm}, 22-\mathrm{I}-2015$, G. Juárez leg., red entomológica, Bosque estacionalmente seco de colina.

Distribución (Provincia) (Paisaje ecológico). (PIU, SUlL, PAi, TAL, SECH, MORR) (DESc, BESr, BESIl, BESc-m).

Comentario. Los adultos se encuentran sobrevolando y/o posadas sobre inflorescencias, en ocasiones también sobre hojas de plántulas y árboles, en solitario. Los adultos se comportan como agentes polinizadores, las larvas como fitófagos (Bobadilla et al., 1987; Toro et al., 1993).

Familia Crambidae Latreille, 1810

Género Spolodea Guenée, 1854

143. Spoladea recurvalis (Fabricius, 1775)

Material examinado. PERÚ. 2 $q$, Piura, Universidad de Piura, 5॰10'11"S-80³6'51"O, 29 msnm, 19-II-2017, U. González leg., red entomológica, Bosque estacionalmente seco de llanura; 1 , Piura, Castilla, Universidad Nacional de Piura, 5¹0'51"S-80³7'31"O, 29 msnm, 12-IV-2017, U. González leg., red entomológica, Bosque estacionalmente seco ribereño;

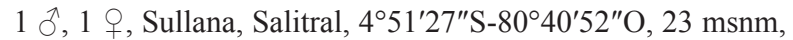
18-I-2016, G. Juárez leg., red entomológica, Bosque estacionalmente seco de llanura.

Distribución (Provincia) (Paisaje ecológico). (PIU, SULL) (BESr, BESll). 
COMENTARIO. Los adultos se encuentran sobre hojas de plántulas y árboles, en solitario. Especie citada también por Juárez et al. (2016).

Género Hymenia Hübner, 1825

144. Hymenia perspectalis (Hübner, 1796)

Material examinado. Perú. 1 q, Piura, Universidad de Piura, $5^{\circ} 10^{\prime} 11^{\prime \prime} \mathrm{S}-80^{\circ} 36^{\prime} 51^{\prime \prime} \mathrm{O}, 29 \mathrm{msnm}, 19-\mathrm{II}-2017$, U. González leg., red entomológica, Bosque estacionalmente seco de llanura; 1 + , Piura, Castilla, Universidad Nacional de Piura, 5¹0'51"S-80³7'31"O, 29 msnm, 12-IV-2017, U. González leg., red entomológica, Bosque estacionalmente seco ribereño; 1 을, Morropón, Chulucanas, $5^{\circ} 05^{\prime} \mathrm{S}-80^{\circ} 99^{\prime} \mathrm{O}, 350 \mathrm{msnm}$, 22-I-2015, G. Juárez leg., red entomológica, Bosque estacionalmente seco de colina.

Distribución (Provincia) (Paisaje ecológico). (PIU, MORR) (BESr, BESll, BESc-m).

Comentario. Los adultos se encuentran sobre hojas de plántulas y árboles, en solitario. Especie citada también por Juárez et al. (2016).

Género Omiodes Guenée, 1854

145. Omiodes indicata (Fabricius, 1775)

Material examinado. PERÚ. 1 †, 012 LEP-GJN, Piura, Universidad de Piura, $5^{\circ} 10^{\prime} 11^{\prime \prime} \mathrm{S}-80^{\circ} 36^{\prime} 51^{\prime \prime} \mathrm{O}, 29 \mathrm{msnm}$, 19-II-2017, U. González leg., red entomológica, Bosque estacionalmente seco de llanura; 1 , Piura, Castilla, Universidad Nacional de Piura, $5^{\circ} 10^{\prime} 51^{\prime \prime} \mathrm{S}-80^{\circ} 37^{\prime} 31^{\prime \prime} \mathrm{O}$, 29 msnm, 12-IV-2017, U. González leg., red entomológica, Bosque estacionalmente seco ribereño; 1 ㅇ, Talara, Los Órganos, $4^{\circ} 10^{\prime} 38^{\prime \prime} \mathrm{S}-81^{\circ} 07^{\prime} 27^{\prime \prime} \mathrm{O}, 12 \mathrm{msnm}, 05-\mathrm{V}-2017$, G. Juárez leg., red entomológica, Desierto costero; 1 ㅇ, Paita, $5^{\circ} 04^{\prime} \mathrm{S}-81^{\circ} 06^{\prime} \mathrm{O}, 10 \mathrm{msnm}, 21-\mathrm{II}-2017$, G. Juárez leg., red entomológica, Bosque estacionalmente seco de llanura; 1 o. Sechura, Vice, $5^{\circ} 25^{\prime} \mathrm{S}-81^{\circ} 46^{\prime} \mathrm{O}, 10 \mathrm{msnm}, 12-\mathrm{XII}-2017$, U. González leg., red entomológica, Desierto costero; 1 , Sechura, Laguna Napique, $5^{\circ} 34^{\prime} \mathrm{S}-81^{\circ} 16^{\prime} \mathrm{O}, 16 \mathrm{msnm}, 24-\mathrm{VI}-$ 2019, U. González leg., red entomológica, Bosque estacionalmente seco ribereño.

Distribución (Provincia) (PAisaje ecológico). (PIU, PAI, TAL, $\mathrm{SECH})(\mathrm{DESc}, \mathrm{BESr}, \mathrm{BES} 11)$.

Comentario. Especie citada como Omiodes sp en Juárez et al. (2016). Adultos se encuentran sobre hojas de plántulas y árboles, siempre en solitario.

Género Cnaphalocrocis Lereder, 1863

146. Cnaphalocrocis sin identificar sp. 1.

Material examinado. PERÚ. 1 \&, Piura, Universidad de Piura, 5॰10'11"S-80³6'51"O, 29 msnm, 19-II-2017, U. González leg., red entomológica, Bosque estacionalmente seco de llanura.

Distribución (Provincia) (Paisaje ecológico). (PIU) (BESli).

Comentario. Los adultos se encuentran sobre hojas de plántulas y árboles, en solitario. Especie citada también por Juárez et al. (2016).

Familia Sphingidae Latreille, 1802

Género Erinnyis Hübner, 1819

147. Erinnyis sin identificar sp. 1.

Material examinado. Perú. 1 , Piura, Universidad de Piura, 5 10'11"S-80³6'51"O, 29 msnm, 19-II-2017, U. González leg., red entomológica, Bosque estacionalmente seco de llanura.
Distribución (Provincia) (Paisaje ecológico). (PIU) (BESll).

COMENTARIo. El adulto se encontró sobre hojas de árboles, en solitario. Especie citada también por Juárez et al. (2016).

Familia Geometridae Leach, 1815

Género Synchlora Guenée, 1857

148. Synchlora $\sin$ identificar sp 1

Material examinado. PeRÚ. 1 , Piura, Universidad de Piura, 5¹0'11"S-80³6'51"O, 29 msnm, 19-II-2017, U. González leg., red entomológica, Bosque estacionalmente seco de llanura; 1 q, Piura, Castilla, Universidad Nacional de Piura, 5¹0'51"S-80³7'31"O, 29 msnm, 12-IV-2017, U. González leg., red entomológica, Bosque estacionalmente seco ribereño. Distribución (Provincia) (Paisaje ecológico). (PIU) (BESr, BESll).

Comentario. Los adultos se encuentran sobre hojas de plántulas y árboles, en solitario. Especie citada también por Juárez et al. (2016).

Género Cyclophora Hübner, 1822

149. Cyclophora sin identificar sp 1

Material examinado. Perú. 1 \%, Piura, Universidad de Piura, 5¹0'11"S-80³6'51"O, 29 msnm, 19-II-2017, U. González leg., red entomológica, Bosque estacionalmente seco de llanura; 1 +, Piura, Castilla, Universidad Nacional de Piura, 5 $10^{\prime} 51^{\prime \prime}$ S-80³7'31"O, 29 msnm, 12-IV-2017, U. González leg., red entomológica, Bosque estacionalmente seco ribereño. Distribución (Provincia) (Paisaje ecológico). (PIU) (BESr, BESIl).

Comentario. Los adultos se encuentran sobre hojas de plántulas y árboles, en solitario. Especie citada también por Juárez et al. (2016).

Familia Erebidae Leach, 1815

Género Hypercompe Hübner, 1819

150. Hypercompe sin identificar $\mathrm{sp} 1$

Material examinado. PERÚ. 1 , Piura, Universidad de Piura, 5॰10'11"S-80³6'51"O, 29 msnm, 19-II-2017, U. González leg., red entomológica, Bosque estacionalmente seco de llanura; 1 , , Piura, Castilla, Universidad Nacional de Piura, 5¹0'51"S-80³7'31"O, 29 msnm, 12-IV-2017, U. González leg., red entomológica, Bosque estacionalmente seco ribereño; 1 ㅇ, Paita, $5^{\circ} 04^{\prime} \mathrm{S}-81^{\circ} 06^{\prime} \mathrm{O}, 10 \mathrm{msnm}, 21-\mathrm{II}-2017$, G. Juárez leg., red entomológica, Bosque estacionalmente seco de llanura; $1 \delta^{\lambda}$, Sullana, Salitral, $4^{\circ} 51^{\prime} 27^{\prime \prime} \mathrm{S}-80^{\circ} 40^{\prime} 52^{\prime \prime} \mathrm{O}, 23 \mathrm{msnm}$, 18-I-2016, G. Juárez leg., red entomológica, Bosque estacionalmente seco de llanura.

Distribución (Provincia) (Paisaje ecológico). (PIU, SUll, PAi) (BESr, BESIl).

COMEnTARIO. Los adultos se encuentran sobre hojas de plántulas y árboles, en solitario. Especie citada también por Juárez et al. (2016).

Familia Noctuidae Latreille, 1809

Género Melipotis Hübner, 1818

151. Melipotis $\sin$ identificar sp. 1. (Fig. 15)

Material examinado. PERÚ. 2 우, Piura, Universidad de Piura, 5 10'11"S-80³6'51"O, 29 msnm, 19-II-2017, U. González leg., red entomológica, Bosque estacionalmente seco de llanura; 2 우, Piura, Castilla, Universidad Nacional de Piura, 5 10'51"S-80³7'31"O, 29 msnm, 12-IV-2017, U. González leg., red entomológica, Bosque estacionalmente seco ribereño; 1 ô, 1 ㅇ, Sullana, Salitral, 451'27"S-80 40'52"O, 23 msnm, 18-I-2016, G. Juárez leg., red entomológica, Bosque estacionalmente seco de llanura; 1 , , Paita, $5^{\circ} 04^{\prime} \mathrm{S}-81^{\circ} 06^{\prime} \mathrm{O}$, 10 msnm, 21-II-2017, G. Juárez leg., red entomológica, 
Bosque estacionalmente seco de llanura; $1 \hat{\partial}$, Sechura, Vice, $5^{\circ} 25^{\prime} \mathrm{S}-81^{\circ} 46^{\prime} \mathrm{O}, 10 \mathrm{msnm}, 12-\mathrm{XII}-2017$, U. González leg., red entomológica, Desierto costero; $1 \AA$, Sechura, Laguna Ñapique, $5^{\circ} 34^{\prime} \mathrm{S}-81^{\circ} 16^{\prime} \mathrm{O}, 16$ msnm, 24-VI-2019, U. González leg., red entomológica, Bosque estacionalmente seco ribereño; 1 을, Morropón, Chulucanas, $5^{\circ} 05^{\prime} \mathrm{S}-80^{\circ} 99^{\prime} \mathrm{O}, 350 \mathrm{msnm}$, 22-I-2015, G. Juárez leg., red entomológica, Bosque estacionalmente seco de colina.

Distribución (Provincia) (Paisaje ecológico). (PIU, SUll, PAi, SECH, MORR) (DESc, BESr, BESll, BESc-m).

COMENTARIO. Los adultos y larvas se encuentran sobre las hojas de plántulas y árboles, en solitario. Insecto que se comporta como fitófago (Vargas, 2010). Especie citada también por Juárez et al. (2016).

152. Melipotis $\sin$ identificar sp. 2.

Material examinado. Perú. 1 \%, Piura, Universidad de Piura, 5¹0'11"S-80³6'51"O, 29 msnm, 19-II-2017, U. González leg., red entomológica, Bosque estacionalmente seco de llanura; 1 ․, Piura, Castilla, Universidad Nacional de Piura, 5¹0'51"S-80³7'31"O, 29 msnm, 12-IV-2017, U. González leg., red entomológica, Bosque estacionalmente seco ribereño; 1 ㅇ, Sullana, Salitral, $4^{\circ} 51^{\prime} 27^{\prime \prime} \mathrm{S}-80^{\circ} 40^{\prime} 52^{\prime \prime} \mathrm{O}, 23 \mathrm{msnm}, 18-\mathrm{I}-$ 2016, G. Juárez leg., red entomológica, Bosque estacionalmente seco de llanura; 1 \% , Paita, $5^{\circ} 04^{\prime} \mathrm{S}-81^{\circ} 06^{\prime} \mathrm{O}, 10 \mathrm{msnm}$, 21-II-2017, G. Juárez leg., red entomológica, Bosque estacionalmente seco de llanura.

Distribución (Provincia) (Paisaje ecológico). (PIU, SUlL, PAI) (BESr, BESll).

Comentario. Los adultos y Larvas se encuentran sobre las hojas de plántulas y árboles, en solitario. Insecto que se comporta como fitófago (Vargas, 2010). Especie citada también por Juárez et al. (2016).

\section{Género Magusa Walker, 1857}

153. Magusa sin identificar sp. 1. (Fig. 16)

Material examinado. Perú. 1 q, Piura, Universidad de Piura, 5¹0'11"S-80³6'51"O, 29 msnm, 19-II-2017, U. González leg., red entomológica, Bosque estacionalmente seco de llanura; 1 , Piura, Castilla, Universidad Nacional de Piura, $5^{\circ} 10^{\prime} 51^{\prime \prime} \mathrm{S}-80^{\circ} 37^{\prime} 31^{\prime \prime} \mathrm{O}, 29$ msnm, 12-IV-2017, U. González leg., red entomológica, Bosque estacionalmente seco ribereño.

Distribución (Provincia) (PAisaje ecológico). (PIU) (BESr, BESII).

Comentario. Los adultos se encuentran sobre hojas de plántulas y árboles, en solitario. Especie citada también por Juárez et al. (2016).

Orden HYMENOPTERA Linnaeus, 1758

Familia Platygastridae Haliday, $1833 \dagger$

Subfamilia Telenominae Thomson, $1860 \dagger$

Género Telenomus Haliday, 1833 †

154. Telenomus alecto Crawford, $1914+$

Material examinado. Perú. 1 , Piura, Universidad de Piura, $5^{\circ} 10^{\prime} 11^{\prime \prime} \mathrm{S}-80^{\circ} 36^{\prime} 51^{\prime \prime} \mathrm{O}, 29 \mathrm{msnm}, 19-\mathrm{II}-2017$, U. González leg., red entomológica, Bosque estacionalmente seco de llanura; 1 \&, Piura, Castilla, Universidad Nacional de Piura, $5^{\circ} 10^{\prime} 51^{\prime \prime} \mathrm{S}-80^{\circ} 37^{\prime} 31^{\prime \prime} \mathrm{O}, 29 \mathrm{msnm}, 12-\mathrm{IV}-2017$, U. González leg., red entomológica, Bosque estacionalmente seco ribereño; 1 ㅇ, Sullana, Salitral, $4^{\circ} 51^{\prime} 27^{\prime \prime} \mathrm{S}-80^{\circ} 40^{\prime} 52^{\prime \prime} \mathrm{O}, 23 \mathrm{msnm}, 18-\mathrm{I}-$ 2016, G. Juárez leg., red entomológica, Bosque estacionalmente seco de llanura.

Distribución (Provincia) (Paisaje ecológico). (PIU, SUlL) (BESr, BESll).
Comentario. Los adultos se encuentran sobre hojas de plántulas y árboles, en solitario. Controlador biológico que se comporta como parasitoide principalmente de larvas de lepidópteros (Masner, 1976).

Familia Aphelinidae Thomson, 1876

Subfamilia Coccophaginae Förster, 1878 †

Género Encarsia Förster, $1878 \dagger$

155. Encarsia sin identificar sp. $1 . \dagger$

Material examinado. PERÚ. 1 , Piura, Universidad de Piura, 510'11"S-80³6'51"O, 29 msnm, 19-II-2017, U. González leg., red entomológica, Bosque estacionalmente seco de llanura; 1 क, Piura, Castilla, Universidad Nacional de Piura, 5¹0'51"S-80³7'31"O, 29 msnm, 12-IV-2017, U. González leg., red entomológica, Bosque estacionalmente seco ribereño.

Distribución (Provincia) (Paisaje ecológico). (PIU) (BESr, BESli).

Comentario. Los adultos se encuentran sobre hojas de plántulas y árboles, en solitario. Controlador biológico que se comporta como parasitoide principalmente de adultos de Aleyrodidae (Myartseva \& Evans, 2007).

Subfamilia Aphelininae Thomson

Género Aphytis Howard, 1900

156. Aphytis chrysomphali Mercet, 1912

Material eXaminado. PERÚ. 2 우, Piura, Universidad de Piura, 5॰10'11"S-80³6'51"O, 29 msnm, 19-II-2017, U. González leg., red entomológica, Bosque estacionalmente seco de llanura; 1 9, Piura, Castilla, Universidad Nacional de Piura, 5¹0'51"S-80³7'31"O, 29 msnm, 12-IV-2017, U. González leg., red entomológica, Bosque estacionalmente seco ribereño;

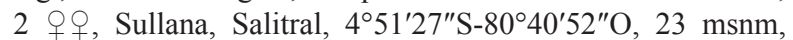
18-I-2016, G. Juárez leg., red entomológica, Bosque estacionalmente seco de llanura.

Distribución (Provincia) (Paisaje ecológico). (PIU, SULL) (BESr, BESll).

Comentario. Especie citada como Aphytis sp en Juárez et al. (2016). Los adultos se encuentran sobre hojas de plántulas y árboles, en solitario. Controlador biológico que se comporta como parasitoide principalmente de adultos de Coccidae (Myartseva et al., 2010).

Familia Chalcididae Latreille, 1817

Subfamilia Chalcidinae Latreille, 1817

Género Brachymeria Westwood, 1829

157. Brachymeria podagrica (Fabricius, 1787)

Material examinado. Perú. 2 우, 015 HYM-GJN, Piura, Universidad de Piura, 5 $5^{\circ} 10^{\prime} 11^{\prime \prime} \mathrm{S}-80^{\circ} 36^{\prime} 51^{\prime \prime} \mathrm{O}, 29 \mathrm{msnm}$, 19-II-2017, U. González leg., red entomológica, Bosque estacionalmente seco de llanura; 1 $\uparrow, 1 \hat{\jmath}$, Piura, Castilla, Universidad Nacional de Piura, $5^{\circ} 10^{\prime} 51^{\prime \prime} \mathrm{S}-80^{\circ} 37^{\prime} 31^{\prime \prime} \mathrm{O}$, 29 msnm, 12-IV-2017, U. González leg., red entomológica, Bosque estacionalmente seco ribereño; $1 \hat{\partial}$, Sullana, Salitral, 451'27"S-8040'52"O, 23 msnm, 18-I-2016, G. Juárez leg., red entomológica, Bosque estacionalmente seco de llanura; 1 ㅇ, Talara, Los Órganos, $4^{\circ} 10^{\prime} 38^{\prime \prime} \mathrm{S}-81^{\circ} 07^{\prime} 27^{\prime \prime} \mathrm{O}, 12 \mathrm{msnm}$, 05-V-2017, G. Juárez leg., red entomológica, Desierto costero; 1 ㅇ, Paita, $5^{\circ} 04^{\prime} \mathrm{S}-81^{\circ} 06^{\prime} \mathrm{O}, 10 \mathrm{msnm}, 21-\mathrm{II}-2017$, G. Juárez leg., red entomológica, Bosque estacionalmente seco de llanura; 1 ㅇ, La Huaca, 454'S-8057'O, 10 msnm, 21-II-2017, G. Juárez leg., red entomológica, Bosque estacionalmente seco de llanura; 1 ㅇ, Sechura, Vice, $5^{\circ} 25^{\prime} \mathrm{S}-81^{\circ} 46^{\prime} \mathrm{O}, 10 \mathrm{msnm}$, 12-XII-2017, U. González leg., red entomológica, Desierto costero; $2 \hat{\partial}^{\hat{\partial}}$, Sechura, Laguna Napique, $5^{\circ} 34^{\prime} \mathrm{S}-81^{\circ} 16^{\prime} \mathrm{O}$, 16 msnm, 24-VI-2019, U. González leg., red entomológica, 
Bosque estacionalmente seco ribereño; 1 \&, Morropón, Chulucanas, $5^{\circ} 05^{\prime} \mathrm{S}-80^{\circ} 99^{\prime} \mathrm{O}, 350 \mathrm{msnm}, 22-\mathrm{I}-2015$, G. Juárez leg., red entomológica, Bosque estacionalmente seco

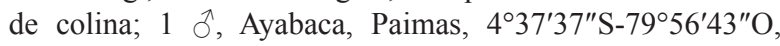
473 msnm, 26-VII-2015, G. Juárez leg., red entomológica, Bosque estacionalmente seco de llanura; 1 त, Huancabamba, Huarmaca, 534'04"S-79³1'26"O, 1223 msnm, 26-VII-2016, G. Juárez leg., red entomológica, Bosque estacionalmente seco de colina.

Distribución (Provincia) (Paisaje ecológico). (PIU, SUlL, PAI, TAL, SECH, MORR, AYA, HUA) (DESc, BESr, BESll, BESc-m).

Comentario. Especie citada como Brachymeria sp en Juárez et al. (2016). Los adultos se encuentran sobre hojas de plántulas y árboles, en solitario. Controlador biológico que se comporta como parasitoide principalmente de larvas de dípteros (Marchiori et al., 2002).

Familia Eulophidae Westwood, 1829

Subfamilia Entedoninae Förster, 1856

Género Chrysocharis Förster, 1856

158. Chrysocharis vonones (Walker, 1839)

Material examinado. PERÚ. 1 q, 020 HYM-GJN, Piura, Universidad de Piura, 5 $5^{\circ} 10^{\prime} 11^{\prime \prime} \mathrm{S}-80^{\circ} 36^{\prime} 51^{\prime \prime} \mathrm{O}, 29 \mathrm{msnm}$, 19-II-2017, U. González leg., red entomológica, Bosque estacionalmente seco de llanura; 1 \&, Piura, Castilla, Universidad Nacional de Piura, $5^{\circ} 10^{\prime} 51^{\prime \prime} \mathrm{S}-80^{\circ} 37^{\prime} 31^{\prime \prime} \mathrm{O}$, 29 msnm, 12-IV-2017, U. González leg., red entomológica, Bosque estacionalmente seco ribereño; $1 \hat{\delta}$, Sullana, Salitral, $4^{\circ} 51^{\prime 2} 27^{\prime \prime S}-80^{\circ} 40^{\prime} 52^{\prime \prime} \mathrm{O}, 23$ msnm, 18-I-2016, G. Juárez leg., red entomológica, Bosque estacionalmente seco de llanura; 1 ․, Talara, Los Órganos, $4^{\circ} 10^{\prime} 38^{\prime \prime} \mathrm{S}-81^{\circ} 07^{\prime} 27^{\prime \prime} \mathrm{O}, 12 \mathrm{msnm}$, 05-V-2017, G. Juárez leg., red entomológica, Desierto costero; 1 을 Paita, $5^{\circ} 04^{\prime} \mathrm{S}-81^{\circ} 06^{\prime} \mathrm{O}, 10 \mathrm{msnm}, 21-\mathrm{II}-2017$, G. Juárez leg., red entomológica, Bosque estacionalmente seco de lla-

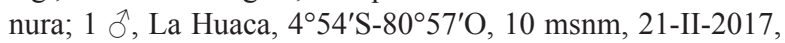
G. Juárez leg., red entomológica, Bosque estacionalmente seco de llanura; $1 \mathrm{O}^{\lambda}$, Sechura, Vice, $5^{\circ} 25^{\prime} \mathrm{S}-81^{\circ} 46^{\prime} \mathrm{O}, 10 \mathrm{msnm}$, 12-XII-2017, U. González leg., red entomológica, Desierto costero; 1 đo, Sechura, Laguna Napique, $5^{\circ} 34^{\prime} \mathrm{S}-81^{\circ} 16^{\prime} \mathrm{O}$, 16 msnm, 24-VI-2019, U. González leg., red entomológica, Bosque estacionalmente seco ribereño.

Distribución (Provincia) (Paisaje ecológico). (PIU, SUlL, PAi, TAL, SECH) (DESc, BESr, BESll, BESc-m).

Comentario. Especie citada como Chrysocharis sp en Juárez et al. (2016). Los adultos se encuentran sobre hojas de plántulas y árboles, en solitario. Controlador biológico que se comporta como parasitoide principalmente de larvas de Agromyzidae (Hansson, 1995).

Familia Pteromalidae Dalman, 1820

Subfamilia Pteromalinae Dalman, 1820

Género Dibrachys Förster, 1856

159. Dibrachys microgastri (Bouché, 1834)

Material examinado. PERÚ. 1 o, 021 HYM-GJN, Piura, Universidad de Piura, 5 $5^{\circ} 10^{\prime} 11^{\prime \prime} \mathrm{S}-80^{\circ} 36^{\prime} 51^{\prime \prime} \mathrm{O}, 29 \mathrm{msnm}$, 19-II-2017, U. González leg., red entomológica, Bosque estacionalmente seco de llanura; 1 , Piura, Castilla, Universidad Nacional de Piura, $5^{\circ} 10^{\prime} 51^{\prime \prime} \mathrm{S}-80^{\circ} 37^{\prime} 31^{\prime \prime} \mathrm{O}$, 29 msnm, 12-IV-2017, U. González leg., red entomológica, Bosque estacionalmente seco ribereño; $1 \hat{\jmath}$, Sullana, Salitral, 451'27"S-8040'52"O, 23 msnm, 18-I-2016, G. Juárez leg., red entomológica, Bosque estacionalmente seco de llanura.

Distribución (Provincia) (Paisaje ecológico). (PIU, SUlL) (BESr, BESll).
Comentario. Especie citada como morfoespecie 1 en Juárez et al. (2016). Los adultos se encuentran sobre hojas de plántulas y árboles, en solitario. Controlador biológico que se comporta como parasitoide principalmente de larvas de dípteros (Peters \& Baur, 2011).

Familia Trichogrammatidae Haliday, 1851

Género Trichogramma Westwood, 1833

160. Trichogramma (Trichogramma) pretiosum Riley, 1879

Material examinado. PERÚ. 1 q, 024 HYM-GJN, Piura, Universidad de Piura, $5^{\circ} 10^{\prime} 11^{\prime \prime} \mathrm{S}-80^{\circ} 36^{\prime} 51^{\prime \prime} \mathrm{O}, 29 \mathrm{msnm}, 19-\mathrm{II}-$ 2017, U. González leg., agitación de follaje, Bosque estacionalmente seco de llanura; 1 , , Piura, Castilla, Universidad Nacional de Piura, $5^{\circ} 10^{\prime} 51^{\prime \prime} \mathrm{S}-80^{\circ} 37^{\prime} 31^{\prime \prime} \mathrm{O}, 29 \mathrm{msnm}, 12-\mathrm{IV}-2017$, U. González leg., agitación de follaje, Bosque estacionalmente seco ribereño; $1 \hat{\jmath}$, Sullana, Salitral, $4^{\circ} 51^{\prime} 27^{\prime \prime} \mathrm{S}-80^{\circ} 40^{\prime} 52^{\prime \prime} \mathrm{O}$, 23 msnm, 18-I-2016, G. Juárez leg., red entomológica, Bosque estacionalmente seco de llanura; 1 , Talara, Los Órganos, $4^{\circ} 10^{\prime} 38^{\prime \prime} \mathrm{S}-81^{\circ} 07^{\prime} 27^{\prime \prime} \mathrm{O}, 12 \mathrm{msnm}, 05-\mathrm{V}-2017$, G. Juárez leg., red entomológica, Desierto costero; 1 , , Paita, $5^{\circ} 04^{\prime} \mathrm{S}-81^{\circ} 06^{\prime} \mathrm{O}$, 10 msnm, 21-II-2017, G. Juárez leg., red entomológica, Bosque estacionalmente seco de llanura; 1 + , La Huaca, $4^{\circ} 54^{\prime} \mathrm{S}-80^{\circ} 57^{\prime} \mathrm{O}$, 10 msnm, 21-II-2017, G. Juárez leg., agitación de follaje, Bosque estacionalmente seco de llanura; 1 ㅇ, Sechura, Vice, 5²5'S-8146'O, 10 msnm, 12-XII-2017, U. González leg., red entomológica, Desierto costero; $1 \hat{\partial}$, Sechura, Laguna Ñapique, $5^{\circ} 34^{\prime} \mathrm{S}-81^{\circ} 16^{\prime} \mathrm{O}, 16$ msnm, 24-VI-2019, U. González leg., red entomológica, Bosque estacionalmente seco ribereño; 1 ㅇ, Morropón, Chulucanas, $5^{\circ} 05^{\prime} \mathrm{S}-80^{\circ} 99^{\prime} \mathrm{O}, 350 \mathrm{msnm}, 22-\mathrm{I}-$ 2015, G. Juárez leg., red entomológica, Bosque estacionalmente seco de colina; $1 \hat{O}^{\lambda}$, Ayabaca, Paimas, 437'37"'S-7956' $43^{\prime \prime} \mathrm{O}$, 473 msnm, 26-VII-2015, G. Juárez leg., red entomológica, Bosque estacionalmente seco de llanura; $1 \hat{\jmath}$, Huancabamba, Huarmaca, 534'04"S-79³1'26"O, 1223 msnm, 26-VII-2016, G. Juárez leg., agitación de follaje, Bosque estacionalmente seco de colina.

Distribución (Provincia) (Paisaje ecológico). (PIU, SUll, PAi, TAL, SECH, MORR, AYA, HUA) (DESc, BESr, BESll, BESc-m).

Comentario. Especie citada como Trichogramma sp en Juárez et al. (2016). Los adultos se encuentran sobre hojas de plántulas y árboles, en solitario. Controlador biológico que se comporta como parasitoide principalmente de larvas de lepidópteros (Whu \& Valdivieso, 1999).

Familia Braconidae Nees, 1811

Subfamilia Microgastrinae Förster, 1862

Género Apanteles Förster, $1862 \dagger$

161. Apanteles $\sin$ identificar sp. $1 . \dagger$

Material examinado. PERÚ. 1 , Piura, Universidad de Piura, 5¹0'11"S-80³6'51"O, 29 msnm, 19-II-2017, U. González leg., red entomológica, Bosque estacionalmente seco de llanura; 1 ㅇ, Piura, Castilla, Universidad Nacional de Piura, 5¹0'51"S-80³7'31"O, 29 msnm, 12-IV-2017, U. González leg., red entomológica, Bosque estacionalmente seco ribereño; 1 ồ, Sullana, Salitral, 451'27"S-8040'52"O, 23 msnm, 18-I2016, G. Juárez leg., red entomológica, Bosque estacionalmente seco de llanura; 1 q, Sechura, Vice, $5^{\circ} 25^{\prime} \mathrm{S}-81^{\circ} 46^{\prime} \mathrm{O}$, 10 msnm, 12-XII-2017, U. González leg., red entomológica, Desierto costero.

Distribución (Provincia) (Paisaje ecológico). (PIU, SULL, SECH) (DESc, BESr, BESll).

Comentario. Los adultos se encuentran sobre hojas de plántulas y árboles, en solitario. 
Género Cotesia Cameron, 1891

162. Cotesia flavipes Cameron, 1891

Material examinado. PeRÚ. 1 q, 029 HYM-GJN, Piura, Universidad de Piura, $5^{\circ} 10^{\prime} 11^{\prime \prime} \mathrm{S}-80^{\circ} 36^{\prime} 51^{\prime \prime} \mathrm{O}, 29 \mathrm{msnm}$, 19-II-2017, U. González leg., red entomológica, Bosque estacionalmente seco de llanura; 1 + , Piura, Castilla, Universidad Nacional de Piura, $5^{\circ} 10^{\prime} 51^{\prime \prime} \mathrm{S}-80^{\circ} 37^{\prime} 31^{\prime \prime} \mathrm{O}$, 29 msnm, 12-IV-2017, U. González leg., red entomológica, Bosque estacionalmente seco ribereño; 1 ते, Sullana, Salitral, 451'27"S-8040'52"O, 23 msnm, 18-I-2016, G. Juárez leg., red entomológica, Bosque estacionalmente seco de llanura.

Distribución (Provincia) (Paisaje ecológico). (PIU, SUlL) (BESr, BES1l).

Comentario. Especie citada como Cotesia sp en Juárez et al. (2016). Los adultos se encuentran sobre hojas de plántulas y árboles, en solitario. Controlador biológico que se comporta como parasitoide principalmente de larvas de lepidópteros (Astola-Mariscal \& Narrea-Cango, 2019).

Subfamilia Aphidiinae Haliday, $1834 \uparrow$

Género Aphidius Nees, $1819 \dagger$

163. Aphidius sin identificar sp. $1 . \dagger$

Material examinado. PERÚ. 1 q, Piura, Universidad de Piura, 5¹0'11"S-80³6'51"O, 29 msnm, 19-II-2017, U. González leg., red entomológica, Bosque estacionalmente seco de llanura; 1 ㅇ, Piura, Castilla, Universidad Nacional de Piura, 5 $10^{\prime} 51^{\prime \prime} \mathrm{S}-80^{\circ} 37^{\prime} 31^{\prime \prime} \mathrm{O}, 29 \mathrm{msnm}, 12-\mathrm{IV}-2017$, U. González leg., red entomológica, Bosque estacionalmente seco ribereño; 1 ठิ, Sullana, Salitral, $4^{\circ} 51^{\prime} 27^{\prime \prime} \mathrm{S}-80^{\circ} 40^{\prime} 52^{\prime \prime} \mathrm{O}$, 23 msnm, 18-I-2016, G. Juárez leg., red entomológica, Bosque estacionalmente seco de llanura; 1 , Talara, Los Órganos, $4^{\circ} 10^{\prime} 38^{\prime \prime} \mathrm{S}-81^{\circ} 07^{\prime} 27^{\prime \prime} \mathrm{O}, 12 \mathrm{msnm}, 05-\mathrm{V}-2017, \mathrm{G}$ Juárez leg., red entomológica, Desierto costero; 1 q, Paita, $5^{\circ} 04^{\prime} \mathrm{S}-81^{\circ} 06^{\prime} \mathrm{O}, 10 \mathrm{msnm}, 21-\mathrm{II}-2017$, G. Juárez leg., red entomológica, Bosque estacionalmente seco de llanura; 1 , La Huaca, $4^{\circ} 54^{\prime} \mathrm{S}-80^{\circ} 57^{\prime} \mathrm{O}, 10$ msnm, 21-II-2017, G. Juárez leg., red entomológica, Bosque estacionalmente seco de llanura.

Distribución (Provincia) (Paisaje ecológico). (PIU, SUll, PAi, TAL) (DESc, BESr, BESll, BESc-m).

Comentario. Los adultos se encuentran sobre hojas de plántulas y árboles, en solitario. Especie citada también por NúñezSacarías (1993).

Subfamilia Braconinae Nees, 1811

Género Habrobracon Ashmead, 1895

164. Habrobracon hebetor (Say, 1836)

Material examinado. PeRÚ. 1 q, Piura, Universidad de Piura, $5^{\circ} 10^{\prime} 11^{\prime \prime} \mathrm{S}-80^{\circ} 36^{\prime} 51^{\prime \prime} \mathrm{O}, 29 \mathrm{msnm}, 19-\mathrm{II}-2017$, U. González leg., red entomológica, Bosque estacionalmente seco de llanura; 1 , Piura, Castilla, Universidad Nacional de

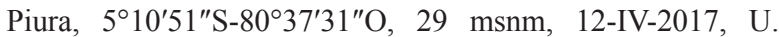
González leg., red entomológica, Bosque estacionalmente seco ribereño; 1 ภ, Sullana, Salitral, $4^{\circ} 51^{\prime} 27^{\prime \prime} \mathrm{S}-80^{\circ} 40^{\prime} 52^{\prime \prime} \mathrm{O}$, 23 msnm, 18-I-2016, G. Juárez leg., red entomológica, Bosque estacionalmente seco de llanura; 1 , Talara, Los Órganos, $4^{\circ} 10^{\prime} 38^{\prime \prime} \mathrm{S}-81^{\circ} 07^{\prime} 27^{\prime \prime} \mathrm{O}, 12 \mathrm{msnm}, 05-\mathrm{V}-2017$, G. Juárez leg., red entomológica, Desierto costero; 1 ㅇ, Paita, $5^{\circ} 04^{\prime} \mathrm{S}-81^{\circ} 06^{\prime} \mathrm{O}, 10 \mathrm{msnm}, 21-\mathrm{II}-2017$, G. Juárez leg., red entomológica, Bosque estacionalmente seco de llanura; 1 우

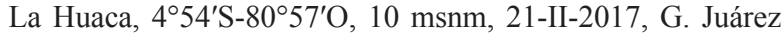
leg., agitación de follaje, Bosque estacionalmente seco de llanura; 1 ㅇ, Sechura, Vice, $5^{\circ} 25^{\prime} \mathrm{S}-81^{\circ} 46^{\prime} \mathrm{O}, 10 \mathrm{msnm}, 12$-XII2017, U. González leg., red entomológica, Desierto costero;
$1 \hat{\partial}$, Sechura, Laguna Napique, $5^{\circ} 34^{\prime} \mathrm{S}-81^{\circ} 16^{\prime} \mathrm{O}, 16 \mathrm{msnm}$, 24-VI-2019, U. González leg., red entomológica, Bosque estacionalmente seco ribereño; 1 +, Morropón, Chulucanas, $5^{\circ} 05^{\prime} \mathrm{S}-80^{\circ} 99^{\prime} \mathrm{O}, 350 \mathrm{msnm}, 22-\mathrm{I}-2015$, G. Juárez leg., red entomológica, Bosque estacionalmente seco de colina; 1

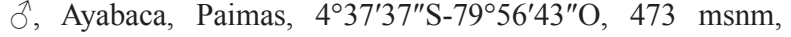
26-VII-2015, G. Juárez leg., red entomológica, Bosque estacionalmente seco de llanura; $1 \hat{\delta}$, Huancabamba, Huarmaca, 5³4'04"S-79³1'26"O, 1223 msnm, 26-VII-2016, G. Juárez leg., red entomológica, Bosque estacionalmente seco de colina.

Distribución (Provincia) (PAisaje ecológico). (PIU, SULL, PAI, TAL, SECH, MORR, AYA, HUA) (DESc, BESr, BESll, BESc-m).

COMEnTARIo. Los adultos se encuentran sobre hojas de plántulas y árboles, en solitario. Controlador biológico que se comporta como parasitoide principalmente de larvas de lepidópteros (Redolfi de Huiza, 1994). Especie citada como Bracon hebetor por Domínguez (1982), Núñez-Sacarías (1993) y Juárez et al. (2016).

Género Digonogastra Viereck, $1912 \dagger$

165. Digonogastra rimac (Wolcott, 1929) $\dagger$

Material examinado. PERÚ. 1 †, Piura, Universidad de Piura, 510'11"S-80³6'51"O, 29 msnm, 19-II-2017, U. González leg., red entomológica, Bosque estacionalmente seco de llanura; 1 ㅇ, Piura, Castilla, Universidad Nacional de Piura, 510'51"S-80³7'31"O, 29 msnm, 12-IV-2017, U. González leg., red entomológica, Bosque estacionalmente seco ribereño; $1 \hat{\partial}$, Sullana, Salitral, $4^{\circ} 51^{\prime} 27^{\prime \prime} \mathrm{S}-80^{\circ} 40^{\prime} 52^{\prime \prime} \mathrm{O}$, 23 msnm, 18-I-2016, G. Juárez leg., red entomológica, Bosque estacionalmente seco de llanura; 1 + , Talara, Los Órganos, $4^{\circ} 10^{\prime} 38^{\prime \prime} \mathrm{S}-81^{\circ} 07^{\prime} 27^{\prime \prime} \mathrm{O}, 12 \mathrm{msnm}, 05-\mathrm{V}-2017$, G. Juárez leg., red entomológica, Desierto costero; 1 , Paita, $5^{\circ} 04^{\prime} \mathrm{S}-81^{\circ} 06^{\prime} \mathrm{O}, 10 \mathrm{msnm}, 21-\mathrm{II}-2017$, G. Juárez leg., red entomológica, Bosque estacionalmente seco de llanura; 1 , La Huaca, 454'S-8057'O, 10 msnm, 21-II-2017, G. Juárez leg., agitación de follaje, Bosque estacionalmente seco de llanura; 1 ㅇ, Sechura, Vice, $5^{\circ} 25^{\prime} \mathrm{S}-81^{\circ} 46^{\prime} \mathrm{O}, 10 \mathrm{msnm}, 12-\mathrm{XII}-$ 2017, U. González leg., red entomológica, Desierto costero; $1 \hat{\partial}$, Sechura, Laguna Ñapique, $5^{\circ} 34^{\prime} \mathrm{S}-81^{\circ} 16^{\prime} \mathrm{O}, 16 \mathrm{msnm}$, 24-VI-2019, U. González leg., red entomológica, Bosque estacionalmente seco ribereño.

Distribución (Provincia) (Paisaje ecológico). (PIU, SUll, PAi, TAL, SECH) (DESc, BESr, BESII).

COMENTARIo. Los adultos se encuentran sobre hojas de plántulas y árboles, en solitario. Controlador biológico que se comporta como parasitoide principalmente de larvas de lepidópteros (Redolfi de Huiza, 1994). Especie citada como Iphiaulax rimac por Domínguez (1982) y Núñez-Sacarías (1993).

Subfamilia Rogadinae Förster, $1862 \dagger$

Género Aleiodes Wesmael, 1838 †

166. Aleiodes gossypii (Muesebeck, 1960) †

Material examinado. PERÚ. 1 + , Piura, Universidad de Piura, 5¹0'11"S-80³6'51"O, 29 msnm, 19-II-2017, U. González leg., red entomológica, Bosque estacionalmente seco de llanura; 1 , Piura, Castilla, Universidad Nacional de Piura, 5¹0'51"S-80³7'31"O, 29 msnm, 12-IV-2017, U. González leg., red entomológica, Bosque estacionalmente seco ribereño; 1 ơ, Sullana, Salitral, 451'27"S-80 40'52"O, 23 msnm, 18-I-2016, G. Juárez leg., red entomológica, Bosque estacionalmente seco de llanura.

Distribución (Provincia) (Paisaje ecológico). (PIU, SULL) (BESr, BESll). 
Comentario. Los adultos se encuentran sobre hojas de plántulas y árboles, en solitario. Controlador biológico que se comporta como parasitoide principalmente de larvas de lepidópteros (Redolfi de Huiza, 1994). Especie citada también por Domínguez (1982) como Rogas gossypii.

Familia Ichneumonidae Latreille, 1802

Subfamilia Ophioninae Shuckard, 1840

Género Enicospilus Stephens, 1835

167. Enicospilus sin identificar sp. 1.

Material examinado. PERÚ. 2 우, Piura, Universidad de Piura, 510'11"S-80³6'51"O, 29 msnm, 19-II-2017, U. González leg., red entomológica, Bosque estacionalmente seco de llanura; 1 \&, Piura, Castilla, Universidad Nacional de Piura, 5¹0'51"S-80³7'31"O, 29 msnm, 12-IV-2017, U. González leg., red entomológica, Bosque estacionalmente seco ribe-

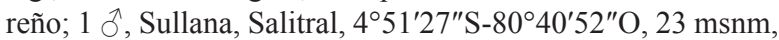
18-I-2016, G. Juárez leg., red entomológica, Bosque estacionalmente seco de llanura.

Distribución (Provincia) (Paisaje ecológico). (PIU, SUlL, PAI, TAL, SECH) (DESc, BESr, BESll).

COMENTARIO. Los adultos se encuentran sobre hojas de plántulas y árboles, en solitario. Especie citada también por Juárez et al. (2016).

Familia Apidae Latreille, 1802

Subfamilia Xylocopinae Latreille, 1802

Género Xylocopa Latreille, 1802

168. Xylocopa (Schonnherria) piurensis Cockerell, 1912

Material examinado. PERÚ. 1 †, 055 HYM-GJN, Piura, Universidad de Piura, $5^{\circ} 10^{\prime} 11^{\prime \prime} \mathrm{S}-80^{\circ} 36^{\prime} 51^{\prime \prime} \mathrm{O}, 29 \mathrm{msnm}$, 19-II-2017, U. González leg., red entomológica, Bosque estacionalmente seco de llanura; 2 우, Piura, Castilla, Universidad Nacional de Piura, $5^{\circ} 10^{\prime} 51^{\prime \prime} \mathrm{S}-80^{\circ} 37^{\prime} 31^{\prime \prime} \mathrm{O}$, 29 msnm, 12-IV-2017, U. González leg., red entomológica, Bosque estacionalmente seco ribereño; 1 , Sullana, Salitral, 451'27"S-8040'52"O, 23 msnm, 18-I-2016, G. Juárez leg., red entomológica, Bosque estacionalmente seco de llanura; 1 ㅇ, Talara, Los Órganos, $4^{\circ} 10^{\prime} 38^{\prime \prime} \mathrm{S}-81^{\circ} 07^{\prime} 27^{\prime \prime} \mathrm{O}, 12 \mathrm{msnm}$, 05-V-2017, G. Juárez leg., red entomológica, Desierto costero; 1 ㅇ, Paita, $5^{\circ} 04^{\prime} \mathrm{S}-81^{\circ} 06^{\prime} \mathrm{O}, 10 \mathrm{msnm}, 21-\mathrm{II}-2017$, G. Juárez leg., red entomológica, Bosque estacionalmente seco de llanura; 1 ㅇ, La Huaca, 454'S-8057'O, 10 msnm, 21-II-2017, G. Juárez leg., agitación de follaje, Bosque estacionalmente seco de llanura; 1 + , Sechura, Vice, $5^{\circ} 25^{\prime} \mathrm{S}-81^{\circ} 46^{\prime} \mathrm{O}, 10 \mathrm{msnm}$, 12-XII-2017, U. González leg., red entomológica, Desierto costero; 1 ㅇ, Sechura, Laguna Ñapique, $5^{\circ} 34^{\prime} \mathrm{S}-81^{\circ} 16^{\prime} \mathrm{O}$, 16 msnm, 24-VI-2019, U. González leg., red entomológica, Bosque estacionalmente seco ribereño; 1 , Morropón, Chulucanas, $5^{\circ} 05^{\prime} \mathrm{S}-80^{\circ} 99^{\prime} \mathrm{O}, 350 \mathrm{msnm}, 22-\mathrm{I}-2015$, G. Juárez leg., red entomológica, Bosque estacionalmente seco de colina; 1 을 Ayabaca, Paimas, 4³7'37"S-7956'43"O, 473 msnm, 26-VII-2015, G. Juárez leg., red entomológica, Bosque estacionalmente seco de llanura; 1 + , Huancabamba, Huarmaca, 534'04"S-79³1'26"O, 1000 msnm, 26-VII-2016, G. Juárez leg., red entomológica, Bosque estacionalmente seco de colina.

Distribución (Provincia) (Paisaje ecológico). (PIU, SUlL, PAi, TAL, SECH, MORR, AYA, HUA) (DESc, BESr, BESIl, BESc-m).

Comentario. Especie citada como Xylocopa sp en Juárez et al. (2016). Los adultos se encuentran sobrevolando y/o posadas sobre inflorescencias. Insecto que se comporta como polinizador.
Subfamilia Apinae Latreille, 1802

Género Apis Linnaeus, 1758

169. Apis mellifera Linnaeus, 1758

Material eXAminado. PERÚ. 2 o 9 , Piura, Universidad de Piura, 5¹0'11"S-80³6'51"O, 29 msnm, 19-II-2017, U. González leg., red entomológica, Bosque estacionalmente seco de llanura; 1 q, 1 ${ }^{\lambda}$, Piura, Castilla, Universidad Nacional de Piura, 5¹0'51"S-80³7'31"O, 29 msnm, 12-IV-2017, U. González leg., red entomológica, Bosque estacionalmente seco ribereño; 2 ठำ, Sullana, Salitral, $4^{\circ} 51^{\prime} 27^{\prime \prime} \mathrm{S}-80^{\circ} 40^{\prime} 52^{\prime \prime} \mathrm{O}$, 23 msnm, 18-I-2016, G. Juárez leg., red entomológica, Bosque estacionalmente seco de llanura; 1 +, 1 $\delta$, Talara, Los Órganos, $4^{\circ} 10^{\prime} 38^{\prime \prime} \mathrm{S}-81^{\circ} 07^{\prime} 27^{\prime \prime} \mathrm{O}, 12 \mathrm{msnm}, 05-\mathrm{V}-2017$, G. Juárez leg., red entomológica, Desierto costero; 2 우오, Paita, 504'S-81ํㅇ' O, 10 msnm, 21-II-2017, G. Juárez leg., red entomológica, Bosque estacionalmente seco de llanura;

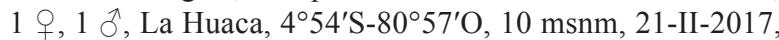
G. Juárez leg., agitación de follaje, Bosque estacionalmente seco de llanura; 1 ㅇ, 1 $\delta^{\prime}$, Sechura, Vice, $5^{\circ} 25^{\prime} \mathrm{S}-81^{\circ} 46^{\prime} \mathrm{O}$, 10 msnm, 12-XII-2017, U. González leg., red entomológica, Desierto costero; 1 ก, 2 우, Sechura, Laguna Ñapique, 5³4'S-81²16'O, 16 msnm, 24-VI-2019, U. González leg., red entomológica, Bosque estacionalmente seco ribereño; 2 우오, Morropón, Chulucanas, $5^{\circ} 05^{\prime} \mathrm{S}-80^{\circ} 99^{\prime} \mathrm{O}, 350 \mathrm{msnm}$, 22-I-2015, G. Juárez leg., red entomológica, Bosque estacionalmente seco de colina; 1 $\hat{\jmath}$, Ayabaca, Paimas, 4³7'37"S-7956'43"O, 473 msnm, 26-VII-2015, G. Juárez leg., red entomológica, Bosque estacionalmente seco de lla-

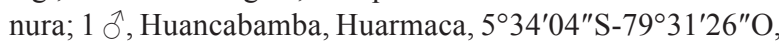
1000 msnm, 26-VII-2016, G. Juárez leg., red entomológica, Bosque estacionalmente seco de colina.

Distribución (Provincia) (Paisaje ecológico). (PIU, SUlL, PAI, TAL, SECH, MORR, AYA, HUA) (DESc, BESr, BESIl, BESc-m).

COMENTARIO. Los adultos se encuentran sobrevolando y/o posadas sobre inflorescencias, incluso construyen sus colonias en la copa de árboles. Insecto que se comporta como polinizador. Especie citada también por Domínguez (1982) y Juárez et al. (2016).

Género Nannotrigona Cockerell, 1922

170. Nannotrigona mellaria (Smith, 1862) (Fig. 17)

Material examinado. PERÚ. 1 q, 060 HYM-GJN, Piura, Universidad de Piura, 5¹0'11"S-80 36'51"O, 29 msnm, 19-II2017, U. González leg., red entomológica, Bosque estacionalmente seco de llanura; 1 , Piura, Castilla, Universidad Nacional de Piura, 5¹0'51"S-80³7'31"O, 29 msnm, 12-IV-2017, U. González leg., red entomológica, Bosque estacionalmente seco ribereño; $1 \delta^{\lambda}$, Sullana, Salitral, $4^{\circ} 51^{\prime} 27^{\prime \prime} \mathrm{S}-80^{\circ} 40^{\prime} 52^{\prime \prime} \mathrm{O}$, 23 msnm, 18-I-2016, G. Juárez leg., red entomológica, Bosque estacionalmente seco de llanura; 1 , Talara, Los Órganos, $4^{\circ} 10^{\prime} 38^{\prime \prime} \mathrm{S}-81^{\circ} 07^{\prime} 27^{\prime \prime} \mathrm{O}, 12$ msnm, 05-V-2017, G. Juárez leg., red entomológica, Desierto costero; 1 ㅇ, Paita, $5^{\circ} 04^{\prime} \mathrm{S}-81^{\circ} 06^{\prime} \mathrm{O}$, 10 msnm, 21-II-2017, G. Juárez leg., red entomológica, Bosque estacionalmente seco de llanura; 1 , , La Huaca, $4^{\circ} 54^{\prime} \mathrm{S}-80^{\circ} 57^{\prime} \mathrm{O}$, 10 msnm, 21-II-2017, G. Juárez leg., agitación de follaje, Bosque estacionalmente seco de llanura; 1 ㅇ, Sechura, Vice, $5^{\circ} 25^{\prime} \mathrm{S}-81^{\circ} 46^{\prime} \mathrm{O}, 10 \mathrm{msnm}, 12-\mathrm{XII}-2017$, U. González leg., red entomológica, Desierto costero; $1 \hat{\partial}$, Sechura, Laguna Napique, 534'S-81¹6'O, 16 msnm, 24-VI-2019, U. González leg., red entomológica, Bosque estacionalmente seco ribereño; 1 q, Morropón, Chulucanas, $5^{\circ} 05^{\prime} \mathrm{S}-80^{\circ} 99^{\prime} \mathrm{O}, 350 \mathrm{msnm}, 22-\mathrm{I}-2015$, G. Juárez leg., red entomológica, Bosque estacionalmente seco de colina. 
Distribución (Provincia) (Paisaje ecológico). (PIU, SUlL, PAI, TAL, SECH, MORR) (DESc, BESr, BESIl, BESc-m).

Comentario. Especie citada como Nannotrigona sp en Juárez et al. (2016). Los adultos se encuentran sobrevolando y/o posadas sobre inflorescencias, incluso construyen sus colonias sobre el tronco o grietas de árboles. Insecto que se comporta como polinizador.

Familia Crabronidae Latreille, $1802 \dagger$

Subfamilia Philanthinae Latreille, $1802 \dagger$

Género Cerceris Latreille, $1802 \dagger$

171. Cerceris sin identificar sp. $1 . \dagger$

Material examinado. PERÚ. $29 q$, Piura, Universidad de

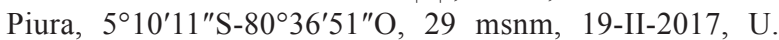
González leg., red entomológica, Bosque estacionalmente seco de llanura; 1 ㅇ, 1 $\hat{\jmath}$, Piura, Castilla, Universidad

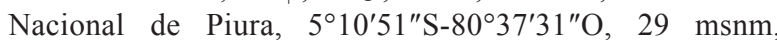
12-IV-2017, U. González leg., red entomológica, Bosque estacionalmente seco ribereño; $2 \hat{\jmath} \hat{o}$, Sullana, Salitral, 451'27"S-8040'52"O, 23 msnm, 18-I-2016, G. Juárez leg., red entomológica, Bosque estacionalmente seco de llanura; 1 , 1 Jे, Talara, Los Órganos, $4^{\circ} 10^{\prime} 38^{\prime \prime} \mathrm{S}-81^{\circ} 07^{\prime} 27^{\prime \prime} \mathrm{O}$, 12 msnm, 05-V-2017, G. Juárez leg., red entomológica, Desierto costero; 2 우, Paita, $5^{\circ} 04^{\prime} \mathrm{S}-81^{\circ} 06^{\prime} \mathrm{O}, 10 \mathrm{msnm}$, 21-II-2017, G. Juárez leg., red entomológica, Bosque estacionalmente seco de llanura; 1, 1 $\hat{O}$, La Huaca, 454'S-8057'O, 10 msnm, 21-II-2017, G. Juárez leg., agitación de follaje, Bosque estacionalmente seco de llanura; 1 ㅇ, $1 \hat{\delta}$, Sechura, Vice, $5^{\circ} 25^{\prime} \mathrm{S}-81^{\circ} 46^{\prime} \mathrm{O}, 10 \mathrm{msnm}, 12$-XII2017, U. González leg., red entomológica, Desierto costero; 1 ภ, 2 우, Sechura, Laguna Ñapique, $5^{\circ} 34^{\prime} \mathrm{S}-81^{\circ} 16^{\prime} \mathrm{O}$, 16 msnm, 24-VI-2019, U. González leg., red entomológica, Bosque estacionalmente seco ribereño; 2 우, Morropón, Chulucanas, $5^{\circ} 05^{\prime} \mathrm{S}-80^{\circ} 99^{\prime} \mathrm{O}, 350 \mathrm{msnm}, 22-\mathrm{I}-2015$, G. Juárez leg., red entomológica, Bosque estacionalmente seco

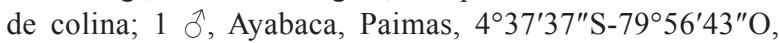
473 msnm, 26-VII-2015, G. Juárez leg., red entomológica, Bosque estacionalmente seco de llanura; 1 त. Huancabamba, Huarmaca, 5 $34^{\prime} 04^{\prime \prime} \mathrm{S}-79^{\circ} 31^{\prime} 26^{\prime \prime} \mathrm{O}, 1000 \mathrm{msnm}$, 26-VII2016, G. Juárez leg., red entomológica, Bosque estacionalmente seco de colina.

Distribución (Provincia) (Paisaje ecológico). (PIU, SUll, PAi, TAL, SECH, MORR, AYA, HUA) (DESc, BESr, BESll, BESc-m).

Comentario. Adultos se encuentran sobre hojas de plántulas y árboles, también sobrevolando alrededor de inflorescencias.

Familia Formicidae Latreille, 1809

Subfamilia Ponerinae Lepeletier de Saint-Fargeau, 1835

Género Odontomachus Latreille, 1804

172. Odontomachus sin identificar sp. 1.

Material examinado. PERÚ. 2 우, Piura, Universidad de Piura, 5¹0'11"S-80³6'51"O, 29 msnm, 19-II-2017, U. González leg., red entomológica, Bosque estacionalmente seco de lla-

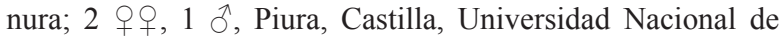

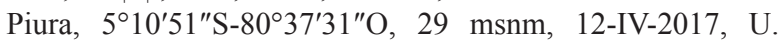
González leg., colecta manual, Bosque estacionalmente seco

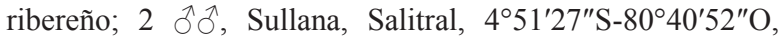
23 msnm, 18-I-2016, G. Juárez leg., agitación de follaje, Bosque estacionalmente seco de llanura; $1 \uparrow, 1 \hat{\jmath}$, Talara, Los Órganos, $4^{\circ} 10^{\prime} 38^{\prime \prime} \mathrm{S}-81^{\circ} 07^{\prime} 27^{\prime \prime} \mathrm{O}, 12 \mathrm{msnm}, 05-\mathrm{V}-2017$, G. Juárez leg., red entomológica, Desierto costero; 2 우, Paita, $5^{\circ} 04^{\prime} \mathrm{S}-81^{\circ} 06^{\prime} \mathrm{O}, 10 \mathrm{msnm}, 21-\mathrm{II}-2017$, G. Juárez leg., colecta manual, Bosque estacionalmente seco de llanura; 1 \%, $\mathrm{La}$

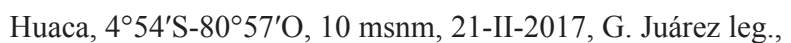
agitación de follaje, Bosque estacionalmente seco de llanura; 1 q, Sechura, Vice, $5^{\circ} 25^{\prime} \mathrm{S}-81^{\circ} 46^{\prime} \mathrm{O}, 10 \mathrm{msnm}, 12-\mathrm{XII}-2017$, U. González leg., red entomológica, Desierto costero; 1 रे, 1 ㅇ, Sechura, Laguna Ñapique, $5^{\circ} 34^{\prime} \mathrm{S}-81^{\circ} 16^{\prime} \mathrm{O}, 16 \mathrm{msnm}$, 24-VI-2019, U. González leg., colecta manual, Bosque estacionalmente seco ribereño; 1 + , Morropón, Chulucanas, $5^{\circ} 05^{\prime} \mathrm{S}-80^{\circ} 99^{\prime} \mathrm{O}, 350 \mathrm{msnm}, 22-\mathrm{I}-2015$, G. Juárez leg., agitación de follaje, Bosque estacionalmente seco de colina; 2

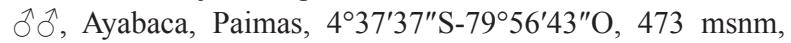
26-VII-2015, G. Juárez leg., colecta manual, Bosque estacionalmente seco de llanura; $1 \hat{\partial}$, Huancabamba, Huarmaca, 5³4'04"S-79³1'26"O, 1000 msnm, 26-VII-2016, G. Juárez leg., red entomológica, Bosque estacionalmente seco de colina.

Distribución (Provincia) (Paisaje ecológico). (PIU, SUlL, PAi, TAL, SECH, MORR, AYA, HUA) (DESc, BESr, BESll, BESc-m).

Comentario. Adultos se encuentran a ras del suelo muy cercanos a troncos de árboles, también sobre hojas, ramas y troncos de plántulas y árboles, en solitario. Especie que se comporta como controlador biológico. Especie citada también por Juárez et al. (2016).

Subfamilia Dolichoderinae Forel, 1878

Género Dorymyrmex Mayr, 1866

173. Dorymyrmex pyramicus peruvianus Wheeler W. M., 1919 (Fig. 18)

Material examinado. PERÚ. 2 q 9 , Piura, Universidad de Piura, 5¹0'11"S-80³6'51"O, 29 msnm, 04-IV-2015, U. González leg., colecta manual, Bosque estacionalmente seco de llanura; 3 우, $2 \hat{\jmath} \hat{\jmath}$, Piura, Castilla, Universidad Nacional de Piura, 5 $10^{\prime} 51^{\prime \prime S}-80^{\circ} 37^{\prime} 31^{\prime \prime} \mathrm{O}, 29 \mathrm{msnm}, 2-\mathrm{II}-2015$, U. González leg., colecta manual, Bosque estacionalmente seco ribereño; $2 \partial^{\lambda} \partial^{\prime}$, Sullana, Salitral, $4^{\circ} 51^{\prime} 27^{\prime \prime} \mathrm{S}-80^{\circ} 40^{\prime} 52^{\prime \prime} \mathrm{O}$, $23 \mathrm{msnm}, 28-\mathrm{X}-2017$, G. Juárez leg., agitación de follaje, Bosque estacionalmente seco de llanura; 2 우, Talara, El Alto, $4^{\circ} 16^{\prime} 04^{\prime \prime} \mathrm{S}-81^{\circ} 13^{\prime} 09^{\prime \prime} \mathrm{O}, 5 \mathrm{msnm}, 23-\mathrm{IV}-2015$, G. Juárez leg., red entomológica, Desierto; 1 q, 1 $\widehat{\jmath}$, Sullana, Miguel Checa, 45'ㄴ'S-8048'O, 10 msnm, 12-III-2016, G. Juárez leg., agitación de follaje, Bosque estacionalmente seco de llanura;

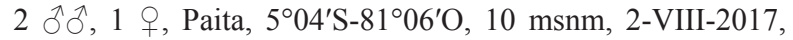
G. Juárez leg., agitación de follaje, Bosque estacionalmente seco de llanura; 1 ㅇ, 2 Јे $^{\lambda}$, Sechura, Vice, $5^{\circ} 25^{\prime} \mathrm{S}-81^{\circ} 46^{\prime} \mathrm{O}$, 10 msnm, 17-VIII-2015, U. González leg., agitación de follaje, Desierto costero; 1 ㅇ, 1 q , Sechura, Illescas, $5^{\circ} 58^{\prime} \mathrm{S}-81^{\circ} 05^{\prime} \mathrm{O}$, 10 msnm, 12-XI-2017, U. González leg., agitación de follaje, Matorral Xérico; 2 $\widehat{\jmath}$, Morropón, Morropón, 505'51"S-8009'44"O, 557 msnm, 14-V-2017, G. Juárez leg., red entomológica, Bosque estacionalmente seco de colina;

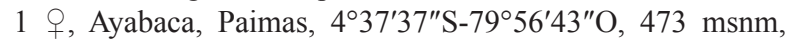
26-VII-2015, G. Juárez leg., red entomológica, Bosque estacionalmente seco de llanura; 1 †, $1 \hat{\delta}$, Huancabamba, Huarmaca, 5³4'04"S-79³1'26"O, 1223 msnm, 26-VII-2016, G. Juárez leg., red entomológica, Bosque estacionalmente seco de colina.

Distribución (Provincia) (Paisaje ecológico). (PIU, SUlL, PAi, TAL, SECH, MORR, AYA, HUA) (MatX, DESc, BESr, BESll, BESc-m).

COMENTARIO. Los adultos se encuentran sobre hojas, ramas y troncos de plántulas y árboles, en solitario o grupos de más de dos individuos. Especie que se comporta como controlador biológico, depreda larvas de E. discordis. Especie citada también por Juárez et al. (2016). 
Subfamilia Formicinae Latreille, 1809

Género Camponotus Mayr, 1861

174. Camponotus sin identificar sp. 1.

Material examinado. PERÚ. 2 우, Piura, Universidad de Piura, $5^{\circ} 10^{\prime} 11^{\prime \prime} \mathrm{S}-80^{\circ} 36^{\prime} 51^{\prime \prime} \mathrm{O}, 29 \mathrm{msnm}, 04-\mathrm{IV}-2015$, U. González leg., colecta manual, Bosque estacionalmente seco de llanura;

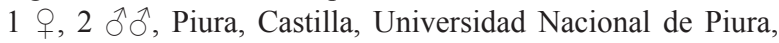
5¹0'51"S-80³7'31"O, 29 msnm, 2-II-2015, U. González leg., colecta manual, Bosque estacionalmente seco ribereño; 1

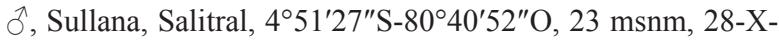
2017, G. Juárez leg., colecta manual, Bosque estacionalmente seco de llanura; 1 ㅇ, Talara, El Alto, $4^{\circ} 16^{\prime} 04^{\prime \prime} \mathrm{S}-81^{\circ} 13^{\prime} 09^{\prime \prime} \mathrm{O}$, 5 msnm, 23-IV-2015, G. Juárez leg., colecta manual, Desierto; 1 ㅇ, 1 ơ , Sullana, Miguel Checa, $4^{\circ} 54^{\prime} \mathrm{S}-80^{\circ} 48^{\prime} \mathrm{O}, 10 \mathrm{msnm}$, 12-III-2016, G. Juárez leg., colecta manual, Bosque estacio-

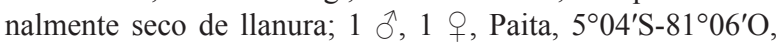
10 msnm, 2-VIII-2017, G. Juárez leg., colecta manual, Bosque estacionalmente seco de llanura; 2 웅, $2 \hat{\jmath} \widehat{\jmath}$, Sechura, Vice, $5^{\circ} 25^{\prime} \mathrm{S}-81^{\circ} 46^{\prime} \mathrm{O}, 10 \mathrm{msnm}, 17-\mathrm{VIII}-2015$, U. González leg., colecta manual, Desierto costero; 1 \& 1 , , Sechura, Illescas, $5^{\circ} 58^{\prime} \mathrm{S}-81^{\circ} 05^{\prime} \mathrm{O}, 10 \mathrm{msnm}, 12-\mathrm{XI}-2017$, U. González leg., colecta manual, Matorral Xérico; 1 $\widehat{\delta}$, Morropón, Morropón, 505'51"S-8009'44"O, 557 msnm, 14-V-2017, G. Juárez leg., colecta manual, Bosque estacionalmente seco de colina.

Distribución (Provincia) (Paisaje ecológico). (PIU, SUlL, PAi, TAL, SECH, MORR) (MatX, DESc, BESr, BESll, BESc-m).

Comentario. Los adultos se encuentran sobre y escondidas en grietas de troncos de árboles, en solitario o grupo de más de dos individuos. Insecto que se comporta como fitófago, nidifica en el interior de troncos vivos o muertos formando grandes colonias. Especie citada también por Domínguez (1982) y Juárez et al. (2016).

Género Paratrechina Motschoulsky, $1863 \dagger$

175. Paratrechina longicornis Latreille, $1802 \dagger$

Material examinado. Perú. 1 , Piura, Universidad de Piura, 5¹0'11"S-80³6'51"O, 29 msnm, 04-IV-2015, U. González leg., colecta manual, Bosque estacionalmente seco de llanura; 1 , , Piura, Castilla, Universidad Nacional de Piura, 5¹0'51"S-80³7'31"O, 29 msnm, 2-II-2015, U. González leg., colecta manual, Bosque estacionalmente seco ribereño; $1 \hat{\delta}$, Sullana, Salitral, 451'27"S-8040'52"O, 23 msnm, 28-X-2017, G. Juárez leg., agitación de follaje, Bosque estacionalmente seco de llanura; 1 ㅇ, Talara, El Alto, $4^{\circ} 16^{\prime} 04^{\prime \prime} \mathrm{S}-81^{\circ} 13^{\prime} 09^{\prime \prime} \mathrm{O}$, 5 msnm, 23-IV-2015, G. Juárez leg., colecta manual, Desierto; 1 ㅇ, 1 ô, Sullana, Miguel Checa, $4^{\circ} 54^{\prime} \mathrm{S}-80^{\circ} 48^{\prime} \mathrm{O}, 10 \mathrm{msnm}$, 12-III-2016, G. Juárez leg., colecta manual, Bosque estacionalmente seco de llanura; 1 ㅅ, 1 ㅇ, Paita, $5^{\circ} 04^{\prime} \mathrm{S}-81^{\circ} 06^{\prime} \mathrm{O}$, 10 msnm, 2-VIII-2017, G. Juárez leg., agitación de follaje, Bosque estacionalmente seco de llanura; 2 우, Sechura, Vice,

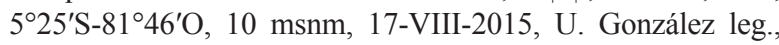
colecta manual, Desierto costero; 1 त, Morropón, Morropón, 505'51"S-8009'44"O, 557 msnm, 14-V-2017, G. Juárez leg., agitación de follaje, Bosque estacionalmente seco de colina.

Distribución (Provincia) (Paisaje ecológico). (PIU, SUll, PAi, TAL, SECH, MORR, HUA) (DESc, BESr, BESll, BESc-m).
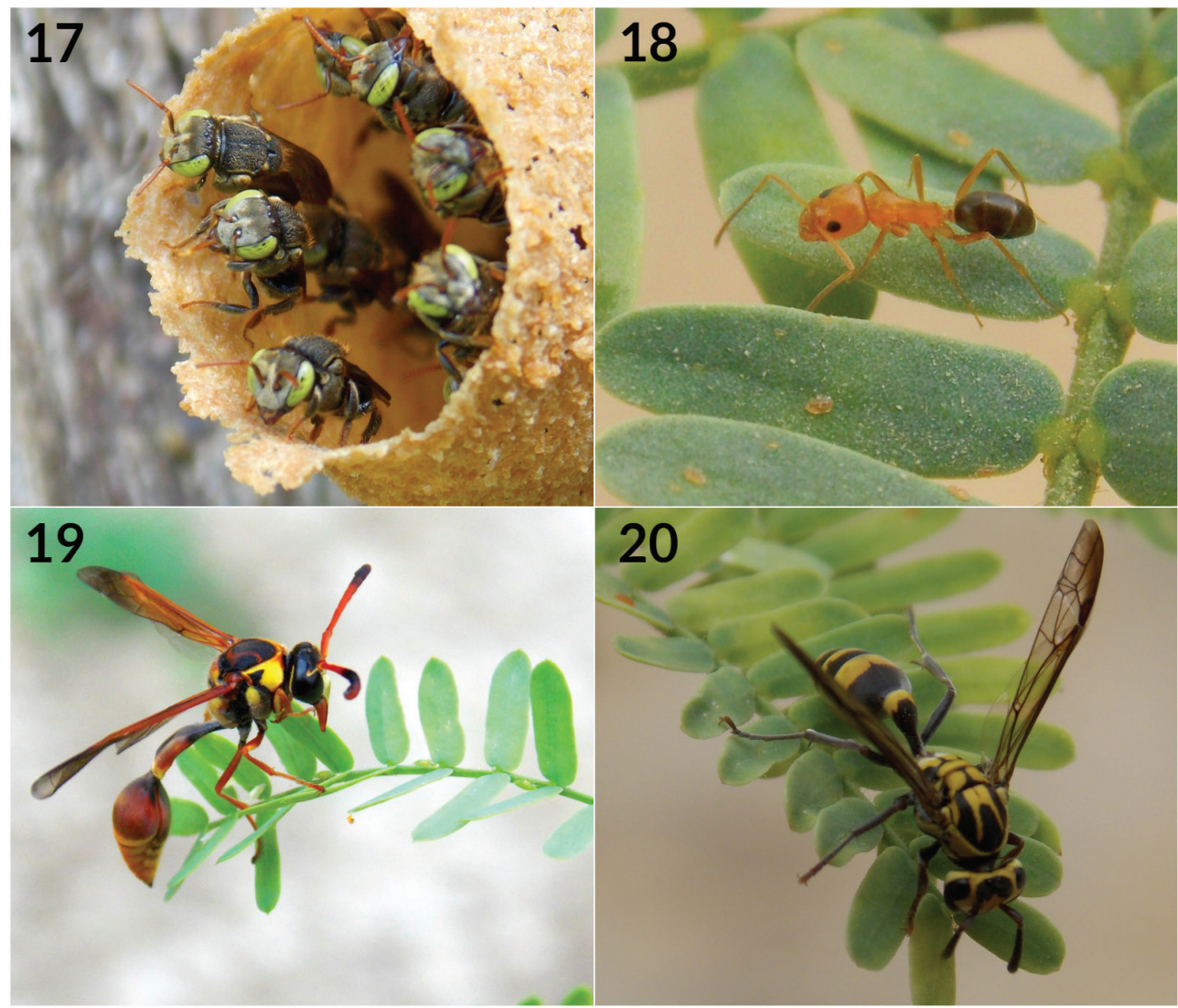

Figs. 17-20.- Habitus. 17. Nannotrigona mellaria (Smith, 1862). 18. Dorymyrmex pyramicus peruvianus Wheeler, 1919.19. Zeta argillaceum Linnaeus, 1758. 20. Polybia sin identificar sp 1. [Fotografías G. Juárez y U. González].

Figs. 17-20.- Habitus. 17. Nannotrigona mellaria (Smith, 1862). 18. Dorymyrmex pyramicus peruvianus Wheeler, 1919.19. Zeta argillaceum Linnaeus, 1758. 20. Polybia unidentified sp 1. [Photographs by G. Juárez and U. González]. 
Comentario. Los adultos se encuentran sobre hojas, ramas de plántulas y árboles, en solitario o grupos de dos a cinco individuos. Aprovechan exudados en plántulas y árboles para alimentarse.

Subfamilia Myrmicinae Lepeletier de Saint-Fargeau, 1835

Género Cephalotes Latreille, 1802

176. Cephalotes inca (Santschi, 1911)

Material examinado. PERÚ. 2 q 9063 HYM-GJN. Piura,

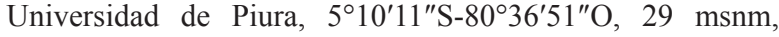
04-IV-2015, U. González leg., colecta manual, Bosque estacionalmente seco de llanura; 2 우, $2 \hat{\jmath} \widehat{\partial}$, Piura, Castilla, Universidad Nacional de Piura, $5^{\circ} 10^{\prime} 51^{\prime \prime} \mathrm{S}-80^{\circ} 37^{\prime} 31^{\prime \prime} \mathrm{O}$, 29 msnm, 2-II-2015, U. González leg., colecta manual, Bosque estacionalmente seco ribereño; $2 \hat{\partial} \hat{\partial}, 1$, Sullana, Salitral, 451'27"S-8040'52"O, 23 msnm, 28-X-2017, G. Juárez leg., agitación de follaje, Bosque estacionalmente seco de llanura; 2 우우, 2 구우, Talara, El Alto, $4^{\circ} 16^{\prime} 04^{\prime \prime} \mathrm{S}-81^{\circ} 13^{\prime} 09^{\prime \prime} \mathrm{O}, 5 \mathrm{msnm}$, 23-IV-2015, G. Juárez leg., red entomológica, Desierto; 1 , $1 \partial^{\lambda}$, Sullana, Miguel Checa, $4^{\circ} 54^{\prime} \mathrm{S}-80^{\circ} 48^{\prime} \mathrm{O}, 10 \mathrm{msnm}, 12-\mathrm{III}-$ 2016, G. Juárez leg., agitación de follaje, Bosque estacional-

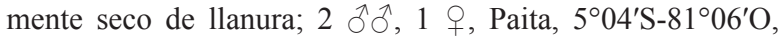
10 msnm, 2-VIII-2017, G. Juárez leg., agitación de follaje, Bosque estacionalmente seco de llanura; 1 ㅇ, 2 ถึ่ $\hat{0}$, Sechura, Vice, $5^{\circ} 25^{\prime} \mathrm{S}-81^{\circ} 46^{\prime} \mathrm{O}, 10 \mathrm{msnm}, 17-$ VIII-2015, U. González leg., agitación de follaje, Desierto costero; 2 오오, $1 \mathrm{O}^{\lambda}$, Sechura, Illescas, $5^{\circ} 58^{\prime} \mathrm{S}-81^{\circ} 05^{\prime} \mathrm{O}, 10 \mathrm{msnm}$, 12-XI-2017, U. González leg., agitación de follaje, Matorral Xérico; $1 \partial^{7}$, Morropón, Morropón, $5^{\circ} 05^{\prime} 51^{\prime \prime} \mathrm{S}-80^{\circ} 09^{\prime} 44^{\prime \prime} \mathrm{O}$, 557 msnm, 14-V-2017, G. Juárez leg., red entomológica, Bosque estacionalmente seco de colina; 1 +, Ayabaca, Paimas, 437'37"'S-7956'43"O, 473 msnm, 26-VII-2015, G. Juárez leg., red entomológica, Bosque estacionalmente seco de llanura; 1 q, 1 $\hat{\jmath}$, Huancabamba, Huarmaca, 534'04"S-79³1'26"O, 1223 msnm, 26-VII-2016, G. Juárez leg., red entomológica, Bosque estacionalmente seco de colina.

Distribución (Provincia) (Paisaje ecológico). (PIU, SULL, PAI, TAL, SECH, MORR, AYA, HUA) (MatX, DESc, BESr, BESll, BESc-m).

Comentario. Especie citada como Cephalotes sp en Juárez et al. (2016). Los adultos se encuentran sobre ramas y troncos de árboles, en solitario o en grupos de dos a más individuos, aprovechan grietas en troncos vivos y muertos para construir sus colonias.

Género Crematogaster Lund, 1831

177. Crematogaster crinosa Mayr, 1862

Material examinado. PERÚ. 2 qo, 071 HYM-GJN, Piura, Universidad de Piura, 5 $5^{\circ} 10^{\prime} 11^{\prime \prime} \mathrm{S}-80^{\circ} 36^{\prime} 51^{\prime \prime} \mathrm{O}, 29 \mathrm{msnm}$, 04-IV-2015, U. González leg., colecta manual, Bosque estacionalmente seco de llanura; 2 우, $2 \hat{\jmath} \widehat{\jmath}$, Piura, Castilla, Universidad Nacional de Piura, $5^{\circ} 10^{\prime} 51^{\prime \prime} \mathrm{S}-80^{\circ} 37^{\prime} 31^{\prime \prime} \mathrm{O}$, 29 msnm, 2-II-2015, U. González leg., colecta manual, Bosque estacionalmente seco ribereño; $2 \hat{\jmath} \hat{\partial}, 1$ Q, Sullana, Salitral, 451'27"S-8040'52"O, 23 msnm, 28-X2017, G. Juárez leg., agitación de follaje, Bosque estacionalmente seco de llanura; 2 우, 2 ऊ̄ô, Talara, El Alto, $4^{\circ} 16^{\prime} 04^{\prime \prime S}-81^{\circ} 13^{\prime} 09^{\prime \prime} \mathrm{O}, 5$ msnm, 23-IV-2015, G. Juárez leg., red entomológica, Desierto; 1 + 1 1 , Sullana, Miguel Checa, $4^{\circ} 54^{\prime} \mathrm{S}-80^{\circ} 48^{\prime} \mathrm{O}, 10 \mathrm{msnm}, 12-\mathrm{III}-2016$, G. Juárez leg., agitación de follaje, Bosque estacionalmente seco de llanura;

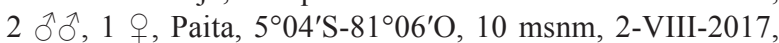
G. Juárez leg., agitación de follaje, Bosque estacionalmente

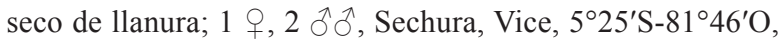

10 msnm, 17-VIII-2015, U. González leg., agitación de follaje, Desierto costero; 1 + 1 ô, Sechura, Illescas,

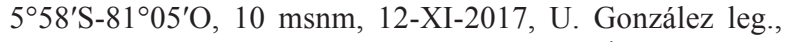
agitación de follaje, Matorral Xérico; 1 đ̂, Morropón, Morropón, $5^{\circ} 05^{\prime} 51^{\prime \prime} \mathrm{S}-80^{\circ} 09^{\prime} 44^{\prime \prime} \mathrm{O}, 557 \mathrm{msnm}, 14-\mathrm{V}-2017$, G. Juárez leg., red entomológica, Bosque estacionalmente seco

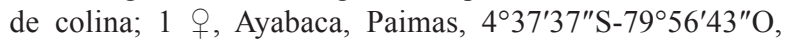
473 msnm, 26-VII-2015, G. Juárez leg., red entomológica, Bosque estacionalmente seco de llanura; 1 , $1 \hat{\mathrm{O}}$, Huancabamba, Huarmaca, $5^{\circ} 34^{\prime} 04^{\prime \prime} \mathrm{S}-79^{\circ} 31^{\prime} 26^{\prime \prime} \mathrm{O}$, 1223 msnm, 26-VII-2016, G. Juárez leg., red entomológica, Bosque estacionalmente seco de colina.

Distribución (Provincia) (Paisaje ecológico). (PIU, SUll, PAi, TAL, SECH, MORR, AYA, HUA) (MatX, DESc, BESr, BESll, BESc-m).

Comentario. Especie citada como Crematogaster sp en Juárez et al. (2016). Los adultos se encuentran sobre hojas, ramas y troncos de plántulas y árboles, en grupos de dos a más individuos. Aprovechan grietas en troncos vivos y muertos para formar sus colonias y también exudados en plántulas y árboles para alimentarse.

Género Pheidole Westwood, $1839 \dagger$

178. Pheidole chilensis Mayr, $1862 \dagger$

Material eXaminado. PERÚ. 1 \%, Piura, Universidad de Piura, 5 10'11"S-80³6'51"O, 29 msnm, 04-IV-2015, U. González leg., colecta manual, Bosque estacionalmente seco de llanura; 1 9, Piura, Castilla, Universidad Nacional de Piura, 5¹0'51"S-80³7'31"O, 29 msnm, 2-II-2015, U. González leg., colecta manual, Bosque estacionalmente seco ribereño; 1 o, Sullana, Salitral, 4 $4^{\circ} 51^{\prime} 27^{\prime \prime} \mathrm{S}-80^{\circ} 40^{\prime} 52^{\prime \prime} \mathrm{O}, 23 \mathrm{msnm}$, 28-X-2017, G. Juárez leg., agitación de follaje, Bosque estacionalmente seco de llanura; 1 q, 1 $\hat{\mathrm{N}}$, Talara, El Alto, $4^{\circ} 16^{\prime} 04^{\prime \prime} \mathrm{S}-81^{\circ} 13^{\prime} 09^{\prime \prime} \mathrm{O}, 5$ msnm, 23-IV-2015, G. Juárez leg., red entomológica, Desierto; 1 ㅇ, $1 \hat{\mathrm{O}}$, Sullana, Miguel Checa, 454'S-8048'O, 10 msnm, 12-III-2016, G. Juárez leg., agitación de follaje, Bosque estacionalmente seco de llanura; 1 ․ Paita, $5^{\circ} 04^{\prime} \mathrm{S}-81^{\circ} 06^{\prime} \mathrm{O}, 10 \mathrm{msnm}, 2$-VIII-2017, G. Juárez leg., agitación de follaje, Bosque estacionalmente seco de llanura; 1 ㅇ, Sechura, Vice, $5^{\circ} 25^{\prime} \mathrm{S}-81^{\circ} 46^{\prime} \mathrm{O}, 10 \mathrm{msnm}$, 17-VIII-2015, U. González leg., agitación de follaje, Desierto costero; 1 q, Sechura, Illescas, $5^{\circ} 58^{\prime} \mathrm{S}-81^{\circ} 05^{\prime} \mathrm{O}, 10 \mathrm{msnm}$, 12-XI-2017, U. González leg., agitación de follaje, Matorral Xérico; 1 $\widehat{O}$, Morropón, Morropón, 505'51"S- $80^{\circ} 09^{\prime} 44^{\prime \prime} \mathrm{O}$, 557 msnm, 14-V-2017, G. Juárez leg., red entomológica, Bosque estacionalmente seco de colina; 1 , Ayabaca, Paimas, 4³7'37"S-7956'43"O, 473 msnm, 26-VII-2015, G. Juárez leg., red entomológica, Bosque estacionalmente seco de llanura;

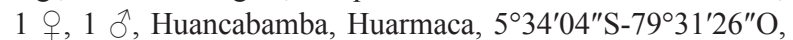
1223 msnm, 26-VII-2016, G. Juárez leg., agitación de follaje, Bosque estacionalmente seco de colina.

Distribución (Provincia) (Paisaje ecológico). (PIU, SUlL, PAi, TAL, SECH, MORR, AYA, HUA) (MatX, DESc, BESr, BESll, BESc-m).

Comentario. Los adultos se encuentran a ras del suelo muy cercano a troncos de árboles, en solitario.

\section{Subfamilia Pseudomyrmecinae Smith, 1952}

Género Pseudomyrmex Lund, 1831

179. Pseudomyrmex gracilis (Fabricius, 1804)

Material examinado. Perú. 3 우, 085 HYM-GJN, Piura, Universidad de Piura, $5^{\circ} 10^{\prime} 11^{\prime \prime} \mathrm{S}-80^{\circ} 36^{\prime} 51^{\prime \prime} \mathrm{O}, 29 \mathrm{msnm}$, 04-IV-2015, U. González leg., colecta manual, Bosque estacionalmente seco de llanura; 2 우, Piura, Castilla, Universidad 
Nacional de Piura, 5¹0'51'S-80³7'31'O, 29 msnm, 2-II2015, U. González leg., agitación de follaje, Bosque estacionalmente seco ribereño; 1, 1 , Sullana, Salitral, 451'27"S-8040'52"O, 23 msnm, 28-X-2017, G. Juárez leg., agitación de follaje, Bosque estacionalmente seco de llanura; 1 q, 1 o, Talara, El Alto, $4^{\circ} 16^{\prime} 04^{\prime \prime} \mathrm{S}-81^{\circ} 13^{\prime} 09^{\prime \prime} \mathrm{O}, 5 \mathrm{msnm}$, 23-IV-2015, G. Juárez leg., red entomológica, Desierto; 2 우오, Sullana, Miguel Checa, $4^{\circ} 54^{\prime} \mathrm{S}-80^{\circ} 48^{\prime} \mathrm{O}, 10 \mathrm{msnm}$, 12-III-2016, G. Juárez leg., agitación de follaje, Bosque estacionalmente seco de llanura; 2 오, Paita, $5^{\circ} 04^{\prime} \mathrm{S}-81^{\circ} 06^{\prime} \mathrm{O}$, 10 msnm, 2-VIII-2017, G. Juárez leg., agitación de follaje, Bosque estacionalmente seco de llanura; 1 + 1 त, Sechura, Vice, $5^{\circ} 25^{\prime} \mathrm{S}-81^{\circ} 46^{\prime} \mathrm{O}, 10 \mathrm{msnm}, 17-\mathrm{VIII}-2015$, U. González leg., agitación de follaje, Desierto costero; 2 우, Sechura, Illescas, 558'S-81 $05^{\prime} \mathrm{O}, 10 \mathrm{msnm}, 12-\mathrm{XI}-2017$, U. González leg., agitación de follaje, Matorral Xérico; 1 ઈ, 2 우, Morropón, Morropón, 505'51"S-8009'44"O, $557 \mathrm{msnm}$, 14-V-2017, G. Juárez leg., red entomológica, Bosque estacionalmente seco de colina; 2 우, Ayabaca, Paimas, 4³7'37"S-7956'43"O, 473 msnm, 26-VII-2015, G. Juárez leg., red entomológica, Bosque estacionalmente seco de llanura; 1 ㅇ, 1 ô, Huancabamba, Huarmaca, 5³4'04"S-79³1'26"O, 1223 msnm, 26-VII-2016, G. Juárez leg., agitación de follaje, Bosque estacionalmente seco de colina.

Distribución (Provincia) (Paisaje ecológico). (PIU, SUlL, PAI, TAL, SECH, MORR, AYA, HUA) (MatX, DESc, BESr, BESll, BESc-m).

Comentario. Especie citada como Pseudomyrmex sp 1 en Juárez et al. (2016). Los adultos se encuentran sobre hojas, ramas y troncos de plántulas y árboles, en solitario. Especie citada también por Domínguez (1982).

180. Pseudomyrmex simplex (Smith, 1877)

Material examinado. Perú. 1 +, 087 HYM-GJN, Piura, Universidad de Piura, 5 $5^{\circ} 10^{\prime} 11^{\prime \prime} \mathrm{S}-80^{\circ} 36^{\prime} 51^{\prime \prime} \mathrm{O}, 29 \mathrm{msnm}$, 04-IV-2015, U. González leg., colecta manual, Bosque estacionalmente seco de llanura; 1 q, Piura, Castilla, Universidad Nacional de Piura, $5^{\circ} 10^{\prime} 51^{\prime \prime} \mathrm{S}-80^{\circ} 37^{\prime} 31^{\prime \prime} \mathrm{O}, 29 \mathrm{msnm}, 2-\mathrm{II}-$ 2015, U. González leg., agitación de follaje, Bosque estacionalmente seco ribereño; 1 q, 1 $\hat{\partial}$, Sullana, Salitral, 451'27"S-8040'52"O, 23 msnm, 28-X-2017, G. Juárez leg., agitación de follaje, Bosque estacionalmente seco de llanura; 1 ㅇ, 1 ㅇ․, Talara, El Alto, $4^{\circ} 16^{\prime} 04^{\prime \prime} \mathrm{S}-81^{\circ} 13^{\prime} 09^{\prime \prime} \mathrm{O}, 5 \mathrm{msnm}$, 23-IV-2015, G. Juárez leg., red entomológica, Desierto; 1 ㅇ, Sullana, Miguel Checa, $4^{\circ} 54^{\prime} \mathrm{S}-80^{\circ} 48^{\prime} \mathrm{O}, 10 \mathrm{msnm}$, 12-III2016, G. Juárez leg., agitación de follaje, Bosque estacionalmente seco de llanura; 2 우, Paita, $5^{\circ} 04^{\prime} \mathrm{S}-81^{\circ} 06^{\prime} \mathrm{O}, 10 \mathrm{msnm}$, 2-VIII-2017, G. Juárez leg., agitación de follaje, Bosque estacionalmente seco de llanura; 1 ㅇ, 1 $\hat{\sigma}$, Sechura, Vice, 5²5'S-81 $46^{\prime} \mathrm{O}, 10$ msnm, 17-VIII-2015, U. González leg., agitación de follaje, Desierto costero; 2 우우, Sechura, Illescas, $5^{\circ} 58^{\prime} \mathrm{S}-81^{\circ} 05^{\prime} \mathrm{O}, 10 \mathrm{msnm}, 12-\mathrm{XI}-2017$, U. González leg., agitación de follaje, Matorral Xérico; 1 $\widehat{O}, 1$ ㅇ, Morropón, Morropón, 505'51"S-8009'44"O, 557 msnm, 14-V-2017, G. Juárez leg., red entomológica, Bosque estacionalmente seco de colina; 1 \% , Ayabaca, Paimas, 4³7'37"S-7956'43"O, 473 msnm, 26-VII-2015, G. Juárez leg., red entomológica, Bosque estacionalmente seco de llanura; 1 , 1 ô, Huancabamba, Huarmaca, 5³4'04"S-79³1'26"O, 1000 msnm, 26-VII-2016, G. Juárez leg., agitación de follaje, Bosque estacionalmente seco de colina.

Distribución (Provincia) (Paisaje ecológico). (PIU, SUlL, PAi, TAL, SECH, MORR, AYA, HUA) (MatX, DESc, BESr, BESll, BESc-m).
Comentario. Especie citada como Pseudomyrmex sp 2 en Juárez et al. (2016). Los adultos se encuentran sobre hojas, ramas y troncos de plántulas y árboles, en solitario.

181. Pseudomyrmex sin identificar sp. 1.

Material examinado. PERÚ. 3 우, Piura, Universidad de Piura, 5 10'11"S-80³6'51"O, 29 msnm, 04-IV-2015, U. González leg., colecta manual, Bosque estacionalmente seco de llanura; 2 우, Piura, Castilla, Universidad Nacional de Piura, $5^{\circ} 10^{\prime} 51^{\prime \prime} \mathrm{S}-80^{\circ} 37^{\prime} 31^{\prime \prime} \mathrm{O}, 29 \mathrm{msnm}, 2-\mathrm{II}-2015$, U. González leg., agitación de follaje, Bosque estacionalmente seco ribereño; 1 ㅇ, 1 ô, Sullana, Salitral, 4 ${ }^{\circ} 51^{\prime} 27^{\prime \prime} \mathrm{S}-80^{\circ} 40^{\prime} 52^{\prime \prime} \mathrm{O}$, 23 msnm, 28-X-2017, G. Juárez leg., agitación de follaje, Bosque estacionalmente seco de llanura; $1 \stackrel{+}{ }, 1 \hat{\delta}$, Talara, El Alto, $4^{\circ} 16^{\prime} 04^{\prime \prime S}-81^{\circ} 13^{\prime} 09^{\prime \prime} \mathrm{O}, 5$ msnm, 23-IV-2015, G. Juárez leg., red entomológica, Desierto; 2 우, Sullana, Miguel Checa, 45ㄴ'S-8048'O, 10 msnm, 12-III-2016, G. Juárez leg., agitación de follaje, Bosque estacionalmente seco de llanura; 1 ㅇ, $1 \mathrm{o}^{\circ}$, Sechura, Vice, $5^{\circ} 25^{\prime} \mathrm{S}-81^{\circ} 46^{\prime} \mathrm{O}, 10 \mathrm{msnm}, 17$-VIII2015, U. González leg., agitación de follaje, Desierto costero.

Distribución (Provincia) (Paisaje ecológico). (PIU, SULL, SECH) (DESc, BESr, BESIl).

COMEnTARIO. Los adultos se encuentran sobre hojas, ramas y troncos de plántulas y árboles, en solitario. Especie citada también por Juárez et al. (2016).

Familia Scoliidae Leach, 1815

Subfamilia Campsomerinae Leach, 1815

Género Campsomeris Guérin-Méneville, 1839

182. Campsomeris sin identificar sp. 1.

Material examinado. PeRÚ. 1 \%, Piura, Universidad de Piura, 5॰10'11"S-80³6'51"O, 29 msnm, 04-IV-2015, U. González leg., colecta manual, Bosque estacionalmente seco de 1lanura; 1 ㅇ, Piura, Castilla, Universidad Nacional de Piura, 5¹0'51"S-80³7'31"O, 29 msnm, 2-II-2015, U. González leg., agitación de follaje, Bosque estacionalmente seco ribereño; 1 ㅇ, $1 \hat{\partial}$, Sullana, Salitral, $4^{\circ} 51^{\prime} 27^{\prime \prime} \mathrm{S}-80^{\circ} 40^{\prime} 52^{\prime \prime} \mathrm{O}$, 23 msnm, 28-X-2017, G. Juárez leg., agitación de follaje, Bosque estacionalmente seco de llanura; 1 , 1 $\delta^{\text {, Talara, El }}$ Alto, $4^{\circ} 16^{\prime} 04^{\prime \prime S}-81^{\circ} 13^{\prime} 09^{\prime \prime} \mathrm{O}, 5$ msnm, 23-IV-2015, G. Juárez leg., red entomológica, Desierto; 1 \%, Sullana, Miguel Checa, 45ㄴ'S-8048'O, 10 msnm, 12-III-2016, G. Juárez leg., agitación de follaje, Bosque estacionalmente seco de llanura; 2 우우, Paita, $5^{\circ} 04^{\prime} \mathrm{S}-81^{\circ} 06^{\prime} \mathrm{O}, 10 \mathrm{msnm}, 2$-VIII-2017, G. Juárez leg., agitación de follaje, Bosque estacionalmente seco de llanura; 1 ㅇ, $10^{\top}$, Sechura, Vice, $5^{\circ} 25^{\prime} \mathrm{S}-81^{\circ} 46^{\prime} \mathrm{O}, 10 \mathrm{msnm}, 17-\mathrm{VIII}-$ 2015, U. González leg., agitación de follaje, Desierto costero; 2 우우, Sechura, Illescas, $5^{\circ} 58^{\prime} \mathrm{S}-81^{\circ} 05^{\prime} \mathrm{O}, 10 \mathrm{msnm}, 12-\mathrm{XI}-$ 2017, U. González leg., agitación de follaje, Matorral Xérico;

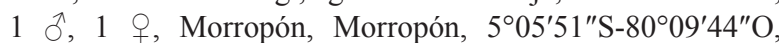
557 msnm, 14-V-2017, G. Juárez leg., red entomológica, Bosque estacionalmente seco de colina; 1 , Ayabaca, Paimas, 4³7'37"S-7956'43"O, 473 msnm, 26-VII-2015, G. Juárez leg., red entomológica, Bosque estacional-

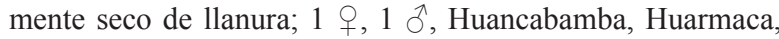
5³4'04"S-79³1'26"O, 1000 msnm, 26-VII-2016, G. Juárez leg., agitación de follaje, Bosque estacionalmente seco de colina.

Distribución (Provincia) (Paisaje ecológico). (PIU, SUlL, PAi, TAL, SECH, MORR, AYA, HUA) (MatX, DESc, BESr, BESll, BESc-m).

COMENTARIO. Los adultos se encuentran sobrevolando y/o posando sobre inflorescencias. Especie citada también por Juárez et al. (2016) 
Familia Tiphiidae Leach, $1815 \dagger$

Subfamilia Myzininae Leach, $1815 \dagger$

Género Myzinum Latreille, $1803 \dagger$

183. Myzinum $\sin$ identificar sp. $1 . \dagger$

Material examinado. PeRÚ. 1 , Piura, Universidad de Piura, $5^{\circ} 10^{\prime} 11^{\prime \prime} \mathrm{S}-80^{\circ} 36^{\prime} 51^{\prime \prime} \mathrm{O}, 29$ msnm, 04-IV-2015, U. González leg., red entomológica, Bosque estacionalmente seco de llanura; 1 q, Piura, Castilla, Universidad Nacional de Piura, 510'51"S-80³7'31"O, 29 msnm, 2-II-2015, U. González leg., red entomológica, Bosque estacionalmente seco ribereño; 1 ว , Sullana, Salitral, $4^{\circ} 51^{\prime} 27^{\prime \prime} \mathrm{S}-80^{\circ} 40^{\prime} 52^{\prime \prime} \mathrm{O}, 23 \mathrm{msnm}$, 28-X-2017, G. Juárez leg., red entomológica, Bosque estacionalmente seco de llanura; $1 \stackrel{+}{\circ} 1 \hat{\delta}$, Talara, El Alto, $4^{\circ} 16^{\prime} 04^{\prime \prime} \mathrm{S}-81^{\circ} 13^{\prime} 09^{\prime \prime} \mathrm{O}, 5$ msnm, 23-IV-2015, G. Juárez leg., red entomológica, Desierto; 1 क, Sullana, Miguel Checa, $4^{\circ} 54^{\prime} \mathrm{S}-80^{\circ} 48^{\prime} \mathrm{O}$, $10 \mathrm{msnm}, 12-\mathrm{III}-2016$, G. Juárez leg., red entomológica, Bosque estacionalmente seco de llanura; 2 우우, Paita, $5^{\circ} 04^{\prime} \mathrm{S}-81^{\circ} 06^{\prime} \mathrm{O}, 10$ msnm, 2-VIII-2017, G. Juárez leg., red entomológica, Bosque estacionalmente seco de llanura; 1 ㅇ, $1 \mathrm{O}^{\lambda}$, Sechura, Vice, $5^{\circ} 25^{\prime} \mathrm{S}-81^{\circ} 46^{\prime} \mathrm{O}, 10 \mathrm{msnm}$, 17-VIII2015, U. González leg., red entomológica, Desierto costero; 1 q, Sechura, Illescas, $5^{\circ} 58^{\prime} \mathrm{S}-81^{\circ} 05^{\prime} \mathrm{O}, 10 \mathrm{msnm}, 12-\mathrm{XI}-$ 2017, U. González leg., red entomológica, Matorral Xérico;

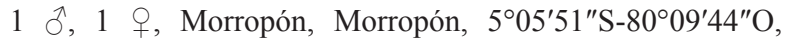
557 msnm, 14-V-2017, G. Juárez leg., red entomológica, Bosque estacionalmente seco de colina; 1 ‥ Ayabaca, Paimas, 437'37"S-7956'43"O, 473 msnm, 26-VII-2015, G. Juárez leg., red entomológica, Bosque estacionalmente seco de llanura; 1 , 1 ${ }^{\lambda}$, Huancabamba, Huarmaca, 5³4'04"S-79³1'26"O, 1000 msnm, 26-VII-2016, G. Juárez leg., red entomológica, Bosque estacionalmente seco de colina.

Distribución (Provincia) (PAisaje ecológico). (PIU, SUlL, PAi, TAL, SECH, MORR, AYA, HUA) (MatX, DESc, BESr, BESll, BESc-m).

Comentario. Adultos se encuentran sobre hojas de plántulas y árboles, sobrevolando y/o posando sobre inflorescencias.

Familia Vespidae Leach, 1815

Subfamilia Eumeninae Leach, 1815

Género Monobia de Saussure, $1852 \dagger$

184. Monobia cyanipennis (Guérin-Méneville, 1831) †

Material examinado. PERÚ. 1 , Piura, Universidad de Piura, $5^{\circ} 10^{\prime} 11^{\prime \prime} \mathrm{S}-80^{\circ} 36^{\prime} 51^{\prime \prime} \mathrm{O}, 29 \mathrm{msnm}, 04-\mathrm{IV}-2015$, U. González leg., red entomológica, Bosque estacionalmente seco de llanura; 1 q, Piura, Castilla, Universidad Nacional de Piura, 5¹0'51"S-80³7'31"O, 29 msnm, 2-II-2015, U. González leg., red entomológica, Bosque estacionalmente seco ribereño; 1 $\widehat{\text {, }}$ Sullana, Salitral, $4^{\circ} 51^{\prime} 27^{\prime \prime S}-80^{\circ} 40^{\prime} 52^{\prime \prime}$ O, 23 msnm, 28-X-2017, G. Juárez leg., red entomológica, Bosque estacionalmente seco de llanura; 1 ㅇ, 1 ô, Talara, El Alto, $4^{\circ} 16^{\prime} 04^{\prime \prime} \mathrm{S}-81^{\circ} 13^{\prime} 09^{\prime \prime} \mathrm{O}$, 5 msnm, 23-IV-2015, G. Juárez leg., red entomológica, Desierto costero; 1 ㅇ, Sullana, Miguel Checa, $4^{\circ} 54^{\prime} \mathrm{S}-80^{\circ} 48^{\prime} \mathrm{O}$, 10 msnm, 12-III-2016, G. Juárez leg., red entomológica, Bosque estacionalmente seco de llanura; 2 우우, Paita, $5^{\circ} 04^{\prime} \mathrm{S}-81^{\circ} 06^{\prime} \mathrm{O}$, 10 msnm, 2-VIII-2017, G. Juárez leg., red entomológica, Bosque estacionalmente seco de llanura; 1 , $1 \hat{\jmath}$, Sechura, Vice, $5^{\circ} 25^{\prime} \mathrm{S}-81^{\circ} 46^{\prime} \mathrm{O}, 10 \mathrm{msnm}, 17-\mathrm{VIII}-2015$, U. González leg., red entomológica, Desierto costero; 1 , Sechura, Illescas, $5^{\circ} 58^{\prime} \mathrm{S}-81^{\circ} 05^{\prime} \mathrm{O}, 10 \mathrm{msnm}, 12-\mathrm{XI}-2017$, U. González leg., red entomológica, Matorral Xérico; 1 đ̂, 1 ㅇ, Morropón, Morropón, 505'51"S-8009'44"O, 557 msnm, 14-V-2017, G. Juárez leg., red entomológica, Bosque estacionalmente seco de colina;

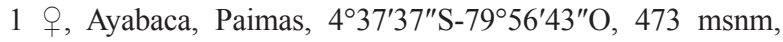

26-VII-2015, G. Juárez leg., red entomológica, Bosque estacionalmente seco de llanura; 1 \&, $1 \hat{\jmath}$, Huancabamba, Huarmaca, 5³4'04"S-79³1'26"O, 1000 msnm, 26-VII-2016, G. Juárez leg., red entomológica, Bosque estacionalmente seco de colina.

Distribución (Provincia) (Paisaje ecológico). (PIU, SUlL, PAi, TAL, SECH, MORR, AYA, HUA) (MatX, DESc, BESr, BESll, BESc-m).

COMEnTARIO. Los adultos se encuentran sobre hojas de plántulas y árboles, en solitario.

Género Pachodynerus de Saussure, 1870

185. Pachodynerus sin identificar sp. 1.

Material eXAminado. PERÚ. 2 9 , Piura, Universidad de Piura, 5 10'11"S-80³6'51"O, 29 msnm, 04-IV-2015, U. González leg., red entomológica, Bosque estacionalmente seco de llanura; 1 q, 1 $\hat{\text {, }}$, Piura, Castilla, Universidad Nacional de Piura, $5^{\circ} 10^{\prime} 51^{\prime \prime} \mathrm{S}-80^{\circ} 37^{\prime} 31^{\prime \prime} \mathrm{O}, 29 \mathrm{msnm}, 2-\mathrm{II}-2015$, U. González leg., red entomológica, Bosque estacionalmente seco ribereño; $1 \hat{\partial}$, Sullana, Salitral, $4^{\circ} 51^{\prime} 27^{\prime \prime} \mathrm{S}-80^{\circ} 40^{\prime} 52^{\prime \prime} \mathrm{O}$, 23 msnm, 28-X-2017, G. Juárez leg., red entomológica,

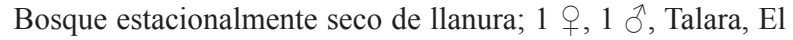
Alto, $4^{\circ} 16^{\prime} 04^{\prime \prime} \mathrm{S}-81^{\circ} 13^{\prime} 09^{\prime \prime} \mathrm{O}, 5$ msnm, 23-IV-2015, G. Juárez leg., red entomológica, Desierto; 1 ㅇ, Sullana, Miguel Checa, 454'S-80²8'O, 10 msnm, 12-III-2016, G. Juárez leg., red entomológica, Bosque estacionalmente seco de llanura; 2 오, Paita, $5^{\circ} 04^{\prime} \mathrm{S}-81^{\circ} 06^{\prime} \mathrm{O}, 10 \mathrm{msnm}, 2$-VIII-2017, G. Juárez leg., red entomológica, Bosque estacionalmente seco de llanura; 1 ㅇ, 1 ô, Sechura, Vice, $5^{\circ} 25^{\prime} \mathrm{S}-81^{\circ} 46^{\prime} \mathrm{O}, 10 \mathrm{msnm}$, 17-VIII-2015, U. González leg., red entomológica, Desierto costero; 3 우, Sechura, Illescas, $5^{\circ} 58^{\prime} \mathrm{S}-81^{\circ} 05^{\prime} \mathrm{O}, 10 \mathrm{msnm}$, 12-XI-2017, U. González leg., red entomológica, Matorral Xérico; 1 ․, Morropón, Morropón, 505'51"S-8009'44"O, 557 msnm, 14-V-2017, G. Juárez leg., red entomológica, Bosque estacionalmente seco de colina; 2 우, Ayabaca,

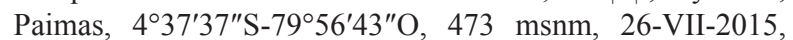
G. Juárez leg., red entomológica, Bosque estacionalmente seco de llanura; 1 ㅇ, 1 $\hat{\jmath}$, Huancabamba, Huarmaca, 5³4'04"S-79³1'26"O, 1000 msnm, 26-VII-2016, G. Juárez leg., red entomológica, Bosque estacionalmente seco de colina.

Distribución (Provincia) (Paisaje ecológico). (PIU, SUlL, PAi, TAL, SECH, MORR, AYA, HUA) (MatX, DESc, BESr, BESll, BESc-m).

Comentario. Los adultos se encuentran sobre hojas de plántulas y árboles, sobrevolando y/o posadas sobre inflorescencias en solitario o grupos de dos o más individuos, construyen sus colmenas en la copa de árboles. Insecto que se comporta como controlador biológico, adultos son predatores de larvas de E. discordis y lepidópteros además como agente polinizador (Juárez et al., 2016). Especie citada también por Juárez et al. (2016)

Género Zeta de Saussure, 1855

186. Zeta argillaceum (Linnaeus, 1758) (Fig. 19)

Material examinado. PERÚ. 2 우, Piura, Universidad de Piura, 5¹0'11"S-80³6'51"O, 29 msnm, 04-IV-2015, U. González leg., red entomológica, Bosque estacionalmente seco de

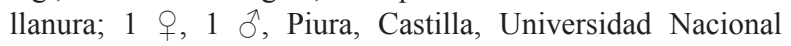
de Piura, 5 $5^{\circ} 10^{\prime} 51^{\prime \prime} \mathrm{S}-80^{\circ} 37^{\prime} 31^{\prime \prime} \mathrm{O}, 29 \mathrm{msnm}, 2-\mathrm{II}-2015$, U. González leg., red entomológica, Bosque estacionalmente

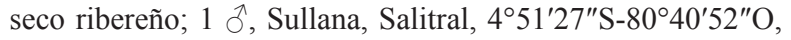
23 msnm, 28-X-2017, G. Juárez leg., red entomológica, Bosque estacionalmente seco de llanura; $1 \stackrel{+}{\circ} 1 \hat{\delta}$, Talara, El Alto, $4^{\circ} 16^{\prime} 04^{\prime \prime} \mathrm{S}-81^{\circ} 13^{\prime} 09^{\prime \prime} \mathrm{O}, 5$ msnm, 23-IV-2015, G. Juárez 
leg., red entomológica, Desierto; 1 , , Sullana, Miguel Checa, $4^{\circ} 54^{\prime} \mathrm{S}-80^{\circ} 48^{\prime} \mathrm{O}, 10 \mathrm{msnm}, 12-\mathrm{III}-2016$, G. Juárez leg., red entomológica, Bosque estacionalmente seco de llanura; 2 우우, Paita, $5^{\circ} 04^{\prime} \mathrm{S}-81^{\circ} 06^{\prime} \mathrm{O}, 10 \mathrm{msnm}, 2-\mathrm{VIII}-2017$, G. Juárez leg., red entomológica, Bosque estacionalmente seco de llanura; 3 우, 1 ô, Sechura, Vice, $5^{\circ} 25^{\prime} \mathrm{S}-81^{\circ} 46^{\prime} \mathrm{O}, 10 \mathrm{msnm}$, 17-VIII-2015, U. González leg., red entomológica, Desierto costero; 1 \% , Sechura, Illescas, $5^{\circ} 58^{\prime} \mathrm{S}-81^{\circ} 05^{\prime} \mathrm{O}, 10 \mathrm{msnm}$, 12-XI-2017, U. González leg., red entomológica, Matorral Xérico; 1 ㅇ, Morropón, Morropón, 505'51"S-8009'44"O, 557 msnm, 14-V-2017, G. Juárez leg., red entomológica, Bosque estacionalmente seco de colina; $1+$, Ayabaca, Paimas, 4³7'37"S-7956'43"O, 473 msnm, 26-VII-2015, G. Juárez leg., red entomológica, Bosque estacionalmente seco de llanura; 1 ㅇ, $1 \mathrm{o}^{\top}$, Huancabamba, Huarmaca, 534'04"S-79³1'26"O, 1000 msnm, 26-VII-2016, G. Juárez leg., red entomológica, Bosque estacionalmente seco de colina.

Distribución (Provincia) (Paisaje ecológico). (PIU, SUll, PAi, TAL, SECH, MORR, AYA, HUA) (MatX, DESc, BESr, BES1l, BESc-m).

Comentario. Los adultos se encuentran sobre hojas y ramas de plántulas y árboles, en solitario o grupo de dos a cuatro individuos. Insecto que se comporta como controlador biológico, adultos son predatores de larvas de coleópteros y lepidópteros, además se comportan como agente polinizador (Juárez et al., 2016). Especie citada también por Juárez et al. (2016).

Subfamilia Polistinae Lepeletier, 1836

Género Brachygastra Perty, 1833

187. Brachygastra lecheguana (Latreille, 1824)

Material examinado. PERÚ. 2 qo, 091 HYM-GJN, Piura, Universidad de Piura, 5 $5^{\circ} 10^{\prime} 11^{\prime \prime} \mathrm{S}-80^{\circ} 36^{\prime} 51^{\prime \prime} \mathrm{O}, 29 \mathrm{msnm}$, 04-IV-2015, U. González leg., red entomológica, Bosque estacionalmente seco de llanura; 1 ㅇ, $1 \curvearrowright$, Piura, Castilla,

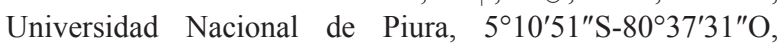
29 msnm, 2-II-2015, U. González leg., red entomológica, Bosque estacionalmente seco ribereño; 1 đ, Sullana, Salitral, 451'27"S-8040'52"O, 23 msnm, 28-X-2017, G. Juárez leg., red entomológica, Bosque estacionalmente seco de llanura; 1 ㅇ, 1 ऽ, Talara, El Alto, $4^{\circ} 16^{\prime} 04^{\prime \prime} \mathrm{S}-81^{\circ} 13^{\prime} 09^{\prime \prime} \mathrm{O}, 5 \mathrm{msnm}$, 23-IV-2015, G. Juárez leg., red entomológica, Desierto; 1 , Sullana, Miguel Checa, $4^{\circ} 54^{\prime} \mathrm{S}-80^{\circ} 48^{\prime} \mathrm{O}, 10 \mathrm{msnm}$, 12-III2016, G. Juárez leg., red entomológica, Bosque estacionalmente seco de llanura; 2 우, Paita, $5^{\circ} 04^{\prime} \mathrm{S}-81^{\circ} 06^{\prime} \mathrm{O}, 10 \mathrm{msnm}$, 2-VIII-2017, G. Juárez leg., red entomológica, Bosque estacionalmente seco de llanura; 1 ㅇ, $1 \hat{\delta}$, Sechura, Vice, 525'S-81ํ6ㅇ' O, 10 msnm, 17-VIII-2015, U. González leg., red entomológica, Desierto costero; 3 우, Sechura, Illescas, $5^{\circ} 58^{\prime} \mathrm{S}-81^{\circ} 05^{\prime} \mathrm{O}, 10 \mathrm{msnm}, 12-\mathrm{XI}-2017$, U. González leg., red entomológica, Matorral Xérico; 1 \%, Morropón, Morropón, 505'51"S-8009'44"O, 557 msnm, 14-V-2017, G. Juárez leg., red entomológica, Bosque estacionalmente seco de colina; 2 우으, Ayabaca, Paimas, 437'37"S-7956'43"O, 473 msnm, 26-VII-2015, G. Juárez leg., red entomológica, Bosque estacionalmente seco de llanura; 1 क , $1 \hat{0}$, Huancabamba, Huarmaca, 53 $34^{\prime} 04^{\prime \prime} \mathrm{S}-79^{\circ} 31^{\prime} 26^{\prime \prime} \mathrm{O}, 1000 \mathrm{msnm}, 26-\mathrm{VII}-2016$, G. Juárez leg., red entomológica, Bosque estacionalmente seco de colina.

Distribución (Provincia) (Paisaje ecológico). (PIU, SUlL, PAi, TAL, SECH, MORR, HUA, AYA) (MatX, DESc, BESr, BESll, BESc-m).

Comentario. Especie citada como Brachygastra sp en Juárez et al. (2016). Los adultos se encuentran sobre hojas de plántulas y árboles, sobrevolando y/o posadas sobre inflorescencias en solitario o grupos de dos o más individuos, construyen sus colmenas en la copa de árboles. Insecto que se comporta como controlador biológico, adultos son predatores de larvas de $E$. discordis y lepidópteros, además como agente polinizador (Juárez et al., 2016).

Género Polybia Lepeletier de Saint Fargeau, 1836

188. Polybia sin identificar sp. 1. (Fig. 20)

Material examinado. PERÚ. 2 우, Piura, Universidad de Piura, 5¹0'11"S-80³6'51"O, 29 msnm, 04-IV-2015, U. González leg., red entomológica, Bosque estacionalmente seco de llanura; 1 o, 1 त, Piura, Castilla, Universidad Nacional de Piura, $5^{\circ} 10^{\prime} 51^{\prime \prime} \mathrm{S}-80^{\circ} 37^{\prime} 31^{\prime \prime} \mathrm{O}, 29 \mathrm{msnm}, 2-\mathrm{II}-2015$, U. González leg., red entomológica, Bosque estacionalmente seco ribereño; $1 \delta^{\prime}$, Sullana, Salitral, 4 $51^{\circ} 27^{\prime \prime} \mathrm{S}-80^{\circ} 40^{\prime} 52^{\prime \prime} \mathrm{O}$, 23 msnm, 28-X-2017, G. Juárez leg., red entomológica, Bosque estacionalmente seco de llanura; 1 ๆ, 1 $\delta$, Talara, El Alto, $4^{\circ} 16^{\prime} 04^{\prime \prime S}-81^{\circ} 13^{\prime} 09^{\prime \prime} \mathrm{O}, 5$ msnm, 23-IV-2015, G. Juárez leg., red entomológica, Desierto; 1 , , Sullana, Miguel Checa, $4^{\circ} 54^{\prime} \mathrm{S}-80^{\circ} 48^{\prime} \mathrm{O}, 10 \mathrm{msnm}, 12-\mathrm{III}-2016$, G. Juárez leg., red entomológica, Bosque estacionalmente seco de llanura; 2 우우, Paita, $5^{\circ} 04^{\prime} \mathrm{S}-81^{\circ} 06^{\prime} \mathrm{O}, 10 \mathrm{msnm}, 2-\mathrm{VIII}-2017$, G. Juárez leg., red entomológica, Bosque estacionalmente seco de llanura; 1 ㅇ, $1{ }^{\wedge}$, Sechura, Vice, $5^{\circ} 25^{\prime} \mathrm{S}-81^{\circ} 46^{\prime} \mathrm{O}, 10 \mathrm{msnm}, 17-\mathrm{VIII}-$ 2015, U. González leg., red entomológica, Desierto costero; 3 오오, Sechura, Illescas, $5^{\circ} 58^{\prime} \mathrm{S}-81^{\circ} 05^{\prime} \mathrm{O}, 10 \mathrm{msnm}, 12-\mathrm{XI}-$ 2017, U. González leg., red entomológica, Matorral Xérico; 1 ㅇ, Morropón, Morropón, $5^{\circ} 05^{\prime} 51^{\prime \prime} \mathrm{S}-80^{\circ} 09^{\prime} 44^{\prime \prime} \mathrm{O}, 557 \mathrm{msnm}$, 14-V-2017, G. Juárez leg., red entomológica, Bosque estacionalmente seco de colina; 2 우, Ayabaca, Paimas, 4³7'37"S-7956'43"O, 473 msnm, 26-VII-2015, G. Juárez leg., red entomológica, Bosque estacionalmente seco de llanura;

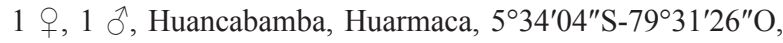
1000 msnm, 26-VII-2016, G. Juárez leg., red entomológica, Bosque estacionalmente seco de colina.

Distribución (Provincia) (Paisaje ecológico). (PIU, SUll, PAi, TAL, SECH, MORR, AYA, HUA) (MatX, DESc, BESr, BESll, BESc-m).

COMEnTARio. Adultos se encuentran sobre hojas, ramas y troncos de plántulas y árboles, sobrevolando y/o posadas sobre inflorescencias, en solitario o grupo de dos a cuatro individuos. Insecto que se comporta como controlador biológico, adultos depredan larvas de E. discordis y pequeñas de lepidópteros, además se comporta como agente polinizador. Especie citada también por Domínguez (1982) y Juárez et al. (2016)

\section{Género Polistes Latreille, 1802}

189. Polistes (Aphanilopterus) versicolor versicolor (Olivier, 1791) Material examinado. PERÚ. 1 \%, Piura, Universidad de Piura, 5¹0'11"S-80³6'51"O, 29 msnm, 04-IV-2015, U. González leg., red entomológica, Bosque estacionalmente seco de llanura; 1 , Piura, Castilla, Universidad Nacional de Piura, 5¹0'51"S-80³7'31"O, 29 msnm, 2-II-2015, U. González leg., red entomológica, Bosque estacionalmente seco

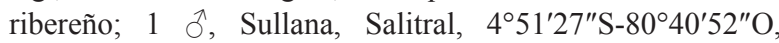
23 msnm, 28-X-2017, G. Juárez leg., red entomológica, Bosque estacionalmente seco de llanura; 1 , Talara, El Alto, $4^{\circ} 16^{\prime} 04^{\prime \prime S}-81^{\circ} 13^{\prime} 09^{\prime \prime} \mathrm{O}, 5$ msnm, 23-IV-2015, G. Juárez leg., red entomológica, Desierto; 1 \%, Sullana, Miguel Checa, 454'S-8048'O, 10 msnm, 12-III-2016, G. Juárez leg., red entomológica, Bosque estacionalmente seco de llanura; 1 ․ Paita, $5^{\circ} 04^{\prime} \mathrm{S}-81^{\circ} 06^{\prime} \mathrm{O}, 10 \mathrm{msnm}, 2$-VIII-2017, G. Juárez leg., red entomológica, Bosque estacionalmente seco de llanura; 1 , $1 \stackrel{\jmath}{2}$, Sechura, Vice, $5^{\circ} 25^{\prime} \mathrm{S}-81^{\circ} 46^{\prime} \mathrm{O}, 10 \mathrm{msnm}$, 
17-VIII-2015, U. González leg., red entomológica, Desierto costero; 1 ㅇ, Sechura, Illescas, $5^{\circ} 58^{\prime} \mathrm{S}-81^{\circ} 05^{\prime} \mathrm{O}, 10 \mathrm{msnm}$, 12-XI-2017, U. González leg., red entomológica, Matorral Xérico; 1 ㅇ, Morropón, Morropón, 505'51"S-8009'44"O, 557 msnm, 14-V-2017, G. Juárez leg., red entomológica, Bosque estacionalmente seco de colina; 1 , Ayabaca, Paimas, 4³7'37"S-7956'43"O, 473 msnm, 26-VII-2015, G. Juárez leg.,red entomológica, Bosque estacionalmente seco de llanura; 1 , 1 ò, Huancabamba, Huarmaca, 5³4'04"S-79³1'26"O, 1000 msnm, 26-VII-2016, G. Juárez leg., red entomológica, Bosque estacionalmente seco de colina.

Distribución (Provincia) (Paisaje ecológico). (PIU, SUlL, PAi, TAL, SECH, MORR, AYA, HUA) (MatX, DESc, BESr, BESll, BESc-m).

Comentario. Los adultos se encuentran sobre hojas, ramas y troncos de plántulas y árboles, sobrevolando y/o posadas sobre inflorescencias, en solitario o grupo de dos a cuatro individuos. Insecto que se comporta como controlador biológico, adultos depredan larvas pequeñas de lepidópteros, además como agente polinizador. Especie citada también por Domínguez (1982) y Juárez et al. (2016).

\section{Agradecimientos}

A Raymond J. Gagné y Stephen Gaimari por el envío de material bibliográfico y ayuda en la identificación de las especies de la familia Cecidomyiidae y Therevidae (Diptera), a Rudolf Scheffrahn por su ayuda en la identificación de las especies de Kalotermitidae (Blattodea). A los ingenieros Gastón Cruz y Nora Grados de la Universidad de Piura por el envío de material bibliográfico, así como también por el apoyo y permiso para los muestreos en dicho campus universitario. A Jorge Llontop Llaque y Juan Otivo Meza (SERFOR-Piura) por el envío de informes relacionados con algarrobo de la región Piura.

\section{Referencias}

Achterberg, C. van, 1993. Illustrated key to the subfamilies of the Braconidae (Hymenoptera: Ichneumonoidea). Zoologische Verhandelingen, 283: 1-189.

Aguirre-Tapiero, M., 2009. Clave de identificación conocidos y esperados de Elateridae Leach (Coleoptera: Elateroidea) en Colombia. Boletín del Museo de Entomología de la Universidad del Valle, 10(2): 25-35.

Arcaya, E., Mengual, X., Pérez-Bañón, C. \& Rojo, S., 2018. Aspectos biológicos de Pseudodoros clavatus (Fabricius) (Diptera: Syrphidae) alimentado con el áfido de las leguminosas Aphis craccivora Koch (Hemiptera: Aphididae). IDESIA (Arica), 36(2): 1-6. https://doi. org/10.4067/S0718-34292018005000102

Artigas, J. N. \& Hengst, M. B., 1999. Clave ilustrada para los géneros de aślidos argentinos (Diptera: Asilidae). Revista Chilena de Historia Natural, 72: 107-150.

Aspöck, U. \& Aspöck, H., 2007. Verbliebene Vielfalt vergangener Blüte. Zur Evolution, Phylogenie und Biodiversität der Neuropterida (Insecta: Endopterygota). Denisia, 20: 451-516.

Astola-Mariscal, S. Z. \& Narrea-Cango, M., 2019. Biología y comportamiento de Cotesia flavipes Cameron (Braconidae) parasitoide de Diatraea saccharalis Fabricius (Crambidae). Ecología Aplicada, 18(1): 77-83. https:// doi.org/10.21704/rea.v18i1.1309
Barber, H. S., 1936. A new ecuadorian fleabeetle injuring crucifers (Coleoptera: Chrysomelidae). Journal of the Washington Academy of Sciences, 26(4): 181-182.

Beccaloni, G. \& Eggleton, P., 2013. Order Blattodea. In: Zhang, Z. Q. (ed.). Animal Biodiversity: An Outline of Higher-level Classification and Survey of Taxonomic Richness (Addenda 2013). Zootaxa, 3707: 46-48. https://doi.org/10.11646/zootaxa.3703.1.10

Binda, F. \& Joly, F., 1991. Los Bostrichidae (Coleoptera) de Venezuela. Boletín de Entomología Venezolana, 6: 83-133.

Blake, D. H., 1950. A revision of the beetles of the genus Myochrous. Proceedings of the United States National Museum, 101(3271): 1-64. https://doi.org/10.5479/ si.00963801.101-3271.1

Bertolaccini, I. Bouzo, C. Larsen, N \& Favaro, J. C., 2010. Especies del género Euxesta (Diptera: Ulidiidae = Otitidae) plagas de maíces dulces $B t$ en la provincia de Santa Fe, Argentina. Revista de la Sociedad Entomológica Argentina, 69(1-2): 123-126.

Bobadilla D. Cortés, R \& Vargas, H., 1987. Estudio de los insectos que atacan al tamarugo (Prosopis tamarugo Phil.) y al algarrobo (Prosopis chilensis (Mol.) Stuncz). Informe FAO-PNUD-UTA. Universidad de Tarapacá. 168 pp.

Bolton, B., 2019. AntWeb. Disponible en http://www. antweb.org/ (consultado 28.04.2020).

Bouchard, P., Bousquet, Y., Davies, A., Alonso-Zarazaga, M. A., Lawrence, J., Lyal, C., Newton, A., Reid, C., Schmitt, M., Slipinski, A. \& Smith, A., 2011. Family-group names in Coleoptera (Insecta). ZooKeys, 88: 1-972. https://doi.org/10.3897/zookeys.88.807

Burckhardt, D., 1994. Generic key to Chilean jumping plant-lice (Homoptera: Psylloidea) with inclusion of potential exotic pests. Revista Chilena de Entomología, 21: 57-67.

Burghardt, A., Brizuela, M., Mom, M., Albán, L. \& Palacios, R., 2010. Análisis numérico de las especies de Prosopis L. (Fabaceae) de las costas de Perú y Ecuador. Revista Peruana de Biología, 17(3): 317-323.

Cadena-Castañeda, O \& Cardona-Granda, J.M., 2015. Introducción a los saltamontes de Colombia (Orthoptera: Caelifera, Acridomorpha, Tetrigoidea \& Tridactyloidea). Lulu.com. Colombia. 536 pp.

Carbonell, C. S \& Descamps, M., 1978. Revue des Ommatolampae (Acridoidea, Ommatolampinae). Annales de la Société Entomologique de France, 14(1): 1-35.

Carpenter, J. \& Garcete-Barrett, B., 2002. A key to the neotropical genera of Eumeninae (Hymenoptera: Vespidae). Boletín Museo Nacional Historia Natural Paraguay, 14(1-2): 52-73.

Chandler, D., 2016. Beetles (Coleoptera) of Peru: a survey of the families. Anthicidae Latreille, 1824. Journal of the Kansas Entomological Society, 89(2): 182-190. https://doi.org/10.2317/150920.1

Chiappa, E., Villaseñor, R., Toro, H. \& Covarrubias, R., 1997. Táctica reproductiva de Prosopis (Mimosaceae) y asociaciones ecológicas de sus polinizadores, en el desierto del norte de Chile. Multequina, 6: 9-20.

Chipana-Auris, K. G., 2019. Ocurrencia estacional de un Cecidomyiidae en algarrobo (Prosopis pallida) H.B.K. en Pacasmayo - Perú. Tesis para optar título de 
Ingeniera Agrónoma. Universidad Nacional Agraria La Molina. $98 \mathrm{pp}$.

Caudell, A. N., 1912. A new Proscopiid Grasshopper from Perú. Psyche, 19: 12-13.

Cobos, A., 1972. Ensayo monográfico sobre las Anthaxia Eschs., Coleoptera Buprestidae, de America. Tercera parte subgénero Agrilaxia Kerremans. Archivos del Instituto de Aclimatación, 16: 1-246.

Cobos, A., 1980. Ensayo sobre los géneros de la subfamilia Polycestinae (Coleoptera, Buprestidae). Parte I. Eos, 44: 15-94.

Córdova, A. A. Mazzuferi, V. Coirini, R. O. Karlin, U \& Casanoves, F., 2000. Torneutes pallidipennis Reich (Coleoptera: Cerambycidae) en algarrobos negros del Chaco árido de Córdoba. Efecto de la Condición de sitio en el grado de infestación. Multequina, 9: 99-110.

Cruzado-Jacinto, L. Chávez-Villavicencio, C \& Charcape-Ravelo, J., 2019. Uso y selección de las partes aéreas del algarrobo Prosopis pallida (Fabaceae) por reptiles, aves y mamíferos en Sechura (Piura - Perú). Revista Peruana de Biología, 26(1): 81-86. https://doi. org/10.15381/rpb.v26i1.15417

Cryan, J. R \& Urban, J. M., 2012. Higher-level phylogeny of the insect order Hemiptera: is Auchenorrhyncha really paraphyletic? Systematic Entomology, 37: 7-21. https://doi.org/10.1111/j.1365-3113.2011.00611.x

D'Abrera, B., 1994. Butterflies of the world. Butterflies of the Neotropical region. Part VI (Riodinidae). Hill House Publisher. 217 pp.

D'Abrera, B., 1995. Butterflies of the world. Butterflies of the Neotropical region. Part VII (Lycaenidae). Hill House Publisher. 173 pp.

Depenthal, J. \& Meitzner-Yoder, L., 2018. Community use and knowledge of Algarrobo (Prosopis pallida) and implications for peruvian dry forest conservation. Revista de Ciencias Ambientales, 52(1): 49-70. https:// doi.org/10.15359/rca.52-1.3

Díaz-Celis, A., 1995. Los Algarrobos. CONCYTEC, Lima. $217 \mathrm{pp}$.

Dijkstra, K-D., Bechly, B., Bybee, G., Dow, S. M., Dumont, R. A., Fleck, H. J., Garrison, G., Hämäläinen, R. W., Kalkman, M., Karube, V. J., May, H., Orr, M. L., Paulson, A. G., Rehn, D. R., Theischinger, A. C., Trueman, G., Tol, J. W. H., van. Ellenrieder, J. \& Ware, J., 2013. The classification and diversity of dragonflies and damselflies (Odonata). In: Zhang, Z. Q. (ed.). Animal Biodiversity: An Outline of Higher-level Classification and Survey of Taxonomic Richness (Addenda 2013). Zootaxa, 3707: 1-82. http://dx.doi.org/10.11646/zootaxa.3703.1.9

Dealy, B., 2000. A revision of the genus Piezogaster Amyot \& Serville (Heteroptera: Coreidae: Nematopodini) and the description of two new species. Thesis of Master of Science. Fort Hays State University. 121 pp.

Derunkov, A., Konstantinov, A. Tishechkin, A. Hartje, L \& Redford, A. J., 2013. Diabrotica ID: Identification of Diabrotica species (Coleoptera: Chrysomelidae) from North and Central America. USDA APHIS PPQ Center for Plant Health Science and Technology, USDA Agricultural Research Service, University of Maryland, and Louisiana State University.
Disponible en http://idtools.org/id/beetles/diabrotica/ index.php (consultado 2.05.2020).

Dombroskie, J. J., 2011. A matrix key to families, subfamilies and fribes of Lepidoptera of Canada. Canadian Journal of Arthropod Identification, 17: 1-129.

Domínguez, G., 1982. Introducción al estudio del algarrobo (Prosopis sp) en Piura, con especial referencia a su fauna entomológica. Tesis para ingeniero forestal. Universidad Nacional Agraria La Molina. 312 pp.

Dostert, N., Roque, J., Cano, A., La Torre, M. \& Weigend, M., 2012. Hoja Botánica: Algarrobo, Prosopis pallida (Humb. \& Bonpl. ex Willd.) Kunth. Reporte técnico. Proyecto Perúbiodiverso, Lima. 17 pp.

Dugdale, J. S., 1988. Lepidoptera - annotated catalogue, and keys to family-group taxa. Fauna of New Zealand, 14: 1-269. https://doi.org/10.7931/J2/FNZ.14

Escalona, H. E. \& Joly, L. J., 2006. El género Ligyrus Burmeister, 1847 en Venezuela (Coleoptera: Scarabaeidae: Dynastinae: Pentodontini). Boletín Sociedad Entomológica Aragonesa, 39: 111-137.

Fagg, C. W. \& Stewart, J. L., 1994. The value of Acacia and Prosopis in arid and semiarid environments. Journal of arid Environment, 27: 3-25.

Fernández, F., 2003. Introducción a las hormigas de la región Neotropical. Instituto de Investigación de Recursos Biológicos Alexander von Humboldt. Bogotá. 398 pp.

Fernández, F \& Sharkey, M., 2006. Introducción a los Hymenoptera de la Región Neotropical. Sociedad Colombiana de Entomología, Bogotá. 894 pp.

Ferrer, J., 2011. Revisión del género Zophobas Dejean, 1834 (Coleoptera, Tenebrionidae, Tenebrionini). Boletín de la Sociedad Entomológica Aragonesa, 48: 287-319.

Fisher, W., 1950. A revision of the North American species of beetles belonging to the Family Bostrichidae. Miscellaneous Publication No. 698. United States Department of Agriculture. $157 \mathrm{pp}$.

Freude, H., 1967. Revision der Epitragini (Col., Tenebrionidae) I. Teil. Entomologischen Arbeiten aus dem Museum G. Frey, 18: 142-242.

Gagné, R. J \& Jaschhof, M., 2017. A Catalog of Cecidomyiidae (Diptera) of the world. Fourth Edition. Digital. $762 \mathrm{pp}$.

Gagné, R. J. \& Whaley, O. Q., 2020. The larva of Enallodiplosis discordis (Diptera: Cecidomyiidae: Cecidomyiidinae), a pest of Prosopis spp. (Fabaceae) in Perú and Chile. Proceedings of the Entomological Society of Washington, 122(1): 243-247. https://doi. org/10.4289/0013-8797.122.1.243

Galileo, M. \& Martins, U., 1996. Revisão do genero Nesozineus Linsley \& Chemsak, 1966 (Acanthoderini). Revista Brasileira Entomologia, 40(1): 41-46.

Galileo, M. \& Martins, U., 2007. Notes e descrição em Acanthoderini (Coleoptera, Cerambycidae, Lamiinae). II. Espécies novas do genero Nesozineus. Revista Brasileira Entomologia, 24(3): 631-634. https://doi. org/10.1590/S0101-81752007000300014

Garrison, R. W., Von Ellenrieder, N. \& Louton, J. A., 2006. Dragonfly Genera of the New World An illustrated and annotated key to the Anisoptera. The Johns Hopkins University Press. 368 pp. 
Garrison, R. W., Von Ellenrieder, N. \& Louton, J. A., 2010. Damselfly Genera of the New World An illustrated and annotated key to the Zygoptera. The Johns Hopkins University Press. 490 pp.

Gidaspow, T., 1963. The genus Calosoma in Central America, The Antilles and South America (Coleoptera, Carabidae). Bulletin of the American Museum of Natural History, 124(7): 1-44. Disponible en http://digitallibrary. amnh.org/handle/2246/1214 (consultado 2.05.2020).

Gilbert, F. S., 1981. Foraging ecology of hoverfies: morphology of the mouthparts in relation to feeding on nectar and pollen in some common urban species. Ecologycal Entomology, 6(3): 245-262. https://doi. org/10.1111/j.1365-2311.1981.tb00612.x

Giraldo-Mendoza, A. E. \& Flores, G., 2019. A revision of the Peruvian Edrotini (Coleoptera: Tenebrionidae: Pimeliinae). Annales Zoologici (Warszawa), 69(1): 83-98. https://doi.org/10.3161/00034541ANZ2019.69.1.004

Goding, F.W., 1929. The Membracidae of South America and the Antilles IV: Subfamilies Hoplophorininae, Darninae, Smiliinae, Tragopinae (Homoptera). Transactions of the American Entomological Society, 55: 197-300.

González, G. 2007. Los Coccinellidae de Perú. Disponible en http://www.coccinellidae.cl.PaginasWebPerú/Paginas/ InicioPerú.php (consultado 28.04.2020).

Goulet, H \& Huber, J. T., 1993. Hymenoptera of the world: an Identification guide to families. Canada Communication Group. Ottawa. 668 pp.

Grados, N., Ruíz, W., Cruz, G., Díaz, C. \& Puicón, J., 2000. Productos industrializables de la algarroba peruana (Prosopis pallida): algarrobina y harina de algarroba. Multequina, 9(2): 119-132.

Grant, H. J., 1964. Revision of the genera Ceraia and Euceraia, with notes on their relationship to Scudderia (Orthoptera; Tettigoniidae; Phaneropterinae). Proceedings of the Academy of Natural Sciences of Philadelphia, 116: 29-117.

Habeck, D. H., 2002. Nitidulidae. In: Arnett, R. H. Thomas, M. C. Skelley, P.E. \& Frank, J. H. (Eds.). American Beetles. Volumen II. CRC Press. Boca Raton: 311-315.

Hansson, C., 1995. Revised keys to the Nearctic species of Chrysocharis Föster (Hymenoptera: Eulophidae), including three new species. Journal of Hymenoptera Research, 4: 80-98.

Huertas, P., 1987. Insectos consumidores de vainas de Prosopis en Olmos, departamento de Lambayeque-Perú. Zonas Áridas, 5: 53-56.

Ingrisch, S. 2011. Order Orthoptera Oliver, 1789. In: Zhang, Z.-Q. (ed.). Animal biodiversity: An Outline of higher-level classification and survey of taxonomic richness. Zootaxa, 3148: 195-197.

Juárez, G., 2014. Cuatro nuevos registros de insectos en los bosques de la Región Piura, Perú. The Biologist (Lima), 12(2): 297-304.

Juárez, G. \& González, U., 2015. Primer registro de Gymnetis stellata Latreille, 1833 (Scarabaeidae: Cetoniinae) para Perú. The Biologist (Lima), 13(2), 193-199.

Juárez, G. \& González, U., 2016a. Coleópteros (Insecta: Coleoptera) del campus de la Universidad de Piura. The Biologist (Lima), 14(2): 183-198.
Juárez, G. \& González, U., 2016b. Primer registro de Sinoxylon anale Lesne, 1897 para Perú (Coleoptera: Bostrichidae). Boletín de la Sociedad Entomológica Aragonesa, 59: 255-256.

Juárez, G. \& González, U., 2016c.Nuevos registros de la tribu Nematopodini (Hemiptera: Heteroptera: Coreidae) para Perú. Boletín de la Sociedad Entomológica Aragonesa, 59: 204-206.

Juárez, G., González, U. \& Háva, J., 2015. Primer registro de Dolichobostrychus angustus Steinheil, 1872 (Coleoptera: Bostrichidae) para Perú. The Biologist (Lima), 13(2): 437-441.

Juárez, G., Grados, N. \& Cruz, G., 2016. Insectos asociados a Prosopis pallida (Humb. \& Bonpl. ex. Wild.) en el campus de la Universidad de Piura, Perú. Zonas Áridas, 16(1): 28-51.

Juárez-Noé, G. \& González-Coronado, U., 2018. Lista de coleópteros (Insecta: Coleoptera) de la región Piura, Perú. Folia Entomológica Mexicana (nueva serie), 4(1): 1-27.

Juárez-Noé, G. \& González-Coronado, U., 2019. Actualización a la lista de coleópteros (Insecta: Coleoptera) de la región Piura, Perú. Graellsia, 75(2): e097. https://doi. org/10.3989/graellsia.2019.v75.233

Kameneva, E. P \& Korneyev, V. A., 2016. Revision of the genus Physiphora Fallén 1810 (Diptera: Ulidiidae: Ulidiinae). Zootaxa, 4087(1): 1-88. https://doi. org/10.11646/zootaxa.4087.1.1

Kassebeer, C., 2000. Zur Gattung Pseudodorus Becker, 1903 (Diptera, Syrphidae). Dipteron, 3(1): 73-92.

Kits, J., Marshall, S. \& Evenhuis, N., 2008. The bee flies (Diptera: Bombyliidae) of Ontario, with a key to the species of Eastern Canada. Canadian Journal of Arthropod Identification, 6: 1-52. https://doi.org/10.3752/ cjai.2008.06

Korytkowski, C. A., 2014. Contribución al conocimiento de los Agromyzidae (Diptera: Muscomorpha) en el Perú. Revista Peruana de Entomología, 49(1): 1-106.

Korytkowski, C. A. \& Ojeda, D., 1971. Revisión de las especies de la familia Lonchaeidae en el Perú (Diptera: Acalyptratae). Revista Peruana de Entomología, 14(1): 83-116.

Kulzer, H., 1958. Monographie der südamerikanische Tribus Praocini (Col.). Entomologische Arbeiten Aus dem Museum G. Frey, 9(1): 1-105.

Lamas, G., 1972. A catalogue of Peruvian Asilidae (Diptera), with keys to the identification and descriptions of two new species. Revista Peruana Entomología, 15(2): 304-316.

Lesne, P., 1896. Révision des Coléoptères de la famille des Bostrychides. Bostrychinae. Annales de la Société Entomologique de France, 65: 95-127.

Llontop-Llaque, J. A., 2013. Impactos del cambio climático y medidas de adaptación para la conservación del bosque seco y sostenibilidad de la cadena de valor de derivados de algarroba en la Región Piura. Informe Final. Gobierno Regional de Piura. 147 pp.

López, R. Araya, J. E \& Sazo, L., 2012. Colectas de Syrphidae en alfalfa en Colina, región Metropolitana, Chile, y clave de identificación de seis especies de Allograpta. Boletín de Sanidad Vegetal - Plagas, 38: 3-15. 
López-García, M., Giraldo-Mendoza, A. \& Deloya, C., 2019. Taxonomic synopsis of the genus Tomarus Erichson, 1847 (Coleoptera: Scarabaeidae: Dynastinae) in Perú. Zootaxa, 4604(3): 428-440. https://doi. org/10.11646/zootaxa.4604.3.2

Marchiori, C. H. Pereira, L. A \& Filho, O. M. S., 2002. Brachymeria podagrica (Fabricius) (Hymenoptera: Chalcididae) as a parasitoid of Chrysomya albiceps (Wiedemann) (Diptera: Calliphoridae): first report in Brazil. Arquivo Brasileiro de Medicina Veterinária e Zootecnia, 54(5): 555-557.

Marcuzzzi, G., 1961. Revisione delle specie Venezuelane della tribu Epitragini (Col. Tenebr.) con appunti su altre specie neotropicali. Annali del Museo Civico di Storia Naturale di Genova, 72: 313-352.

Martins, U., 1999. Cerambycidae Sul-Americanos (Coleoptera). Taxonomia Volume III. São Paulo. Sociedade Brasileira de Entomologia, 3: 1-418

Martins, U., 2002. Cerambycidae Sul-Americanos (Coleoptera). Taxonomia Volume IV. São Paulo. Sociedade Brasileira de Entomologia, 4: 1-265.

Martins, U., 2003. Cerambycidae Sul-Americanos (Coleoptera). Taxonomia Volume VI. São Paulo. Sociedade Brasileira de Entomologia, 6: 1-232.

Masner, L., 1976. Revisionary notes and keys to world genera of Scelionidae (Hymenoptera: Proctotrupoidea). Memoirs of the Entomological Society of Canada, 97: 1-87.

Mazzuferi, V., 2000. Plagas en Prosopis. Multequina, 9(2): 107-117.

Mengual, X., Ruiz, C., Rojo, S., Ståhls, G. \& Thompson, F.C., 2009. A conspectus of the flower fly genus Allograpta (Diptera: Syrphidae) with description of a new subgenus and species. Zootaxa, 2214: 1-28. https://doi. org/10.11646/zootaxa.2214.1.1

Mengual, X. \& Thompson, F., 2008. A taxonomic review of the Palpada ruficeps species group, with the description of a new flower fly from Colombia (Diptera: Syrphidae). Zootaxa, 1741: 31-36. https://doi.org/10.11646/ zootaxa.1741.1.3

Mengual, X. \& Thompson, F., 2011. Carmine cochineal killers: the flower fly genus Eosalpingogaster Hull (Diptera: Syrphidae) revised. Systematic Entomology, 36:713731. https://doi.org/10.1111/j.1365-3113.2011.00588.x

MINAM (Ministerio Del Ambiente), 2015. Guía de inventario de la flora y vegetación. Ministerio Del Ambiente, Dirección General de Evaluación, Valoración y Financiamiento Del Patrimonio Natural. Lima. 50 pp.

MINAM (Ministerio Del Ambiente), 2018. Mapa Nacional de Ecosistemas Del Perú. Memoria Descriptiva. Ministerio Del Ambiente. Lima. 60 pp.

Mom, M. P. Burghardt, A. D. Palacios R. A \& Albán L., 2002. Los algarrobos peruanos: Prosopis pallida y su delimitación. Arnaldoa, 9 (1):39-48.

Mondaca, J., 2011. Primer registro de Cyclocephala modesta (Scarabaeidae: Dynastinae: Cyclocephalini) en Chile. Revista Chilena de Entomología, 36: 33-38.

Mondaca, J., 2012. Paranomala undulata peruviana (Scarabaeidae: Rutelinae): Un nuevo escarabajo exótico introducido en chile. Revista Chilena de Entomología, 37: 75-80.
Monné, M., 1972. Revision parcial del género Achryson Serville, 1933 (Coleoptera, Cerambycidae, Achrysonini). Revista Peruana de Entomología, 15(1): 103-112.

Moore, T. \& Diéguez, V., 2008. Aporte al conocimiento del género Polycesta Dejean, 1833 en las regiones neotropical y andina, con descripción de especies nuevas (Coleoptera: Buprestidae: Polycestini). Acta Entomológica Chilena, 32(1): 7-22.

More, A., Villegas, P. \& Alzamora, M., 2014. Piura, Áreas prioritarias para la conservación de la biodiversidad. Naturaleza y Cultura Internacional-PROFONANPE, Lima, 166 pp.

Mormontoy del Pino, S. D., 2015. Infestación, daños y enemigos naturales del "psílido del algarrobo" Heteropsylla texana Crawford (Hemiptera-Psyllidae) en el bosque seco de la comunidad de Tongorrape-Motupe-Lambayeque. Tesis para Ingeniero Forestal. Universidad Nacional Agraria La Molina. 90 pp.

Morón, M., Ratcliffe, B. \& Deloya, C., 1997. Atlas de los escarabajos de México. Coleoptera: Lamellicornia. Vol I. Familia Melolonthidae. Conabio, México D.F. 280 pp.

Mound, L. A., 2013. Order Thysanoptera Haliday, 1836. In: Zhang, Z. Q. (ed.). Animal Biodiversity: An Outline of Higher-level Classification and Survey of Taxonomic Richness (Addenda 2013). Zootaxa, 3703: 49-50. https://doi.org/10.11646/zootaxa.3703.1.11

Myartseva, S. \& Evans, G., 2007. Genus Encarsia Fórster of Mexico (Hymenoptera: Chalcidoidea: Aphelinidae). $A$ revision, key and description of new species. Serie Avispas parasíticas de plagas y otros insectos. Universidad Autónoma de Tamaulipas. 323 pp.

Myartseva, S., Ruíz-Cancino, E. \& Coronado-Blanco, J. M., 2010. El género Aphytis Howard (Hymenoptera: Chalcidoidea: Aphelinidae) en México, clave de especies y descripción de una especie nueva. Dugesiana, 17(1): 81-94.

Naumann, M. G., 1968. A revision of the genus Brachygastra (Hymenoptera: Vespidae). University of Kansas Science Bulletin, 17: 929-1003.

Naviaux, R., 2007. Tetracha (Coleoptera, Cicindelidae, Megacephalina); Revision du genre et descriptions de nouveaux taxons. Mémories de la Société entomologique de France, 7: 1-197.

Nieukerken, E. J. van, Kaila, L., Kitching, I. J., Kristensen, N. P., Lees, D. C., Minet, J., Mitter, C., Mutanen, M., Regier, J. C., Simonsen, T. J., Wahlberg, N., Yen, S-H., Zahiri, R., Adamski, D., Baixeras, J., Bartsch, Bengtsson, B. A., Brown, J. W., Bucheli, S. R., Davis, D.R., De Prins, J., De Prins, W., Epstein, M. E., Gentili-Poole, P., Gielis, C., Hättenschwiler, P., Hausmann, A., Holloway, J. D., Kallies, A., Karsholt, O., Kawahara, A. Y., Koster, S., Kozlov, M. V., Lafontaine, J. D., Lamas, G., Landry, J-F., Lee, S., Nuss, M., Park, K-T., Penz, C., Rota, J., Schintlmeister, A., Schmidt, B. C., Sohn, J.-C., Solis, M. A., Tarmann, G. M. Warren, A. D., Weller, S., Yakovlev, R. V., Zolotuhin, V. V. \& Zwick, A. 2011. Order Lepidoptera Linnaeus, 1758. In: Zhang, Z.-Q. (ed.). Animal biodiversity: An outline of higher-level classification and survey of taxonomic richness. Zootaxa, 3148: 212-221. 
Noonan, G. R., 1981. South American species of the subgenus Anisotarsus Chaudoir (genus Notiobia Perty: Carabidae: Coleoptera). Part I: Taxonomy and Natural History. Contributions in Biology and Geology, 44: 1-84.

Núñez, E., 1988. Chrysopidae (Neuroptera) del Perú y sus especies más comunes. Revista Peruana de Entomología, 31: 69-75.

Núñez-Sacarías, E., 1993. Insectos del algarrobo (Prosopis spp.) en el Perú: costa norte (Piura) y costa central (Ica). Revista Peruana de Entomología, 36: 69-83.

Opitz, W., 2013. Revision of the New World genus Neorthopleura Barr (Coleoptera: Cleridae). Annales de la Société entomologique de France (N. S.), 49(1): 1.35. https://doi.org/10.1080/00379271.2013.775797

Otte, D., 1979. Revision of the Grasshopper Tribe Orphulellini (Gomphocerinae: Acrididae). Proceedings of the Academy of Natural Sciences of Philadelphia, 131: 52-88. Disponible en http://www.jstor.org/ stable/4064782 (consultado 2.05.2020).

Palacios, R. A. Burghardt, A. D. Frías-Hernández, J. T. Olalde- Portugal, V. Grados, N. Albán, L \& Martínez-de la Vega, O., 2011. Comparative study (AFLP and morphology) of three species of Prosopis of the Section Algarobia: P. juliflora, P. pallida, and P. limensis. Evidence for resolution of the "P. pallida-P. juliflora complex". Plant Systematics and Evolution, 298: 165-171. https://doi.org/10.1007/s00606-011-0535-y

Panizzi, A. R \& Grazia, J. (Eds.), 2015. True bugs (Heteroptera) of the Neotropics. Entomology in Focus. Volume 2. 904 pp. https://doi.org/10.1007/978-94-017-9861-7

Pape, T., Blagoderov, V. \& Mostovski, M. B., 2011. Order Diptera. In: Zhang, Z. Q. (ed.). Animal Biodiversity: An Outline of Higher-level Classification and Survey of Taxonomic Richness. Zootaxa, 3148: 222-229.

Pasiecznik, N. M., 2001. The Prosopis juliflora-Prosopis pallida complex: a monograph. Henry Doubleday Research Association (HDRA). Coventry. 162 pp.

Pearson, D. L. Buestán, J \& Navarrete, R., 1999. The tiger beetles of Ecuador: their identification, distribution and natural history (Coleoptera: Cicindelidae). Contributions on Entomology, International, 3(2): 189-315.

Peña, L., 1973. Nuevas especies del genero Psammetichus Latr., (Coleoptera-Tenebrionidae) para Chile y Perú. Revista Chilena de Entomología, 7: 137-144.

Peña, L., 1994. Nuevas especies de Tenebrionidae (Insecta-Coleoptera) de la region Neotropical. Gayana Zoologia, 58: 151-168.

Peters, R. S. \& Baur, H., 2011. A revision of the Dibrachys cavus species complex (Hymenoptera: Chalcidoidea: Pteromalidae). Zootaxa, 2937: 1-30. https://doi. org/10.11646/zootaxa.2937.1.1

Potin-Téllez, C. A., 2008. Tabla de vida del depredador Zelus renardii (Kolenati) (Hemiptera: Heteroptera: Reduviidae) en laboratorio. Tesis para título profesional de Ingeniero Agrónomo. Universidad de Chile. 34 pp.

Rasmussen, C. \& González, V., 2017. The neotropical stingless bee genus Nannotrigona Cockerell (Hymenoptera: Apidae: Meliponini): An illustrated key, notes on the types, and designation of lectotypes. Zootaxa, 4299(2): 191-220. https://doi.org/10.11646/zootaxa.4299.2.2
Ratcliffe, B. C., 2018. A monographic revision of the genus Gymnetis MacLeay, 1819 (Coleoptera: Scarabaeidae: Cetoniinae). Bulletin of the University of Nebraska State Museum, 31: 1-250.

Razowski, J., Landry, B. \& Roque-Albelo, I., 2008. The Tortricidae (Lepidoptera) of the Galapagos Islands, Ecuador. Revue Suisse de Zoologie, 115, 185-220.

Redolfi de Huiza, I., 1994. Diversidad de Braconidae (Hymenoptera) en el Perú. Revista Peruana de Entomología, 37:11-22.

Rehn, J. A., 1939. The South American Species of the Oedipodine Genus Trimerotropis (Orthoptera: Acrididae). Transactions of the American Entomological Society, 65: 395-414. Disponible en http://www.jstor. org/stable/25077447 (consultado 2.05.2020).

Rengifo-Correa, L. \& González, R., 2011. Clave ilustrada para la identificación de las familias de Pentatomomorpha (Hemiptera: Heteroptera) de distribución neotropical. Boletín Científico del Museo de Historia Natural, 15(1): 168-187.

Reyes-Gallego, K., Montoya-Lerma, J., Giraldo-Echeverri, G. \& Brown, J. W., 2012. Description of the early stages of Eccopsis galapagana Razowski \& Landry (Tortricidae), a defoliator of Prosopis juliflora (SW.) DC. (Fabaceae) in Colombia. Journal of the Lepidopterists Society, 66(3): 156-164. https://doi.org/10.18473/lepi. v66i3.a6

Ribeiro, P. B. \& Carvalho, C. J. B., 1998. Pictorial key to Calliphoridae genera (Diptera) in Southern Brazil. Revista Brasileira Parasitologia Veterinaria, 7(2): 137-140.

Rivera, J., 2001. Sobre la identidad de Vates peruviana Rehn, 1911 (Mantodea: Vatidae). Revista Peruana de Entomología, 42: 93-96.

Rivera, J. \& Vergara-Cobián, C., 2017. A checklist of the praying mantises of Perú: new records, one new genus (Piscomantis gen. n.) and biogeographic remarks (Insecta, Mantodea). Zootaxa, 4337(3): 361-389. https:// doi.org/10.11646/zootaxa.4337.3.3

Romero, C., Araya, J. E., Guerrero, M. A., Curkovic, T. \& Vihuela, E., 2007. Biología del depredador generalista Nabis punctipennis Blanchard (Hemiptera: Nabidae). Phytoma, 191: 36-44.

Rondón, S. \& Vergara, C., 2003. Efecto de insecticidas en la dinámica poblacional de Labiduria riparia (Pallas) (Dermaptera: Labiduridae) en cuatro cultivares de camote, en Cañete, Lima, Perú. Revista Peruana de Entomología, 43: 121-127.

Roth, L., 1998. The cockroach genus Pycnoscelus Scudder, with a description of Pycnoscelus femapterus, sp. nov. (Blattaria: Blaberidae: Pycnoscelinae). Oriental Insects, 32: 93-130. https://doi.org/10.1080/00305316.1998.104 33770

Sabrosky, C. W., 1981. A partial revision of the genus Eucelatoria (Diptera: Tachinidae), including important parasites of Heliothis. United States Department of Agriculture, Technical Bulletin, 1635: 1-16.

Scheffrahn, R. H., Krecek, J., Tapia, R. \& Luppichini, P., 2009. Endemic origin and vast anthropogenic dispersal of the West Indian drywood termite. Biological 
invasions, 11: 787-799. https://doi.org/10.1007/ s10530-008-9293-3

Sharkey, M., 2007. Phylogeny and classification of Hymenoptera. In: Zhang, Z.-Q. \& W.A. Shear (eds.). Linnaeus Tercentenary: Progress in Invertebrate Taxonomy. Zootaxa, 1668: 521-548.

SENASA (Servicio Nacional de Sanidad Agraria), 2016. Situación fitosanitaria del algarrobo (Prosopis pallida) en la costa norte del Perú. Subdirección de Análisis de Riesgo y Vigilancia Fitosanitaria, Dirección de Sanidad Vegetal. Lima. 47 pp.

SENASA (Servicio Nacional de Sanidad Agraria), 2020. Lista de plagas cuarentenarias no presentes en Perú. Disponible en https://www.senasa.gob.pe/ senasa/plagas-cuarentenarias-no-presentes/ (consultado 28.04.2020).

Silvestro, V., Giraldo, A. \& Flores, G., 2015. Pumiliofossorum: A new genus of Scotobiini (Coleoptera: Tenebrionidae) with two new species from Perú, and a revised key for the genera of the tribe. Zootaxa, 3986(4): 461-471. https://doi.org/10.11646/zootaxa.3986.4.5

Simbaqueda, R., Serna, F. \& Posada-Flores, F. J., 2014. Curaduría, morfología e identificación de áfidos (Hemiptera: Aphididae) del museo entomológico UNAB. Primera aproximación. Boletín científico del Museo de Historia Natural, 18(1): 221-245.

Song, H., 2009. Schistocerca Information Site. Taxonomic Identification Key to Schistocerca species. Disponible en https://www.schistocerca.org/key.htm (consultado 2.05.2020).

Soto-Rodríguez, G., Rodrígez-Arrieta, J. A., González-Muñoz, C., Cambero-Campos, J. \& Retana-Salazar, A. P., 2017. Clave para la identificación de géneros de Thrips (Insecta: Thysanoptera) comúnmente asociados a plantas ornamentales en Centroamérica. Acta Zoológica Mexicana (Nueva Serie), 33(3): 454-463.

Stange, L. A., 1989. Review of the new world Dimarini with the description of a new genus from Perú (Neuroptera: Myrmeleontidae). Florida Entomologist, 72(3): 450-463.

Straneo, S. L., 1986. Sul genere Blennidus Motschulsky 1865 (Col. Carabidae, Pterostichini). Bollettino del Museo Regionale di Scienze Naturali Torino, 4(2): 369-393.

Taucare-Ríos, A., Carvajal, M. \& Faúndez, E. I., 2018. Primer registro de Pycnoscelus surinamensis (Linnaeus, 1758) (Blattodea: Blaberidae) en Chile Continental. Boletín de la Sociedad Entomológica Aragonesa, 63: 240-242.

Thompson, F., 1991. The flower fly genus Ornidia (Diptera: Syrphidae). Proceedings of the Entomological Society of Washington, 93(2): 248-261. Disponible en https://repository.si.edu/handle/10088/17487 (consultado 2.05.2020).

Toro, H., 2002. Pollination of Prosopis tamarugo in the Atacama Desert With Remarks on the Roles of Associated Plants. In: Kevan P. \& I. Fonseca (Eds.). Pollinating
Bees - The Conservation Link Between Agriculture and Nature. Ministry of Environment. Brasilia: 267-273.

Toro, H., Chiappa, E., Covarrubias, R. \& Villaseñor, R., 1993. Interrelaciones de polinización en zonas áridas del norte de chile. Acta entomológica chilena, 17: 1-10.

Tricone, F. \& Anderson, T. R., 2018. Guía para la instalación de parcelas de monitoreo de vegetación. Sarteneja. $60 \mathrm{pp}$.

Van Dyke, E. C., 1953. The Coleoptera of Galapagos Islands. Occasional Papers of the California Academy of Sciences, 22: 1-181.

Vargas, H. \& Bobadilla, G., 2000. Insectos asociados al bosque de tamarugo. In: Baldini A \& L. Pancel (eds.). Agentes de daño en el bosque nativo. Editorial Universitaria. Santiago de Chile: 283-318.

Vargas, H. A., 2010. Larva del último instar y pupa de Melipotis cellaris (Guenée) (Lepidoptera: Noctuidae). Neotropical Entomology, 39(5): 736-741. https://doi. org/10.1590/S1519-566X2010000500011

Vargas, H. A., 2011. A new species of Eccopsis Zeller (Lepidoptera, Tortricidae) from the coastal valleys of northern Chile, with the first continental record of $E$. galapagana Razowski \& Landry. Revista Brasileira Entomologia, 55:216-218.

Vargas-Ortiz, M., Bobadilla, D. \& Vargas, H. A., 2017. Exploring DNA barcodes of neotropical and afrotropical species of Eccopsis Zeller (Lepidoptera: Tortricidae). Journal of the Lepidopterists' Society, 71(4): 211-217. https://doi.org/10.18473/lepi.71i4.a3

Whaley, O., Beresford-Jones, D., Milliken, W., Orellana, A., Smyk, A. \& Leguía, J., 2010. An ecosystem approach to restoration and sustainable management of dry forest in Southern Perú. Kew Bulletin, 65(4): 613-641. https:// doi.org/10.1007/s12225-010-9235-y

Whaley, O., Orellana-García, A. \& Pecho-Quispe, J. O., 2019. An annotated checklist to vascular flora of the Ica Region, Perú - with notes on endemic species, habitat, climate and agrobiodiversity. Phytotaxa, 389(1):1-125. https://doi.org/10.11646/phytotaxa.389.1.1

Whu, M. \& Valdivieso, I., 1999. Distribución y comportamiento de ocho especies de Trichogramma y Trichogrammatoidea (Hymenoptera: Trichogrammatidae) en el Perú. Revista Peruana de Entomología, 41: 61-68.

Willink, A. \& Roig-Alsina, A., 1995. Revisión del género Pachodynerus Saussure (Hymenoptera, Vespidae, Eumeninae). Contributions of the American Entomological Institute, 30(5): 1-117.

Wilson, M. R. Turner, J. A \& Mckamey, S. H., 2009. Sharpshooter leafhoppers of the world (Hemiptera: Cicadellidae subfamily Cicadellinae). Amgueddfa Cymru - National Museum Wales. Disponible en http://naturalhistory.museumwales.ac.uk/Sharpshooters (consultado 2.05.2020)

Zamudio, P. \& Claps, L. E., 2005. Diaspididae (Hemiptera: Coccoidea) asociadas a frutales en la Argentina. Neotropical Entomology, 34(2): 255-272. https://doi. org/10.1590/S1519-566X2005000200014 
Apéndice 1.- Localidades de muestreo de colectas de insectos asociados a Prosopis pallida en la región Piura, Perú.

Appendix 1.- Sampling localities of insects collections associated with Prosopis pallida in the Piura region, Perú.

\begin{tabular}{|c|c|c|c|c|}
\hline Provincia & Localidad de muestreo & Coordenadas & Paisaje ecológico & Altura (msnm) \\
\hline \multirow[t]{4}{*}{ Piura } & Distrito Castilla & $5^{\circ} 11^{\prime} 05^{\prime \prime} \mathrm{S}-80^{\circ} 57^{\prime} 27^{\prime \prime O}$ & BESII & 29 \\
\hline & Distrito Catacaos & $5^{\circ} 15^{\prime} 55^{\prime \prime} \mathrm{S}-80^{\circ} 40^{\prime} 30^{\prime \prime} \mathrm{O}$ & BESII & 29 \\
\hline & Universidad Nacional de Piura & $5^{\circ} 10^{\prime} 51^{\prime \prime} \mathrm{S}-80^{\circ} 37^{\prime} 31^{\prime \prime O}$ & BESII-BESr & 29 \\
\hline & Universidad de Piura & $5^{\circ} 10^{\prime} 11^{\prime \prime S}-80^{\circ} 36^{\prime} 51^{\prime \prime} \mathrm{O}$ & BESII & 29 \\
\hline \multirow[t]{4}{*}{ Sullana } & Distrito Salitral & $4^{\circ} 51^{\prime} 27^{\prime \prime S}-80^{\circ} 40^{\prime} 52^{\prime \prime} \mathrm{O}$ & BESII & 23 \\
\hline & Distrito Lancones & $4^{\circ} 38^{\prime} 27^{\prime \prime} \mathrm{S}-80^{\circ} 32^{\prime} 55^{\prime \prime} \mathrm{O}$ & BESc-m & 23 \\
\hline & Distrito Miguel Checa & $4^{\circ} 54^{\prime} \mathrm{S}-80^{\circ} 48^{\prime} \mathrm{O}$ & BESII & 23 \\
\hline & Distrito Querecotillo & $4^{\circ} 50^{\prime} 24^{\prime \prime} \mathrm{S}-80^{\circ} 38^{\prime} 57^{\prime \prime} \mathrm{O}$ & BESII & 23 \\
\hline \multirow[t]{3}{*}{ Paita } & Distrito de Paita & $5^{\circ} 04^{\prime} \mathrm{S}-81^{\circ} 06^{\prime} \mathrm{O}$ & BESII & $0-20$ \\
\hline & Distrito La Huaca & $4^{\circ} 54^{\prime} 36^{\prime \prime} \mathrm{S}-80^{\circ} 57^{\prime} 42^{\prime \prime} \mathrm{O}$ & BESII & $0-20$ \\
\hline & Distrito Vichayal & $4^{\circ} 51^{\prime} 55^{\prime \prime} \mathrm{S}-81^{\circ} 04^{\prime} 19^{\prime \prime} \mathrm{O}$ & BESII & $0-20$ \\
\hline \multirow[t]{2}{*}{ Talara } & Distrito Lobitos & $4^{\circ} 27^{\prime} 20^{\prime \prime S}-81^{\circ} 16^{\prime} 57^{\prime \prime} \mathrm{O}$ & DESc-BESII & $0-100$ \\
\hline & $\begin{array}{l}\text { Distrito de Los Órganos } \\
\text { Distrito de El Alto }\end{array}$ & $\begin{array}{l}4^{\circ} 10^{\prime} 38^{\prime \prime} \mathrm{S}-81^{\circ} 07^{\prime} 29^{\prime \prime} \mathrm{O} \\
4^{\circ} 16^{\prime} 04^{\prime \prime} \mathrm{S}-81^{\circ} 13^{\prime} 09^{\prime \prime} \mathrm{O}\end{array}$ & $\begin{array}{l}\text { DESc } \\
\text { DESc }\end{array}$ & $\begin{array}{l}0-10 \\
0-10\end{array}$ \\
\hline \multirow[t]{2}{*}{ Sechura } & Distrito de Sechura & $5^{\circ} 29^{\prime} 37^{\prime \prime S}-80^{\circ} 44^{\prime} 28^{\prime \prime} \mathrm{O}$ & DESc-BESII & $0-20$ \\
\hline & $\begin{array}{l}\text { Distrito de Vice } \\
\text { Laguna Ñapique } \\
\text { Illescas } \\
\text { Desierto de Sechura }\end{array}$ & $\begin{array}{l}5^{\circ} 25^{\prime} \mathrm{S}-81^{\circ} 46^{\prime} \mathrm{O} \\
5^{\circ} 34^{\prime} \mathrm{S}-81^{\circ} 16^{\prime} \mathrm{O} \\
5^{\circ} 58^{\prime} \mathrm{S}-81^{\circ} 05^{\prime} \mathrm{O} \\
5^{\circ} 59^{\prime} 47^{\prime \prime} \mathrm{S}-80^{\circ} 27^{\prime} 02^{\prime \prime} \mathrm{O}\end{array}$ & $\begin{array}{l}\text { DESc-BESII } \\
\text { BESr } \\
\text { MatX } \\
\text { DESc }\end{array}$ & $\begin{array}{l}0-20 \\
0-20 \\
0-10 \\
0-20\end{array}$ \\
\hline \multirow[t]{2}{*}{ Morropón } & Distrito de Chulucanas & $5^{\circ} 05^{\prime} \mathrm{S}-80^{\circ} 99^{\prime} \mathrm{O}$ & BESc-m & $300-1000$ \\
\hline & $\begin{array}{l}\text { Distrito de Morropón } \\
\text { Caserío Piedra del Toro }\end{array}$ & $\begin{array}{l}5^{\circ} 05^{\prime} 51^{\prime \prime} \mathrm{S}-80^{\circ} 09^{\prime} 44^{\prime \prime} \mathrm{O} \\
5^{\circ} 11^{\prime} \mathrm{S}-79^{\circ} 55^{\prime} \mathrm{O}\end{array}$ & $\begin{array}{l}\text { BESc-m } \\
\text { BESc-m }\end{array}$ & $\begin{array}{l}300-1000 \\
300-1000\end{array}$ \\
\hline Huancabamba & Distrito de Huarmaca & $5^{\circ} 34^{\prime} 04^{\prime \prime} \mathrm{S}-79^{\circ} 31^{\prime} 26^{\prime \prime} \mathrm{O}$ & BESc-m & $300-1000$ \\
\hline \multirow[t]{2}{*}{ Ayabaca } & Distrito Suyo & $4^{\circ} 30^{\prime} 45^{\prime \prime} \mathrm{S}-80^{\circ} 02^{\prime} 10^{\prime \prime} \mathrm{O}$ & BESc-m & $300-1000$ \\
\hline & Distrito de Paimas & $4^{\circ} 37^{\prime} 37^{\prime \prime S}-79^{\circ} 56^{\prime} 43^{\prime \prime O}$ & BESII & $300-1000$ \\
\hline
\end{tabular}

